\title{
26. LITHOSTRATIGRAPHIC EVOLUTION OF AN IN-SITU SECTION OF OCEANIC LAYER $3^{1}$
}

\author{
Henry J.B. Dick, ${ }^{2}$ Peter S. Meyer, ${ }^{2}$ Sherman Bloomer ${ }^{3}$ Steve Kirby,${ }^{4}$ Debra Stakes,${ }^{5}$ and Christopher Mawer ${ }^{6}$
}

\begin{abstract}
We redescribed the $-0.5-\mathrm{km}$ gabbro section drilled in Hole $735 \mathrm{~B}$ at the Ocean Drilling Program Gulf Coast Repository. Included in this work was a redivision and clarification of the location and nature of the major lithologic boundaries and a division of the major units into subunits. In all, we found 495 distinct lithologic intervals in the core. Most of the section consists of a single olivine gabbro body having only minor cryptic variations, which we think represents a small intrusion. At the top of the section, the olivine gabbro is intercalated with a medium- to coarse-grained gabbronorite, which we postulate was intruded by the olivine gabbro. The base of the olivine gabbro has been intruded by troctolites and troctolitic gabbros, which may be the precursors of a major troctolite intrusive body immediately below the base of the hole. This section is variously crosscut by small microgabbro bodies, which are the products of crystallization and wall-rock reaction of small magma bodies that migrated through the olivine gabbro prior to complete solidification. Overall, the plutonic section drilled in Hole 735B is unlike those found at layered intrusions as it lacks evidence for extensive magmatic sedimentation. Rather, it appears to represent a plutonic basement composed of small, relatively short-lived, rapidly crystallized intrusions. This is consistent with the ephemeral volcanism and low rates of magma supply postulated for very slow-spreading ocean ridges.

This whole section underwent "syntectonic differentiation": a process in which deformation and compaction of a rigid, partially molten gabbro drove intercumulus melt out of the olivine gabbro into ductile shear zones. Chemical exchange, precipitation of oxides, and trapping of the migrating melt at the end of deformation altered the gabbro in the shear zones to ferrogabbro. These oxide-rich horizons have the potential to be major shallow-dipping seismic reflectors. The largest such zone is $103 \mathrm{~m}$ thick and consists of foliated disseminated oxide olivine and oxide olivine gabbros of lithologic Units III and IV.

The last igneous event was back-intrusion of trondhjemite veins that formed either by fractional crystallization from the interstitial melt and/or by wall rock anatexis of intruded amphibolites.

Alteration and relatively rapid cooling of the gabbro body occurred by penetration and circulation of seawater into the plutonic section caused by thermal contraction and cracking under tensile stress, much as envisaged by Lister (1970). Initially, this circulation was greatly enhanced tectonically by the tensile component provided by lithospheric necking and the formation of brittle-ductile faults beneath the median valley. This circulation was sufficiently pervasive to alter about $25 \%$ of all the matrix pyroxene in the body, mostly to amphibole, in the amphibolite facies. Alteration was heaviest in the vicinity of the brittle-ductile faults, where formation of crack networks, cataclasis, and granulation were ongoing processes continuously creating porosity and permeability during deformation.

At the end of the brittle-ductile deformation phase, the brittle-ductile fault zones became the most impermeable horizons in the core and suffered little additional alteration. This was due to the extensive syntectonic recrystallization of the matrix mineralogy, which effectively reset the stored elastic thermal strain to zero. In the relatively undeformed horizons, where the stored elastic thermal strain remained substantial, cracking and alteration continued under static conditions as the gabbro cooled, though at lower rates of seawater circulation, following a similar pattern to layered intrusions such as the Skaergaard Complex (e.g., Bird, 1986).

Alteration of the massif nearly stopped within the middle amphibolite facies with the cessation of brittle-ductile deformation. Significant lower amphibolite facies diopside-bearing vein networks occur only within the undeformed olivine gabbros in Unit V. Only minor amounts of greenschist and zeolite facies mineralization are found, primarily overprinting early higher-temperature vein and crack networks in the undeformed gabbros. The sharp decrease in alteration below middle amphibolite facies is thought to result from reduced circulation of seawater that accompanied a sharp drop in the available tensile stress for cracking. This probably reflected the transfer of the gabbro body out of the zone of brittle-ductile deformation and lithospheric necking by the formation of a new set of master faults in the median valley closer to the axis of volcanism. Following this, alteration continued under static conditions and accompanying lower rates of seawater circulation with initiation of block uplift of the gabbro massif into the transverse ridge of the Atlantis II Fracture Zone.

The last alteration/tectonic event evident within the core is a set of vertically oriented, irregular cracks, frequently covered with smectite. These cracks probably formed during unloading of the gabbros by erosion to sea level after its initial uplift to form an island. They are largely absent from the brittle-ductile deformation zones, indicating that insufficient stored thermal strain was available there (even after cooling from near $500^{\circ} \mathrm{C}$ to ambient temperature) to overcome the internal strength of the rock under lithostatic load.
\end{abstract}

\section{INTRODUCTION}

\footnotetext{
${ }^{1}$ Von Herzen, R. P., Robinson, P. T., et al., 1991. Proc. ODP, Sci. Results, 118: College Station, TX (Ocean Drilling Program).

2 Woods Hole Oceanographic Institution, Woods Hole, MA 02543, U.S.A.

${ }^{3}$ Boston University, Boston, MA, U.S.A.

${ }_{5}^{4}$ U.S. Geological Survey, Denver, CO, U.S.A.

${ }^{5}$ University of South Carolina, Columbia, SC 29208, U.S.A.

${ }^{6}$ University of New Mexico, Albuquerque, NM 87131, U.S.A.
}

During Leg 118, we drilled $500.7 \mathrm{~m}$ of gabbro in an unroofed and uplifted, but otherwise in-situ, section of plutonic rocks on a wave-cut platform flanking the Atlantis II Fracture Zone, recovering approximately $436 \mathrm{~m}$ of rock. Shipboard measurements showed that these rocks have the appropriate density and acoustic velocity for seismic layer 3 , 
while gravity measurements performed during the site survey (H. Dick, unpubl. data) over Site 735 show that the region has anomalously high density. Thus, the section recovered from Hole $735 \mathrm{~B}$ is thought to represent the first direct sampling of an intact portion of that layer. Recovery below 100 mbsf was about $95 \%$ ( $87 \%$ overall), providing a nearly continuous section. This section of gabbro is the first direct coherent sampling of oceanic layer 3 ever achieved and is a unique opportunity to examine and to document the igneous, metamorphic, and tectonic stratigraphy and evolution of a portion of this heretofore unexamined region. On board ship, however, the rapid drilling and high recovery rates created an unprecedented situation for processing and describing hardrock core. This was greatly compounded by exceedingly complex and varied igneous, metamorphic, and tectonic stratigraphies. The core was described by 11 different petrologists (divided between two different shifts), who devised descriptive techniques, rock and lithologic names, and unit characteristics on an ongoing basis as core was brought on deck, processed, and stored in less than a day. Once a preliminary description of a section was done, the core was generally unavailable for reference or a second look. As a consequence, few scientists saw little more than half the core and examined only a fraction of that in detail. The content and detail of descriptions done by individual scientists were highly variable and were not uniform. In particular, the relationships among different lithologic units were poorly described because unit boundaries were often recognized during the hasty synthesis performed after the core was stored for preparing the initial drilling report on the way to port. Thus, the lithostratigraphy prepared on board ship was incomplete and locally inaccurate.

These problems were generally recognized by the shipboard scientists, and it was decided that a subgroup of the scientific party would redescribe and remeasure the core at the Gulf Coast Repository at Texas A\&M University, with the first author coordinating visits with the igneous, structural, and metamorphic petrologists. In all, four man-months of time were needed to redescribe the core. During this time, each piece was reexamined for its igneous, metamorphic, and structural features, which then were measured and recorded in detail. In all, nearly 5000 measurements were performed of the orientation and thickness of metamorphic and igneous laminations, veins, and joints. In addition, the primary igneous characteristics of every rock were identified, and the thickness of the more than 495 discrete lithologic intervals were measured. Nine weeks by the senior author and a total of seven weeks by the coauthors were spent at Texas A\&M University. The resulting data bases are particularly valuable as they allow one to draw a fairly accurate quantitative picture of the core. By combining these data with shipboard and laboratory measurements of the physical and chemical properties of the core, estimates of bulk chemistry, density, magnetic, and seismic characteristics of the drilled section can be directly determined for the entire hole, individual units, or discrete rock types.

\section{GEOLOGIC SETTING}

Extensive swath-mapping of the Atlantis II Fracture Zone during the site survey (Dick et al., this volume) showed that the location of Hole $735 \mathrm{~B}$, informally named the Atlantis Bank, is the largest and shoalest of a series of large tectonic blocks in a 5-km-high mountain range constituting the eastern wall of the transform valley (Fig. 1). This transverse ridge is similar to many previously mapped parallel to Southwest Indian Ridge fracture zones (e.g., Engel and Fisher, 1975; Sclater et al., 1978; Fisher et al., 1986; Dick, 1989), where

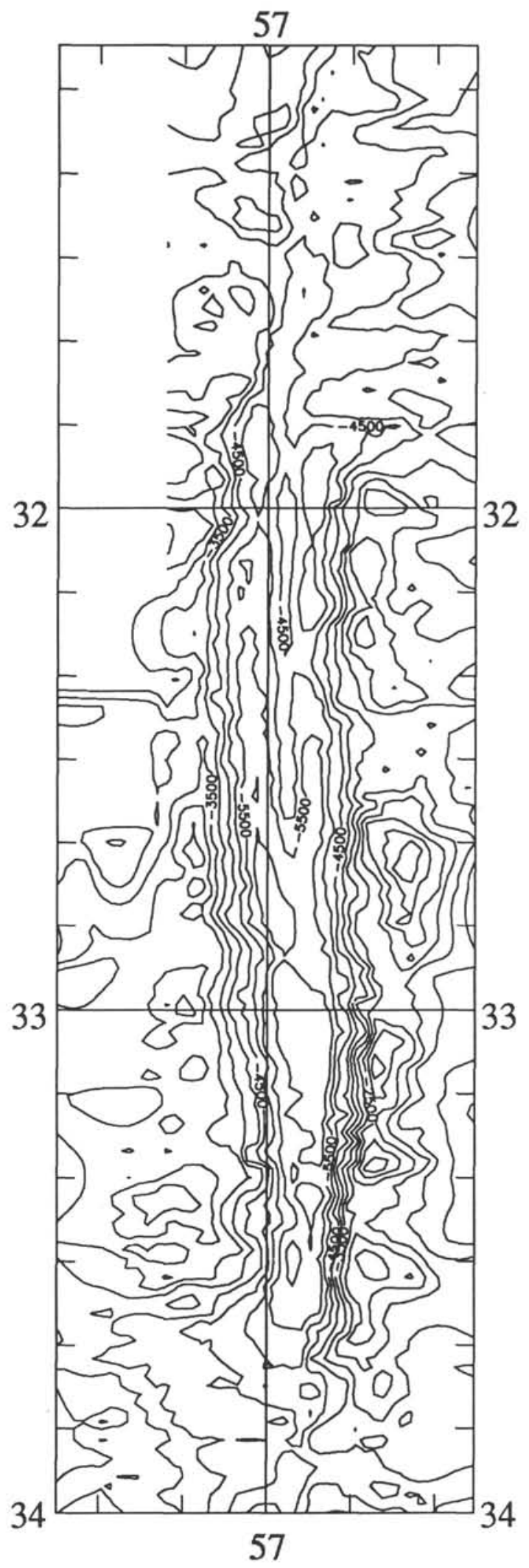

Figure 1. General bathymetry of the Atlantis II Fracture Zone (500-m contour interval). 
abundant plutonic rocks, particularly peridotite, are exposed and uplifted to a shallow level. Other transverse ridges along the Southwest Indian Ridge evidently also have highs that were once emergent. Fisher et al. (1986), for example, reported dredging rounded beach cobbles from a similar site near the crest of a transverse ridge at the DuToit Fracture Zone to the southwest.

Site 735 is located on a shallow platform in about $700 \mathrm{~m}$ of water. The platform, about $9 \mathrm{~km}$ long in a north-south direction and $4 \mathrm{~km}$ wide, is one of a series of uplifted horst blocks that are connected by saddles to form a long, linear ridge parallel to the transform. Locally, over about $20 \mathrm{~km}^{2}$ on the top of the platform one finds less than $60 \mathrm{~m}$ of relief. An extensive $200-\times 200-m$ video survey in the vicinity of the hole by the scientists aboard the JOIDES Resolution showed flat, bare outcrop of foliated and massive jointed gabbro locally covered by sediment drifts. These data indicate that the platform is wave-cut and probably formed by erosion of an island similar to St. Paul's Rocks in the central Atlantic, before subsiding to its present depth from normal lithospheric cooling. Examination of the videotapes made during the survey by the senior author showed that the exposed rocks frequently appeared foliated. Where this foliation was most clearly evident, the apparent strike of the foliation was eastwest parallel to the ridge axis to the north and orthogonal to the adjacent fracture zone. The orientation of the foliated peridotites exposed on St. Paul's Rocks has been measured and is also parallel to the Mid-Atlantic Ridge and orthogonal to St. Paul's Fracture Zone (Melson et al., 1970).

The site is located between magnetic anomalies 5 and $5 \mathrm{a}$, approximately $93 \mathrm{~km}$ south of the present-day axis of the Southwest Indian Ridge and $18.4 \mathrm{~km}$ from the inferred axis of transform faulting on the floor of the Atlantis II Fracture Zone (Dick et al., this volume). Given its position, the relatively constant spreading direction over the last $11 \mathrm{~m} . \mathrm{y}$. and the strike of the local foliation, the Atlantis Bank gabbros must have formed beneath the median valley of the Southwest Indian Ridge, 15 to $19 \mathrm{~km}$ from the ridge-transform intersection about $11 \mathrm{~m} . \mathrm{y}$. ago. These gabbros were then subsequently uplifted 5 to $6 \mathrm{~km}$ as a giant horst block into the transverse ridge. Thus, unlike some rocks dredged from fracture-zone walls, those drilled in Hole 735B formed well away from the transform plate boundary beneath the rift-valley floor and can be regarded as representing what some have called "normal igneous ocean crust,"' even if subsequent uplift processes were extreme.

Dredging and mapping showed that the Atlantis II Fracture Zone transverse ridge exposes largely plutonic rocks from the lower crust and mantle, with an unusual abundance of gabbro relative to peridotite for Southwest Indian Ridge transverse ridges (Dick et al., this volume). Pillow lavas and diabase, which have been shown by DSDP/IPOD drilling to comprise normally seismic layer 2 , are scarce. In contrast, mapped and sampled crust spreading in the opposite direction along a lithospheric flow line away from the active transform is not uplifted and consists of a series of spreading-center parallel ridges and valleys that gently slope down to meet the fossil trace of the fracture zone. This terrane is morphologically characteristic of fissured and faulted pillow basalt flows similar to those seen within and on the walls of a typical slow-spreading ridge rift valley. Only pillow basalts were dredged within this region.

On the basis of the asymmetric distribution of plutonic and volcanic rocks and the striking physiographic contrast between crust spreading in opposite directions at the ridgetransform intersection, Dick et al. (this volume) suggest that a crustal weld has periodically existed between the shallow levels of the ocean crust and the old, cold lithospheric plate at the ridge-transform intersection. Such welds caused the shallow levels of the newly formed ocean crust to spread with the older plate away from the active transform, creating long-lived detachment faults beneath which the deep ocean crust spreading parallel to the transform was unroofed and emplaced up into the rift mountains to form a transverse ridge. This same model was earlier proposed by Dick et al. (1981) to explain a similar asymmetric physiography and distribution of plutonic and volcanic rocks at the Kane Fracture Zone in the North Atlantic, where the surface of the detachment fault was actually observed by submersible dipping down into the nodal basin, adjacent to the floor of the rift valley near the ridgetransform intersection, exposing gabbro.

\section{IGNEOUS LITHOLOGIES AND PETROGENESIS}

\section{Introduction}

The starting point for redescription of the core was to refine the primary igneous stratigraphy established on the ship. To do this, we identified and described more than 500 discrete lithologic intervals in the core at the Ocean Drilling Program's Gulf Coast Repository at Texas A\&M University. This effort recorded nearly the full extent of lithologic variability seen, except in the lowermost portion of the core, where extreme lithologic diversity (often on the scale of centimeters) forced some lumping of different rock types. Initially, we used 74 different working lithologic names, reflecting minor and major variations in mineralogy, mineral proportions, and texture. For a final stratigraphy, a more manageable 21 names have been used that combines minor variants in grain size and relative proportions for rocks that otherwise share common mineralogy and petrographic features (Fig. 2). This reduced the total number of lithologic intervals to 495 and produced the stratigraphy presented in Appendix A.

\section{Igneous Overview}

Given the complexity of the section, and the processes involved in its formation, we present here a brief summary of the igneous petrogenesis so that the reader can get some idea of the basis for classifying the primary igneous lithologies (Table 1).

The rocks recovered from Hole 735B consist almost entirely of deformed and massive gabbros, with only two intervals of crosscutting diabase (Fig. 3). One was relatively unaltered and undeformed and crosscut the gabbro with fine-grained chilled margins, while the other is moderately recrystallized and was intruded or transposed into the foliation plane. The complex interrelationships among different igneous rocks in the hole are often heavily obscured by late amphibolite facies deformation and hydrothermal alteration, which caused extensive recrystallization of the upper $100 \mathrm{~m}$ of the gabbro to form amphibolite gneiss and mylonite. Roughly one-third of the section was gneissic, one-third slightly deformed, and one-third undeformed.

We found that our initial working stratigraphic analogue for the gabbros, used on board ship, of a disrupted section of a sub-sea, layered intrusion broke down completely on the scale of this hole. The only cumulate feature that we attribute with any confidence to crystal settling is a chromian-spinel layer in a small intrusive troctolite body in olivine gabbro in the lowermost unit. The stratigraphy and petrogenesis of the section drilled is strikingly different from that in a layered intrusion. It represents a new paradigm for formation of the lower ocean crust, where low rates of magma supply and interaction of magmatism and brittle-ductile deformation at the late stages of solidification in a dynamic extensional environment play key rolls in its stratigraphy. 
Hole 735B

Whole Rock XRF Average Compositions

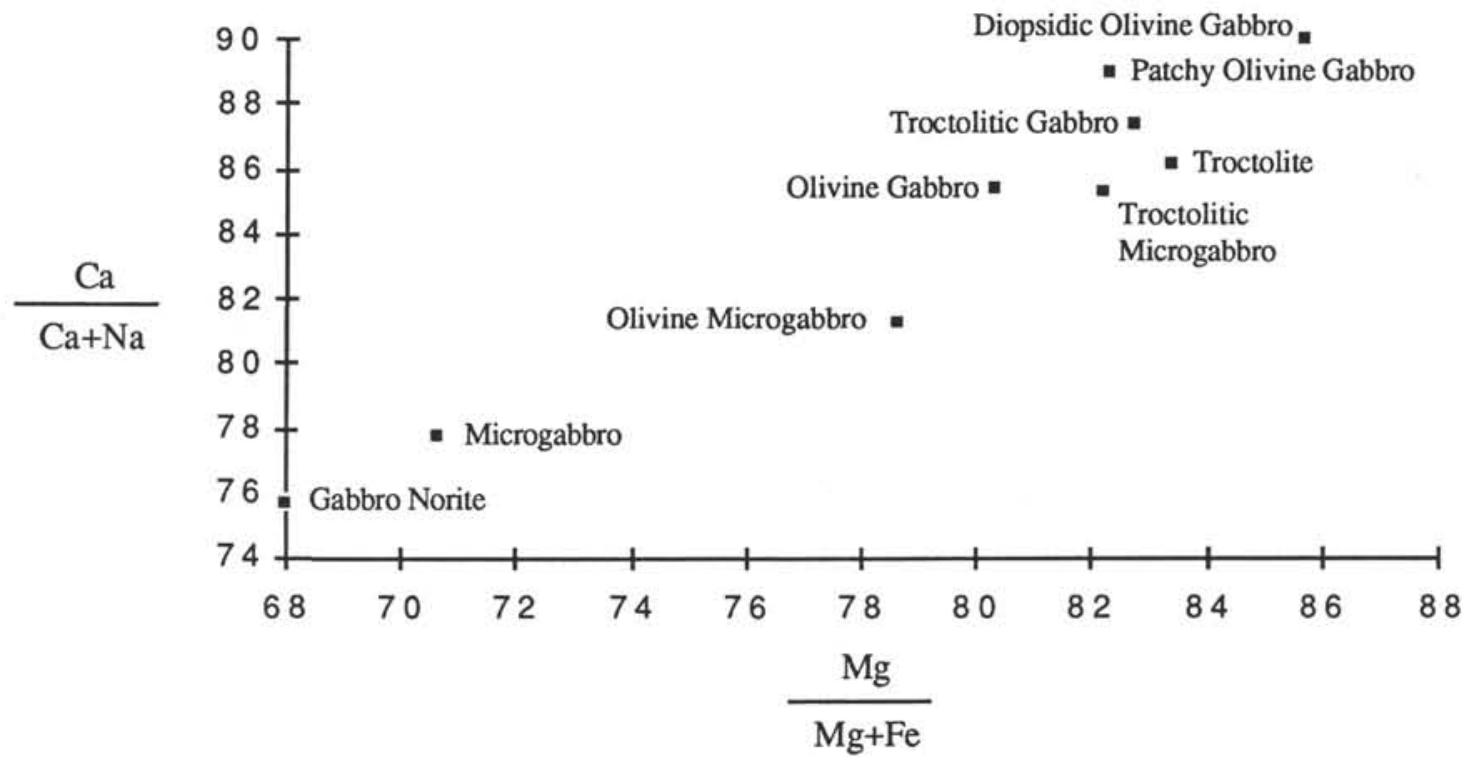

Figure 2. Whole-rock XRF analyses for oxide-free gabbros averaged from Appendix B; molecular ratios calculated excluding ferric iron.

Table 1. Principal igneous lithologies, Hole 735B.

\begin{tabular}{|c|c|c|c|}
\hline \multicolumn{2}{|c|}{ Oxide-free gabbros } & \multicolumn{2}{|c|}{ Oxide-bearing gabbros } \\
\hline Fine to medium-grained & Medium to very coarse & Fine to medium & Medium to very coarse \\
\hline & Gabbro norite & Oxide microgabbro norite & Oxide gabbro norite \\
\hline \multicolumn{2}{|c|}{ Patchy olivine gabbro } & $\begin{array}{r}\text { Oxide olivine microgabbro } \\
\text { Dissem. oxide } \\
\text { (Patchy oxide }\end{array}$ & $\begin{array}{l}\text { Oxide Gabbro } \\
\text { Oxide olivine gabbro } \\
\text { livine gabbro } \\
\text { ivine gabbro) } \\
\text { (Oxide-rich vein) } \\
\text { (Oxide pyroxenite) }\end{array}$ \\
\hline $\begin{array}{c}\text { Troctolitc } \\
\text { Troctolitic microgabbro }\end{array}$ & $\begin{array}{c}\text { Troctolitic gabbro } \\
\text { (Diopsidic olivine gabbro) }\end{array}$ & & Troctolitic oxide gabbro) \\
\hline
\end{tabular}

*Lithologies in small print amount to less than $2 \%$ of the section, and those in parentheses

() are volumetrically minor, amounting to less than $1 \%$ of the drilled section.

The section consists of a 450 -m-thick, chemically uniform equigranular coarse-grained massive olivine gabbro with a relatively small unit of gabbronorite at its top. At its base, the olivine gabbro is intruded by increasingly coarse-grained troctolite and troctolitic gabbros. These suggest a major troctolitic intrusion may be present immediately beneath the bottom of the drill hole. The olivine gabbro contains layers and patches of coarser material and olivine-rich and poor gabbro. These phase and grain-size variations are not thought to result from magmatic sedimentation, as the grain size of the cumulus phases are generally the same and vary together, suggesting that throughout crystallization the liquid was multiply saturated in olivine plagioclase and pyroxene. The grain sizes of different phases in magmatic sediments are not generally uniform due to their differing densities. Rather, modal and grain-size layering in the olivine gabbro is taken to represent local variations in rate of initial nucleation of phases and crystallization of different postcumulus phases (Bloomer et al., this volume). The olivine gabbro is thought to have crystallized rapidly to form a relatively uniform crystal mush, in the initial stages, probably due to undercooling from advection of heat in a convecting well-mixed magma to initially cold wall rocks. As crystallization proceeded, however, the gabbro cooled more slowly when advection became less efficient in a crystal mush and wall rock temperatures increased. This latter period is highlighted by a series of unusual post-cumulus crystallization processes (termed synkinematic differentiation) driven by extension and brittle-ductile deformation in the lower crust, which redistributed late intercumulus melt from the crystallizing gabbro to form late crosscutting igneous layering.

Over the course of its crystallization, the gabbro underwent periodic reintrusion by small bodies of melt migrating through the lower crust. Evidence for this is found from initial formation of a crystal mush through an extensive late-magmatic period, where the body was sufficiently rigid to support shear and the formation of brittle-ductile shear zones. Lo- 


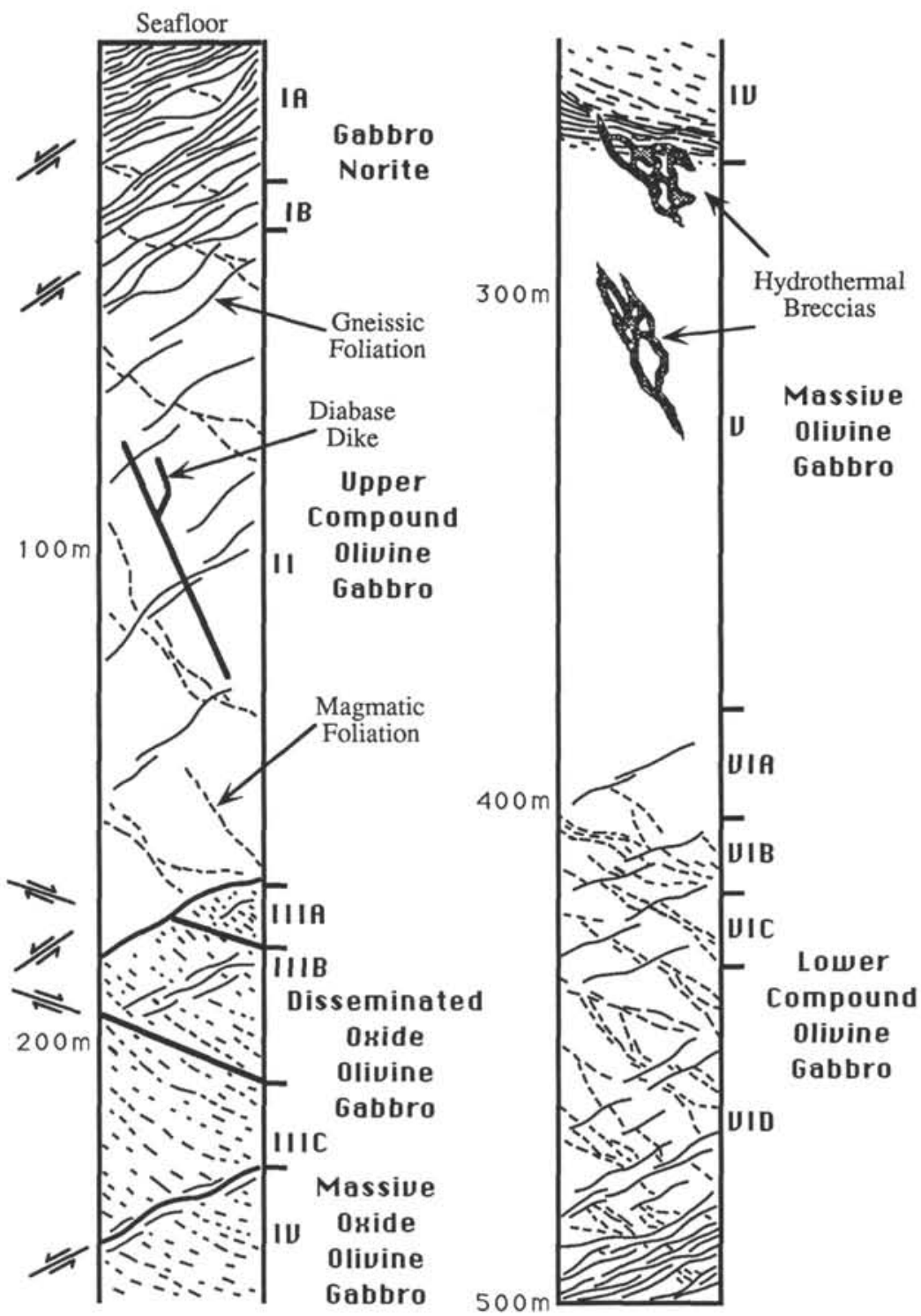

Legend: Hole 735B Igneous Lithostratigraphy

Unit I = Gabbronorite

Subunit $1 \mathrm{~A}=$ Massive gabbronorite

Subunit 1B = Olivine gabbro and gabbronorite

Unit II = Upper compound olivine gabbro

Minor: intrusive microgabbro and olivine microgabbro synkinematic oxide and oxide-olivine gabbro

Unit III = Disseminated oxide-olivine gabbro

Subunit IIIA $=$ Disseminated-oxide-olivine and olivine gabbro

Subunit IIIB = Massive disseminated-oxide-olivine gabbro

Subunit IIIC $=$ Disseminated-oxide-olivine and olivine gabbro

Unit IV = Massive oxide olivine gabbro

Unit $\mathrm{V}=$ Massive olivine gabbro

Unit VI = Lower compound olivine gabbro

Subunit VIA = Compound olivine gabbro

Minor: Intrusive oxide microgabbronorite and olivine microgabbro synkinematic oxide and oxide-olivine gabbro

Subunit VIB = Compound olivine, oxide-olivine, and disseminated oxide-olivine gabbro

Minor: Intrusive olivine and oxide-olivine microgabbro

Subunit VIC $=$ Compound troctolitic and olivine gabbro

Minor $=$ Synkinematic oxide-olivine gabbro and oxide-olivine microgabbro intrusive troctolite and troctolitic microgabbro

Subunit VID $=$ Compound olivine and oxideolivine gabbro

Minor = Intrusive troctolite, diopsidic-olivine and troctolitic gabbro synkinematic disseminated-oxide-olivine and oxide gabbro

Figure 3. Summary lithologic column for Hole 735B. Short dashed lines in all units indicate approximate orientation of magmatic foliation in oxide-bearing gabbros, while long wavy lines indicate the locus of subsolidus amphibolite facies ductile deformation. The strike and dip direction of the subsolidus and late magmatic ductile deformations are assumed to be constant, although this might not be the case. Approximate location of several hydrothermal breccias shown for reference. Note crosscutting relationship at the base of Unit IV. Approximate locations of major subunit boundaries deduced from microfaults in the core are shown for Units III and IVB. Contacts within Units I and II are presumed to lie in the foliation plane.

cally, intrusion overlapped ductile deformation in the still partially molten gabbro, and thus the microgabbros are both crosscut by and crosscut ductile shear zones. The earliest evidence for reintrusion is patchy olivine gabbros characterized by irregular coarse and fine equigranular patches. We think that these represent influx and initial undercooling of new batches of melt in a relatively cool crystal mush, where initial mixing of new magma was inhibited by the relatively high viscosity of the intruded mush. There is a complete textural gradation from the irregular patchy gabbro through microgabbros that have clear irregular intrusive contacts, but lack chill zones, to diabase dikes having chilled margins that were intruded after complete solidification. Microgabbros, crosscutting the olivine gabbro, range from troctolite through olivine gabbro and gabbro to oxide gabbronorite, representing crystallization from liquids ranging from primitive MORB to ferrobasalt. Thus, transport of small batches of melt through the plutonic section was an ongoing process throughout its crystallization history and included melts that spanned the range of erupted ocean ridge basalts.

Toward the end of crystallization, brittle-ductile shear zones representing "ductile faults" formed in the rigid crystal mush and gabbros overlying the solidification front. These acted as zones of enhanced permeability that channeled late-magmatic fluids from the mush zones through the overlying gabbro on scales ranging from millimeter-thick shears to a 100 -m-thick ductile deformation zone. Similar to fault zones in granular aggregates elsewhere, it is likely that dilation in the 


\section{H. J. B. DICK ET AL.}

region of faulting immediately preceded failure. This resulted in an influx of intercumulus fluid from the gabbro into the deformation zone. Gabbro in these late-magmatic shear zones has been impregnated by iron-titanium oxides, principally ilmenite, which precipitated from the migrating intercumulus liquid. Ongoing deformation created additional permeability due to grain boundary sliding, cataclasis, and grain boundary migration, and continued flow of evolving intercumulus melt through the deforming gabbro resulted in local precipitation of as much as $50 \%$ oxides, creating localized ilmenite "ore" bodies. Chemical exchange between migrating melt and deforming gabbro was enhanced by mechanical recrystallization and grain boundary migration. This process produced a bimodal distribution of mineral and rock compositions, unrelated to stratigraphic position, between deformed and undeformed gabbros. This "synkinematic differentiation" forms a previously unrecognized form of igneous layering in the ocean crust that may be of substantial importance to its seismic stratigraphy as well as its igneous petrogenesis.

The intrusive and late magmatic deformation zones are not uniformly distributed throughout the section, which produces a complex tectonic-magmatic igneous stratigraphy unlike that seen in layered intrusions. Thus, the number and proportions of the different igneous rock types vary dramatically downhole from unit to unit (Fig. 4). The boundaries between units and subunits, therefore, are as much tectonic as igneous and represent major changes in the proportion of late microgabbro intrusives and late magmatic deformation, as well as changes in the principal rock type.

\section{Igneous Rock Classification}

\section{Introduction}

We found three principal classes of rocks (Table 1): (1) primary medium- to very-coarse-grained gabbros, (2) late intrusive fine- to medium-grained microgabbros, and (3) synkinematic oxide-bearing gabbros. The large majority of the first two types are olivine gabbros with minor gabbronorite, gabbro, and troctolitic gabbros. The most evolved of these are oxide gabbronorite microgabbros found intruding olivine gabbro in Unit VI. One complex textural variant of the olivine gabbro may be explained by late influx of new magma, when it was a highly viscous crystal mush giving rise to "patchy" olivine gabbros from poor mixing of old and

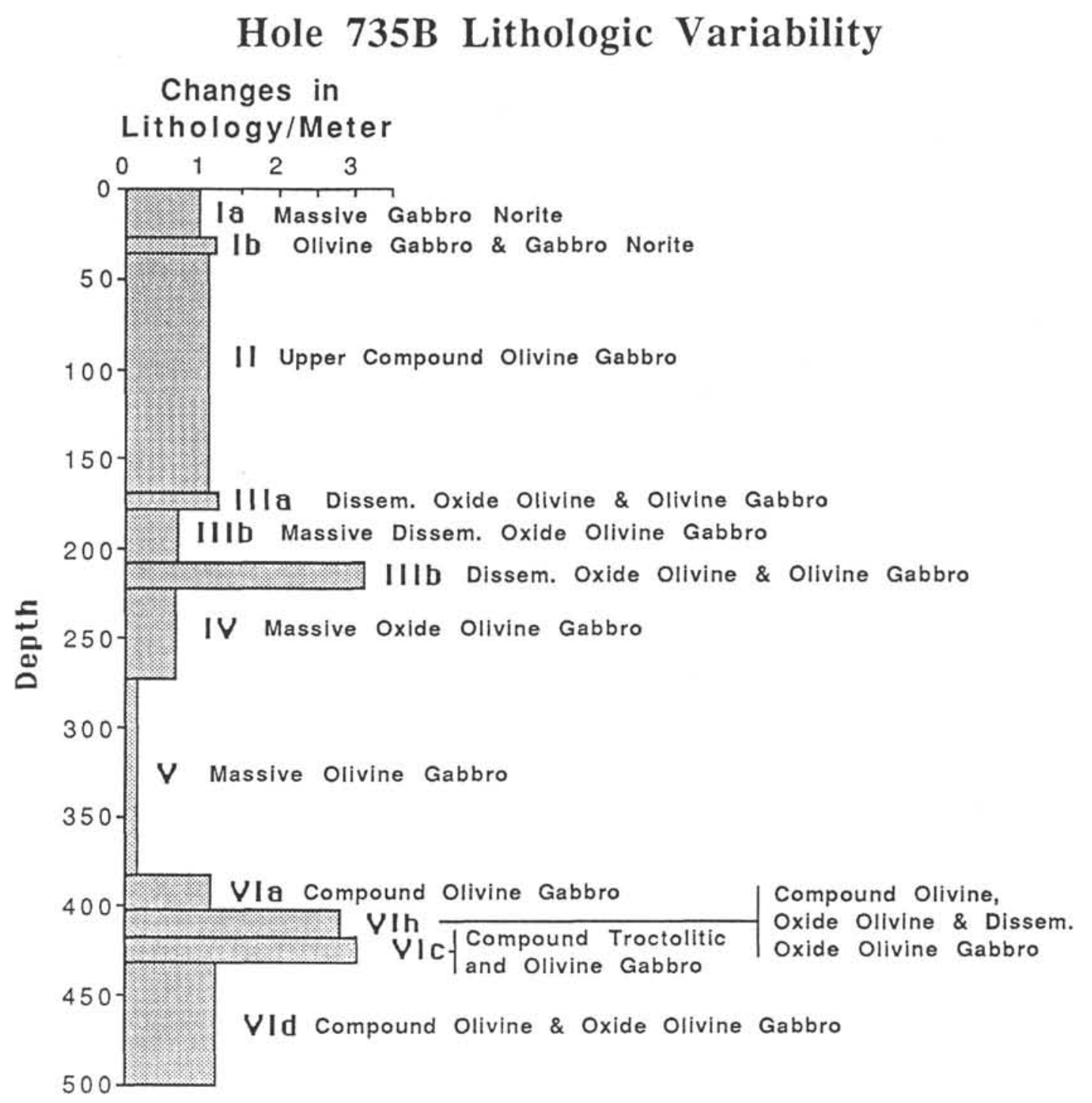

Figure 4. Downhole plot showing the number of changes in primary igneous lithology per meter for each unit and subunit in Hole 735B. 
new magmas. All these mostly oxide-free lithologies underwent local late-magmatic deformation, which channeled iron-rich intercumulus melt through brittle-ductile shear zones. This resulted in the formation of evolved oxidebearing gabbros from precipitation of iron oxides and chemical exchange between the migrating melt and the deforming olivine gabbro matrix.

Sorting the data in Appendix A allowed us to calculate the proportions of different rock types in the drilled section, their average thickness, and their variance. Using the same data, the shipboard XRF analyses, supplemented by additional XRF analyses conducted at Woods Hole Oceanographic Institution (Meyer et al., pers. comm. 1989), were sorted by rock type (Appendix B) to obtain average lithologic chemical compositions and to calculate a bulk hole chemistry. The latter was performed using densities measured on board ship. Results of these computations are given in Table 2, and general descriptions of the principle lithologies are given below. For a more detailed discussion of the mineral chemistry used here for the gabbros, the reader is referred to Bloomer et al. (this volume).

\section{Primary Gabbros}

\section{Gabbronorite}

Twenty gabbronorite intervals were identified that make up a little more than $5 \%$ of the total section. Unfortunately, its primary petrographic characteristics are grossly obscured by extensive dynamic recrystallization to form augen gneiss and mylonite. Where the primary texture has been preserved, it appears to be a medium- to coarse-grained gabbro with intergranular to subophitic texture having interlocking high and low-calcium pyroxene crystallized with and around a mat of plagioclase. Plagioclase is sodic, typically around $\mathrm{An}_{42}$, and clinopyroxene is iron-rich with $\mathrm{Mg} /(\mathrm{Mg}+\mathrm{Fe})$ of about 70 . The whole-rock chemistry of the gabbronorites is the most evolved of the primary and late intrusive gabbros, with moderate silica (52.8\% ave.) and titanium enrichment $(0.63 \%)$, compared with the other gabbros, and the lowest $\mathrm{Mg} /(\mathrm{Mg}+\mathrm{Fe})$ and $\mathrm{Ca} /(\mathrm{Ca}+\mathrm{Na})$ ratios (Fig. 2). The contact relationships of the olivine gabbro with which it is intercalated have been obscured by deformation.

\section{Gabbro}

Four intervals were described as gabbro. These have all been extensively altered, and except for the absence of relict primary olivine, they are identical to typical olivine gabbros. In the absence of any evidence to the contrary, such as the presence of fresh olivine-free gabbro, we assume that these are altered olivine gabbros with olivine completely replaced.

\section{Olivine Gabbro}

Olivine gabbro is by far the most abundant lithology in Hole 735B as it occurs at 176 intervals and makes up $304 \mathrm{~m}$ or $61 \%$ of the core. The larger part of this olivine gabbro is calcic plagioclase, followed by augite. Olivine content is variable and ranges from $1 \%$ to $20 \%$ locally. Oxide is present only in trace amounts of generally less than $0.1 \%$. Olivine, plagioclase, and clinopyroxene tend to be uniform in size and coarsen or fine together as the grain size of the rock varies. The typical olivine gabbro has an equigranular xenomorphic granular to hypidiomorphic granular texture. The former is composed of interlocking anhedral grains of plagioclase, pyroxene, and olivine of roughly equal size. In the latter, anhedral to subhedral plagioclase laths are subophitically enclosed in pyroxene, with olivine occurring as sub- hedral to intergranular grains intergrown with the plagioclase and pyroxene. Local very-coarse-grained rocks contain spectacular augite oikocrysts up to $20 \mathrm{~cm}$ long that enclose mats of plagioclase laths. A little late interstitial brown hornblende can be seen rimming the olivine. Plagioclase is moderately anorthitic and ranges from $\mathrm{Any}_{48}$ to $\mathrm{An}_{60}$. Olivine and clinopyroxene are fairly magnesian $\left(\mathrm{Fo}_{60-80}\right.$, $\left.\mathrm{Mg}_{77-86}\right)$. Mineral compositions in the olivine gabbros are relatively homogeneous, with a standard deviation of only about $5 \%$ for key element ratios. In terms of bulk rock composition, the olivine gabbros lie toward the more primitive end of the compositional spectrum and are noticeably richer in chromium and nickel than the gabbronorites and microgabbros, while less magnesian and anorthitic than the troctolitic rocks (Fig. 2).

\section{Late Intrusives}

These can be separated into two kinds: microgabbros and trondhjemites. The former are volumetrically far more important, although still minor in volume overall. The microgabbros include a wide variety of rock types, all of which have similar fine- to medium-grained textures and highly irregular contacts with the coarse-grained olivine gabbro. These contacts are generally marked by a sharp decrease in grain size, but individual mineral grains are intergrown together across the contact, producing a "sutured" igneous contact. Where the contacts have not been transposed into the deformation plane, they are often highly irregular-often curving in hand specimen, with upper and lower contacts dipping in opposite directions. The contact relationships are similar to those seen between podiform dunites and tectonized harzburgite in alpine-type peridotites, where magmas migrating through the mantle have reacted with and partially assimilated mantle peridotite, at the same time precipitating dunite. In this case, we think that we are viewing rocks formed by related mechanisms as late melts migrated upward through solidifying plutonic crust.

\section{Oxide Microgabbronorite}

This rock type is a fine- to medium-grained equigranular gabbro, with abundant augite hypersthene and plagioclase with subophitic to ophitic pyroxene enclosing plagioclase. The oxide microgabbronorite is thought to have a different petrogenesis than the other oxide-bearing gabbros. Its contacts with olivine gabbro are intrusive and highly irregular in shape. Small, partially digested clasts of olivine gabbro occur locally in the microgabbronorite near the olivine gabbro wall rock. The bulk composition (determined by XRF) is close to ferrobasalt magma, and the abundant iron oxide resembles a primary cumulus phase, with subhedral crystal morphologies, rather than late interstitial as in the other oxide-bearing gabbros. We think that the oxide microgabbronorite formed by fractionation of a primary MORB and was intruded to its present position, where it crystallized in-situ to its present composition, without later modification by late magmatic liquids.

\section{Olivine Microgabbro}

Olivine microgabbros are fine- to medium-grained, equigranular rocks having textures ranging from xenomorphic granular to hypidiomorphic granular. In the latter, subophitic to ophitic pyroxene encloses anhedral to subhedral plagioclase and olivine. Pyroxene in the olivine microgabbros tends to be stubbier than in the troctolites and is reddish brown to yellow-light brown and pale green. Locally, fine-grained intergranular chrome diopside is rimmed by reddish pyroxene, 
Table 2. Average and bulk compositions, Hole 735B.

\begin{tabular}{|c|c|c|c|c|c|c|c|c|c|c|c|c|c|c|c|c|c|c|c|c|c|c|c|c|c|c|c|}
\hline L.tithology & ${ }_{\text {Int }}^{\prime}$ & $\begin{array}{l}\text { Total } \\
\text { Thick. }\end{array}$ & $\begin{array}{l}\text { Ave. } \\
\text { Thick. }\end{array}$ & $\begin{array}{l}\text { Sul. } \\
\text { Dev }\end{array}$ & \begin{tabular}{|c|} 
Vol. \% \\
Rerovery
\end{tabular} & \begin{tabular}{|c|} 
Ave. \\
Density
\end{tabular} & St.Dev. & & \begin{tabular}{|c|} 
WL.\% \\
Recovery
\end{tabular} & $\mathrm{SiO}_{2}$ & $\mathrm{TiO}_{2}$ & $\mathrm{Al}_{1203}$ & $\mathrm{Fe}_{2} \mathrm{OO} 3$ & $\mathrm{FeO}$ & $\mathrm{FeO}^{\circ}$ & $\mathrm{MnO}$ & $\mathrm{MgO}$ & $\mathrm{CaO}$ & $\mathrm{N}_{22} \mathrm{O}$ & $\mathrm{K} 2 \mathrm{O}$ & P2OS & 120 & $\mathrm{CO}_{2}$ & t.ol & Mgt & Catt & $\mathrm{Ca} / \mathrm{Al}$ \\
\hline Diabasce & 2 & 153 & 0.77 & & 0.306 & 2.955 & & 1 & 0.303 & 49.8 & 1.73 & 14.91 & 2.38 & 7.18 & 9.32 & 0.19 & 7.76 & 11.26 & 3.01 & 0.08 & 0.36 & 1.28 & 0.00 & 1.21 & 65.8 & 80.6 & 0.69 \\
\hline Diopsidic Olivine Giabhro & 4 & 4.39 & 1.1 & 0.86 & $0.8 \pi$ & & & 0 & 0.859 & 50.2 & 0.30 & 15.85 & 0.59 & 3.16 & 3.69 & 0.09 & 10.62 & 16.34 & 201 & 0.02 & 0.01 & 0.80 & 0.00 & 0.68 & 85.7 & 90.0 & 0.94 \\
\hline Disseminatad Oxide Olivine Giabhro & 36 & 41.40 & 115 & 2.75 & 8.268 & 2.945 & 0.036 & 15 & 160 & 51.9 & 0.61 & 15.58 & 1.63 & 6.87 & 8.34 & 0.17 & 8.29 & 10.95 & 3.29 & 0.05 & 0.01 & 0.55 & 0.10 & 1.29 & 68.3 & 78.6 & 0.65 \\
\hline Giatbro & 4 & 0.40 & 0.1 & 0.02 & 0.080 & & & & 0.078 & 50.5 & 0.34 & 16.95 & 0.93 & 4.39 & 5.19 & 0.11 & 10.07 & 13.33 & 2.49 & 0.04 & 0.01 & 0.82 & 0.06 & 3.79 & 80.3 & 85.4 & 0.73 \\
\hline ahbro Norite & $2 n$ & 26.86 & 1.34 & .76 & .364 & 2.924 & 0.031 & 6 & 5.256 & 52.8 & 0.63 & 16.29 & 1.98 & 581 & 7.59 & 0.16 & 6.93 & 10.66 & 3.79 & 0.14 & 0.05 & 1.02 & 0.08 & 0.85 & 68.0 & 75.7 & 0.59 \\
\hline Microgahthro & 5 & & 0.22 & 0.11 & 0.220 & & & & 0.215 & 51.7 & 0.48 & 15.78 & 1.41 & 6.28 & 7.55 & 0.14 & 8.47 & 10.84 & 3.43 & 0.03 & 0.00 & 1.48 & 0.00 & 157 & 70.6 & 77.7 & 0.62 \\
\hline Olivine Gabbro & 176 & 303.51 & 1.72 & 3.73 & 60.617 & 2.953 & 0.052 & 31 & 59.975 & 50.5 & 0.34 & 16.95 & 0.93 & 4.39 & 5.19 & 0.11 & 10.97 & 13.33 & 2.49 & 0.04 & 0.01 & 0.82 & 0.06 & 3.79 & 80.3 & 85.4 & 0.73 \\
\hline Olivine Microg abbro & 15 & 5.68 & 0.38 & 0.37 & 1.134 & 2.924 & 0.025 & 6 & 1.111 & 50.1 & 0.26 & 16.96 & 1.19 & 4.83 & 5.90 & 0.11 & 10.72 & 11.48 & 2.92 & 0.10 & 0.00 & 1.33 & 0.06 & 1.23 & 78.6 & 81.3 & 0.62 \\
\hline Oxide Gahbro & 36 & 8.08 & 0.22 & 0.24 & 1.614 & 3.331 & 0.466 & 5 & 1.802 & 48,3 & 3.30 & 14.37 & 1.96 & 10.41 & 1159 & 0.18 & 7.25 & 10.47 & 3.41 & 0.10 & 0.02 & 0.93 & 0.13 & 0.47 & 55.6 & $\pi 2$ & 0.66 \\
\hline Oxide Gahbro Norite & 11 & 2.77 & 0.25 & 0.2 & 0.553 & 3.103 & & 1 & 0575 & 435 & 4.50 & 11.29 & 8.72 & 13.49 & 21.33 & 0.33 & 7.66 & 6.98 & 2.74 & 0.06 & 0.07 & 0.74 & 0.00 & 0.46 & 49.6 & 73.8 & 0.56 \\
\hline Oxide Microgathro Norite & 4 & 152 & 0.38 & 0.23 & 304 & 3.021 & 0.047 & 2 & 0.307 & 50.3 & 1.95 & 14.66 & & 12.23 & 12.23 & 0.22 & 6.60 & 9.95 & 3.69 & 0.08 & 0.10 & & & & 49.0 & 74.9 & 0.62 \\
\hline Oxide Olivinc Gahbro & 121 & 78.43 & 0.65 & 1.63 & 15.664 & 3.114 & 0.116 & 22 & 16.344 & 42.9 & 6.10 & 10.96 & 6.10 & 16.47 & 20.73 & 0.30 & 6.07 & 9.07 & 2.74 & 0.06 & 0.15 & 0.67 & 0.00 & 0.39 & 40.8 & 78.4 & 0.79 \\
\hline Oxide Olivine Micrngabbro & 9 & 1.65 & 0.18 & 0.23 & 0.330 & 3.134 & 0.124 & 2 & 0.346 & 45.6 & 4.18 & 12.56 & 4.77 & 13.98 & 16.84 & 0.24 & 7.03 & 9.60 & 2.97 & 0.04 & 000 & 0.64 & 0.07 & 0.16 & 47.3 & 8.1 & 0.69 \\
\hline Oxide Fyroxenite & 3 & 0.24 & 0.08 & 0.02 & 0.048 & & & 0 & 0.054 & 50.8 & 0.36 & 16.56 & 1.18 & 5.17 & 6.22 & 0.12 & 9.75 & 11.89 & 2.95 & 0.06 & 0.01 & 1.21 & 0.04 & 2.20 & 765 & 815 & 0.66 \\
\hline Oxide-Rich Vein & 3 & 0.20 & 0.07 & 0.07 & 0.040 & & & 0 & 0.045 & 50.8 & 0.36 & 16.56 & 1.18 & 5.17 & 6.22 & 0.12 & 9.75 & 11.89 & 2.95 & 0.06 & 0.01 & 1.21 & .04 & 2.20 & 76.5 & 815 & 0.66 \\
\hline Patchy Olivine Gathro & 14 & 8.07 & 0.58 & 0.57 & 1.612 & 2.919 & 0.030 & 5 & 1577 & 49.7 & 0.28 & 16.52 & 0.94 & 4.45 & 4.73 & 0.09 & 11.64 & 14.37 & 1.95 & 0.02 & 0.01 & 0.46 & 0.08 & 0.60 & 82.3 & 39.0 & 0.80 \\
\hline Patchy Oxide Olivine Gabhro & 3 & 2.37 & 0.79 & 0.49 & 0.473 & & & 0 & 0.528 & 54.0 & 0.49 & 16.56 & 0.92 & 5.95 & 6.78 & 0.16 & 7.02 & 10.19 & 3.90 & 0.06 & 0.06 & 0.62 & $\infty$ & 1.22 & 67.8 & 74.3 & 0.56 \\
\hline Troctolite & 9 & 5.61 & 0.62 & 0.67 & 1.120 & 2.993 & 0.182 & 2 & 1.124 & 45.7 & 0.17 & 16.90 & 0.90 & 6.33 & 6.67 & 0.11 & 17.82 & 9.81 & 1.74 & 0.03 & 0.01 & 1.89 & 0.00 & 1.41 & 83.4 & 86.2 & 0.53 \\
\hline Troctolitic Gathro & 9 & 5.47 & 0.61 & 0.61 & 1.092 & 2.906 & & 1 & 1.06 & 48.7 & 0.20 & 20.15 & 0.61 & 4.32 & 4.68 & 0.09 & 11.60 & 12.74 & 2.03 & 0.2 & 0.01 & 0.65 & $\infty$ & 059 & 82.7 & 87.4 & 0.57 \\
\hline \multirow[t]{2}{*}{ Troctolitic Micrngabbro } & 9 & 1.42 & 0.16 & 0.1 & 0.284 & 2.911 & 0.073 & 2 & 0.277 & 44.9 & 0.28 & 12.67 & 5.45 & 11.88 & 14.33 & 0.24 & 16.36 & 8.60 & 1.56 & 0.07 & 0.01 & 0.74 & 0.00 & 0.11 & 71.1 & 85.9 & 0.62 \\
\hline & 493 & 500,70 & 11.37 & 14.66 & 100 & & & & & & & & & & & & & & & & & & & & & & \\
\hline Rulk Hole 735 & & & & & & 2.984 & & & & 49.3 & 1.41 & 15.72 & 1.97 & 6.92 & 8.44 & 0.15 & 9.15 & 12.12 & 2.67 & 0.05 & 0.04 & 0.80 & 0.05 & 257 & 71.4 & 82.9 & 0.72 \\
\hline Bulk Mlole with Trmn & & & & & & & & & & 49.4 & 1.40 & 15.73 & 1.97 & 6.88 & 8.40 & 0.15 & 9.10 & 1207 & 2.69 & 0.06 & 0.04 & & & & & & \\
\hline
\end{tabular}

Notes: "I Int. is the number of discrete lithologie intervals of each lithology. N is the number of seppanate observations of the density.

\begin{tabular}{|c|c|c|c|c|c|c|c|c|c|c|}
\hline & $\mathrm{v}$ & $\mathrm{C}_{\mathrm{r}}$ & $\mathrm{Ni}$ & $\mathrm{Cu}$ & $\mathrm{Zn}_{\mathbf{n}}$ & $\mathrm{Rb}$ & $S_{t}$ & $\begin{array}{l} \\
Y\end{array}$ & Zs & $\mathrm{Nb}$ \\
\hline Lithology & 242 & 190 & 91 & 61 & 68 & 1.0 & 157 & 43 & 134 & 3.7 \\
\hline Diabase & 162 & 2857 & 190 & 19 & 18 & $<0.8$ & 124 & 9 & 11 & $<0.5$ \\
\hline Diopsidic Olivine Gabbro & 220 & 37 & 48 & 49 & 44 & 1.2 & 179 & 14 & 19 & 0.7 \\
\hline Disseminated Oxide Olivine Gabbro & 130 & 383 & 129 & 45 & 28 & 1.4 & 161 & 11 & 2 & 1.0 \\
\hline Gabbro & 190 & 13 & 45 & 34 & 53 & 22 & 183 & 22 & 186 & 1.0 \\
\hline Gabbro Norite & 224 & 49 & 47 & 9 & 30 & $<0.8$ & 168 & 13 & 13 & $<0.5$ \\
\hline Microgabbro & 130 & 383 & 129 & 45 & 28 & 1.4 & 161 & 11 & 22 & 1.0 \\
\hline Olivine Gabbro & 104 & 241 & 161 & 41 & 27 & $<0.8$ & 168 & 9 & 10 & 0.7 \\
\hline Olivine Microgabbro & 615 & 52 & 107 & 95 & 44 & $<0.8$ & 145 & 32 & 32 & 22 \\
\hline Oxide Gabbro & 880 & 41 & 47 & 122 & 153 & $<0.8$ & 141 & 17 & 42 & 3.0 \\
\hline Oxide Gabbro N & & & & & & & & & & \\
\hline Oxide Microg abbro Norite & 619 & 7 & 21 & 72 & 117 & 0.9 & 162 & 28 & 54 & 4.2 \\
\hline Oxide Olivine Gabbro & 650 & 65 & 35 & 72 & 85 & 0.9 & 167 & 16 & 20 & 1.7 \\
\hline Oxide Olivine Microgabbro & 153 & 224 & 112 & 32 & 28 & $<0.8$ & 166 & 11 & 15 & 0.9 \\
\hline Oxide Pyroxenite. & 153 & 224 & 112 & 32 & 28 & $<0.8$ & 166 & 11 & 15 & 0.9 \\
\hline Oxide-Rich Vein & 108 & 335 & 137 & 108 & 29 & 0.8 & 161 & 6 & 8 & $\cos$ \\
\hline Patchy Olivine Gabbro & 173 & 10 & 24 & 29 & 43 & $<0.8$ & 203 & 10 & 14 & 0.5 \\
\hline Patchy Oxide Olivine Gabbro & 43 & 1314 & 506 & 52 & 41 & 0.9 & 120 & 4 & 7 & 0.6 \\
\hline Troctolite & 75 & 986 & 260 & 63 & 31 & & 146 & 7 & 22 & 0.6 \\
\hline setolitic Gabbro & 102 & 96 & 318 & 93 & 128 & 22 & 47 & it & 18 & 28 \\
\hline ogabbro & 234 & 295 & 105 & 51 & 47 & & 162 & 15 & 36 & \\
\hline
\end{tabular}


suggesting that some of the finer-grained titanaugite may have been chrome diopside.

\section{Troctolite and Troctolitic Microgabbro}

These are fine- to medium- grained equigranular rocks in hand specimen, consisting of about $60 \%$ plagioclase and $20 \%$ to $40 \%$ olivine, with $0 \%$ to $20 \%$ clinopyroxene. They range from pyroxene-poor xenomorphic granular olivine-plagioclase adcumulates and mesocumulates to pyroxene-rich heteroadcumulates. Texturally, olivine is subhedral to anhedral, locally occurring as granular to wormy blebs. It may be intergranular to subophitic to plagioclase. Two kinds of clinopyroxene are present. Most abundant is subophitic to oikocrystic intergranular red clinopyroxene (titaniferrous augite). The rock frequently contains impressive pyroxene oikocrysts, which generally consist of patches where a fine network of about $20 \%$ pyroxene encloses about $80 \%$ discrete plagioclase and olivine grains (chadacrysts). A second kind of clinopyroxene occurs as medium-grained green chrome diopside intergrown locally with coarser stubby plagioclase laths. The chrome diopside is always intergranular to subophitic and stands out in hand specimen due to its green color and comparatively coarse grain size. A distinctive feature of the troctolitic rocks is the presence of chromian spinel, sometimes reddish brown in thin section, but frequently oxidized around its margins or entirely to a titaniferrous ferritchromite (oxidized chromian spinel). In one $2 \mathrm{~m}$ troctolitic layer, a single 10 -cm-thick spinel-rich zone occurs $(-83-7$, Pcs. $4 d$ and $4 c)$ containing about $2 \%$ spinel.

Chemically and mineralogically, with the exception of minor amounts of hybrid diopsidic olivine gabbro, the troctolitic gabbros (Fig. 2) are associated with the most primitive liquids of any Hole 735B gabbro. They have whole-rock $\mathrm{Mg} /(\mathrm{Mg}+\mathrm{Fe})$ ratios that rnage from 78.6 to 86.9 and $\mathrm{Ca} /$ $(\mathrm{Ca}+\mathrm{Na})$ ratios ranging from 83 to 91.8 . Olivine is magnesian, $\mathrm{Fo}_{80-85}$, and plagioclase is calcic $\mathrm{An}_{66-76}$, while chromian spinels (generally $\mathrm{Cr} /(\mathrm{Cr}+\mathrm{Al})=49$ to 61 ) have relatively high chrome contents that extend to the upper limit for spinel in abyssal basalts (Dick and Bullen, 1984). The troctolites are noticeably poor in silica and alumina and rich in iron and magnesium, compared to basaltic liquids, which is consistent with these rocks being olivine.

Spinels in these rocks are iron-rich, compared to that typical for abyssal basalts. They also may have strong irregular zonation, frequently with very titaniferrous cores (up to $4 \% \mathrm{TiO}_{2}$ ). No spinel analyzed in abyssal basalt has been found having a titanium content much in excess of $1 \%$ (e.g. Dick and Bullen, 1984). It seems unlikely that the troctolites and olivine microgabbros might have originally precipitated from an alkaline basalt magma on the basis of their primary silicate mineralogy, which is generally consistent with precipitation from a primitive tholeiite, particularly where the spinels are most titanium-poor and most closely resemble those found in MORBs. We postulate that these spinels initially precipitated from a moderately primitive abyssal tholeiite and then later, underwent incomplete reaction with a second, initially titanium-rich, liquid. The zoning indicates that this liquid evolved to low titanium contents by precipitation of intergranular oxides, even as it continued to react with the spinel (Dick and Angeloni, unpubl. data).

\section{Troctolitic Gabbro}

The troctolitic gabbros are closely associated with the troctolites and troctolitic microgabbros and may be directly related to them. They are also fairly primitive with $0.2 \% \mathrm{TiO}_{2}$, and whole-rock $\mathrm{Mg} /(\mathrm{Mg}+\mathrm{Fe})$ ratios $=80.4$ to 84.3 and $\mathrm{Ca} /(\mathrm{Ca}+\mathrm{Na})$ ratios $=85$ to 89.9 . The troctolitic gabbros are unusual rocks that are heterogeneous mineralogically and texturally. The most prominent characteristic is an exceptional abundance of olivine, such that the gabbro is locally a troctolite. However, this gabbro also contains frequent patches of medium- to very-coarse kelly green chromian diopside. Locally, these might be considered patches of clinopyroxenite (e.g., -80R-1, Pcs. 6a and 6b). Elsewhere, there are anorthositic patches (-79R-5, Pc. 5, 80R-1, Pc. 5) up to 6 to $7 \mathrm{~cm}$ across. Plagioclase has an unusual stubby habit. Olivine is intergranular and may be oikocrystic. Its texture is unusual and hard to describe, grading texturally from oikocrystic into the bleblike texture of aplitic troctolitic microgabbros. Troctolitic gabbros generally have sharp intrusive contacts with the generally coarser grained olivine gabbro.

Both troctolitic gabbros and troctolites are coarse- to medium-grained intrusives. Chemically the troctolitic gabbros are similar to the troctolitic microgabbros (Fig. 2). The troctolitic microgabbros grade compositionally into olivine microgabbros, and the troctolitic gabbros range between troctolite and olivine gabbro. The troctolitic gabbros differ from the troctolites, with higher silica, alumina, soda, and calcium, and lower iron and magnesium. These differences can be accounted for if the troctolite is an olivine adcumulate facies of the troctolitic gabbro (the latter being an ortho- or mesocumulate containing a higher percentage of the parent magma).

\section{Patchy Olivine Gabbro}

These gabbros may best be described as microgabbros with local coarse olivine gabbro patches or, conversely, olivine gabbros with local microgabbro patches. Their origin is problematic, but the fine-grained facies, except for the absence of sharp igneous contacts with the olivine gabbro, is identical to the olivine microgabbros. The coarse-grained patches are identical to the olivine gabbros. We think that the most likely explanation for these rocks is that they represent olivine gabbros intruded by fresh magma while they were still a crystalline mush and insufficiently rigid for intrusive contacts to form-but too viscous for the fresh magma to mix readily with the old.

\section{Diopsidic Olivine Gabbro}

This rock type is a variety of olivine gabbro distinguished by local olivine-rich patches and coarse patches of kelly green diopside. Most of the pyroxene in the diopsidic olivine gabbro, however, is dark brown to reddish augite identical to that in the olivine gabbro. These gabbros are found only adjacent to troctolite and troctolitic gabbros, and the one sample analyzed has the most primitive composition of any gabbro analyzed on board ship from Hole 735B. One can postulate that these are hybrid gabbros, formed most likely by local impregnation of wall rock olivine gabbro by liquid leaked from the troctolites during their intrusion.

\section{Trondhjemite}

Trondhjemitic veins and intrusion breccias, though volumetrically minor $(0.43 \%)$, are present at many levels throughout the core. In thin section (Init. Repts., p. 117), these are medium-grained leucocratic rocks composed of roughly $75 \%$ plagioclase, $20 \%$ quartz, $2 \%$ biotite, $2 \%$ clinopyroxene, and $1 \%$ magnetite. Zircon is present as beautiful, locally abundant, euhedral grains in many trondhjemites. Acicular hornblende crystals are present in some hand samples as well. Clinopyroxene may be subhedral and has been largely replaced by actinolite. Biotite poikilitically encloses euhedral plagioclase crystals. The trondhjemites generally have a granular aplitic texture with interstitial quartz and blocky subhedral plagioclase crystals. The plagioclase may have homogeneous cores 
and strongly zoned rims. The only sample analyzed has a granitic melt composition with a very high albite content and $70.8 \% \mathrm{SiO}_{2}$. The trondhjemites differ from the microgabbros in that they have classic sharp intrusive contacts formed by brittle fracture and intrusion to form vein networks and intrusion breccias. Thus, rather than the sutured intergrown grains found along the contacts between microgabbros and olivine gabbros, individual grains in the olivine gabbro are discontinuous and terminate abruptly at the contact with the trondhjemite.

There are also numerous felsic veins $(0.63 \%)$, some clearly modified igneous trondhjemites, as well as many of ambiguous paragenesis: some problematically igneous, some clearly hydrothermal. A complete gradation between different kinds of felsic veins exists because of ongoing, and often extensive, late hydrothermal alteration and overprinting of earlier veins. Thus, positive identification of and discrimination between hydrothermal and late-magmatic origins for many felsic veins and trondhjemites is difficult. For this reason, and because the trondhjemites morphology is similar to many hydrothermal vein assemblages, they are discussed further in the deformation and alteration section.

\section{Synkinematic Late-Magmatic Gabbros}

Macroscopically, these rocks are strongly associated with penetrative high-temperature deformation and contain ubiquitous iron-titanium oxides. Mineralogically, they contain markedly more sodic plagioclase $\left(A n_{30-45}\right)$, iron-rich olivine $\left(\mathrm{Fo}_{30-60}\right)$, and pyroxene than the olivine gabbros. Their titanium content is highly variable and relates directly to the amount of late intergranular oxide present. They seem to have largely formed in association with high-temperature ductile faults that crosscut the oxide-free olivine gabbro. Final crystallization of late intercumulus iron-titanium-rich melt and precipitation of much of the intergranular oxides post-dates deformation. As will be discussed extensively in this chapter, these are postulated to have formed by deformation channeling late intercumulus liquid along fault zones from partially molten regions of the gabbro. Extensive chemical exchange with the migrating intergranular liquid and precipitation of oxide in the deformation zones transformed the gabbro in these zones to an oxide-bearing deformed textural equivalent of the original rock, but generally of different composition and mineralogy. Locally, the late intercumulus melt was squeezed into brittle fractures out of the deformation zones, where it crystallized to form oxide- and often pyroxene-rich veins.

\section{Oxide Gabbronorite}

This lithology is texturally similar to the gabbronorite above, except for the presence of abundant intergranular iron-titanium oxide (mostly ilmenite) and a consistently foliated or weakly deformed texture.

\section{Oxide Gabbro}

A total of $8.1 \mathrm{~m}$ of oxide gabbro was drilled in Hole 735B. This gabbro is generally an equigranular igneous rock, but in most cases, it has a weak foliation caused by deformation. Locally, this rock type occurs in veins that may be undeformed, but crosscut the olivine gabbro. The average oxide gabbro interval is thin, averaging only $0.2 \mathrm{~m}$ thick, and occurs for the most part in thin seams in olivine gabbro. It is most abundant in the Unit II Compound Olivine Gabbro, but even there the oxide gabbro is a minor lithology. Lower in the core, it occurs only in Unit VI, where it is found as deformed and undeformed veins that crosscut a complex compound olivine gabbro. The absence of olivine in this gabbro suggests an extensive reaction relationship between the late-magmatic liquid and olivine to produce pyroxene, eliminating the olivine from the impregnated olivine-gabbro protolith.

\section{Oxide Olivine Gabbro}

This gabbro is the second most abundant rock type in Hole $735 \mathrm{~B}$, after olivine gabbro, and occurs in every unit except Unit I. It generally occurs in brittle-ductile deformation zones and often criss-crosses massive olivine gabbro formed within or along narrow braided shear zones from millimeters to tens of centimeters thick. Generally, the oxide olivine gabbro occurs as relatively thin seams of sheared to weakly foliated gabbro, except in Unit IV, where it makes up 49 of $50.5 \mathrm{~m}$, and in Subunit VIA, where it makes up 15 of $67 \mathrm{~m}$. Texturally, the oxide olivine gabbro has a consistent very weak to strong penetrative foliation, with equigranular, often interlocking, pyroxene, plagioclase, and olivine. In addition, this gabbro contains $2 \%$ to $50 \%$ (ave. $8 \%$ ) intergranular iron-titanium oxide, mostly ilmenite. The oxide is anhedral and locally may fill cracks, where coarse pyroxene appears to have been pulled apart. Highly anhedral, the intergranular oxide often defines a foliation in the gabbro and may vary radically in abundance on a centimeter-scale.

\section{Disseminated Oxide Olivine Gabbro}

The disseminated oxide olivine gabbro is characterized by less than $2 \%$ oxides and the intermittent appearance of pigeonite. Generally, it occurs as fairly thick intervals (1.2 $\mathrm{m}$ ave.) compared to much of the oxide olivine gabbro $(0.65 \mathrm{~m}$ ave.), which often occurs in very thin seams. Olivine is generally intergranular, while plagioclase often occurs as euhedral to subhedral laths with a strong preferred orientation defining a lamination. Anhedral pyroxene grains are often aligned and elongated in the foliation plane. Mineral grains in the foliation plane are often lineated. Most of the disseminated oxide olivine gabbro ( 35 of $41 \mathrm{~m}$ ) occurs in Unit III, where there is a single interval $15 \mathrm{~m}$ thick. Although the disseminated oxide gabbro locally looks as if it has a simple igneous granular texture; overall, it is characterized by a penetrative foliation or lamination that persists, albeit weakly, even where the texture looks most igneous.

Oxide Olivine Microgabbro, Troctolitic Oxide Gabbro, and Patchy Oxide Olivine Gabbro

Texturally, these rocks are identical to the oxide-free microgabbros described above. The only difference is the presence of from $1 \%$ to $20 \%$ iron-titanium oxides and a weak to strong foliation. Locally, the foliation and the oxide-bearing zones crosscut the contacts between oxide-free olivine gabbro and microgabbro. In Unit VI, oxide-free microgabbros also intrude olivine gabbros that have oxide impregnated brittleductile shear zones crossing them. Where sheared, they contain oxides; where undeformed, they are oxide-free. This suite, and its often contradictory contact relations, are interpreted, like the other oxide gabbros, as being due to syndeformational late-magmatic oxide impregnation that overlapped with a series of minor intrusive events.

\section{Igneous Stratigraphy}

\section{Introduction}

We have followed as closely as possible the original shipboard division of the lithologic section and divided it into six units, distinctive on the basis of their mineralogy, petrology, structure, and lithologic variability (Fig. 3). Exact positions of the unit boundaries are shown in Table 3. These positions are generally slightly different than those given in the original report, and are believed to be less arbitrary as they are based on far more detailed statistics and uniform description 
Table 3. Igneous unit stratigraphic boundaries, Hole 735B.

\begin{tabular}{|c|c|c|c|c|}
\hline \multirow[b]{2}{*}{ Unit } & \multirow{2}{*}{$\begin{array}{c}\text { Base of } \\
\text { unit }\end{array}$} & \multicolumn{2}{|c|}{ Thickness } & \multirow{2}{*}{ Location } \\
\hline & & Subunit & Unit & \\
\hline $\begin{array}{l}\text { IA } \\
\text { IB }\end{array}$ & $\begin{array}{l}27.99 \\
37.41\end{array}$ & $\begin{array}{c}27.99 \\
9.48\end{array}$ & 37.47 & $\begin{array}{l}\text { Core } 7-1,114 \mathrm{~cm}, \mathrm{pc} 14 \\
\text { Core } 10-1,70 \mathrm{~cm}, \mathrm{pc} 2\end{array}$ \\
\hline II & 170.22 & & 132.75 & Core $35-6,72 \mathrm{~cm}$, pc 7 \\
\hline $\begin{array}{l}\text { IIIA } \\
\text { IIIB } \\
\text { IIIC }\end{array}$ & $\begin{array}{l}180.09 \\
209.45 \\
223.57\end{array}$ & $\begin{array}{l}9.87 \\
29.36 \\
14.12\end{array}$ & 53.35 & $\begin{array}{l}\text { Core } 37-3,70 \mathrm{~cm}, \mathrm{pc} 3 \\
\text { Core } 43-3,98 \mathrm{cn}, \mathrm{pc} 1 \mathrm{k} \\
\text { Core } 46-2,150 \mathrm{~cm}, \mathrm{pc} 7 \mathrm{c}\end{array}$ \\
\hline IV & 274.06 & & 50.49 & Core $56-3,116 \mathrm{~cm}$, pc 29 \\
\hline $\mathrm{V}$ & 382.40 & & 108.34 & Core $74-6,3 \mathrm{~cm}, \mathrm{pcl}$ \\
\hline $\begin{array}{l}\text { VIA } \\
\text { VIB } \\
\text { VIC } \\
\text { VID }\end{array}$ & $\begin{array}{l}404.01 \\
419.28 \\
433.77 \\
500.70\end{array}$ & $\begin{array}{l}21.61 \\
15.27 \\
14.49 \\
66.93\end{array}$ & 118.30 & $\begin{array}{l}\text { Core } 77-1,53 \mathrm{~cm}, \mathrm{pc} 2 \mathrm{e} \\
\text { Core } 79-4,56 \mathrm{~cm}, \mathrm{pc} 2 \mathrm{f} \\
\text { Core } 81-1,26 \mathrm{~cm}, \mathrm{pc} 1 \mathrm{~b} \\
\text { Core } 88-1,70 \mathrm{~cm}, \mathrm{pc} 2\end{array}$ \\
\hline
\end{tabular}

of the stratigraphy. Unit names were changed to reflect more accurately their character. We have added new subunits, reflecting changes in the proportion and character of the rock types described within units. The complete stratigraphy is included in Appendix A. In Figure 5, we show only the principal changes in igneous lithology, as we were forced to combine intervals of the same rock type, which differ only in grain size, for clarity of illustration at a publishable scale. This reduces, for example, the number of igneous intervals in Subunit IIIA from 12 to 9 , where we have combined texturally distinct, very coarse-grained olivine gabbro and disseminated oxide olivine gabbro with adjacent coarse-grained varieties of those rock types.

The interval thicknesses reported in Appendix A represent expanded thicknesses, not actual measurements. These were arrived at by expanding the measured position of a contact or break in lithology between two sample fragments in the core liner, using the ratio of the interval actually drilled divided by the amount of rock actually recovered. While the core recovery and total length drilled for each core are included in Table 1, Chapter 6 in the Initial Reports volume of Leg 118, we actually remeasured the core recovery from the photographs in that volume of the core as stored and archived. This was necessary as the addition of plastic dividers between drilling fragments in the core liners before description often greatly expanded the section on which measurements were actually performed. In most cases, the measured thickness and the expanded thickness reported in Appendix A are very close due to the high recovery. In the upper $100 \mathrm{~m}$ of the core, however, the difference can be large as a result of the low recovery rates in many intervals there. Thus, the expanded thickness there may amount to little more than a guess at the original interval thickness.

The major change from the description of the lithologic units in the Initial Reports volume of Leg 118 is that we found that none of the contacts between units are simple faults juxtaposing unrelated rocks. The character of every single interval and unit contact was described individually in our notes. Though the unit contacts are locally deformed and sheared, overall they are gradational, with lithologies from overlying units persisting intermittently into the lower units. The nature of the igneous contacts varies considerably from pegmatoidal patches to intrusive. One would find it difficult to ascribe any contacts to primary layering in magmatic sediments, although there are sharp changes in modal proportions and grain size within the olivine gabbro that might reflect changes in the rate or conditions of crystallization on the walls of a magma chamber (Bloomer et al., this volume). Although numerous highly sheared and deformed contacts occur, from the interval to the unit level they are overwhelmingly igneous in origin. These contacts record a continuous cycle of cross intrusion and syndeformational magmatic activity, beginning while the gabbro was still partially molten, through a hypersolidus period (where it could sustain brittle-ductile deformation), down through the granulite facies to the amphibolite facies, where deformation and magmatic activity abruptly stopped. The proportion of different rock types and the number of individual intervals for the subunits are summarized in Table 4.

\section{Unit I (Gabbronorite)}

\section{Lithologic Summary}

Subunits IA (Massive Gabbronorite) and IB (Olivine Gabbro and Gabbronorite)

Unit I (Fig. 5A) is a gabbronorite with subordinate olivine gabbro. The upper two-thirds, Subunit IA, consists of thick intervals of gabbronorite, alternating with thin olivine gabbro layers. Subunit IB is dominantly olivine gabbro with thin gabbronorite layers and can be regarded as a transition zone to the Unit II olivine gabbro. Oxide-bearing gabbronorite and olivine gabbro are abundant in Subunit Ia, but rare in Subunit IB. The entire section is heavily deformed and hydrothermally altered and consists largely of amphibolite gneiss and mylonite. A major problem was identifying the protoliths of this gneiss: with the identification of individual intervals dependent on the difficult task of identifying relict or pseudomorphed orthopyroxene and olivine in the less deformed patches or locally enclosed in a resistant pyroxene.

As a rule, the rock is too heavily deformed to make out the precise contact position or relations between lithologic intervals and subunits. Occasionally, contacts are weakly deformed, and the two rock types can be seen and traced one to the other. In such cases, the contact is clearly igneous, with a sutured boundary where individual grains interlock across it. These contacts are transposed into or close to the plane of the foliation such that their initial orientation is unknown (e.g., the oxide gabbro-gabbronorite contact in Core $4 \mathrm{H}-2$, Pcs. 3 and 4). Rarely are intervals bounded by clear fault contacts, where there is a sharp discontinuous break in the lithology, though one clear example was found where foliated gabbronorite has been faulted against undeformed gabbro (Fig. 6). The foliation plane in the gneiss and mylonite is not uniform in dip, but ranges from horizontal to about $34^{\circ}$. Steeper dips occur, but are rare. In general, one can see that brittle-ductile deformation zones imbricate around blocks of weakly to undeformed gabbro, where the igneous texture has been preserved with only a little stretching and in the presence of a weak tectonic foliation. These relations suggest imbricate or braided brittle-ductile shear zones with sigmoidal structures (Fig. 7). Foliations that dip at about $30^{\circ}$ are most abundant, and those that dip at about $0^{\circ}$ are next most abundant.

At about $25 \mathrm{~m}$, an interval of partially recrystallized and weakly foliated diabase can be seen (interval 24). The contacts have been obscured by deformation, but may presently lie in the gneissic foliation plane. The basaltic composition of major and trace elements of the interval (Appendix B) contrasts sharply to the adjacent deformed gabbros. Although it is difficult to determine its exact thickness because of the fine grain size of the adjoining gabbro gneisses, the diabase is probably about $0.5 \mathrm{~m}$ thick. This interval was originally identified and reported in the Initial Reports volume of Leg 118 as a mylonitized gabbro because of its fine grain size and the presence of coarse plagioclase augen. In the enclosing gneisses and mylonites, however, plagioclase is extensively recrystallized, while pyroxene forms resistant augen. On 
HOLE 735B ATLANTIS II FRACTURE ZONE

\section{HOLE 735B LEGEND}

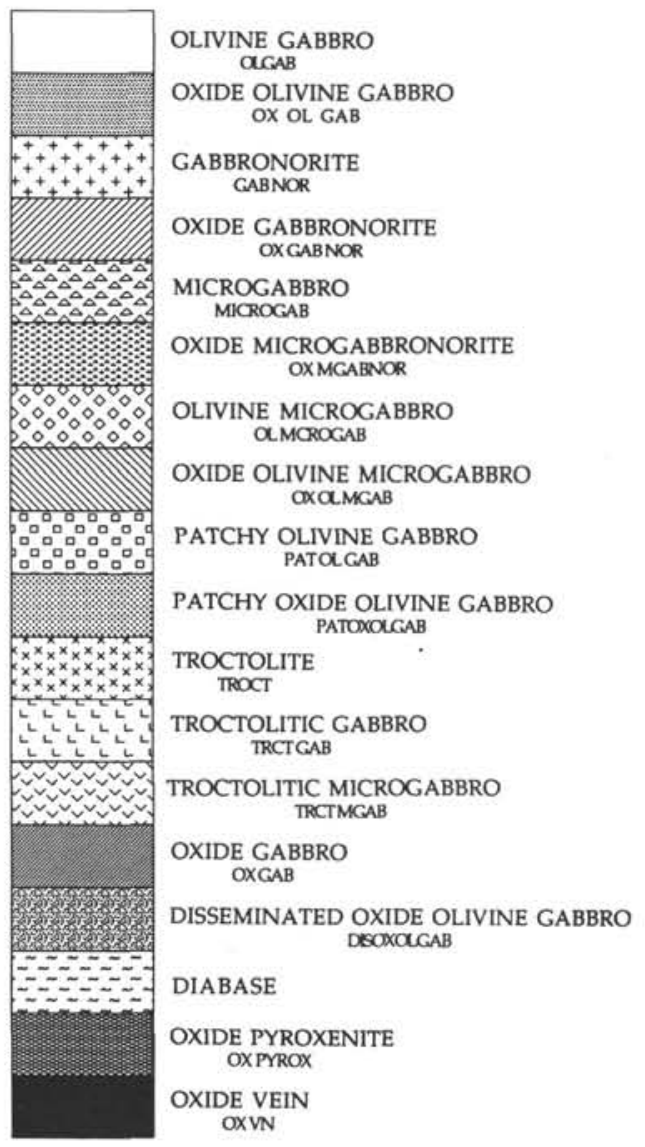

A

SCALE 1:100

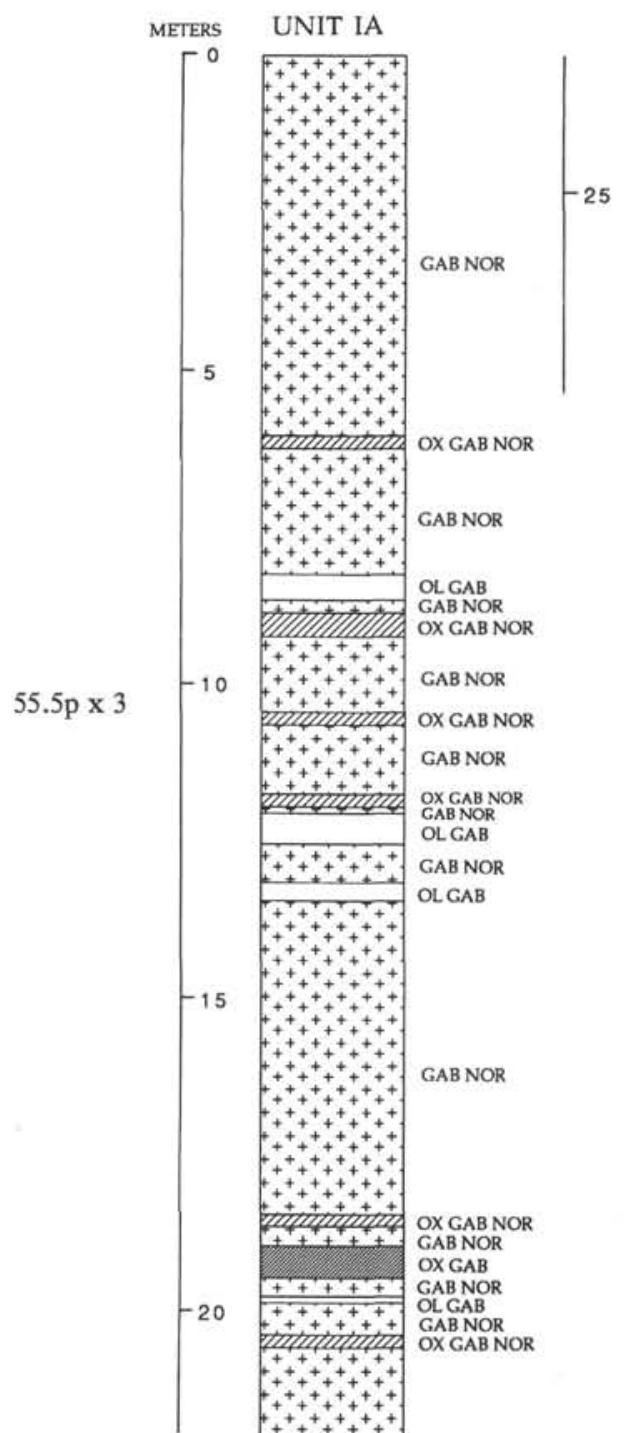

Figure 5. A. Hole 735B stratigraphic column. Unit I lithostratigraphy. B. Unit II lithostratigraphy. C. Unit III lithostratigraphy. D. Unit IV lithostratigraphy. E. Unit V lithostratigraphy. F. Unit VI lithostratigraphy. 


\section{.}

METERS

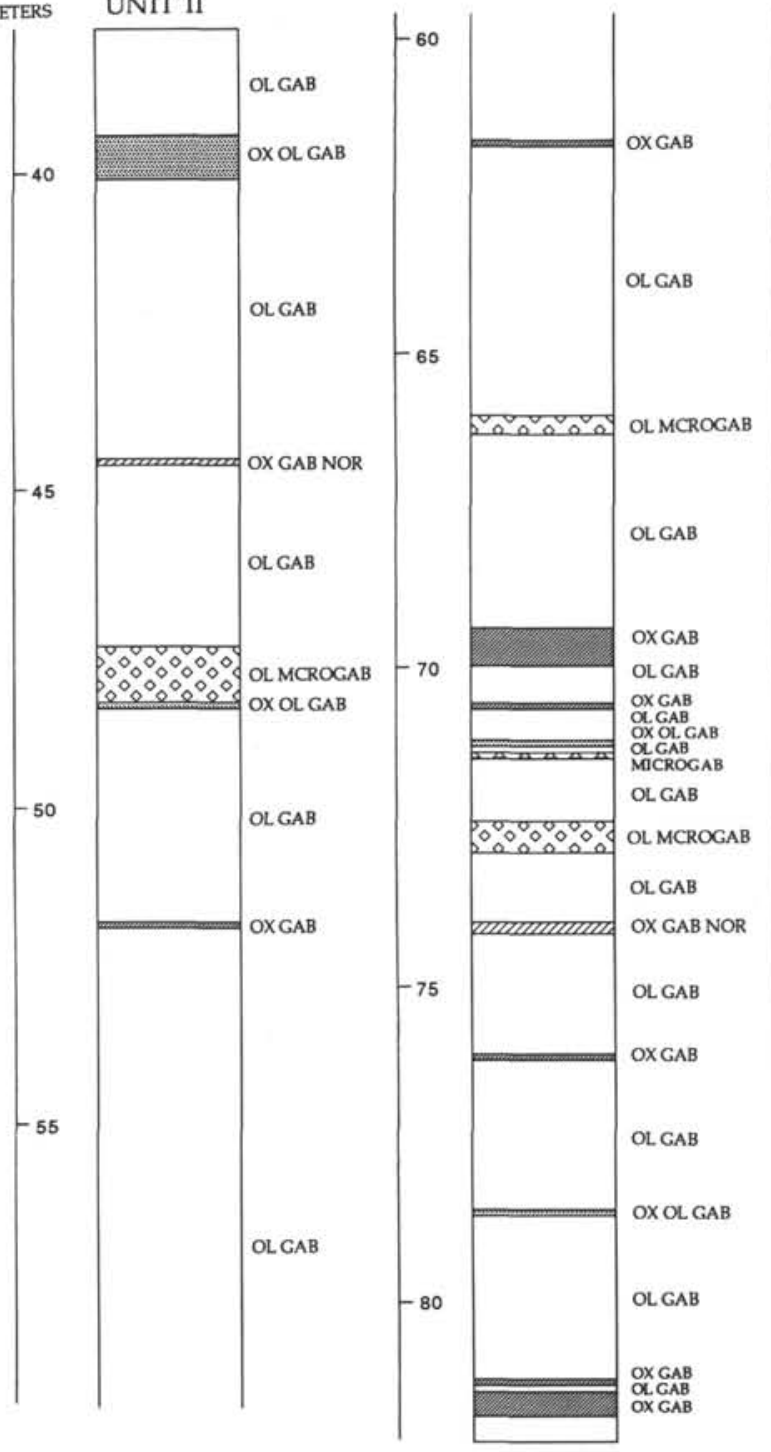

UNIT II (cont'd)

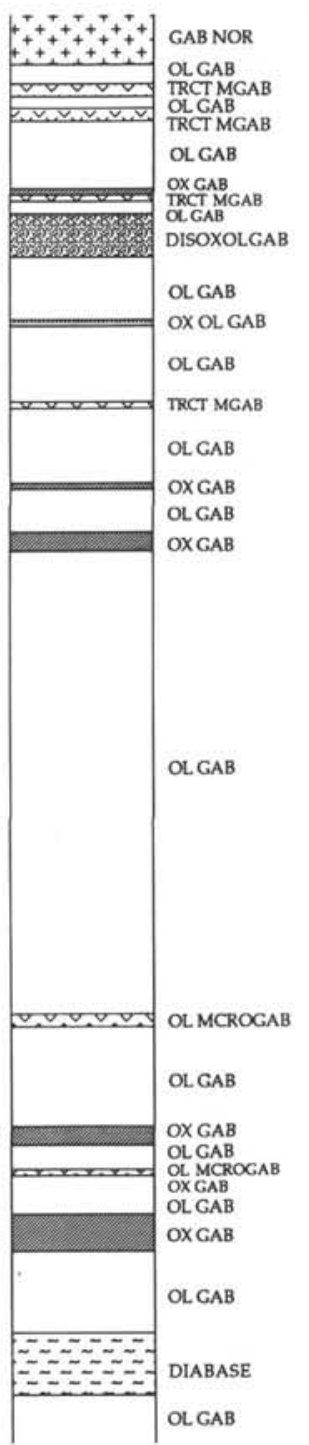

METERS

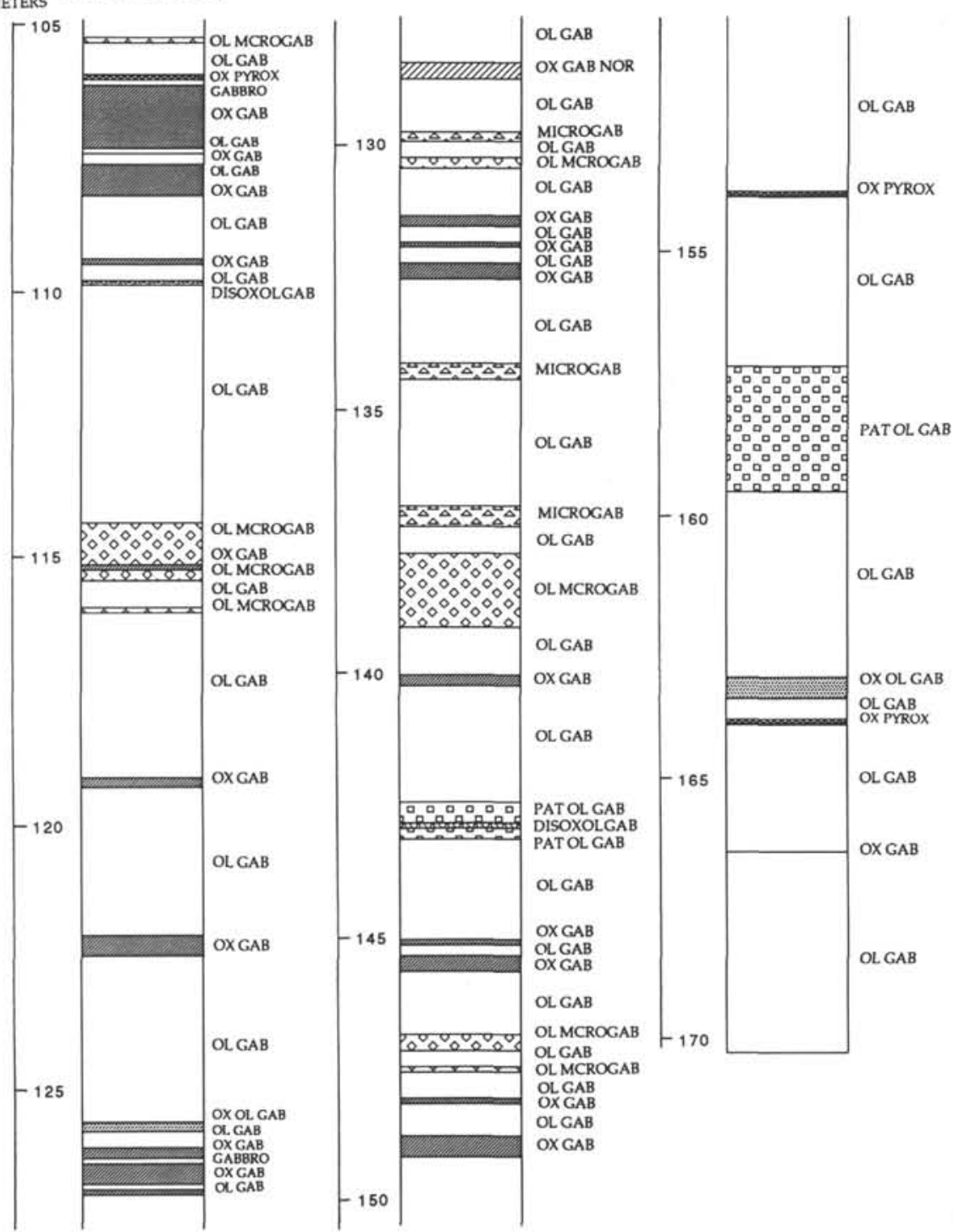

Figure 5 (continued). 


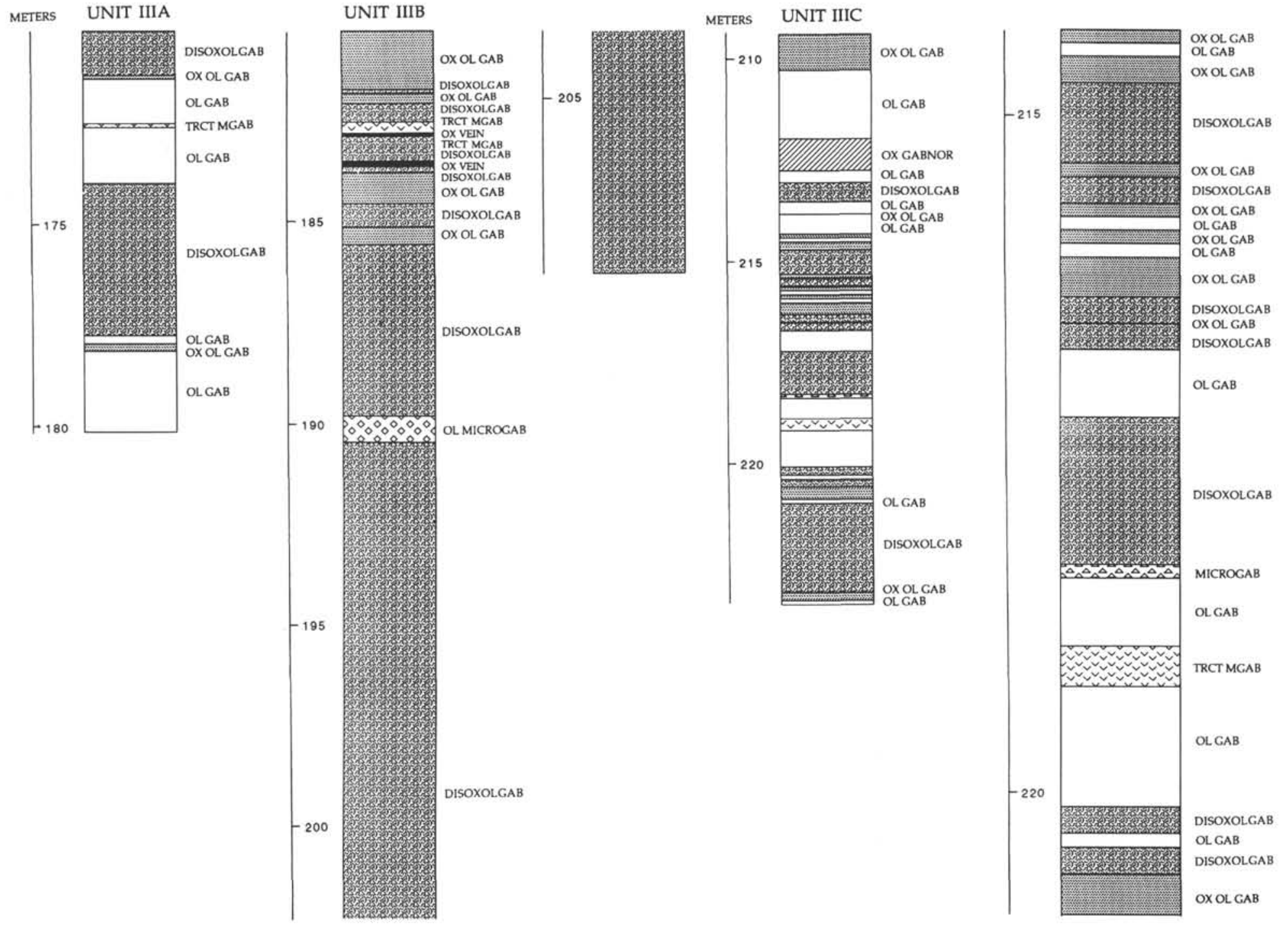


D

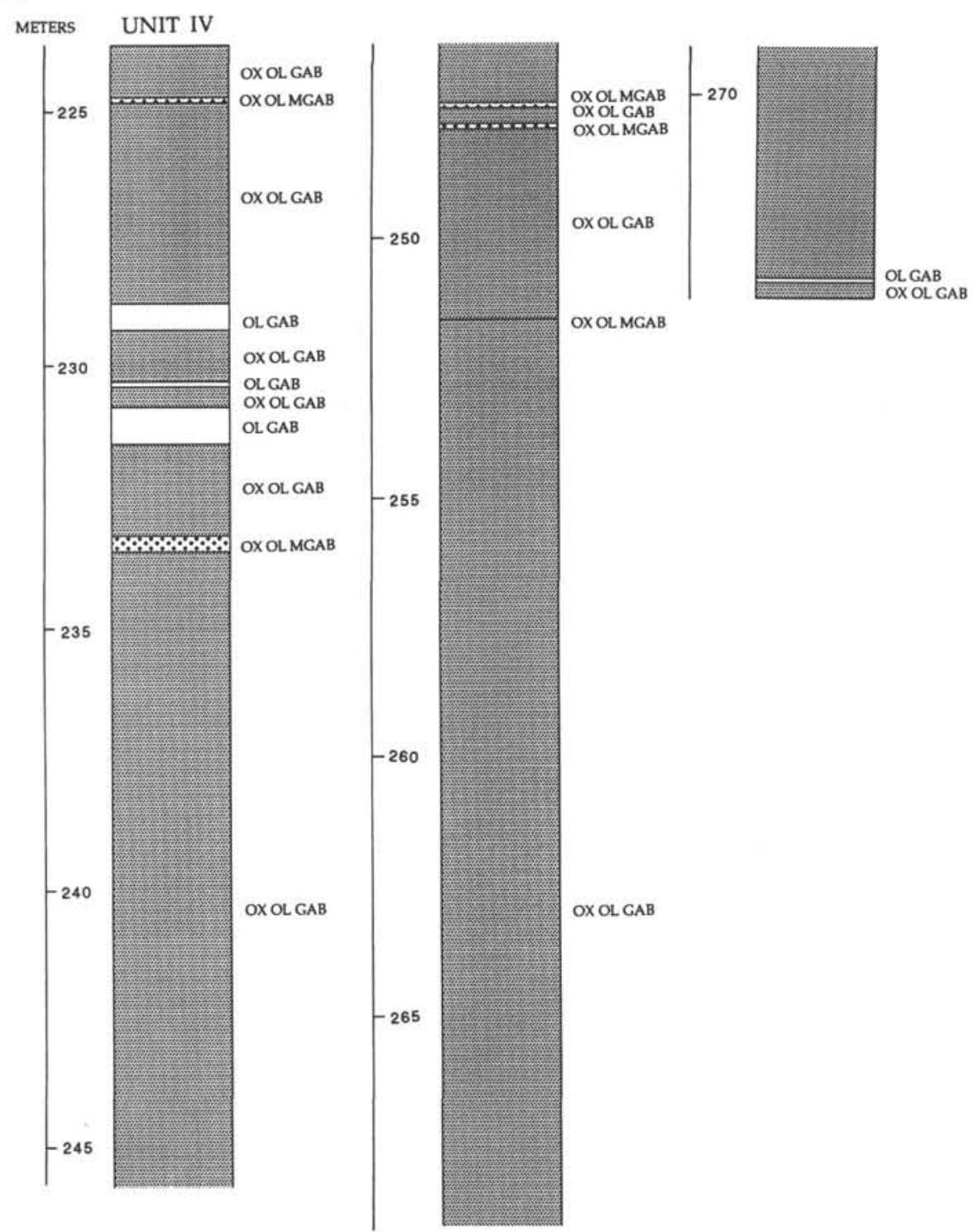

E

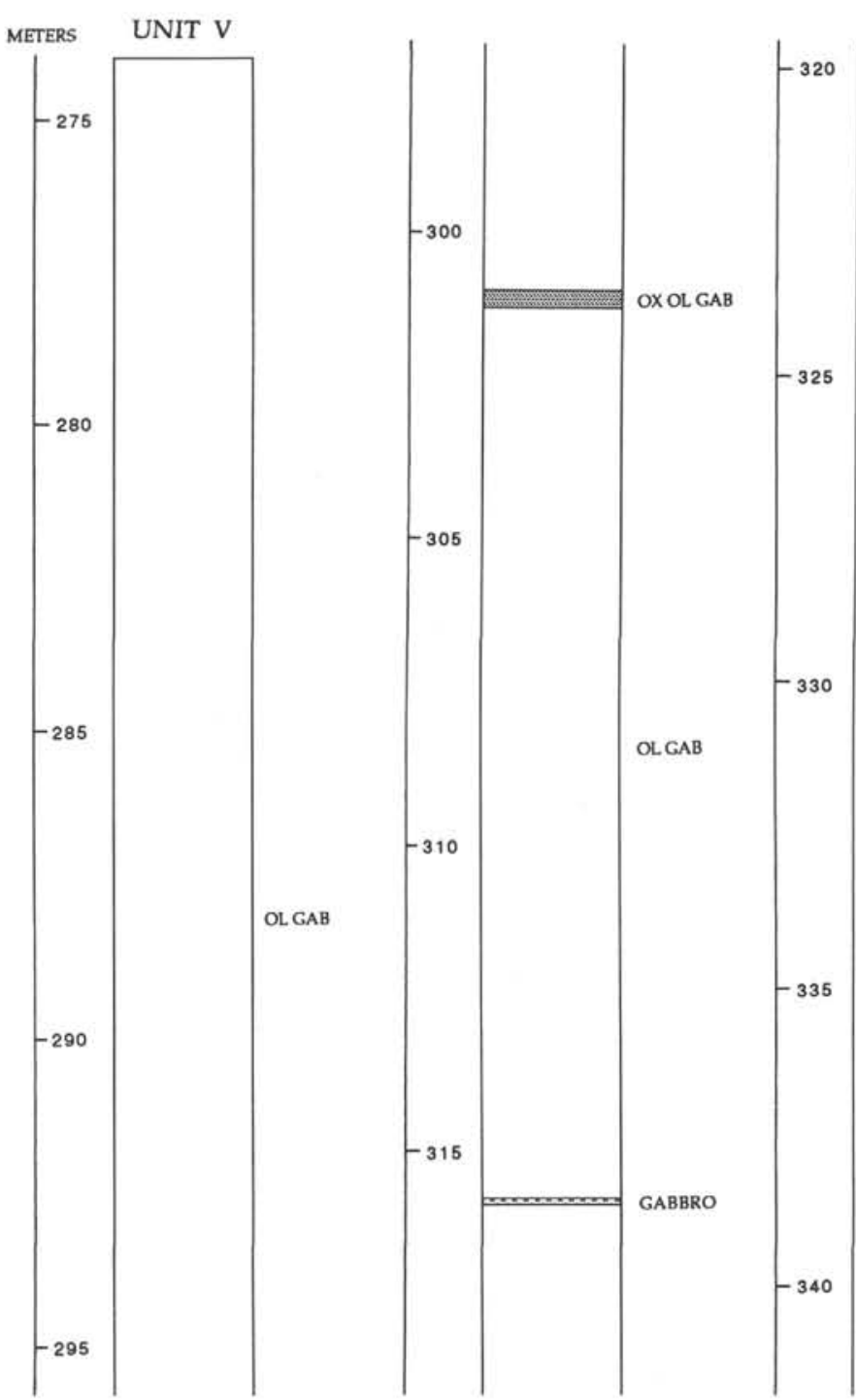

Figure 5 (continued). 
E

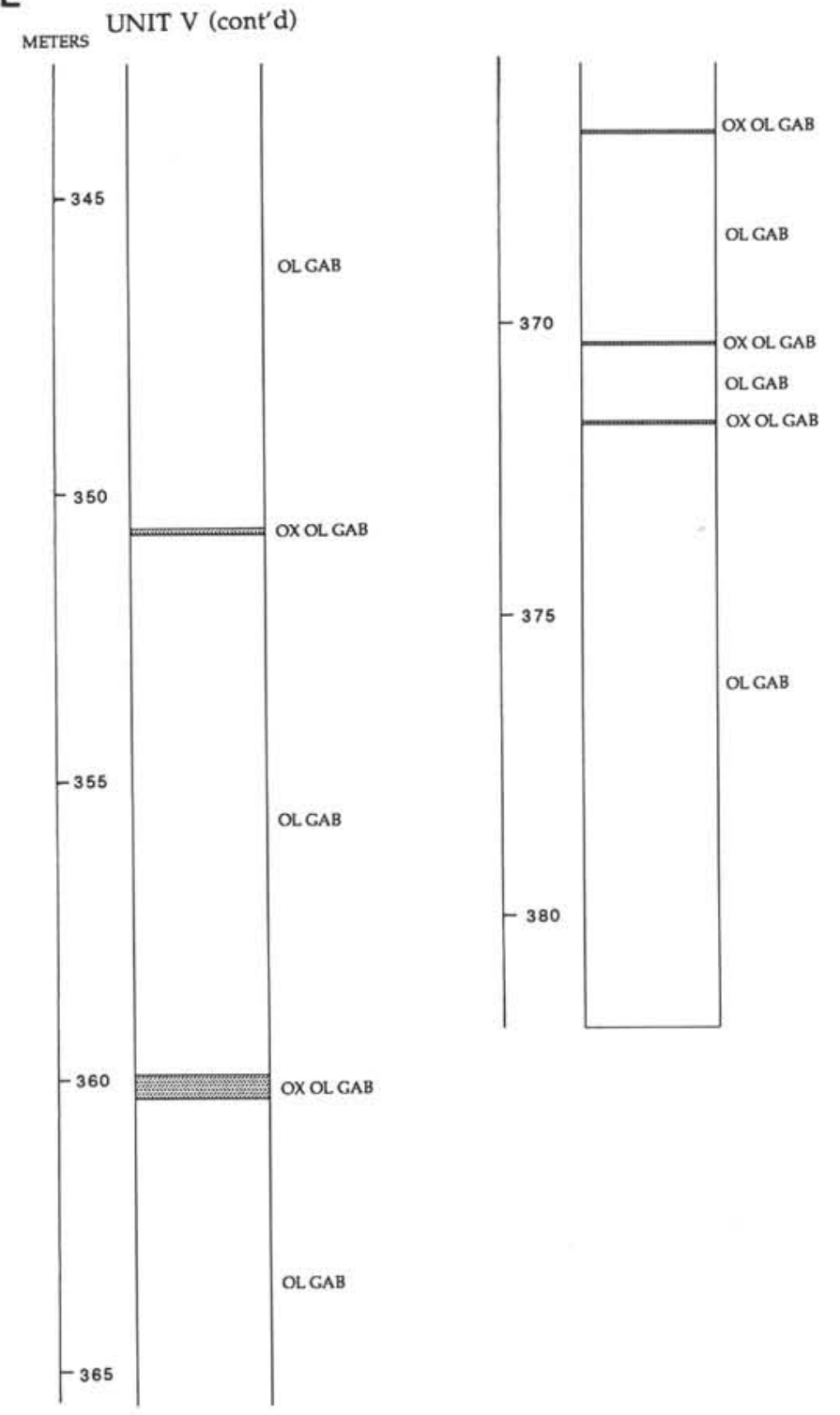

F

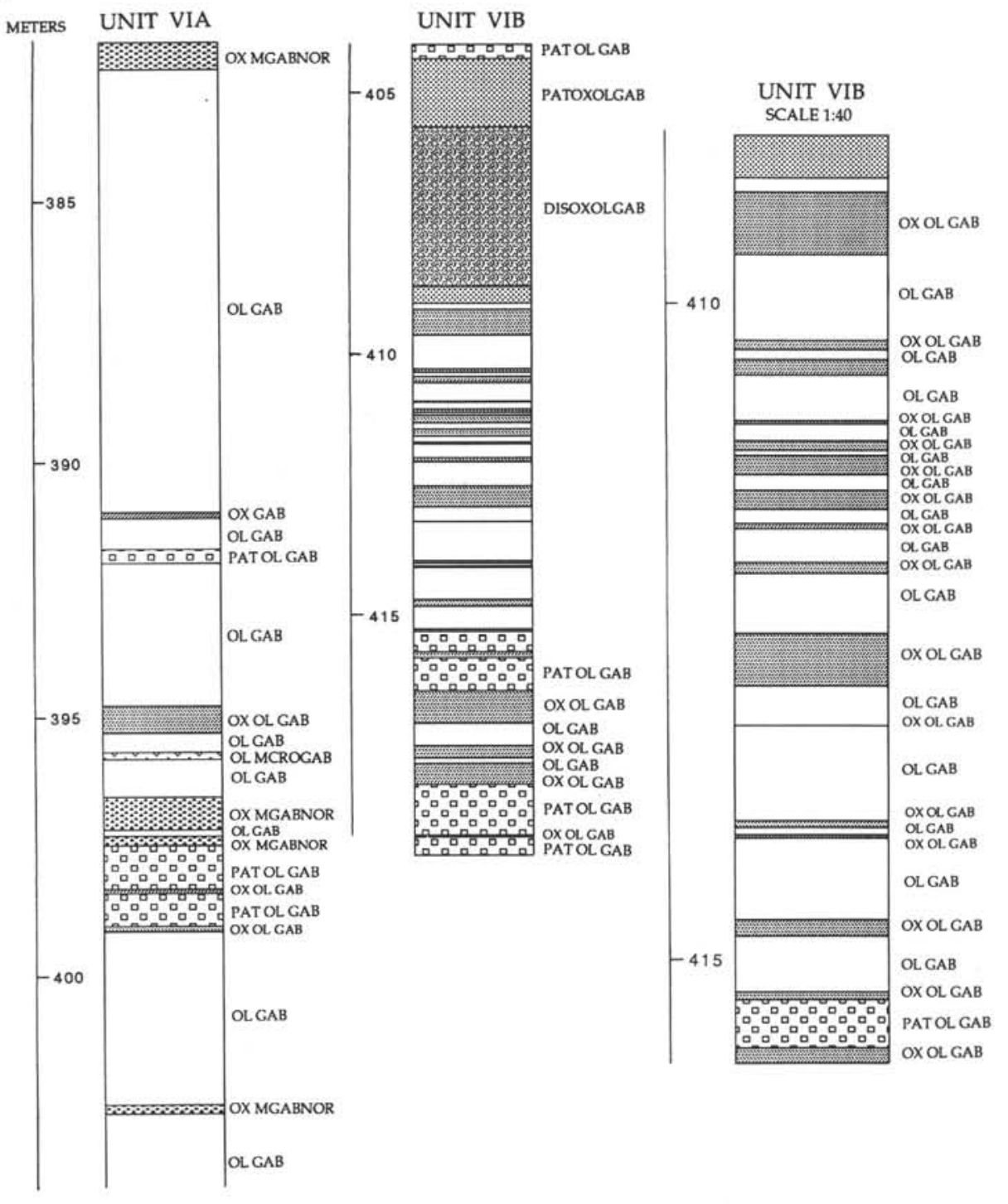

Figure 5 (continued). 


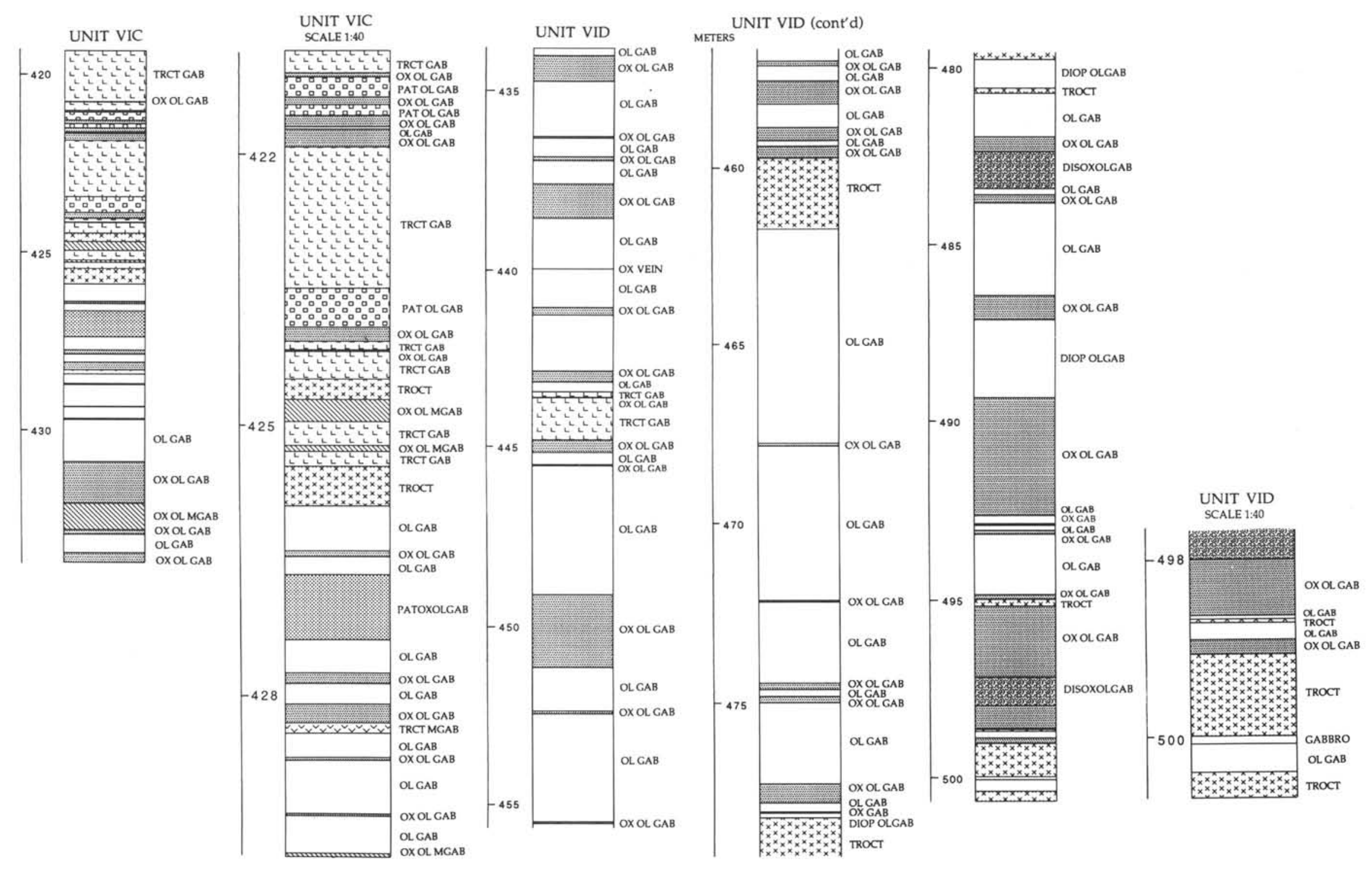

Figure 5 (continued). 
Table 4. Proportion of rock types by subunit, Hole 735B.

\begin{tabular}{|c|c|c|c|c|c|c|c|c|c|c|c|c|c|}
\hline Lithologic Unit: & $\mathrm{IA}$ & $\overline{\mathrm{IB}}$ & II & IIIA & IIIB & IIIC & IV & V & VIA & VIB & VIC & VID & Total \\
\hline \multicolumn{14}{|c|}{ Primary Plutonic Rocks } \\
\hline Gabbro Noritc & $14 / 26^{\circ}$ & $5 / 1.7$ & $1 / 0.8$ & & & & & & & & & & $20 / 27$ \\
\hline Gabbro & & & $2 / 0.2$ & & & & & $1 / 0.1$ & & & & $1 / 0.1$ & $4 / 0.4$ \\
\hline Olivine Gabbro & & $5 / 7.6$ & $66 / 112$ & $5 / 4.7$ & & $14 / 5.4$ & $4 / 1.35$ & $8 / 108$ & $12 / 18$ & $16 / 4.9$ & $10 / 4.3$ & $30 / 40$ & $176 / 304$ \\
\hline \multicolumn{14}{|c|}{ Intrusives } \\
\hline Diabase & $1 / 0.5$ & & $1 / 1.0$ & & & & & & & & & & $2 / 1.5$ \\
\hline Oxide Microgabbro Noritc & & & & & & & & & $4 / 1.5$ & & & & $4 / 1.5$ \\
\hline Microgabbro & & & $4 / 1.0$ & & & $1 / 0.1$ & & & & & & & $5 / 1.1$ \\
\hline Dlivine Microgabbro & $5 / 1.4$ & & $13 / 4.9$ & & $1 / 0.7$ & & & & $1 / 0.1$ & & & & $15 / 5.7$ \\
\hline Troctolite & & & & & & & & & & & $2 / 0.7$ & $7 / 4.9$ & $9 / 5.6$ \\
\hline Troctolitic Gabbro & & & & & & & & & & & $7 / 4.2$ & $2 / 1.3$ & $9 / 5.5$ \\
\hline Troctolitic Microgabbro & & & $4 / 0.6$ & $1 / 0.1$ & $2 / 0.3$ & $1 / 0.3$ & & & & & $1 / 0.1$ & & $9 / 1.4$ \\
\hline \multicolumn{14}{|c|}{ Hybrids } \\
\hline Patchy Olivinc Gabbro & & & $3 / 3.4$ & & & & & & $3 / 1.7$ & $5 / 2.6$ & $3 / 0.8$ & & $14 / 8.1$ \\
\hline Diopsidic Olivine Gabbro & & & & & & & & & & & & $4 / 4.7$ & $4 / 4.7$ \\
\hline Oxide Pyroxcnite & & & $3 / 0.2$ & & & & & & & & & & \\
\hline Oxidc-Rich Vcin & & & & & $2 / 0.3$ & & & & & & & $1 / 0.01$ & $3 / 0.2$ \\
\hline \multicolumn{14}{|c|}{ Synkinematic Gabbros } \\
\hline Oxide Gabbro Noritc & $6 / 1.7$ & $1 / 0.1$ & $3 / 0.6$ & & & $1 / 0.8$ & & & & & & & $11 / 2.8$ \\
\hline Oxidc Gabbro & $1 / 0.5$ & & $32 / 7,4$ & $2 / 0.2$ & & & & & $1 / 0.1$ & & & $2 / 0.1$ & $36 / 8.1$ \\
\hline Oxide Olivininc Gabbro & & & $7 / 1.8$ & & $4 / 2.9$ & $11 / 2.2$ & $23 / 49$ & $6 / 1.0$ & $3 / 0.7$ & $19 / 3.1$ & $16 / 2.7$ & $30 / 15$ & $121 / 78$ \\
\hline Disscm. Oxide Olivine Gabbro & & & $3 / 3$ & $4 / 4.9$ & $11 / 25.2$ & $16 / 5,3$ & & & & $1 / 3.1$ & & $2 / 1.9$ & $36 / 41$ \\
\hline Patchy Oxide Olivine Gabbro & & & & & & & & & & $2 / 1.6$ & $1 / 0.7$ & & $3 / 2.4$ \\
\hline Oxide Olivine Microgabbro & & & & & & & $5 / 0.6$ & & & & $4 / 1.09$ & & $9 / 1.7$ \\
\hline
\end{tabular}

*number of intervals/total meters of rock type.

closer inspection, we found that the plagioclase augen are actually lathlike feldspar phenocrysts having grain boundary recrystallization enclosed in a fine-grained groundmass with well-preserved basaltic igneous texture. The minor recrystallization and rotation of feldspar in the matrix, with stretching of the coarser plagioclase phenocrysts, produced a weak foliation and gave the plagioclase-phyric diabase an apparent gneissic texture.

The relationship between the oxide-bearing and oxide-free gabbros is heavily obscured by the late-stage penetrative deformation, ductile deformation, and amphibolitization. Detailed examination of the oxide-bearing intervals, however, indicates that they are nearly always at least weakly deformed. The oxide is magmatic (see Natland et al. and Ozawa et al., this volume), interstitial to plagioclase, olivine, and pyroxene, and often clearly delineates a pronounced foliation that occurs in elongate intergranular patches. On the basis of, in part, relationships between oxide-bearing and oxide-free gabbros in braided high-temperature shear zones deeper in the hole (which these closely resemble), we found that the gabbros in Unit I underwent two phases of ductile deformation. The earlier of these occurred at magmatic temperatures, and the deformed gabbros are consistently impregnated with iron oxides, largely ilmenite. Contacts between oxide-bearing and oxide-free gabbros also consistently coincide with high-temperature deformed/undeformed contacts. Trondhjemite veins and pegmatites always crosscut this earlier deformation, while they are deformed and transposed into the foliation plane by the latter phase. While the second deformation may preferentially affect oxide-rich zones, the contacts between deformed and undeformed rocks from this phase do not coincide with contacts between oxide-bearing and oxide-free gabbro.

Chemically, the deformed gabbros have been transformed to more iron- and sodium-rich evolved compositions. Thus, the relationship between the two rock types would appear intrusive and were not textural relicts of the olivine gabbro pseudomorphed within the ferrogabbro. We will propose later in this chapter that the oxide gabbros formed because of chemical exchange with and precipitation of oxides and addi-

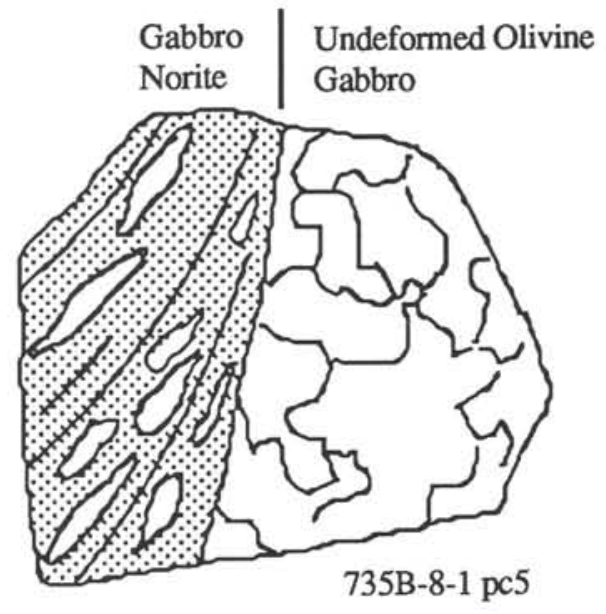

Figure 6. Sketch of an exceptionally sharp faulted and deformed gabbronorite/undeformed olivine gabbro contact in Subunit IA.

tional silicates from iron-titanium-rich melt intruded along grain boundaries in brittle-ductile shear zones formed in the olivine gabbro late in its solidification history. The likely source of the melt was late intercumulus liquid in the olivine gabbro that migrated into and was channeled by the ductile deformation zones.

The relationship between the olivine gabbro and the gabbronorite is too heavily obscured by deformation and alteration to determine whether it is magmatic-sedimentary or intrusive. However, as both have similar medium- to coarsegrained textures, if the relationship is intrusive (as is the case for gabbronorites in Unit VI) it is unclear which is intruding the other.

In all, 38 discrete lithologic intervals occur in Subunits IA and IB. Ignoring the oxide-bearing zones as resulting from syntectonic late-magmatic deformation and impregnation of 


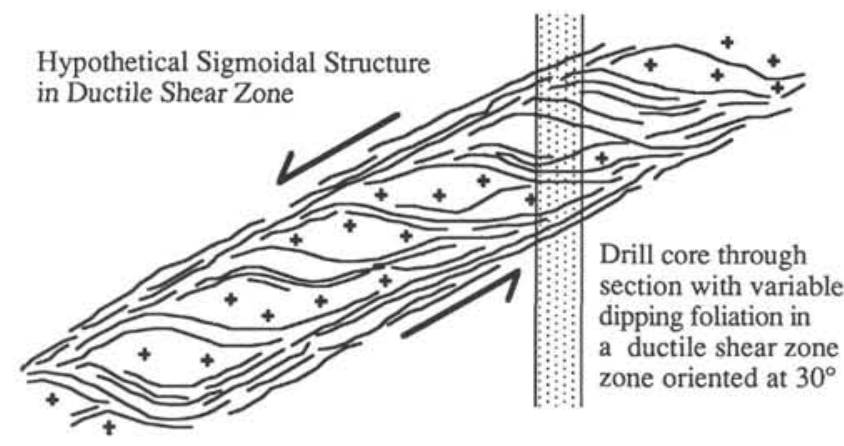

Figure 7. Hypothesized braided deformation zone.

the olivine gabbro and gabbronorite, there are only 21 discrete primary igneous subintervals: 6 gabbronorites comprising 27.9 $\mathrm{m}$ and 5 olivine gabbros comprising $1.4 \mathrm{~m}$ in Subunit IA, and 5 olivine gabbros comprising $7.6 \mathrm{~m}$ and 5 gabbronorites comprising only $1.9 \mathrm{~m}$ in Subunit IB. In Subunit IA, the average gabbronorite is $4.7 \mathrm{~m}$ thick, while the average olivine gabbro is $0.3 \mathrm{~m}$ thick. By contrast, in Subunit IB, the average gabbronorite is only $0.4 \mathrm{~m}$ thick, while the olivine gabbros average $1.5 \mathrm{~m}$ (Fig. 5). The sharp change in thickness and relative proportions of gabbronorite and olivine gabbro is the basis for subdividing Unit I (Fig. 5A).

The intercalation and gradation downward from mostly gabbronorite at the top of Unit I to mostly olivine gabbro in Unit II demonstrates a transition, rather than a sharp break. Subunit IB, consisting of equal numbers of olivine gabbro and gabbronorite subintervals, with a predominance of olivine gabbro, could be grouped equally well with Unit II and provides a clear lithologic bridge between Units I and II. Thus, though these units may have undergone extensive brittle-ductile deformation and minor faulting and may have been considerably thinned tectonically, we see no evidence for a major brittle fault or the juxtaposition of unrelated lithologic units in the transition between them.

\section{Unit II (Upper Compound Olivine Gabbro)}

Minor Lithologies (Intrusive Microgabbro and Olivine Microgabbro and Synkinematic Oxide and Oxide-Olivine Gabbro)

Unit II is $132.7 \mathrm{~m}$ thick and has 142 described lithologic intervals (Fig. 5B). Most are olivine gabbro (112 $\mathrm{m}$ in 64 intervals). Two metagabbros $(0.2 \mathrm{~m})$ were probably also olivine gabbro, though alteration eliminated evidence of olivine. The remaining $20.5 \mathrm{~m}$ includes a wide variety of intrusive microgabbros, a crosscutting diabase dike, 32 thin oxide gabbro zones $(7.4 \mathrm{~m})$, and seven intervals of olivine oxide gabbro $(1.8 \mathrm{~m})$. Three disseminated oxide olivine gabbros (3 $\mathrm{m})$, the major lithology of Unit III, and three patchy olivine gabbros $(3.4 \mathrm{~m})$, a distinctive textural variant of the olivine gabbro, are first identified in this unit. The number of different intervals, rock types, and their multiple origins create considerable stratigraphic complexity, leading to the use of the term compound: compound, because the relationships between different rock types are sometimes intrusive and sometimes arise from late-magmatic processes and deformation, which produces an igneous layering unlike any in layered intrusions studied on land.

The oxide-bearing gabbros are similar to those found elsewhere in the hole and are strongly associated with very weak to strong penetrative deformation and the presence of ubiquitous intergranular magmatic oxides (typically $5 \%$ to $15 \%$ ). A distinctive feature of the oxide gabbros in this unit, however, is that olivine-bearing varieties are rarely found. Elsewhere, the oxide-bearing gabbros generally contain olivine. Thirty-two of the 36 Hole $735 \mathrm{~B}$ oxide gabbro intervals can be found here. In general, these gabbros are also rich in pyroxene. This suggests a reaction-relation between the late magmatic liquid in the deformation zones and olivine to produce pyroxene (as seen, for example, in classical "tholeiitic" intrusions like the Skaergaard Intrusion).

A number of crosscutting pyroxene- and oxide-rich veins and lenses occur locally in the olivine gabbro. These are undeformed and may represent the migration of late intercumulus iron-titanium-rich liquid from the deformation zones into and along brittle fractures and joints in the adjoining olivine gabbro. These veins are consistently olivine-poor and both oxide-and pyroxene-rich, supporting the postulated reaction-relation between the late-magmatic liquid and the olivine gabbro in Unit II. Many irregular oxide-rich patches, pods and seams are also evident in the olivine gabbro. These could represent local pegmatoidal patches where late iron titaniumrich liquid was trapped and crystallized.

Undeformed igneous contacts in the unit include modal, grain size and gradational grain size contacts. Though these all dip in the same direction, their inclinations are highly variable ranging from $10^{\circ}$ to $60^{\circ}$. The average dip of $41^{\circ} \pm 14^{\circ}$ lies near the average dip for gneissic and mylonitic foliations in the unit, suggesting that even where the contacts appear undeformed, they are still transposed toward the foliation plane. It is clearly apparent, however, that igneous contacts within the unit were originally not generally parallel, and thus do not represent simple magmatic sedimentary layering and much of it represents a variety of forms of cross-intrusive relationships.

Though the oxide-bearing gabbros have contacts which curve irregularly within olivine gabbro, numerous contacts are nearly straight, and often give the impression that they could be sedimentary igneous layering. In many examples, igneous textures are well preserved at the contacts between oxide gabbro and olivine gabbro. Such contacts have a sutured appearance, with irregularly shaped individual grains interlocking across the boundary, indicating that the contacts, though frequently lying along shear zones, are igneous. Generally, however, while the contacts between oxide gabbro and olivine gabbro dip in the same direction, they have highly variable inclinations ranging from $6^{\circ}$ to $85^{\circ}$. The average dip of $40^{\circ} \pm 17^{\circ}$ is near that for the foliation, reflecting the tendency of the contacts to lie parallel to the foliation plane in the oxide-bearing gabbro. The oxide gabbro and olivine gabbro may or may not be deformed right at the contact, but the oxide gabbro generally is often deformed within a few millimeters of it, with the contact lying parallel to the foliation plane. These contrasting relationships suggest a combination of structural and lithologic controls on the circulation of the late magmatic liquid from which the oxide precipitated.

A distinctive feature of this unit is the large number of intrusive fine- to medium-grained microgabbros (4), olivine microgabbros (13), and troctolitic microgabbros(4) that appear to intrude it. Contacts between the microgabbros and the olivine gabbro are generally (and often highly) irregular (Fig. 8) Locally, there may be a gradation in grain size at the contact, but more often the contacts appear sharp from a short distance away, marked by an abrupt change in grain size and often accompanied by a change in mineralogy and mineral proportions. In detail, one can see that the contacts are igneous from the sutured boundaries, where individual grains of the microgabbro interlock with coarser grains in the olivine gabbro. These contacts often are transposed by deformation to the foliation plane, giving an erroneous impression of 


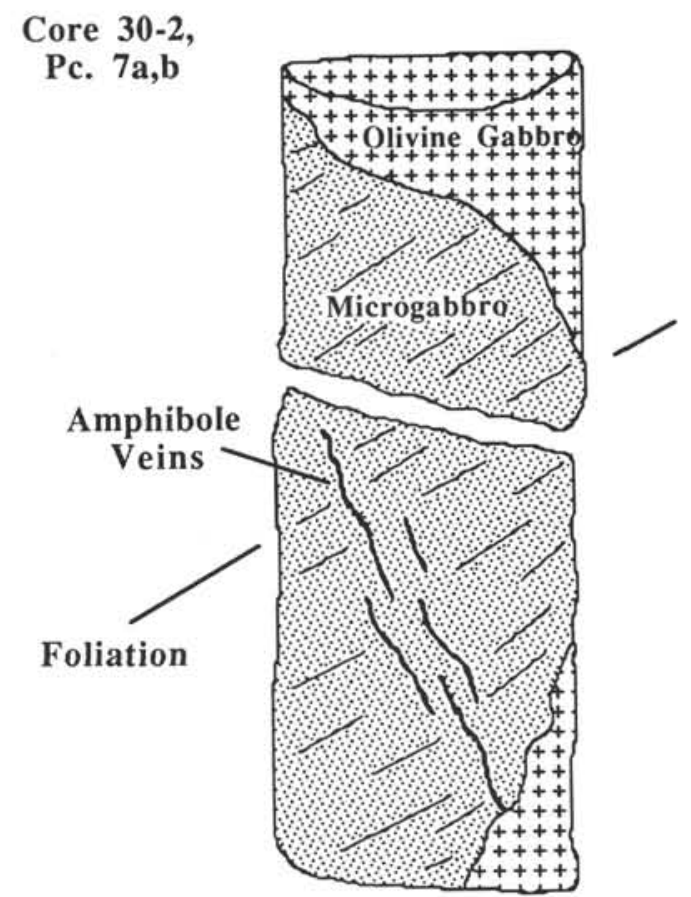

Figure 8. Representative contact morphology for intrusive microgabbros in Unit II.

simple igneous layering. In detail, many such contacts can be seen to lie slightly oblique to foliation (troctolitic microgabbro-olivine gabbro contact in Core 20R-1, Pc. 2b), and others at a steep angle (e.g., in Core 25R-3, Pc. 3b).

The contact relations and finer grain size of these rocks argue for an intrusive origin into the olivine gabbro for all types of microgabbro. These intrusives differ greatly from diabase dikes, particularly in their nonbasaltic compositions. The troctolitic microgabbro in Core 20-2 $(23-27 \mathrm{~cm})$ for example has $22 \% \mathrm{MgO}$ and a $\mathrm{Mg} /(\mathrm{Mg}+\mathrm{Fe})$ of only 0.67 . This is a most unlikely composition for a basalt, but reasonable for olivine cumulate. Even the microgabbro in Core 30-1 (135-138 $\mathrm{cm}$ ), while representing a fair approximation of a basaltic composition in major element chemistry, has far too low a chromium content for a MORB with $\mathrm{Mg} /(\mathrm{Mg}+\mathrm{Fe})$ equal to 70.6. The general chemical features of these rocks may reflect varying degrees of cumulus crystallization of olivine and plagioclase. The various fine-grained intrusives may have crystallized from different magmas, and some may represent a continuum in composition and mineralogy, representing different proportions of plagioclase, pyroxene, olivine, and trapped melt in cumulates that have crystallized from similar melts. Their relatively coarse grain size, general lack of chilled margins, and highly irregular contacts also distinguish them from diabase dikes. These features are all characteristic of intrusives that were emplaced at temperatures similar to the country rock and assimilated wall rock material.

The patchy olivine gabbros, except for their peculiar texture, are similar mineralogically to the olivine gabbro. The fine-grained material in these gabbros is virtually indistinguishable from the intrusive olivine microgabbro, except for the lack of a clear crosscutting relationship, and the patchy gradational appearance of the contacts. Texturally, there may be a complete gradation from clear-cut intrusive olivine microgabbro to patchy microgabbro. This suggests similar petrogenesis. We suggest that the patchy texture might have arisen when the olivine gabbro was intruded by basaltic melts of related composition, prior to the olivine gabbro having sufficiently solidified to sustain a rigid stress. Thus, the intruding melt did not form simple dikes, as the intruded crystal mush behaved plastically. The crystal mush, however, was sufficiently viscous (due to high crystal content) that the intruding basaltic liquid did not mix significantly with it, but formed "intrusive blebs" in the crystal mush instead. Rapid nucleation of numerous plagioclase, pyroxene, and olivine grains in these blebs, due to supercooling by the enclosing partially molten gabbro, then, produced fine grained crystal mush patches in the coarser gabbro mush. Once the blebs reached the temperature of the enclosing crystal mush, their final solidification followed the much slower solidification curve of the gabbro body as a whole, explaining the absence of chilled margins.

There is one $0.8-\mathrm{m}$ gabbronorite interval in Unit II. Its upper contact with the olivine gabbro is well preserved and is cross-foliated, providing a clear-cut igneous contact that has not been transposed into the plane of the foliation. The actual contact is sutured, with grains of coarse olivine gabbro interlocking with medium-grained gabbronorite providing unequivocal evidence that this is an igneous rather than a fault contact. The gabbronorite is medium-grained for $7 \mathrm{~cm}$ below the contact, grading down to coarse-grained through the rest of the section. This might suggest an intrusive relationship, but may also be a coarse-fine interval in a layered zone.

At $105 \mathrm{~m}$, the olivine gabbro is crosscut by an undeformed diabase dike that dips $50^{\circ}$ to $60^{\circ}$, with sharp planar subparallel intrusive contacts and well-developed chilled margins. This diabase is similar in major and trace element composition to the deformed diabase in Unit I (Appendix B), except for a higher water content. This reflects late alteration noted in thin section (see Init. Repts., Vol. 118).

Thus, while stratigraphically complex, the petrogenesis of Unit III may be relatively simple. It consists of a massive relatively coarse-grained olivine gabbro that was variously intruded by numerous related batches of gabbroic melt migrating upward through the solidifying pluton. These locally underwent crystallization and wall-rock reaction to form volumetrically minor microgabbros and patchy olivine gabbros. Brittle-ductile deformation and the formation of shear zones occurred once the massive olivine gabbro was sufficiently rigid to support a shear stress. During this high temperature deformation, the gabbro in the shear zones were impregnated by oxide precipitated from a late-magmatic irontitanium-rich liquid migrating along the faults. The general absence of olivine in the oxide gabbros, suggests an extensive reaction-relation between this late-magmatic liquid and olivine. A reaction that did not occur, at least to the same extent, elsewhere in the section. This suggests that the late-magmatic liquid composition here was different than that involved in producing oxide-bearing gabbros elsewhere in the section.

Throughout Unit II, late-stage subsolidus mylonitic deformation and amphibolitization is strongly associated with oxide bearing layers. This indicates that the oxide bearing zones may be locally less competent than the oxide-free gabbros. This later deformation, however, locally cross-foliates oxide gabbro/olivine gabbro contacts, or is associated with microfaults which cut the earlier high-temperature penetrative foliation.

We mark the Unit II/III contact at the first appearance of long intervals of disseminated oxide olivine gabbros. Oxide gabbro and olivine gabbro both continue to appear intermittently below the Unit II/III contact, however, just as dissem- 
inated oxide-olivine gabbro appears within Unit II, and thus the transition from Unit II to Unit III is transitional, as it is between Units I and II. Subunit IIIA could equally well be included with either Unit II or III. Thus, the Unit II-III contact, though locally microfaulted and deformed, is again gradational, representing an igneous transition which underwent minor tectonic thinning during high-temperature brittleductile deformation, and is not a major fault boundary juxtaposing unrelated lithologic units.

\section{Unit III (Disseminated Oxide-Olivine Gabbro)}

\section{Lithologic Summary}

Subunits IIIA (Disseminated-Oxide-Olivine and Olivine Gabbro), IIIB (Massive Disseminated-Oxide-Olivine Gabbro), and IIIC (Disseminated-Oxide-Olivine and Olivine Gabbro)

Unit III is distinguished by the appearance of voluminous, often massive, disseminated oxide olivine gabbro $(66 \%$ of the unit) containing scattered pigeonite and hypersthene. There is a sharp decrease in olivine gabbro intervals (19\% of the unit), while oxide gabbro $(0.2 \mathrm{~m})$ almost disappears and oxide olivine gabbro $(5.1 \mathrm{~m})$ becomes common. Subunit IIIA $(9.9 \mathrm{~m})$ is transitional from Unit II, consisting of roughly equal proportions of olivine gabbro and disseminated oxide olivine gabbro, while Subunit IIIB (29.3 m) is a thick interval largely comprised of disseminated oxide olivine gabbro, with a single $19 \mathrm{~m}$ thick interval at its base. Subunit IIIC is another mixed interval similar to Subunit IIIA and the top of IIIB, with 14, 16 and 11 intervals of olivine gabbro, disseminated oxide olivine gabbro and oxide olivine gabbro respectively. Subunit IIIc $(14.2 \mathrm{~m})$ could be regarded as transitional to Unit IV, except for the appearance of numerous screens of olivine gabbro, which are only a minor component of the latter. Minor amounts of troctolitic microgabbro, olivine microgabbro and microgabbro cross-intrude Unit III throughout the section.

\section{Contact Relations}

Despite the lithologic diversity of Unit III (76 distinct intervals-Appendix A, Table 4, Fig. 5C), it bears little relation to the layered rocks produced by magmatic sedimentation. With the exception of a few crosscutting microfaults, as far as we can tell lithologic contacts all appear to have similar strike. Contact dips also appear to be uniform in direction, but are highly variable. Contacts between the different oxide-bearing gabbros are often irregular and range in dip from $20^{\circ}$ to $79^{\circ}$. These include contacts between oxide olivine and disseminated oxide olivine gabbros, and between their coarse and fine grained facies. Upper and lower contacts of the oxide-bearing gabbros are often not parallel, and may be cross-foliated or totally transposed into the foliation plane. The mean dip of $43^{\circ} \pm 11^{\circ}$ for 22 measured contacts between different oxide-bearing gabbros is strikingly close to the average of $41.3^{\circ} \pm 12^{\circ}$ for 102 measurements of the dip of the penetrative foliation in Unit III.

Oxide olivine gabbros occur not only as thick, generally penetratively deformed, intervals (up to $1.5 \mathrm{~m}$ ), but as thin layers, small isolated veins, clots, and patches in both olivine gabbros and disseminated oxide olivine gabbros. In some cases the oxide olivine gabbro occurs as highly irregular pods (e.g., Core 44R-3, Pcs. 6b and 6c). The actual contacts between different oxide-bearing gabbros are sutured with individual grains interlocking with an intergranular texture across the boundaries. In many cases, the transition is gradational, in others it is abrupt. In some cases, the actual contacts show little or no deformation and look like simple igneous contacts that could be mistaken for those of a layered se- quence were not the patchy texture and irregular nonparallel upper and lower contacts so obvious upon close inspection.

Olivine gabbro is texturally, mineralogically, and chemically typical of olivine gabbros elsewhere in Hole 735B. Notably, it is generally undeformed but enclosed within penetratively deformed oxide-bearing gabbro with contacts which range from $24^{\circ}$ to $77^{\circ}$. The orientation of these contacts vary irregularly down through the unit. The upper and lower contacts of the olivine gabbros, where both are preserved, are often not parallel, and olivine gabbros separated by a single thin oxide bearing interval (e.g.; intervals 240 and 242) may differ greatly in dip, though they generally share the same strike. Rarely is there evidence for cross-foliation at the contacts between the oxide-bearing and oxide-free olivine gabbros. On a thin section scale the contacts are igneous and generally undeformed, defined by either a sharp or gradual disappearance of intergranular oxide. Locally, the disseminated oxide olivine gabbro is foliated parallel against the usually undeformed contact. These contact relations suggest that the olivine gabbro intervals in Unit III are best interpreted as shear polyhedra in a ductile deformation zone confined to the oxide-bearing gabbros.

\section{Disseminated Oxide Olivine Gabbro}

The disseminated oxide olivine gabbros are distinguished mineralogically from the olivine gabbros by the persistent presence of slightly less than $1 \%$ iron titanium oxides and by the scattered occurrence of pigeonite and hypersthene, which locally occur together. As will be discussed, these oxidebearing gabbros are also chemically distinct from the olivinefree gabbros with substantially more iron and sodium rich silicate compositions. Plagioclase and the low-calcium pyroxene form cumulus grains in the disseminated oxide olivine gabbros. In contrast, the low-calcium pyroxene where it more rarely occurs in the oxide-olivine gabbros, here and in Unit IV, is intergranular. Olivine is less abundant in the disseminated oxide olivine gabbros than in the oxide olivine gabbros, and is intergranular in the former, possibly intercumulus, though its texture may also be due to resorption during cumulus growth of the pyroxene and plagioclase. In contrast, olivine tends to be a cumulus phase in the oxide olivine gabbros.

Except for the penetrative foliation, the disseminated oxide olivine gabbro is macroscopically identical in many respects to the patchy olivine gabbro in hand specimen. Grain size of the disseminated oxide olivine gabbro is variable, though equigranular, with very coarse, coarse and medium to fine grained patches occurring irregularly within it. Often changes in grain size are quite abrupt, with coarse- to very coarsegrained and fine- to medium-grained disseminated oxide olivine gabbros alternating with each other. Pods of coarsergrained material in fine-grained material and vice-versa appear to have been stretched and flattened, often creating the appearance of coarse and fine igneous layering. Locally, the very coarse patches appear pegmatoidal. Though the larger, more uniform patches are described as discrete intervals in Appendix A, they often have highly irregular contacts demonstrating that they are not some form of igneous layering. An example, is the very-coarse disseminated oxide olivine gabbro patch in coarse disseminated oxide olivine gabbro in intervals 206 to 208 . This patch has an upper cross-foliated contact that is steep and irregular, dipping around $85^{\circ}$, while the lower contact dips only $57^{\circ}$ and lies in the foliation plane. Even in Subunit IIIC, the alternating sequence of subparallel coarse to very coarse patches of disseminated oxide olivine gabbro (intervals 248-254) is unlikely to represent simple igneous layering. These intervals have contacts that dip from $35^{\circ}$ to $47^{\circ}$ 
over a distance of only $2 \mathrm{~m}$. These contacts on close inspection have been transposed toward the foliation plane and locally are crosscut by it. For example, interval 251, a 0.25 -m-thick, very coarse-grained band of disseminated oxide olivine gabbro with a spotted texture dips $42^{\circ}$ with a lower contact in the foliation plane, but an upper contact dipping $38^{\circ}$ oblique to the foliation.

\section{Penetrative Foliation in Oxide-Bearing Gabbros}

There is clear evidence of two periods of deformation and faulting in Unit III. Crosscutting the weak penetrative foliation, with opposite dip, is a second stage characterized by narrow (cm scale) zones of mylonite. These zones often have sharp contacts with the adjacent gabbro, and probably represent local microfaults. The earlier foliation often shows drag against these mylonite zones giving a normal shear sense. This latter period of deformation is assumed, due to the similar appearance of the mylonite zones, to be related to the amphibolite facies deformation seen elsewhere in Hole 735B. In the Unit I, II and VI amphibolite gneisses, the intensity of deformation varies widely on a short centimeter-scale, whereas in the disseminated oxide olivine gabbros and the oxide olivine gabbros of Unit III (and IV and VI) the foliation is penetrative and much more uniform, with the gabbros showing a well developed lamination over meters of core with little variation in dip or intensity.

The weak penetrative foliation in the oxide-bearing gabbros was originally described in the Initial Reports volume of Leg 118 as a primary igneous lamination (e.g., Fig. 7, Page $100)$. It is defined both by the alignment of plagioclase grains, locally elongate pyroxene grains and by thin lenses, stringers and layers of iron oxides, principally ilmenite lying-in/defining the foliation plane. Locally, it can be seen that oxide in the layers may be undeformed (e.g., Core 46R-3, 121-128 cm, Pc. 10, see photo in Init. Repts., Page 121). In other samples, the oxide occurs along microfaults and infilling between broken and stretched mineral grains. The latter were assumed to be due to redistribution during later deformation and alteration. However, subsequent examination shows that this is magmatic oxide and, accordingly, precipitated in-situ during or after deformation. If it were redistributed during alteration, its composition should reflect this. Oxide of magmatic composition (e.g., Natland et al., this volume; Ozawa et al., this volume) also fills late fractures crosscutting the olivine gabbro as well as extension cracks in coarse pyroxene augen in the oxide-bearing gabbro.

Close inspection also shows that the laminated gabbros have a very weak to moderately strong mineral lineation in the plane of the foliation. This rules out simple crystal settling as the source of the preferred orientation, which would produce a jackstraw texture with random orientation of the mineral grains in the foliation plane. The mineral lineation indicates instead that viscous flow of some kind was involved in formation of the foliation. As elsewhere in Hole 735B modal, size and compositional layers tend to lie in the foliation plane, often giving the impression that this is magmatic lamination produced by magmatic sedimentation as is seen in layered intrusions.

As noted, we have found numerous examples where igneous modal and grain size contacts between different varieties of oxide-bearing gabbro are cross-foliated by the lamination. Locally, these igneous contacts are steep, even perpendicular, to the foliation. Of particular interest, in this light, is the highly irregular troctolitic microgabbro/disseminated oxide olivine gabbro contact (intervals 119 and 200) where the troctolite intrudes disseminated oxide olivine gabbro. The contact between these two is clearly cross-foliated, and thus the pene- trative deformation locally postdates intrusion. Similar relationships are observed between intrusive oxide-olivine microgabbro and oxide-olivine gabbro (Fig. 9). In contrast, the oxide-free microgabbro (interval 237) and troctolitic microgabbros (intervals 184 and 239) that crosscut oxide-free olivine gabbro in Subunits IIIA and IIIC are undeformed. These relationships demonstrate that the foliation was produced due to deformation and flow of the gabbro after intrusion of the microgabbros, but did not affect intrusions where they cross undeformed oxide-free olivine gabbro shear polyhedra.

\section{Magmatic Extension Cracks}

The oxide-rich gabbros often occur as narrow veins or lenses, as well as in massive oxide olivine gabbro intervals. In one case (Core $36 \mathrm{R}-1, \mathrm{Pc} .3$ ), a 1.5 - to 2.0 -cm-thick vertical dike occurs in olivine gabbro of almost pure oxide and pyroxene with about $35 \%$ oxide, which clearly suggests infilling of a vertical fracture by a late-magmatic liquid. Similar narrow seams and oxide-rich veins are found throughout the section (e.g., Core 37R-2, Pcs. 1a and 1b; Core 38R-2, Pc. 3; Core 38R-2, Pcs. 4c and 4d; Core 45R-4, Pc. 3). These veins crosscut olivine gabbros, intrusive troctolitic microgabbros, and disseminated oxide olivine gabbros. A characteristic of these seams is the bleached appearance of pyroxene, which has a pale green-brown cast. Where the veins crosscut undeformed olivine gabbro, they are sometimes oriented subperpendicular or at a steep angle to the foliation in adjacent foliated oxide olivine gabbros, and thus appear to represent in-filling of extension cracks in resistant shear polyhedra within a ductile deformation zone by fluid squeezed out of the deforming zones. Thus, the oxide-rich veins constitute major evidence that the deformation was magmatic and that the olivine gabbro was not intruded into the oxide-bearing gabbros, but rather represent preexisting, relatively impermeable, resistant blocks in a brittle-ductile shear zone along which a late iron-titanium-rich liquid migrated.

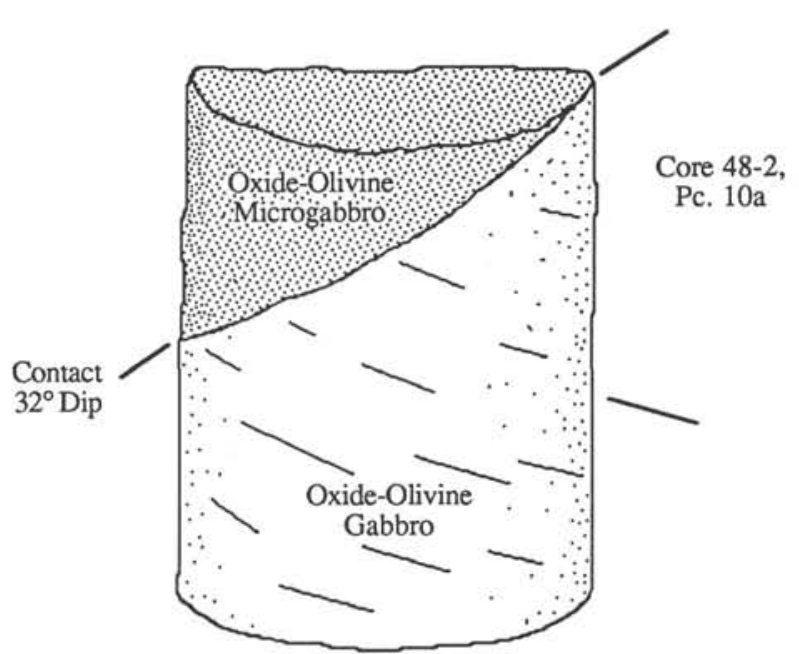

Figure 9. Cross-foliated contact between intrusive oxide-olivine microgabbro and medium-grained oxide-olivine gabbro in Core 48R-2, Pc. 6. Foliation is hard to see in the microgabbro. Note that intrusive microgabbros of all kinds only have oxide when they are intruding oxide-bearing olivine gabbros. This leads to the suggestion that the oxide in the intrusive microgabbros and their adjacent wall rocks is often secondary, precipitated from late intercumulus melt that migrated through the section, along a fault zone during or immediately after penetrative deformation. 


\section{Textural Relationships in the Oxide-Bearing Gabbros}

The microtexture and fabric of the penetratively deformed disseminated oxide olivine gabbros and oxide olivine gabbros are different, for the most part, from that of the amphibolite mylonitic and gneissic gabbros in Units I and II. In the latter, pyroxene crystals with huge length-to-width ratios occur due to stretching in a matrix of finer grained recrystallized feldspar. Primary igneous textures frequently are totally obscured by this syntectonic recrystallization and cataclasis, and the deformation is generally accompanied by amphibolitization of pyroxene and albitization of plagioclase. In the oxide-bearing gabbros, however, there is often little direct evidence for groundmass recrystallization or great stretching of pyroxene grains on a hand-specimen scale, and the mineralogy lacks hydrous alteration. Many of these rocks rank with the freshest undeformed gabbros in Hole 735B. In many medium-grained gabbros, pyroxene and olivine may appear stretched in hand specimen, but length-to-width ratios are only $1: 2$ to $1: 4$. Locally, an igneous intergranular-to-intersertal texture occurs (e.g., Core 36-3, Pc. 1a-coarse-grained, Core 37-2, Pcs. 1a and $1 \mathrm{e}-$-medium-grained), even where macroscopically (on a meter scale) the gabbros appear clearly foliated laminated and lineated. Examination of the grain contacts in many of the disseminated oxide olivine gabbros reveals an igneous texture, even in well-foliated rocks, with sutured boundaries between interlocking individual granular to slightly subophitic grains. Many of these, as previously noted, have aligned plagioclase laths, with the appearance of an igneous lamination. The pyroxene morphology, however, is generally blocky and equigranular, clearly different from the typical subophitic to oikocrystic pyroxene in oxide-free olivine gabbros.

In the very coarse-grained oxide olivine gabbros, pyroxene occurs as large, equant, often rolled or abraded grains. This distinctive texture gives the gabbros a peculiar spotted appearance. These spotted gabbros can be seen to be coarsegrained patches, similar to those in the patchy olivine gabbros, which have been stretched and elongated parallel to the foliation; often forming bands on the scale of a single core sample $5 \mathrm{~cm}$ or more across. Careful examination of the pyroxene in these bands and stretched patches, reveals cracks and pull-apart texture, that are orthogonal to foliation filled with magmatic oxides. A notable feature of all other varieties of gabbros throughout the core are the equigranular textures. In some samples here, plagioclase is nearly as coarse-grained as the pyroxene, but locally plagioclase grain boundary recrystallization and neoblast formation can be seen. In many cases, however, fine or medium grained plagioclase surrounds the coarse pyroxene augen in these "spotted gabbros." This suggests to us, even though the characteristic deformed mineral grains, and polygonalized or cataclastic fabrics may be absent in hand specimen, that the plagioclase may reflect contrasting mechanical behavior to the resistant pyroxene "augen" during deformation: the feldspar undergoing size reduction and cataclasis accompanied by recrystallization during ductile flow. We speculate that the characteristic textures of the mechanical deformation processes were eliminated in plagioclase (and also in olivine and pyroxene) by late post-cumulate growth, recrystallization and enhanced grain boundary growth and migration at high temperatures in the presence of intragranular (intercumulus) melt.

The variety of textures in these rocks suggests unusual conditions of deformation. The available evidence demonstrates that deformation occurred in the presence of melt. This evidence includes the presence of granular magmatic textures on a thin section scale in clearly cross-foliated rocks, and late magmatic oxide precipitated in cracks, pressure shadows and pulled apart grains. Locally, however, in the most intensely deformed zones, the texture resembles that of the amphibolite mylonites and gneisses. Here, the strain rate was probably sufficiently high, or the melt percentage present so low, that the rate-competitive creep process was cataclasis, and intragranular deformation and recrystallization, as in the lowertemperature ductily deformed amphibolitized gneisses and mylonites. There appears to be a complete gradation between rocks where the feldspar has undergone complete syntectonic recrystallization and plastic flow, to rocks in which the mineral grains have been rotated and aligned with an undeformed igneous texture. The latter textures are similar to those we have seen in gabbros in the Oman ophiolite described by Nicolas et al. (1990) as having undergone magmatic deformation. If these rocks were partially molten at the time of deformation, high temperatures and the presence of late trapped melt may have caused free-rotation of mineral grains, enhanced grain boundary sliding, and pressure-solution to be the principal deformation mechanisms throughout much of the deformation. Locally, though solid-state creep processes may have predominated during deformation, post-tectonic adcumulate crystal growth from trapped melt, as well as annealing recrystallization and high-temperature grain boundary migration in the presence of melt films, may effectively eliminate much of the microtextural evidence of solid-state ductile deformation mechanisms.

\section{Trondhjemites}

Unit III contains numerous trondhjemitic veins and vein networks, with some local brecciation indicated by free rotation of foliated clasts of the disseminated oxide olivine gabbro. As discussed elsewhere, trondhjemites appear to be substantially more abundant in the oxide bearing intervals than in oxide-free gabbros. This relationship is expected if the trondhjemites formed in-situ. The trondhjemites are likely to have been produced either by fractional crystallization or by liquid immiscibility of an evolving intercumulus melt due to the more evolved liquids which would be in equilibrium with the oxide-bearing gabbros than with the oxide-free gabbros. The trondhjemites are generally undeformed, and in only a few cases show the weakest sign of deformation. Thus, if the trondhjemites did form in-situ, it is clear that deformation had largely ceased by the time the intercumulus liquid was evolved sufficiently for them to form. This is consistent with the textural evidence considered above, that static crystallization of intercumulus liquid in the oxide-bearing gabbros followed deformation and eliminated much of the physical evidence of solid-state deformation mechanisms.

\section{Origin of the Disseminated Oxide Olivine and Related Oxide Gabbros}

The lithostratigraphic relations and textural evidence reviewed here show that Unit III consists of ductily sheared oxide-bearing gabbros which locally enclose oxide-free shear polyhedra, or screens, of olivine gabbro. The strings and thin layers of undeformed magmatic ilmenite in the foliation plane and along microfaults demonstrate that the deformation was magmatic, that is, at a point where the gabbro was sufficiently solidified to support a shear stress, but prior to complete solidification. Transposition of contacts in an equigranular partially solidified, cross-intruded, patchy gabbro account for local parallel layers and mineral foliation. On a thin section scale, the oxide gabbros have undeformed sutured igneous contacts with the olivine gabbro where intercumulus ilmenite is intergrown with mineral grains projecting from the oxidefree gabbro. 
It would seem reasonable to interpret the oxide-free gabbros as resistant blocks in a melt-rich shear zone. It is clear that they lacked intercumulus melt from which oxides could have precipitated, though such melt was squeezed out of the adjacent deforming oxide gabbros to fill extension cracks in these blocks. They could represent resistant patches of more solidified gabbro in a ductily deforming melt-rich shear zone, and we note that such shear polyhedra exist in many ductile deformation zones on land. Sheared serpentinite belts, for example, commonly contain shear polyhedra, whose cores may consist of relatively unaltered and undeformed peridotite. In the serpentinite case, alteration and shearing are clearly related, presumably the deformation controlled and channeled the altering fluids. We believe that this is also the case here: that faulting and ductile (often brittle-ductile on a hand specimen scale) deformation in the section controlled the circulation and eventual distribution of late intercumulus liquid, and hence magmatic ilmenite and magnetite. The actual percentage of liquid present during deformation is a matter of speculation, but was probably highly variable and could have run as high as $20 \%$ or $30 \%$ locally. Some of this liquid may have been trapped and crystallized completely in-situ, though a substantial portion may have migrated and passed through the deformation zone.

The large variations in grain size (where coarse and medium-grained intervals alternate throughout the section) is not characteristic of the massive olivine gabbro, which constitutes $80 \%$ of the oxide-free rocks. Such variations in grain size are characteristic of the patchy olivine gabbro seen in Unit II, which the disseminated oxide olivine gabbro closely resembles. The patchy olivine gabbros are clearly associated with and grade into zones where olivine gabbro is cross intruded by various microgabbros, and thus probably represent zones of repeated cross intrusion at different stages of solidification of the main gabbro. Locally, within Unit III, as in the Unit II gabbros, clear-cut intrusive contacts can be seen where finegrained olivine microgabbros, identical to those in Unit II, except for the presence of oxide, have intruded coarse-grained disseminated oxide olivine gabbros (Fig. 9). Thus, it is most likely that Unit III was initially a partially molten compound olivine gabbro similar to Unit II, with a high percentage of intrusive microgabbros and olivine microgabbros and extensive patchy olivine gabbros. Areas with a higher percentage of intrusives are likely to represent relatively weak zones in a solidifying rigid crystal mush and, thus, are a logical place for mechanical failure and formation of ductile shear zones.

\section{Unit III/Unit IV Contact}

The Unit III/Unit IV contact is gradational, in a gross sense, in that many of the same general rock types occur both above and below the contact and the units across the contact appear to be related. The contact, as we have somewhat arbitrarily chosen it, consists of a narrow brittle-ductile shear zone with a normal shear sense juxtaposing an olivine gabbro against an oxide olivine gabbro. This fault contact has a dip opposite to the foliation in the oxide gabbros (Fig. 10). There are several other mylonite zones similar to the one we chose as the unit boundary within a $60-\mathrm{cm}$ interval at the base of Unit III, and one more just below in Unit IV. These also juxtapose different lithologies against each other with dips of $38^{\circ}, 28^{\circ}, 40^{\circ}$, and $48^{\circ}$, respectively. The sense of shear producing these mylonites can be determined from the foliation in the underlying gabbros, which has been rotated toward the mylonite shear zone and indicates a normal shear sense (Plate 2). In general mylonite bands have sharp contacts with the medium- to coarse-grained gabbro. Thus, local microfaulting and stretching, accompanying subsolidus brittle-ductile deformation have again locally thinned an igneous transition at the Unit III/IV contact, but have not juxtaposed unrelated lithologic units.

\section{Unit IV (Massive Oxide Oliving Gabbro)}

Unit IV is a remarkable $50.5-\mathrm{m}$-thick, coarse- to mediumgrained, oxide-rich oxide olivine gabbro. The principal characteristic feature of Unit IV that distinguishes it from Unit III is the absence of disseminated oxide olivine gabbro and a predominance of oxide olivine gabbro. Based on Appendix A, the unit has an average oxide content (mostly ilmenite) of $10.1 \%$, and locally may contain up to $50 \%$ oxide on a centimeter scale. This contrasts sharply with the oxide content of Units III and V (1.78\% and $0.05 \%$, respectively-Table 5), and the unit might be considered a titanium ore deposit on land. In all, excluding crosscutting trondhjemite veins, there are 32 distinct lithologic intervals of variable thickness. There are 19 medium-grained and 4 coarse-grained oxide olivine gabbros, and 5 oxide olivine microgabbros. There are only 4 oxide-free olivine gabbros, comprising $1.4 \mathrm{~m}$ in the unit. The different lithologies are not uniformly distributed, with the coarse oxide olivine gabbros confined to the upper half of the unit and olivine-rich oxide gabbros confined to the lower half of the unit. Three of the four oxide-free olivine gabbros occur in the upper half of the unit. Pigeonite is also most abundant in the upper half and uncommon in the bottom half of the unit. The abundance of olivine varies greatly in the oxide olivine gabbro, ranging from none to $20 \%$. Olivine-rich oxide gabbros (excluding microgabbros) are limited to the lower half of the section.

Oxide olivine-rich-microgabbros and oxide olivine microgabbros are scattered up and down the upper half of the unit. These may be hybrid rocks. Locally one piece of oxide olivine-rich microgabbro (Core 48R-2, Pc. 9) has a patch of nearly oxide-free troctolitic microgabbro on its back. Except for the presence of oxide, this troctolitic gabbro is texturally nearly identical to the oxide bearing microgabbro. This suggests that this microgabbro may have originally been a troctolitic microgabbro which was impregnated with ilmenite precipitated from a late-magmatic iron-titanium-rich liquid which did not uniformly infiltrate the protolith.

Generally, undeformed trondhjemitic veins similar to those seen in Unit III locally network the unit. In some cases foliated angular clasts of oxide-bearing gabbro are rotated with respect to the intruded gabbro (e.g., Core 53R-4, Pc. 7a) indicating the formation of local intrusion breccias (Fig. 5D).

\section{Contact Relations}

Contacts between the oxide olivine gabbros and oxide-free olivine gabbros generally have the same strike and dip directions, but the inclination of the dip is highly variable and upper and lower contacts are different where both contacts are preserved. The olivine gabbro at interval 263, for example, has upper and lower contacts with penetratively deformed oxide olivine gabbro of $72^{\circ}$ and $32^{\circ}$, respectively. The olivine gabbro itself is undeformed, even at its contacts with the oxide gabbro. Two oxide rich veins crosscut undeformed olivine gabbro intervals, these are oriented subvertically at a steep angle to the foliation. The most spectacular seam is a $5-\mathrm{mm}$ thick vein in olivine gabbro interval 264 that dies out upward and thickens downward until it meets a 1.1-m-thick coarse oxide olivine gabbro interval (265) that dips $32^{\circ}$ at its contact with the olivine gabbro (Fig. 11). One can reasonably interpret this vein, similar to those in Unit III, as crystallized from iron-titanium-rich late-magmatic fluid that migrated up an extension crack in a resistant olivine gabbro block from an underlying melt-rich brittle-ductile deformation zone. 


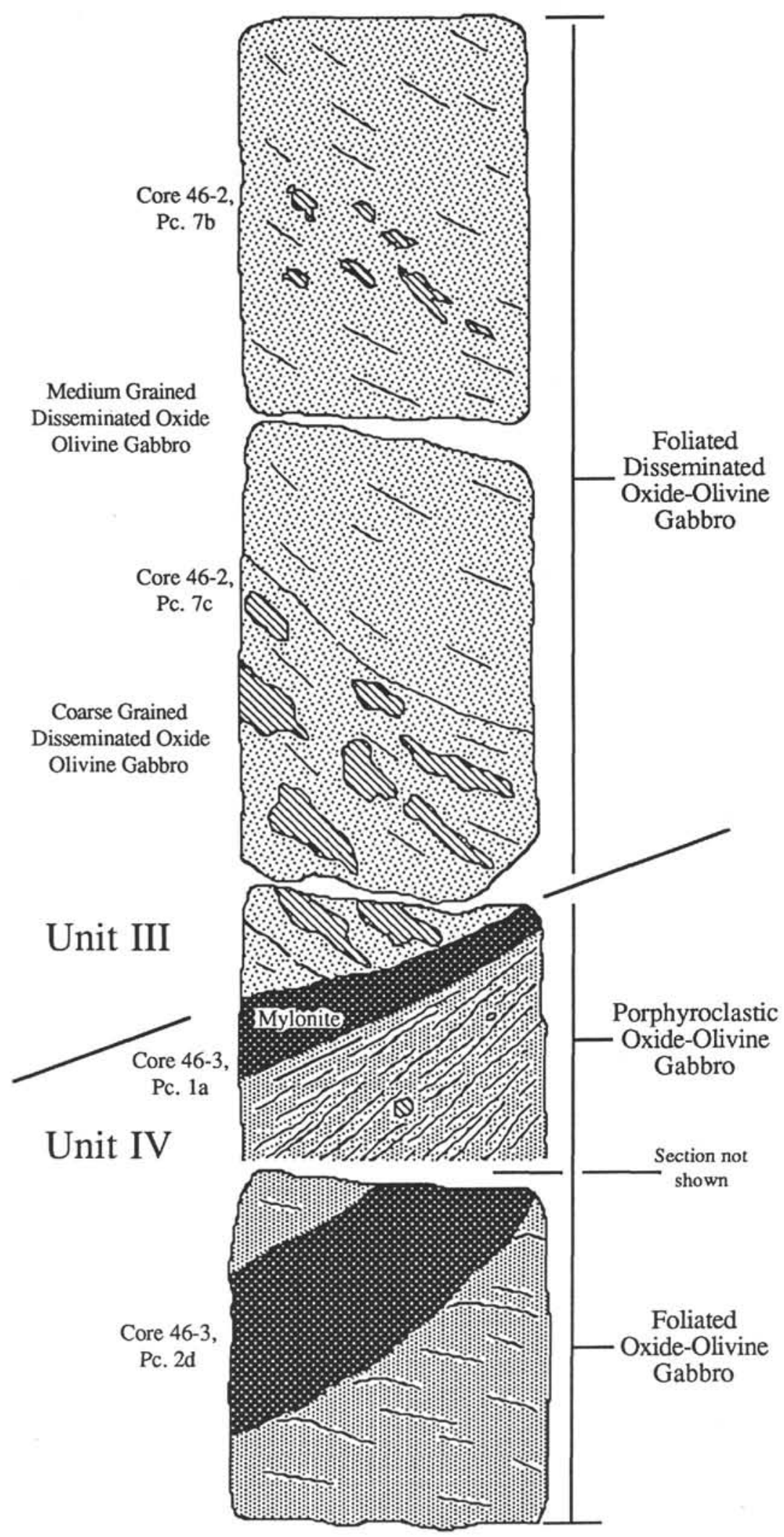

Figure 10. Unit III/Unit IV Contact. 
Table 5. Average contents of iron-titanium oxide, Hole 735B.

\begin{tabular}{||c|c||}
\hline $\begin{array}{c}\text { Hole 735B Average Iron-Titanium Oxide Contents } \\
\text { Unit }\end{array}$ & Average \% Oxide \\
\hline I & 0.38 \\
II & 0.71 \\
III & 1.78 \\
IV & 10.1 \\
V & 0.05 \\
VI & 1.42 \\
Hole 735B & 1.78 \\
\hline
\end{tabular}

The oxide olivine gabbros occur in several different varieties, distinguishable on the basis of grain size (e.g., intervals 257 to 260 ), or modal mineralogy with alternating olivine-rich and olivine poor horizons (e.g., intervals 276 to 286). The thickness of these different intervals are not uniform, and vary considerably (Appendix A, Fig. 5D). In general, all of Unit IV is weakly deformed except for the principle oxide-free olivine gabbro intervals, though the deformation is not always easy to see in hand specimen. The contacts between the different varieties of oxide olivine gabbro are rarely parallel, and where they are, there is evidence that they have been transposed into the foliation plane by deformation (e.g., the alternating olivine rich and poor oxide gabbro in intervals 278 to 282 where several of the subparallel contacts clearly lie in the foliation plane). Intervals 257 to 260 differ only in grain size and have contacts ranging from $32^{\circ}$ to $65^{\circ}$ with each other. The overall impression is that this interval, though it consists of equigranular gabbros, has irregular, often sharp, variations in grain size, with numerous irregular coarse- to very-coarse-grained patches. While the contacts between the various oxide gabbros frequently lie in the foliation plane, locally they can be seen to be cross-foliated (e.g., the interval 257/interval 258 contact).

Four oxide-olivine microgabbros are present in the section between 233 and 252 meters. These have contacts with highly variable dip, which often dip in opposing directions. Though sometimes the contacts are near parallel where they lie within the foliation plane (e.g., interval 275 with upper and lower contacts of $23^{\circ}$ and $32^{\circ}$, respectively), in general they are not, and are frequently cross-foliated at a steep angle (e.g., interval 269). The transition at the contacts is usually a very sharp drop in grain size. The highly irregular morphology of the contacts indicates that they are intrusive. The lack of chilled margins is attributed to intrusion while the country rock was still partially molten.

These relationships show that the grain size variations which distinguish the various types of oxide olivine gabbro in Unit IV and the emplacement of intrusive microgabbros all predated formation of the penetrative foliation and precipitation of the intergranular oxide as was also the case for the oxide-bearing gabbros of Unit III.

\section{Oxide Olivine Gabbro}

All the oxide-bearing gabbros are granular and have intergranular oxide. In some veins, the oxide is more granular than intergranular. The oxide olivine gabbros differ from the olivine gabbros in addition to their high oxide contents in having coarse granular pyroxene. The latter have a uniform subophitic texture with pyroxene subpoikilitic to often lath-like plagioclase and granular olivine. The oxide olivine gabbros also have cumulus olivine which is a notable difference from the Unit III disseminated oxide olivine gabbros, which contained largely intergranular olivine. As in Unit III, the Unit IV olivine gabbros lack or have only a weak penetrative deformation. Although the oxide-bearing gabbros in Unit IV, particularly in the upper portion, appear less well-foliated than in Unit III, we believe this is related to the generally coarser grain size of the Unit IV oxide olivine gabbros rather than any less deformation. The peculiar appearance of these gabbros, compared to similar coarse grained patchy oxide-free olivine gabbros elsewhere in Hole $735 \mathrm{~B}$ is attributed to ductile deformation in the presence of melt as were the textural peculiarities of the spotted gabbros in Unit III. The generally less deformed appearance compared to the disseminated oxide olivine gabbros of Unit III is attributed to the differing response of coarser grained rocks to deformation compared to that of finer grained gabbros. Medium-grained oxide olivine gabbros in Unit IV immediately below olivine gabbros do, in fact, have a clear penetrative foliation similar to that seen in the Unit III disseminated oxide olivine gabbros.

Modal abundance of ilmenite and grain size can be variable on the centimeter scale. For example, in oxide olivine gabbro interval 270 (Core 50-3, Pc. 1c), the ilmenite grain size varies over a $24-\mathrm{cm}$ interval from very-coarse in predominantly coarse-grained oxide olivine gabbro to fine in predominantly medium-grained oxide olivine gabbro. It also occurs in subhorizontal zones up to 1 to $2 \mathrm{~cm}$ thick that contain $50 \%$ oxide, while adjacent layers contain only $10 \%$ to $15 \%$. As in Unit III, the oxide is predominantly intergranular and may fill extension cracks in pyroxene grains.

\section{Origin of the Oxide Olivine Gabbro}

The lithostratigraphic relations in Unit IV are very similar in detail to those in Unit III and indicate the same origin: ductile deformation controlling late stage melt migration in a relatively rigid but still partially molten patchy olivine gabbro cross-intruded by olivine microgabbros. We cannot determine if the alternating intervals of olivine-rich and olivine-poor oxide-olivine gabbro near the base of the unit indicate local magmatic sedimentation and the formation of phase layering early in the crystallization history of the gabbro, or whether these are simply pegmatoidal olivine-rich patches. The thickness and the massive extremely oxide-rich and often coarse grained character of this unit compared to other deformed

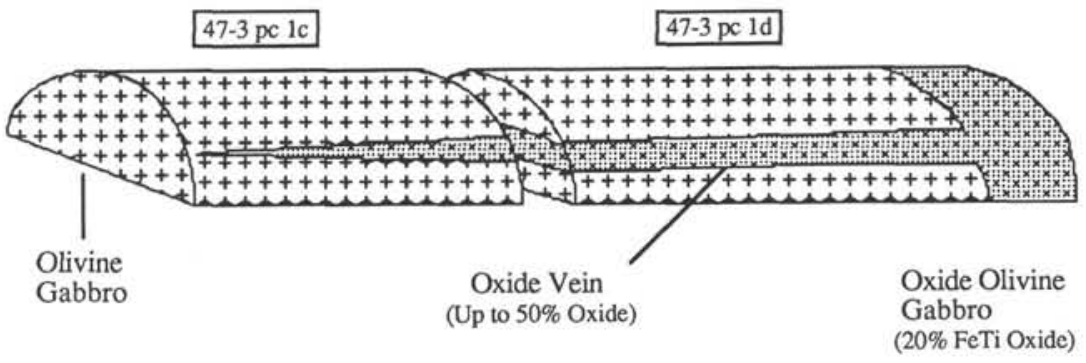

Figure 11. Oxide gabbro vein crosscutting undeformed oxide-free olivine gabbro in Unit IV. 
oxide bearing gabbros has led some to suggest that this unit actually crystallized from an intrusive body of iron titaniumrich melt. On close examination, however, it contains, on grander scale, the same general textural and morphologic characteristics found in the oxide-olivine gabbros in Unit III and VI, where the hybrid origin due to melt infiltration along deformation zones can be more unequivocally demonstrated on casual inspection.

Key to this interpretation are the same features described in Unit III: relict textures which often look like deformed versions of textures seen in patchy olivine gabbros, including cataclasized coarse pyroxene patches and pull-apart texture with interstitial magmatic ilmenite, and the presence of intrusive olivine microgabbros impregnated by interstitial oxides precipitated during and at the end of deformation. Locally, as discussed in the deformation section, foliated gabbros in this unit sometimes have the appearance of complex cross-bedding with highly variable strike locally. Identical textures can be seen in deformed Oman Ophiolite gabbros, where late magmatic deformation has disrupted and locally transposed pre-existing magmatic layering (Nicolas et al.., 1990). In this particular case, however, the foliation does not appear to have formed as simple sedimentary magmatic layering. Like Unit III, undeformed oxide-free olivine gabbro horizons with irregular contacts appear to be shear polyhedra within a broad deformation zone.

\section{Unit IV/Unit V Contact}

The contact between Units IV and V has been redrawn from the shipboard description to lie below the major $1.8 \mathrm{~m}$ thick mylonite zone at the base of interval 288 (Core 56R-1, $109 \mathrm{~cm}$, to Core 56R-3, $10 \mathrm{~cm}$ ). This mylonite (Fig. 12) is variable in intensity, ranging downward from weakly foliated gabbro to strongly foliated and porphyroclastic mylonite in core $56-2$, and then is reversely graded downward to less deformed rocks in Core 56R-3, where it is crosscut by a set of trondhjemitic veins. Associated with the trondhjemitic intrusion is extensive local brecciation and albitization of the gabbro, and probable local assimilation of the oxide olivine gabbro. The otherwise pale greenish gray mylonite is albitized near where it is intruded, giving it a gneissic appearance where the white albitized feldspar bands stand out from the mafic minerals. There is no igneous lithologic break at the base of the mylonite, however, and oxide gabbro extends through the mylonite into the breccia zone, where the oxide olivine gabbro is extensively albitized and intruded by trondhjemitic veins up to $1 \mathrm{~cm}$ thick. The intrusion breccia appears undeformed in hand specimen. The matrix around the clasts extends from white to gray, and it is very difficult to tell what is albitization of preexisting material and what is intrusive-or a hybrid formed by partial assimilation of oxide gabbro (assimilation is clear-cut higher in the section where penetratively deformed and foliated gabbro is intruded by trondhjemite in Core 53R-5, Pc. 3). Clasts within the breccia below the mylonite frequently are deformed and foliated. For example, the gabbro in Core $56 \mathrm{R}-3$, Pc. 22 is an albitized grade 2 (see deformation and alteration section) porphyroclastic strongly foliated to mylonitic metagabbro. The end of the Unit IV oxide gabbros occurs in relatively undeformed material in Core 56R-3, Pc. 29. Contacts between deformed and undeformed gabbro occur in Core 56R-3, Pcs. 18 and 25. The actual Unit IV/Unit V contact occurs between pieces of drilling breccia, and therefore cannot be observed. The trondhjemitic intrusion zone ends at Core 58R-2, Pcs. 1b or 1d, well down in Unit V.

Thus, there is no a sharp tectonic contact between the thick mylonite zone in Core 56 and undeformed olivine gabbro, but rather an underlying zone in which the mylonitization becomes intermittent and dies out. This was not recognized during shipboard description of the core due to the late-stage hydrothermal alteration and brecciation. Rocks from this zone were also reduced to drilling breccia during coring, further obscuring the relationships. The hydrothermal breccia may have originally been thicker, as only gravel was recovered from this zone, and the recovery in Core 58 was $1 \mathrm{~m}$ less than what was drilled. Thus, the lower boundary of Unit IV is transitional similar to the other Hole 735B unit boundaries. It is a transition of intercalated igneous lithologies, locally thinned and disrupted by brittleductile deformation. Once again unrelated lithologies are not juxtaposed across a major fault contact.

\section{Unit V (Massive Olivine Gabbro)}

Unit V is a $108-\mathrm{m}$-thick, homogeneous, massive olivine gabbro (Fig. 5E), which provides an abrupt and striking contrast to the lithologically and texturally complex overlying Unit IV massive oxide olivine gabbro. Not only does it have the lowest lithologic variability in the hole, but is virtually undeformed. The only evidence of deformation are a few narrow oxide-rich shear zones less than a few centimeters thick. The oxide content of this unit averages out at $0.05 \%$ from Appendix A, although this is only a minimum estimate as the majority of the unit has trace oxide which was listed as nil content in the appendix.

Unit V olivine gabbros have a mostly equigranular texture ranging from granular to subophitic with large intervals of poikilitic gabbro with oikocrysts up to $16 \mathrm{~mm}$ long and $6.5 \mathrm{~mm}$ wide. The common chadacrysts are euhedral to subhedral plagioclase laths. Olivine ranges from granular to intergranular aggregates. Modal olivine varies from about $1 \%$ to $20 \%$ in the medium- to coarse-grained gabbros with a typical value of about $7 \%$. In the coarse- to very-coarse gabbros, olivine is noticeably lower in abundance and tends to be more granular. In poikilitic gabbros, olivine was not noted as chadacrysts (occluded mineral grains) in the large pyroxene oikocrysts examined in hand sample. Instead, it occurs as intergranular to granular aggregates, with plagioclase between oikocrysts. Plagioclase ranges from randomly oriented euhedral to subhedral laths in the poikilitic gabbros to subhedral to granular anhedral grains in the remaining gabbros. Pyroxene and olivine aggregates generally are intergranular to plagioclase in subophitic gabbros. Pyroxene ranges from granular anhedral grains to large anhedral oikocrysts and in subophitic gabbros, it is the common ophitic phase. Oxides examined in these rocks are only rarely euhedral and are generally intergranular to the silicates where they occur.

Modal variations in the proportions of the silicates do occur in Unit V, though they tend to be gradual rather than abrupt. One small patch of coarse olivine-free gabbro occurs with microgabbro in this unit, but is anomalous and may simply represent an unusual pegmatite patch. Several sharp changes in modal olivine occur, but correspond to an abrupt change in the grain size of pyroxene and plagioclase in granular gabbros upward from coarse- to medium-grained, with olivine increasing to $20 \%$ in the medium-grained intervals for about 10 to $20 \mathrm{~cm}$ and then decreasing upwards to the 'background' level of about $7 \%$.

Overall, most of the unit is oxide-free with only an occasional grain found in the olivine gabbro. Locally small oxide-rich intervals were noted. Four of these were moderate to steeply dipping veins from $1 \mathrm{~mm}$ to $2 \mathrm{~cm}$ thick that appear to crosscut the gabbro. On closer examination, the oxide is intergranular to silicates extending from the wall rock into the vein, whereas within the vein the silicates are often finer-grained; olivine is difficult to find; and pyroxene is more abundant. The texture of the vein silicates tends to be granular, with the oxide intergran- 


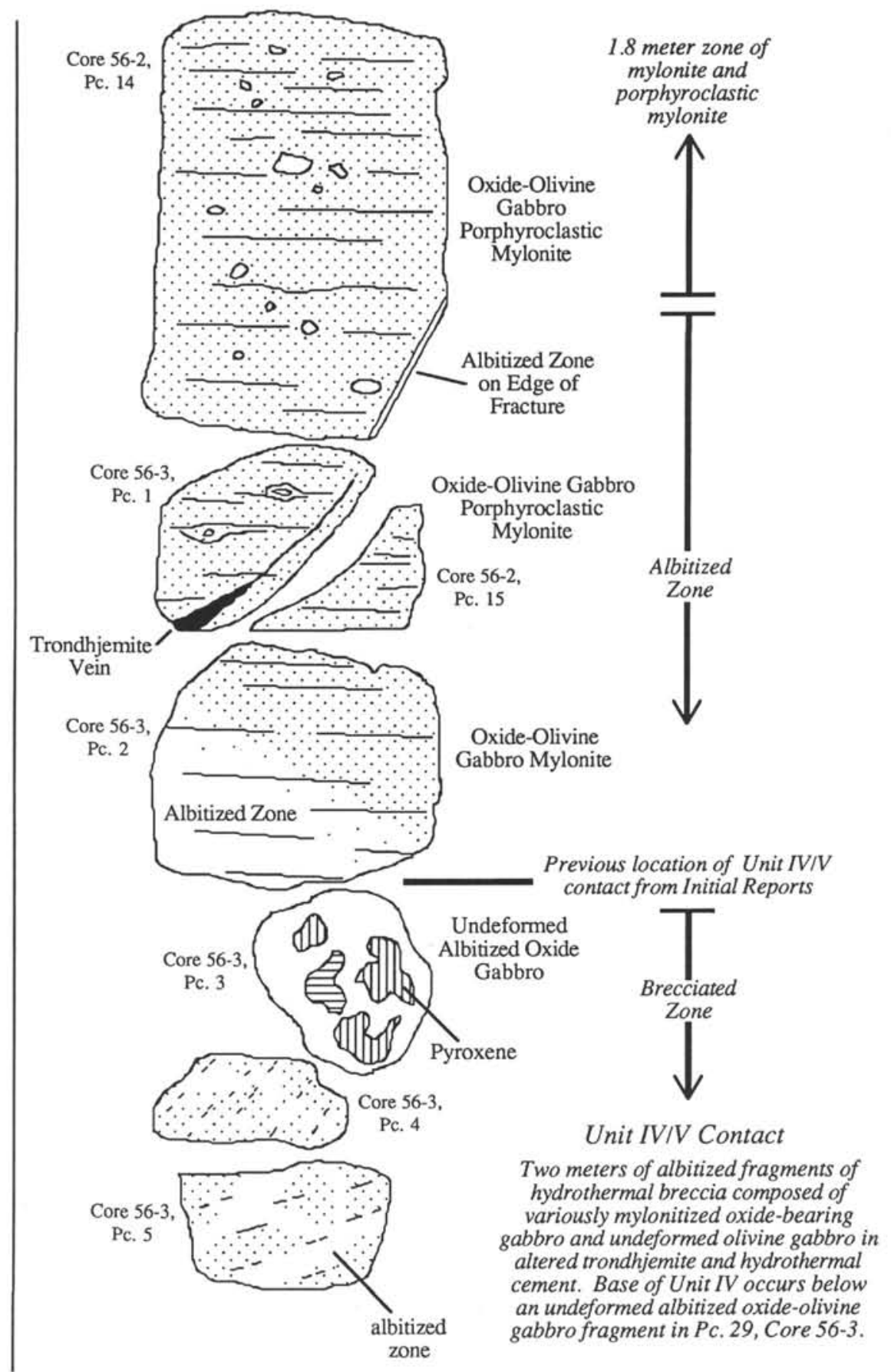

Figure 12. Lithostratigraphic relationships above the Unit IV/V contact, with the previous location of this contact as described in the Initial Reports volume of Leg 118 by the Shipboard Scientific Party shown for reference. For additional discussion of this contact see Figure 30 and accompanying discussion in the "Deformation and Alteration" section (this chapter).

ular. The two oxide-rich zones not clearly identified as veins have irregular boundaries and may simply be oxide-rich patches or irregular veins. These oxide-rich intervals are believed to have formed due to the same processes as those in the rest of the section.

Numerous felsic veins and vein networks cut the gabbro in Unit V. These are morphologically similar to the trondhjemitic vein networks and local intrusion breccias seen in
Units III and IV, but often have more complex mineralogies. Originally, some may have been trondhjemites, but the silicates are often now prehnite and other lower-temperature minerals. One notices immediately a set of compound plagioclase diopside veins (which locally grade into felsic veins), where zones of medium- to fine-grained diopside occupy the center of the veins. Many of the felsic veins contain zones of what may be epidote or zoisite. 
Unit VI (Lower Compound Olivine Gabbro)

Lithologic Summary

Subunit VIA (Compound Olivine Gabbro)

Minor Lithologies (Intrusive Olivine Microgabbronorite and Olivine Microgabbro and Synkinematic Olivine and OxideOlivine Gabbro)

Subunit VIB (Compound Olivine, Oxide-Olivine, and Disseminated Oxide-Olivine Gabbro

Minor Lithologies (Intrusive Olivine and Oxide-Olivine Microgabbro)

Subunit VIC (Compound Troctolitic and Olivine Gabbro)

Minor Lithologies (Synkinematic Oxide-Olivine Gabbro and Oxide-Olivine Microgabbro and Intrusive Troctolite and Troctolitic Microgabbro)

Subunit VID (Compound Olivine and Oxide-Olivine Gabbro)

Minor Lithologies (Intrusive Troctolite, Diopsidic-Olivine, and Troctolitic Gabbro and Synkinematic Disseminated-Oxide-Olivine and Olivine Gabbro)

The olivine gabbro in Unit V continues throughout Unit VI, which is an extremely complex zone of deformation and microgabbro intrusion. Unit VI has an incredibly complicated stratigraphy, with 190 discrete lithologic intervals in $119 \mathrm{~m}$. We have divided these intervals into four subunits of 21.7 , $15.3,14.5$, and $66.9 \mathrm{~m}$, respectively (Fig. $5 \mathrm{~F}$ ). About $18 \%$ of this unit is intrusive oxide microgabbronorite, microgabbro, olivine microgabbro, troctolitic gabbro, and troctolite. These are most abundant in Units VIB and C, which also have the most intense late-magmatic deformation and oxide impregnation. Units VIA and D have the smallest number of intrusives and are the least deformed and impregnated by oxide. Throughout Unit VI, the numerous small intrusive microgabbros are crisscrossed by numerous thin shear zones, where the gabbro and the microgabbros were variously impregnated by oxides, primarily ilmenite. Locally coarse/fine intrusive contacts can be traced through the oxide impregnated shear zones, demonstrating unequivocally the hybrid magmatic origin of the oxide-bearing gabbros.

The Unit V/Unit VI boundary was designated arbitrarily at the first intrusive microgabbro in Hole 735B below the Unit IV massive oxide gabbro. There is a striking change in the composition, and some coarsening of grain size, of these intrusives downward from fine- to medium-grained oxide gabbronorite at the top of Subunit VIA to medium- to coarsegrained troctolite at the base of Subunit VID.

The systematic variation in intensity of the high-temperature late magmatic deformation in Unit VI is complicated by a second, lower temperature deformation phase. Substantial, subsolidus amphibolite facies brittle-ductile deformation and hydrothermal alteration overprints the complex intrusive and latemagmatic deformation events in Subunit VID. The alteration occurs in zones starting in Core $85 \mathrm{R}-1$, and becomes more common and pervasive downward; with most of the rock showing some amphibolitization and albitization. The alteration is greatest in and around the locally intense subsolidus brittleductile shear zones. The late deformation and alteration tends to preferentially affect oxide-rich zones. However, this is an overprint, and is not contemporaneous with oxide precipitation. This is clearly demonstrated by hydrothermally altered mylonites that offset oxide layers with markedly different strike. In addition, unlike the deformation associated with unaltered oxide-bearing zones, the subsolidus deformation often affects oxide-free gabbro $10 \mathrm{~cm}$ or more to either side of oxide-bearing zones, and hydrothermal alteration affects broad zones of the gabbro beyond the shear zones.

\section{Subunit VIA}

This unit is $22.14 \mathrm{~m}$ thick and contains 24 discrete intervals (Fig. 5F). Only about $20 \%$ of Subunit VIA is locally weakly to very weakly deformed. There are four intrusive microgabbronorites, an olivine microgabbro, three brittle-ductile deformation zones impregnated with minor oxides that cross the olivine gabbro, and a coarse-grained olivine-poor oxide gabbro (possibly weakly deformed). There is also a patchy olivine gabbro similar to the Unit V olivine gabbro, but with rapid irregular variations in grain size. This patchy olivine gabbro appears consistently very-weakly deformed, although similar gabbro in Subunit VIB is undeformed. About $80 \%$ of the subunit consists of undeformed olivine gabbro screens.

Oxide microgabbronorites, which appear only in Subunit VIA, are fine-grained granular to subophitic rocks, with an "aplitic" appearance in hand specimen, texturally similar to the microgabbros, olivine microgabbros, and fine-grained areas in the patchy olivine gabbros, but containing primary hypersthene, apatite, biotite, and iron-oxide. The oxide microgabbronorite at the top of the section has highly irregular contacts with the olivine gabbro which curve irregularly in hand specimen (Plate 3). The top contact is subhorizontal, the bottom is subvertical. These are not the kind of razor sharp straight contacts bounding the diabase dikes. There are no chilled margins in the finer-grained microgabbro against the coarser grained olivine gabbro. Rather, the contact is sutured on a thin section scale, with fine and coarse grained granular to subophitic silicates interlocking across a sharp grain size boundary. Near the top of the uppermost oxide microgabbronorite are a few coarser patches that appear to be partially assimilated xenoliths of the olivine gabbro wall rock. The lack of parallel walls, lack of chilled margins, and the igneous appearing contacts all suggest assimilative intrusion.

All the other three lower intervals of oxide microgabbronorite appear to be weakly deformed versions of the uppermost oxide gabbronorite. The deformation has dragged and rotated their contacts, obscuring their original intrusive character. The oxide microgabbronorite in Core 76R-3, Pcs. $2 \mathrm{~b}$ and $2 \mathrm{c}$, encloses a large angular clast of olivine gabbro which may be a deformed xenolith of the wall rock. Locally, the oxide microgabbronorite appears to grade into the olivine gabbro, which may represent interaction with, and partial assimilation of, the olivine gabbro. Unlike the other oxidebearing gabbros drilled in Hole $735 \mathrm{~B}$, the oxide microgabbronorites in Unit VIA have a bulk composition close to ferrobasalt, and though lower in incompatible elements, they are close to liquid compositions. They are not thought to be hybrids formed by impregnation of a more primitive protolith by late intercumulus liquid, as is the case for the other oxide-bearing gabbros in the unit. The oxide is believed primary, crystallized at the time of intrusion of the microgabbro, and is texturally distinct from that in the other oxidebearing gabbros in the section.

The olivine microgabbro and patchy olivine gabbros macroscopically, have the same intrusive relationship to the olivine gabbro as the oxide microgabbronorites, with nearly identical textures, and irregular, nonparallel, sutured igneous contacts with the olivine gabbro. The olivine microgabbro is a fine- to medium-grained ( $\mathrm{mm}$ ) aplitic rock generally containing $60 \%$ plagioclase plus pyroxene and olivine in varying proportions, with local coarser patches that resemble the olivine gabbro country rock. Contacts between the olivine 
microgabbro and olivine gabbro within the patchy olivine gabbros are irregular and frequently the olivine gabbro has the appearance of partially assimilated xenoliths. The olivine microgabbro (interval 316 in Appendix A) has an interesting lower contact with a coarse-grained olivine gabbro whose crystals appear to be suborthogonal (crescumulate or harrisitic) to the contact and overlying microgabbro. We note that the only significant difference in hand specimen between the oxide-free and oxide-bearing patchy olivine gabbro is the presence of disseminated oxide and penetrative weak deformation of the latter.

The oxide olivine gabbros in this unit all lie in weakly ductily deformed shear zones and criss-cross the olivine gabbro with irregularly varying dip. The shear zones are braided and enclose numerous blocks of undeformed oxidefree olivine gabbro. The oxide is intergranular, often occurring in intergranular lenses and strings in the foliation plane, and frequently appears undeformed, suggesting that its precipitation continued at the end of deformation. One exceptional interval, without any evidence of deformation, is a $0.5-\mathrm{m}$, coarse- to very-coarse-grained, oxide-bearing, olivine-poor gabbro (interval 314, Appendix A) that is texturally distinct. It contains $4 \%$ iron oxides, and has only $1 \%$ to $2 \%$ olivine. Olivine is much more abundant in the medium-grained olivine gabbro above and below this interval. If deformation is present in this coarse gabbro, the macroscopic effects are very slight, and we regard this interval as anomalous compared to the other oxide gabbros in Hole 735B, and texturally it looks like a pegmatitic olivine-poor patch or horizon of the olivine gabbro. There is no particular reason why some of the intercumulus melt may not have crystallized locally in the undeformed gabbro to form such pegmatitic patches.

\section{Subunits VIB and VIC}

These subunits are 15.3 and $14.5 \mathrm{~m}$ thick and have 43 and 44 lithologic intervals respectively. These include long intervals of penetratively deformed oxide-bearing olivine gabbro, oxide microgabbro, and numerous intensely deformed oxiderich ductile deformation bands in the olivine gabbro. Late micro-intrusive gabbros also occur here in some abundance. This is the second most oxide-rich zone in the entire coreapproximately $41 \%$ is oxide-bearing. Numerous fine-grained aplitic intervals of microgabbro or patchy olivine or oxideolivine gabbro also occur in this zone, both sheared and unsheared. Microgabbro of one sort or another makes up roughly $42 \%$ of these two subunits, whereas similar finegrained rocks make up only about $10 \%$ of Subunit IVA. Roughly $35 \%$ of the rock shows the effects of deformation, whereas only $13 \%$ of the rock in VIA has weak deformation The deformed rock is almost entirely oxide-bearing. The extreme lithologic variability, abundant late intrusives, and more pervasive and locally intense deformation distinguish these units from Subunit VIA.

Olivine gabbro, texturally identical to that in Unit V, remains the most abundant rock type in Subunits VIB and VIC, constituting 26 of the 87 discrete lithologic units described and $31 \%$ of the interval. Subunit VIC is distinguished from Subunit VIB by the appearance of abundant intrusive troctolite, troctolitic gabbro, troctolitic microgabbro, and related oxide-bearing equivalents ( $42 \%$ of Subunit VIC).

Olivine microgabbros having clear intrusive contacts were identified in Subunits VIB and VIC, but were lumped with the patchy olivine and oxide olivine microgabbro in Table 4 and Appendix A due to the local complexity and disruption of the unit by deformation and cross impregnation by late-magmatic oxide. As elsewhere, the olivine microgabbros are interpreted as intrusive into the olivine gabbro. In two cases, the contacts of the olivine microgabbros are size graded over about $1 \mathrm{~cm}$ from medium- to fine-grained. In another case, a sharp coarse-fine transition occurs at the upper contact, which is somewhat irregular, whereas the lower contact is razor sharp and straight, with fine- to medium-grained olivine microgabbro against weakly deformed olivine gabbro. It is difficult to see any deformation of this microgabbro, which suggests that its intrusion locally postdates deformation of the olivine gabbro. The olivine microgabbro also contains coarser medium-grained patches. This and the gradational contacts in other olivine microgabbros suggest considerable assimilation of coarse olivine gabbro into the intrusive microgabbro.

In all, $28 \%$ of Subunit VIB is patchy olivine gabbro and olivine microgabbro. As for intrusive microgabbros and patchy olivine gabbros higher in the section, we think these represent intrusion of basaltic melt into the massive olivine gabbro ranging from when it was a highly viscous crystal mush, unable to support a shear stress, to a time when it became sufficiently rigid for intrusive contacts to form.

Troctolite occurs in Subunit VIC in intervals 389 and 394 (Appendix A) and consists of fine- to medium-grained (0.5-1.0 $\mathrm{mm}$ ) equigranular olivine, plagioclase, and pyroxene. Locally, plagioclase coarsens to form stubby medium-grained laths. Patches of medium- to coarse-grained chrome diopside also occur in the troctolite. Subhedral chrome spinel, often with opaque extensively altered rims (possibly due to reaction with late magmatic liquids), is common in the troctolites. The troctolites are both overlain by coarser troctolitic gabbro, which contain up to $5-\times 5-\mathrm{cm}$ chrome diopside oikocrysts enclosing olivine and plagioclase. Undeformed troctolite has a typical sharp intrusive grain size contact with undeformed olivine gabbro at the base of interval 394, and is in contact with penetratively deformed olivine-rich oxide microgabbro in interval 389 . There the contact is deformed and oxide is concentrated along and adjacent to the contact. In addition, troctolite often occurs as a fine grained facies in patchy olivine gabbro and as deformed patches within sheared oxide olivine gabbro (e.g., interval 383). Locally, deformed oxide-bearing zones cross the troctolite in these mixed zones.

One interval containing troctolitic microgabbro was found in Subunit VIC. The troctolitic microgabbro has an irregular sharp igneous contact with the olivine gabbro, generally marked by an abrupt drop in grain size, and is sutured on a thin section scale, with fine and coarse grains interlocking along the contact. Patches of olivine gabbro occur within the troctolitic microgabbro. These may represent partly assimilated or reacted olivine gabbro xenoliths or alternatively micropegmatite patches where trapped melt in the microintrusion crystallized locally.

Troctolitic gabbro appears in seven intervals and may represent a coarser-grained, comparatively pyroxene-rich, variety of the troctolite in which a higher proportion of the parent liquid was trapped, or where a greater extent of post-cumulus growth of pyroxene from that liquid occurred. Contacts between troctolitic microgabbro and troctolite are clearly igneous but do not look intrusive. Rather, the troctolitic gabbro often looks like a coarser-grained local, sometimes micropegmatitic, facies of the troctolite. The contacts are frequently undeformed and may be sutured, representing a fairly sharp decrease in grain size (e.g., Core 79R-6, Pcs. 5b and $5 \mathrm{c}$ ) or gradational (Core $79 \mathrm{R}-6, \mathrm{Pc} .4$ ) or modal (Core $80 \mathrm{R}-1, \mathrm{Pc} .7)$. The troctolitic gabbro also occurs as centimeter scale patches in troctolite. Contacts between troctolite and olivine gabbro are difficult to find, but in Core 79-7, Pcs. 5b and $5 \mathrm{a}$, they appear to have sutured igneous intrusive contacts. 
Because of the complexity of Subunits VIB and VIC, care was taken to lay out the core and measure the various types of intrusives, with the foliated oxide-bearing zones measured on the basis of their protolith. When this was done for Core 79, we found that it contained three troctolitic gabbro/microgabbro intervals of 50,135 , and $152 \mathrm{~cm}$ thick, respectively. These are probably fairly representative of the original dimensions of the intrusive units in the complexly deformed and crossimpregnated Subunits VIB and VIC.

Oxide-bearing gabbros in Unit VI, including Subunits VIB and VIC, coincide with brittle-ductile deformation zones. These zones crosscut both the olivine gabbro and, locally, all the intrusive microgabbro and troctolitic lithologies. The original coarse-grained/medium-grained lithologic contacts of the microgabbros and troctolitic rocks with the olivine gabbro can often be traced from oxide-free regions through the crosscutting oxide-bearing deformed zones. This provides clear evidence that the various oxide bearing gabbros formed by precipitation of oxide in deforming preexisting lithologies, overprinting the primary textural relationships between different pre-existing lithologies.

The intensity of the oxide-bearing brittle-ductile deformation zones varies from barely discernable to mylonitic and their thicknesses vary from a few millimeters to $10 \mathrm{~cm}$. These shear zones are clearly braided, with deformed layers diverging locally within the core, and varying radically in thickness. There is a striking tendency for oxide in the shear zones to be concentrated adjacent to the contacts, and to be less abundant in the centers of the shear zones. Undeformed oxide-free shear polyhedra of olivine gabbro, troctolite, microgabbro, and troctolitic gabbro are common (Fig. 13) within the oxidebearing ductile shear zones. Due to the range in degree of deformation (and a wide range in oxide concentration) there is no doubt that the oxide-bearing brittle-ductile deformation zones have all of these rock types as protoliths. These rocks were evidently crosscut by braided brittle-ductile shear zones that acted as channels for flow of an iron-titanium-rich fluid. There is rarely deformation without oxide present, and oxide is rarely present without deformation. Oxide-bearing shear zones have been found that crosscut contacts between all the oxide-free lithologies in Units VIB and VIC.
A higher percentage of the troctolitic gabbro and microgabbro intrusives are undeformed in Subunits VIB and VIC than the host olivine gabbro. Locally, some intrusive microgabbros can be seen to crosscut foliated oxide olivine gabbro. This demonstrates that intrusion of various microgabbros and troctolitic rocks overlapped with, and locally continued after, ductile deformation and formation of oxide gabbro.

The deformation is often intense and almost certainly occurred at high hypersolidus temperatures. Contacts between deformed and undeformed rocks have themselves been folded. Locally, "similar"' style folds are associated with flow of ductily deformed recrystallized olivine and plagioclase between necking, relatively rigid, olivine gabbro boudins in apparently less competent olivine microgabbro (Plate 4). The absence of an axial-plane penetrative mineral foliation in these folds suggests very high temperature plastic deformation. Nicolas (1990) has suggested that similar folds in gabbros in the Oman Ophiolite formed during late-magmatic deformation of a crystal mush. This would appear to be confirmed here by the presence of magmatic ilmenite in the deformed zones.

Locally, penetratively deformed oxide olivine gabbro zones of some thickness are similar to the thick zones described in Unit III. The largest of these (in the lower half of Subunit VIC) is more than $2 \mathrm{~m}$ thick. It is weakly deformed and varies considerably in lithology from sheared oxide olivine gabbro, olivine-rich oxide olivine gabbro, oxide olivine microgabbro, back to oxide olivine gabbro, which would seem to represent wholesale deformation of an interval of olivine gabbro which was intruded by troctolitic olivine gabbro and troctolite or olivine microgabbro prior to deformation and oxide impregnation. The percentage of oxide through this interval varies considerably: It is highest at the top (about $15 \%$ ) and drops towards the base (about 2\%) with local variations through the section.

The largest oxide-bearing zone in Subunit VIB is $5 \mathrm{~m}$ thick, starting just below the somewhat arbitrary Subunit VIA/ Subunit VIB boundary. The distinguishing feature of this long interval of oxide-bearing gabbro is the uniform weak penetrative foliation. The section is mostly disseminated oxide olivine gabbro, with local oxide-olivine gabbro patches. The protolith was mixed olivine gabbro and patchy olivine gabbro with

\section{Foliated Oxide Bearing Ductile Shear} Zones In Olivine Gabbro
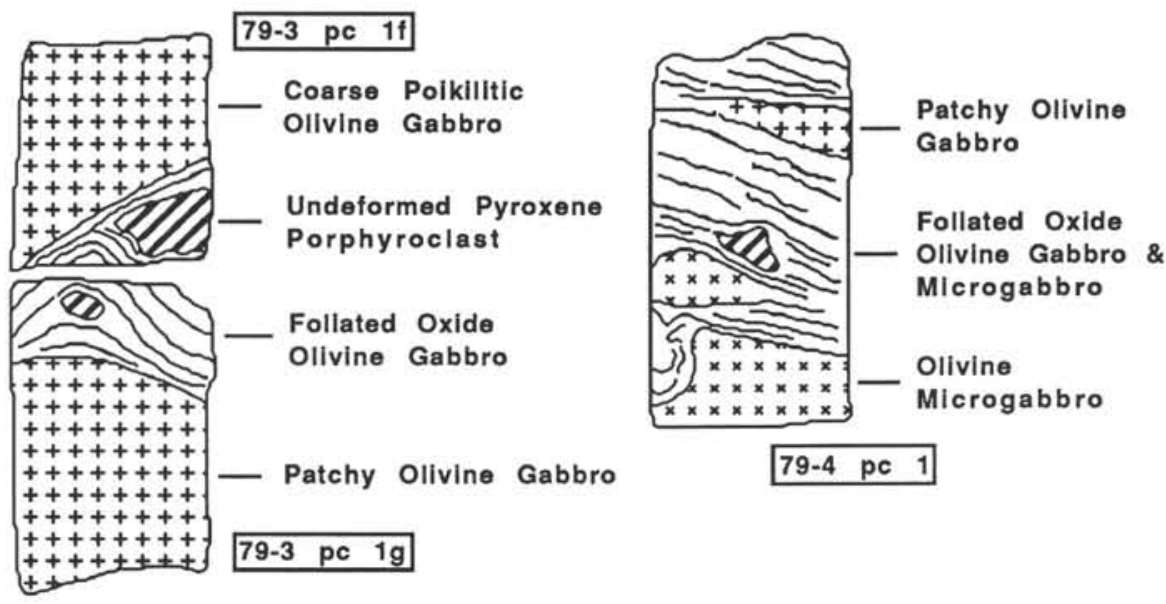

Figure 13. Small, oxide-impregnated ductile shear zones crosscutting oxide-free olivine gabbro and microgabbro. 
roughly equal proportions of long fine- to medium-grained and coarse-grained intervals. At numerous locations, deformed rotated and cross-foliated patches of fine- or coarse-grained oxide-bearing gabbro occur, clearly demonstrating a local patchy olivine gabbro protolith. In some fine-grained intervals, however, the deformation associated with oxide impregnation may have reduced an originally coarser-grained olivine gabbro to medium- to fine-grained, giving the appearance of a microgabbro protolith. In other long coarse zones, though, the protolith was clearly coarse olivine gabbro.

A patchy olivine gabbro protolith similar to that suggested above was postulated for a much thicker disseminated oxide olivine gabbro in Unit III. Given the relatively small percentage of oxide-free patchy olivine gabbro in Hole 735B, there is a rough correlation between the formation of such rocks, other abundant varieties of late intrusive microgabbro and late-magmatic brittle-ductile deformation and oxide impregnation (Fig. 14). This evidence argues that such zones were the preferred locus for intrusion through the cumulate pile or vice versa: that the formation of brittle-ductile shear zones produced zones of preferred intrusion.

\section{Subunit VID}

This unit resembles Subunit VIA in having a predominance of undeformed (excluding subsolidus deformation) oxide-free olivine gabbro ( $60 \%$ of subunit), and a similar proportion of intrusives and patchy olivine gabbros (14\%). It has a larger amount of deformed oxide-bearing gabbros than Subunits VIA ( $25 \%$ vs $10.4 \%$ ), but significantly less than Subunits VIA and VIB. The oxide-bearing gabbros have the same contact relationships with undeformed olivine gabbros as those in the overlying gabbros, and exhibit the same textural relationships indicating that penetrative deformation and precipitation of oxides are directly related. Again, oxide gabbros occur with irregularly dipping contacts, but relatively uniform strike, are generally penetratively deformed, and surround blocks of undeformed oxide-free olivine gabbro and microgabbro intrusives. The contacts are often undeformed between the two, but commonly lie in the foliation plane where foliated oxidebearing gabbro lies against undeformed oxide-free gabbro. It can be seen that undeformed oxide occurs with intergranular

Hole 735B Correlation Between Oxide-Rich Zones and Late Intrusives

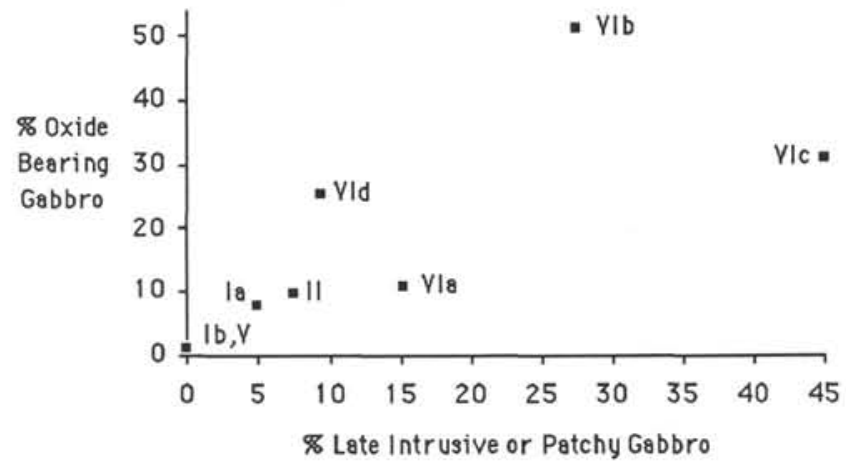

Figure 14. Correlation between foliated oxide-bearing gabbros and late intrusives (microgabbronorite, microgabbro, olivine microgabbro, troctolites, troctolitic gabbros, and oxide-bearing varieties), suggesting a relationship between zones of late-magmatic brittleductile deformation and the locus of microgabbro intrusion. Units III and IV are excluded because the degree of late-magmatic impregnation and brittle-ductile deformation precluded reliable identification of intrusive protoliths. undeformed silicates along these contacts. Notably, some of the coarse silicate grains extend across the contact from the oxide-free zone.

Unlike Subunit VIA, the intrusives in Subunit VID are mainly troctolite and troctolitic gabbro. These troctolitic intervals are noticeably less deformed than those in the overlying subunit, and tend to be coarser-grained. Contact relations between troctolites and olivine gabbro are often missing, but where present, are igneous with interlocking grains lying along a sharp sutured boundary marked by an abrupt change in grain size. An exception is the troctolite at the base of the hole where the contact is more gradational. Green diopsidic patches, often coarse-grained, occur locally in the troctolite. These tend to be coarse granular to anhedral intergranular patches and locally may subophitically enclose coarse euhedral to subhedral plagioclase laths. As in Subunit VIC, bright green patches of diopside also occur in the gabbro near the major troctolitic intervals. These may have crystallized from intercumulus melt that escaped an intrusive troctolitic mush and penetrated the wall rock olivine gabbro.

One of the troctolites contains a number of features that may represent magmatic sedimentary layering $\left(\mathrm{S}_{1}\right)$. A 10 -cm-thick, spinel-rich layer, with about $2 \%$ subhedral chromian spinel, occurs in Core 83R-7, Pcs. $4 \mathrm{~d}$ and $4 \mathrm{c}$. This layer lies at the center of a $2 \mathrm{~m}$ thick troctolite, $112 \mathrm{~cm}$ from the top and $94 \mathrm{~cm}$ from the base, and is phase graded, with the highest concentration of spinel at its center. The olivine in the troctolite varies from fineto medium-grained several times down the interval, and the spinel layer lies within one of the fine-grained zones. There are local variations in the amount of olivine in the interval as well, with a $30 \mathrm{~cm}$ plagioclase-rich zone locally terminating at a $1 \mathrm{~cm}$ thick inclined $\left(36^{\circ}\right)$ olivine-rich layer. Generally, the fine and coarse intervals grade into each other, though in Core 83-7, Pc. $7 \mathrm{~d}$, there is a fairly sharp transition from fine- $(1 \mathrm{~mm})$ to medium-grained ( $2 \mathrm{~mm})$ troctolite.

Throughout Unit VI, there is a systematic change from evolved to increasingly primitive micro-intrusives downhole. Oxide gabbronorites, chemically similar to evolved ferrobasalt, and one olivine microgabbro occur in Subunit VIA, while more primitive olivine microgabbro and patchy olivine gabbro occur in Subunit VIB, and olivine microgabbro, and patchy olivine gabbro, occur with the first appearance of troctolitic microgabbro and troctolite (with high-magnesium olivine and chrome spinel consistent with precipitation from a primitive MORB), down to medium-grained troctolite in Subunit VID. An important feature of the local stratigraphy is the coarsening of troctolites with depth, and the disappearance of transitional troctolitic microgabbros. These systematics suggest the presence of a steep thermal gradient at the time of emplacement of these intrusives, consistent with their representing apophyses of a major intrusive body just below the base of Hole 735B. This body could be logically inferred to have crystallized from a primitive MORB, given the predominance of troctolite at the base of the hole. It is possible that the suite of late intrusives crosscutting the olivine gabbro throughout the overlying section were derived by successively tapping small amounts of liquid from this intrusion as it solidified.

\section{CHEMISTRY AND IGNEOUS MINERALOGY}

\section{Lithologic Variability}

The chemical variability of the Hole $735 \mathrm{~B}$ gabbros can be seen in the AFM diagram in Figure 15A. The overall chemical variability is quite large, and is equal or greater than that seen in the layered Skaergaard Intrusion in East Greenland. This is striking as the Skaergaard Intrusion is a $2.5-\mathrm{km}$ section of what is thought to be the remains of a large, approximately 

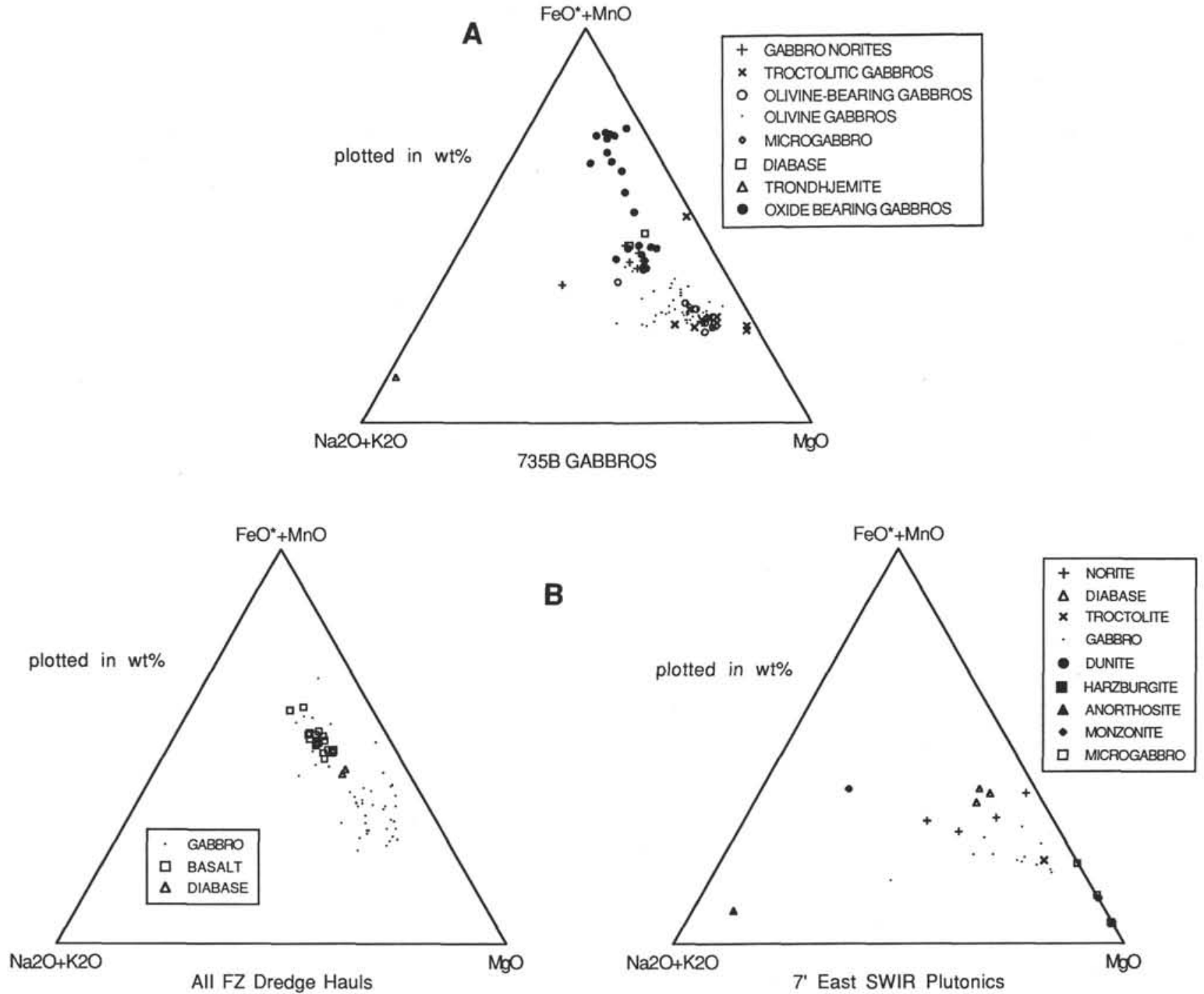

Figure 15. Ternary AFM plots (wt\% oxide) with all iron as FeO. A. Hole 735B gabbros and diabase. B. Dredged gabbros, diabase, and basalt from the Atlantis II Fracture Zone and for $7^{\circ} \mathrm{E}$ on the South'vest Indian Ridge (data from Meyer et al., 1989).

6-km-thick magma chamber, while the section drilled in Hole $735 \mathrm{~B}$ is only $500 \mathrm{~m}$ thick. Whereas the Skaergaard Intrusion is thought to have formed by a relatively "simple" combination of fractional crystallization and post-cumulus growth processes in a large magma chamber (Wager and Deer, 1967), the complex drilled in Hole 735B clearly has a different, more complex, petrogenesis that has produced a similar large chemical variability, but in a significantly different dynamic environment. From the discussion to this point, it is evident that while the chemical variation of the $735 \mathrm{~B}$ gabbros may emulate that of a layered complex, the Hole 735B section almost entirely lacks evidence for simple magmatic sedimentary layering, and formed in an environment where there is a strong interplay between tectonic and magmatic processes. It is this interplay, the fractionation of melts within a crystal mush, in a complex extensional tectonic environment, rather than simple fractional crystallization and magmatic sedimentation in a magma chamber, which has produced the large lithologic variability seen at this site.

It is of interest to compare the Hole 735B gabbros with the basalts and gabbros dredged from the Atlantis II Fracture Zone during the Site Survey (Meyer et al., unpubl. data, 1990). The basalt compositions represent a reasonable spec- trum of potential parent liquids, ranging from moderately primitive $\left(\mathrm{Mg} /\left\{\mathrm{Mg}+\mathrm{Fe}^{*}\right\}=0.63\right)$ to moderately evolved $\left(\mathrm{Mg} /\left\{\mathrm{Mg}+\mathrm{Fe}^{*}\right\}=0.50\right)$ liquids (data in Dick et al., this volume). The basalts overlap the composition of the dredged gabbros, which define a linear trend subparallel to the ironmagnesium join, with slightly increasing alkalis and iron. This trend is typical for many tholeiitic basalts and gabbros dredged from ocean ridges, and lies close to the well-know Skaergaard differentiation trend.

The basalts lie at the iron-rich end of the spectrum, while two dredged diabases are slightly more primitive, in a position similar to that for the two drilled diabases (unfortunately, four diabases are an insufficient sampling to tell if this is a systematic difference). This would be expected because the composition of a gabbro crystallized from a basalt liquid will have a composition that lies between a mineral assemblage of primary liquidus mineral phase compositions and the solidus composition of the magma. A melt trapped and homogeneously crystallized in-situ will have mineral and bulk compositions the same as the solidus compositions of the initial liquid, while an early magmatic sediment, where all intercumulus liquid was expelled by cumulus crystal growth filling in the pore space, will have a composition close to the initial basalt 
liquidus phase compositions. Any rock that is a mixture of trapped melt and cumulus crystals will lie between these two compositional extremes. Thus, the basalt compositions erupted from a magma chamber will be, on average, more evolved than the rocks that crystallize from the same liquids at depth. The most magnesian olivine in the cumulus troctolites $\left(\mathrm{Fo}_{86}\right)$ represents the approximate liquidus composition of olivine in the more primitive dredged basalts.

The dredged gabbros do appear to be different overall from the drilled gabbros, and have less chemical variability, but extend to more magnesian compositions. Care must be taken when interpreting the differences among these suites. Statistically, the oxide gabbros represent $27 \%$ of the section drilled at Hole $735 \mathrm{~B}$, and $26 \%$ of the analyses in Appendix B. However, geologists generally select the most interesting, not necessarily the most representative sample, and it is entirely likely that with an entire section laid out, there was some bias toward sampling extreme end-members. It is reasonable, however, that a similar bias existed for sampling the dredge collection, particularly as this was done by a subgroup of the Leg 118 Shipboard Scientific Party. Thus, sampling bias probably played a minor role in the differences seen here. The dredge collection represents a fairly extensive random sampling of what has been exposed on the walls of the transform (gabbro was recovered in 17 of 37 dredge hauls at the Atlantis II Fracture Zone during the site survey, Dick et al., this volume). These rocks come from all levels from the walls of the transform, and represent rocks from the crest of the transverse ridge to samples from the median tectonic ridge on the floor of the fracture zone adjacent to the transform fault. This is clearly not the case for the drilled suite, which represents a thorough sampling at one geographic point relatively far from the fracture zone. Thus, the differences between the suites could reflect bias in the dredge collections to sampling the lower crust away from the midpoint of a ridge volcanic segment, close to a fracture zone, where the crust may be anomalously thin. Alternatively, it may be due to biased depth of sampling in the crust; that is, the faults exposing plutonic rocks in fracture zones may not sample the crust to as deep a level as the drilling.

The question of whether samples dredged from fracture zones might be compositionally distinct from the plutonic crust beneath the midpoint of a volcanic segment has been addressed by a number of authors. Hekinian and Thompson (1976), le Roex and Dick (1981), and Langmuir and Bender (1984) noted a predominance of evolved MORB, particularly ferrobasalt, at some fracture zones at fast and slow-spreading ridges. They suggested that transform basalts reflect lower degrees of melting in the underlying mantle, possibly due to a transform edge effect due to the juxtaposition of old cold lithosphere against hot upwelling asthenosphere beneath the ridge axis at a fracture zone. Le Roex et al. (1981, $1983,1985,1990)$, however, have reported a systematic sampling of basalts from fracture zones and ridge segments along the Southwest Indian and American Antarctic ridges and found that, with the exception of the Conrad Fracture Zone and the anomalous Speiss Seamount, there is no great difference in transform and ridge axis basalt geochemistry, and that evolved ferrobasalts are uncommon. However, Bloomer et al. (1989), Meyer et al. (1989), and Dick (1989) noted that in general there may be a bias toward more iron-enriched, oxide-rich gabbros in fracture-zone dredge suites from these same ridges. These latter authors feel that this apparent contradiction reflects preferential sampling of the plutonic sequence at the distal ends of volcanic segments near fracture zones at slow-spreading ridges, where magmatism is probably ephemeral. Dick (1989), for example, pro- duced detailed dredging statistics for Southwest Indian Ridge transforms to show that a gabbroic layer 3, and hence magma chambers, is largely absent near these fracture zones. Thus gabbros dredged near fracture zones on the Southwest Indian Ridge might largely represent extreme differentiates from relatively stagnant satellite magma chambers or from the distal ends of larger ephemeral chambers centered beneath the adjoining ridge segment. The differences between the basalts and gabbros dredged in the fracture zones could be attributed to emplacement of basalt by relatively rapid eruption down the rift valley fissure system from a central chamber delivering relatively primitive melts to the seafloor in the transform (dominating the eruptive budget on the seafloor near the transform). Gabbros, migrating and cooling more slowly at depth, on the other hand, would be relatively fractionated by the time they were emplaced beneath the fracture zone floor.

We find, however, that the Hole $735 \mathrm{~B}$ gabbros, which can be traced back on a lithospheric flow line to near the inferred midpoint of a volcanic segment, are more iron-rich and evolved than the dredge collections. Thus, we cannot attribute the chemical differences between dredged and drilled gabbros here to different spatial proximity to the transform or to a simple transform edge effect.

The question of whether there is a difference in the level of the crust sampled by dredging the walls of fracture zones from that sampled in Hole 735B seems best addressed by examining the total sample dredged from the Atlantis II Fracture Zone and other comparable fracture zones. We note that basalt, diabase, gabbro, dunite, and residual mantle peridotite have been systematically dredged up the walls of these fracture zones. Bonatti and Honnorez (1976) and Engel and Fisher (1975) suggested that such sections represent fairly complete, though dismembered, cross sections of the ocean crust. One can reasonably argue that such crustal sections are not simple (Francheteau et al., 1976), but it seems undeniable that the tectonics of fracture zones do produce at least a composite sampling of a cross section of the ocean crust (e.g., Dick, 1989). The suite of gabbros presently available from ocean transforms, collectively, was dredged both along the crest of transverse ridges flanking the transform valleys and down their walls. Mantle peridotites are exposed along the crests of many transverse ridges, as well as at all levels on their walls, indicating that tectonics have exposed the deepest levels of the crust and shallow mantle. Thus, while a bias may exist toward sampling near transform faults, the overall suite should also include a sampling of the lower crust well away from the transform as the crests of the transverse ridges are typically 10 to $20 \mathrm{~km}$ from the transform valley floor. Because the Atlantis II Fracture Zone dredge samples extend to more primitive gabbros (magnesium-rich), which might reasonably be expected to come from deeper levels of the crust, we dismiss the idea that drilling at Hole 735B sampled an exceptionally deep portion of the lower crust.

Meyer et al. (1989) examined a suite of gabbros from a single dredge haul from the walls of the Southwest Indian Ridge rift valley near the midpoint of a volcanic segment at $7^{\circ} \mathrm{E}$. Compositions of these gabbros also are shown in Figure 15 , and they are similar to the oxide-free gabbros from Hole 735B but do not include iron-rich, oxide-bearing gabbros like those from the Atlantis II Fracture Zone. A prominent characteristic of the $7^{\circ} \mathrm{E}$ gabbros is the small amount of trapped intercumulus melt required to explain their composition (Meyer et al., 1989). This is a chemical characteristic of adcumulates, where most intercumulus melt has been expelled from the residue by a combination of postcumulus crystal growth and compaction. 
The plutonic crust in a slow-spreading ridge environment is likely to be heterogeneous with major fault zones randomly spaced through it (e.g., CATROUGH, 1979; Fox and Stroup; 1981; Malcolm, 1981). We suggest that the difference in chemistry between the dredged and drilled gabbros at the Atlantis II Fracture Zone reflects this. We drilled a particular section of crust representing a nonuniform process. That process is, in all likelihood, the brittle-ductile deformation and late-magmatic impregnation process forming the Hole 735B oxide-bearing gabbros. This is not an anomalous or unusual phenomenon in the ocean crust, as is shown by the many oxide gabbros dredged from similar fracture zones throughout the Indian and Atlantic oceans (Bloomer et al., 1989; Dick, 1989).

Few Hole 735B gabbros represent simple liquid compositions and, hence, can be regarded largely as "cumulate" gabbros. This can be seen from Figures 16, 17, and 18, where we have plotted $\mathrm{TiO}_{2}, \mathrm{Mg} /(\mathrm{Mg}+\mathrm{Fe})$ and $\mathrm{Ca} /(\mathrm{Ca}+\mathrm{Na})$ for Hole 735B gabbros and the Atlantis II Fracture Zone basalts. As can be seen, there are clear bimodal distributions for oxidefree and oxide-bearing gabbro compositions, as there are in al the chemical plots we examined, with only a few oxide gabbros and the oxide microgabbronorite from Subunit VIA lying consistently within the field of the basalts. The remaining Hole 735B gabbros all lie outside the field of the basalts or its linear extension to reasonable values of $\mathrm{Ca} /(\mathrm{Ca}+\mathrm{Na})$ and $\mathrm{Mg} /(\mathrm{Mg}+\mathrm{Fe})$ for primitive basalts on one plot or the other.

The oxide-free gabbros (mostly olivine gabbro) plot at much lower $\mathrm{TiO}_{2}$ contents than the basalts-too low for any known MORB, and far too low for any known MORB dredged from the Atlantis II Fracture Zone. While the oxide-free gabbros do define weak trends in many of the plots, these trends do not lie along or on an extension of the trend for the basalts, precluding the possibility that they may represent primitive liquids from which the basalts evolved by fractional crystallization. A simple adcumulate or mesocumulate origin, then, is proposed for most of the oxide-free gabbros, wherein cumulus crystal growth and compaction in an olivine-plagioclase-pyroxene crystal mush expelled the majority of the intercumulus melt, producing rocks having uniformly low incompatible element concentrations. This is confirmed by the relatively high $\mathrm{Mg} /(\mathrm{Mg}+\mathrm{Fe})$ and $\mathrm{Ca} / \mathrm{Ca}+\mathrm{Mg}$ ratios of the gabbros, which are far higher than those of the basalts. These are close to the compositions of liquidus, rather than solidus, phases. That is, the silicates in the gabbros are similar to compositions for microphenocrysts in the dredged basalt glasses. If such phenocrysts settled out, they would form a mineral sediment similar to the gabbros drilled if the trapped liquid were expelled from the crystal pile. If phenocrysts and melt are held in equilibrium together throughout solidification, the mineral compositions would have lower $\mathrm{Mg} /(\mathrm{Mg}+\mathrm{Fe})$ and $\mathrm{Ca} /(\mathrm{Ca}+\mathrm{Na})$ ratios, reflecting the initial basalt solidus compositions.

The bulk compositions of the oxide-bearing gabbros vary widely, extending from extraordinarily high $\mathrm{TiO}_{2}$ contents to the low values found in the oxide-free olivine gabbros. The $\mathrm{TiO}_{2}$ contents for many of the gabbros are far too high to represent any simple hybrid of trapped basaltic melt and an oxide-free olivine gabbro cumulate, which should lie on a simple mixing line between the basalts and gabbros. Rather, it is clear that these compositions reflect wide variations in the

\section{B WHOLE ROCK TIO2 vs MG\#}

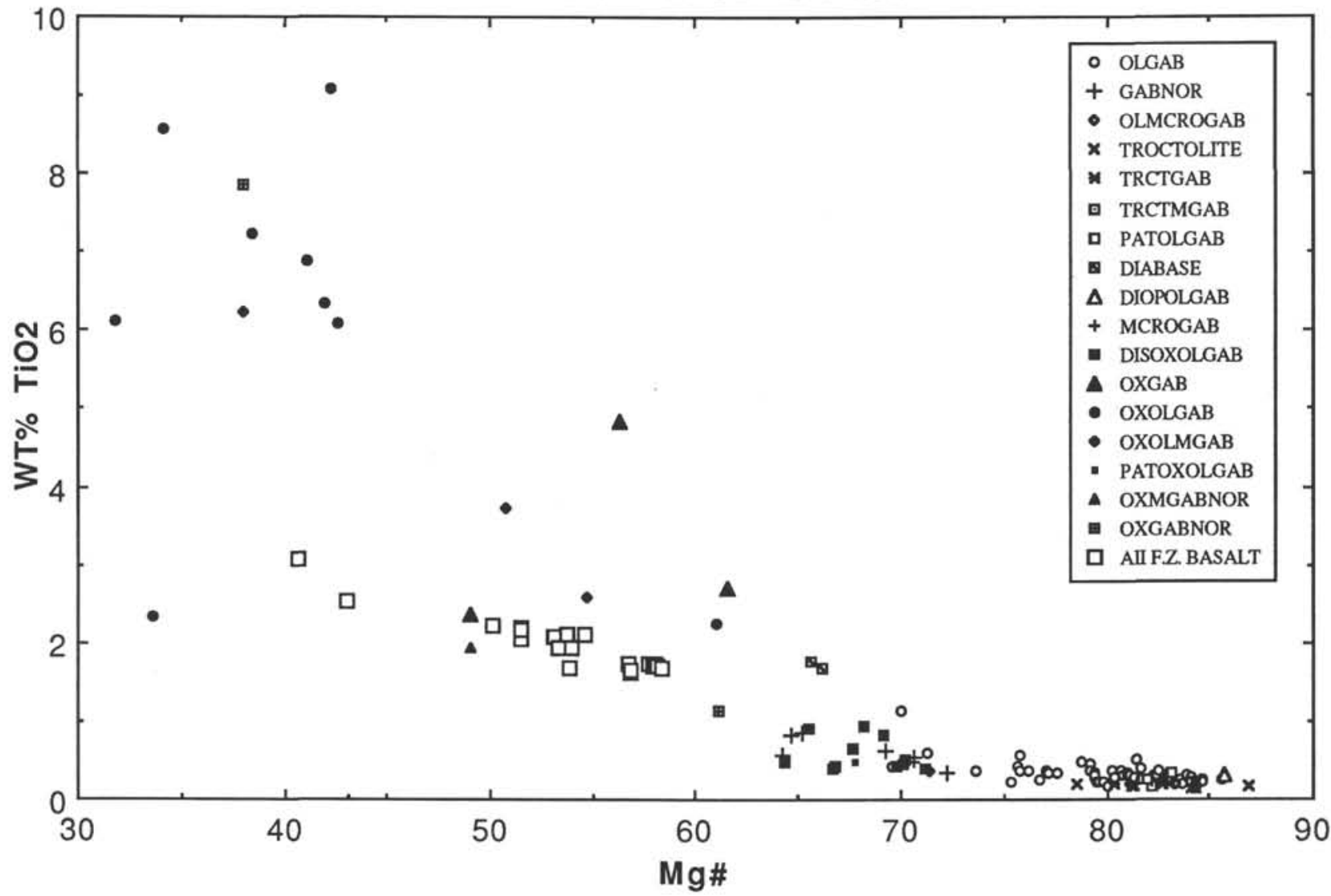

Figure 16. Whole-rock $\mathrm{TiO}_{2}$ vs. $\mathrm{Mg} /(\mathrm{Mg}+\mathrm{Fe})$ for Hole $735 \mathrm{~B}$ gabbros and for basalts dredged from the Atlantis II Fracture Zone. 


\section{B WHOLE ROCK TIO2 vs CA\#}

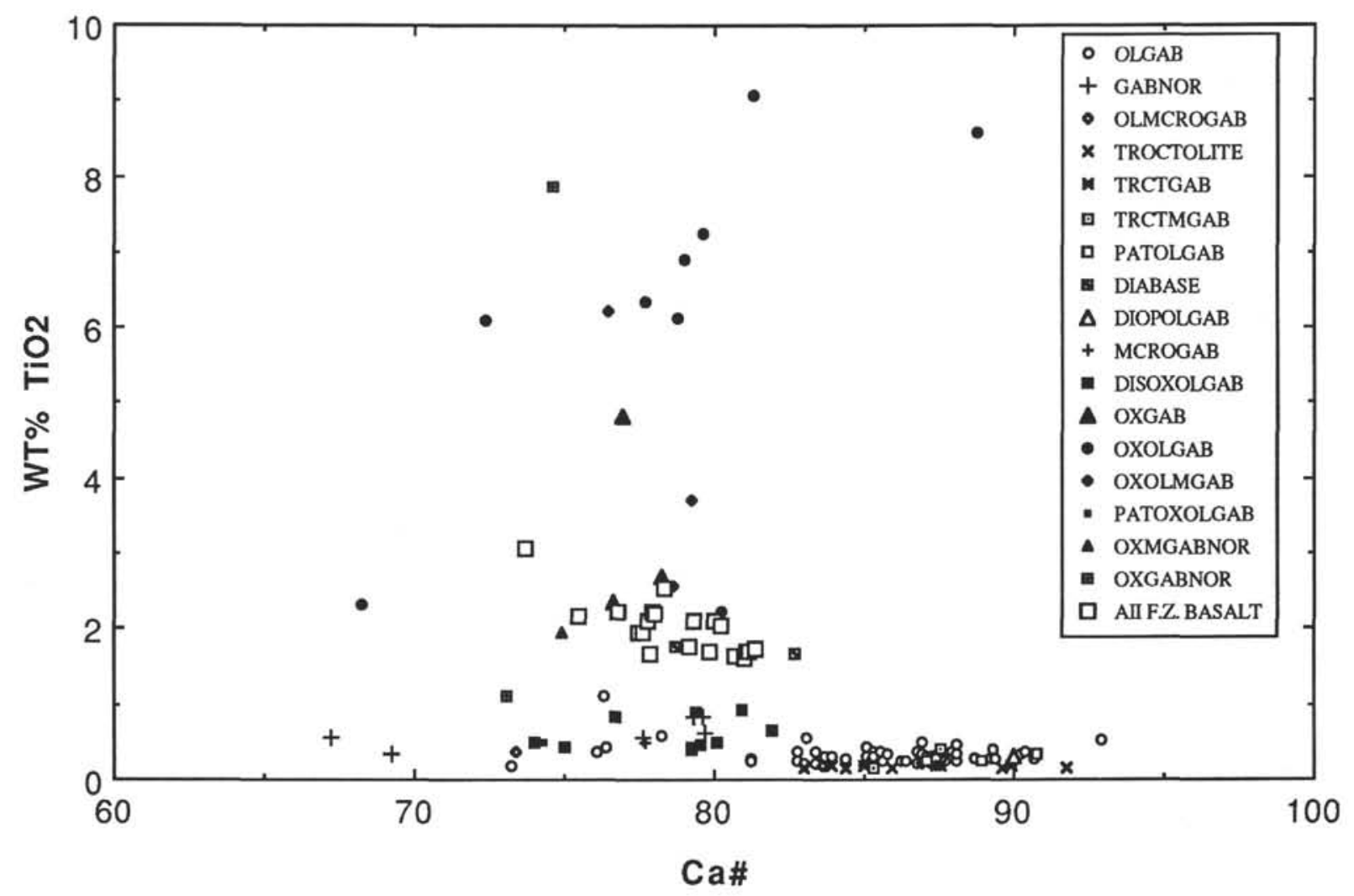

Figure 17. Whole-rock $\mathrm{TiO}_{2}$ vs. $\mathrm{Ca} /(\mathrm{Ca}+\mathrm{Na})$ for Atlantis II Fracture Zones basalts and Hole $735 \mathrm{~B}$ gabbros.

ilmenite content of these gabbros. If these compositions represent liquids, then these liquids have a wide and extraordinary range, without any simple relationship between them. Rather, it is clear that these rocks must represent some form of hybrid rock or heteradcumulate.

The late intrusive microgabbros are key to understanding the petro-tectonic evolution of Hole $735 \mathrm{~B}$. These range from oxide gabbronorites, through microgabbro, olivine microgabbro, and troctolitic gabbro to troctolites. Their compositions include basaltic (e.g., the Unit VIA oxide gabbronorites which are close to liquid compositions), but are mostly meso- or adcumulate, where the incompatible element concentrations mimic those in the olivine-free gabbro. For the most part, they resemble the compositions of mineralogically similar coarsegrained gabbros in the section, and may represent simple fine-grained equivalents of them (Fig. 2). Consistent with the lithostratigraphic evidence, the microgabbros probably represent small cumulus lag deposits and local intrusions from a range of basaltic melts migrating through the cumulate pile from below. Their mineralogy suggests that they were generally multiply saturated in plagioclase and olivine, and in some cases, pyroxene (also ilmenite in the oxide gabbronorites) as well. As discussed previously, the morphology of the intrusives contacts and relation to their wall rocks are similar in many respects to crosscutting podiform dunites left behind in residual mantle peridotites by melts migrating out of and interacting with the mantle, and suggest that the migrating melts were also assimilating gabbroic wall rock.

\section{Downhole Chemistry and Mineralogy}

Downhole shipboard plots of the chemistry showed that the chemistry varies erratically, with tremendous scatter and little coherent chemical variation anywhere. Although a few additional whole-rock XRF analyses are included in Appendix B (P. S. Meyer, pers. comm., 1990), there is, on average, only one analysis for only every $4.5 \mathrm{~m}$ of core. This is also the case for the compilation of mineral data presented here. With 495 discrete lithologic intervals in the section, there is an insufficient sampling to depict cryptic chemical variations for anything less than about a $20-\mathrm{m}$ scale. Because the average lithologic interval is much smaller than this, chemical variability within layers is outside the scope of this study.

In Figures 19 to 21, we have plotted the data sorted by lithology to examine the downhole chemical variability of different rock types. For sorting the analyses, we used the bottom of the actual interval sampled for thin sections or XRF analysis to assign a rock name. Since the core is often a loose collection of rock fragments, many of which are able to slide up and down the core liner, a given sample's position is not actually fixed and can vary by centimeters. This can lead to errors when assigning rock names using Appendix A for rocks sampled on board ship. In addition, petrologists sampling the core tended to make thin sections across lithologic contacts, and where an analysis was made above a contact in a thin section, it is incorrectly assigned the rock name of the lower interval by the computer. As we had available thin sections made from the samples chosen for XRF, we were able to double check the assignment of rock names for the whole rock analyses. This was unfortunately not the case for the mineral analyses. This was due to a lack of time and unavailability of the thin sections for samples analyzed by our colleagues elsewhere for double checking at the time of writing. Thus, in the downhole plots of mineral chemistry there are some 


\section{B WHOLE ROCK MG\# vs CA\#}

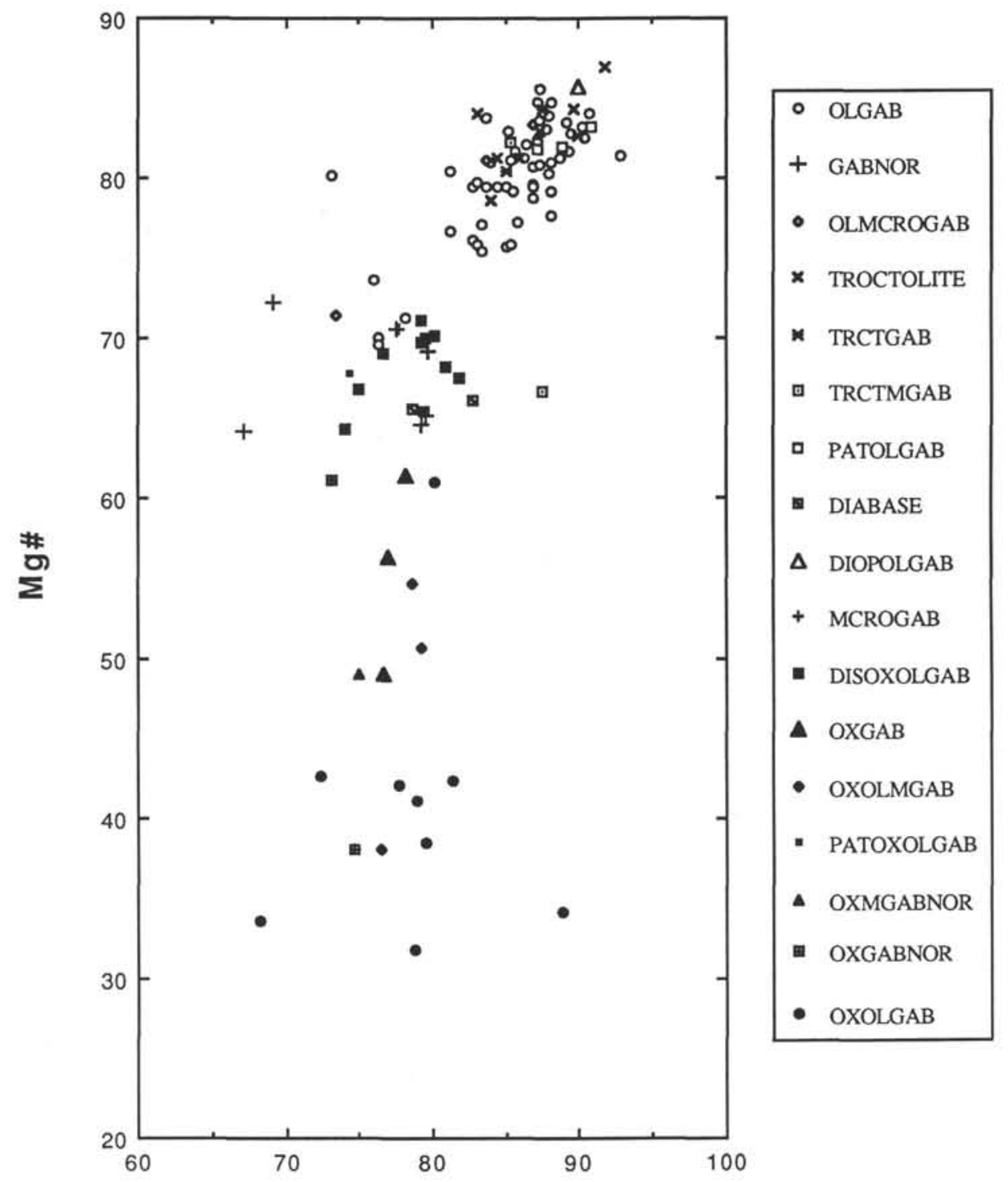

\section{Ca\#}

Figure 18. Whole-rock $\mathrm{Mg} /(\mathrm{Mg}+\mathrm{Fe})$ vs. $\mathrm{Ca} /(\mathrm{Ca}+\mathrm{Na})$ and Hole $735 \mathrm{~B}$ gabbros.

misassignments of rock name. This likely explains those mineral analyses from oxide-free gabbros that plot on the trends for oxide-bearing gabbros and vice versa.

The downhole chemical variations are only irregular and large when considering the oxide-bearing and oxide-free gabbros together. Once the chemical and mineral analyses are sorted by rock type, inspection of the downhole whole rock and mineral chemistry plots show that the compositions of Hole 735B gabbros have a bimodal distribution along the length of the section cored. The oxide-bearing gabbros have systematically higher $\mathrm{Na}_{2} \mathrm{O}, \mathrm{TiO}_{2}$, and lower chrome contents, $\mathrm{Mg} /(\mathrm{Mg}+\mathrm{Fe})$, and $\mathrm{Ca} /(\mathrm{Ca}+\mathrm{Na})$ ratios than the oxide-free gabbros. Considered separately, the oxide-bearing and oxide free gabbros show striking uniformity through the section, with locally coherent trends in mineral composition and whole rock chemistry. There is also a clear composition gap between oxide-bearing and oxide-free gabbros, which is most clear for $\mathrm{Mg} /(\mathrm{Mg}+\mathrm{Fe})$ of olivine and pyroxene and for $\mathrm{Ca} /(\mathrm{Ca}+\mathrm{Na})$ of plagioclase. As already noted, the few mineral analyses shown as oxide-free gabbros plotting with the oxide-bearing gabbros and vice-versa, are probably artifacts of the sorting procedure.

\section{Oxide-Free Gabbros}

There is an overall systematic increase in whole-rock $\mathrm{Na}_{2} \mathrm{O}$, from an average value of nearly $2 \mathrm{wt} \%$ at the base of the hole to about $3 \mathrm{wt} \%$ at the top. The scatter along this trend, particularly in Unit II, may represent local cryptic and modal variations and small-scale layering. There is also a slight upward decrease in $\mathrm{Mg} /(\mathrm{Mg}+\mathrm{Fe})$ and $\mathrm{Ca} /(\mathrm{Ca}+\mathrm{Na})$ ratios, 


\section{WHOLE ROCK MG\# Oxide-free Gabbros}

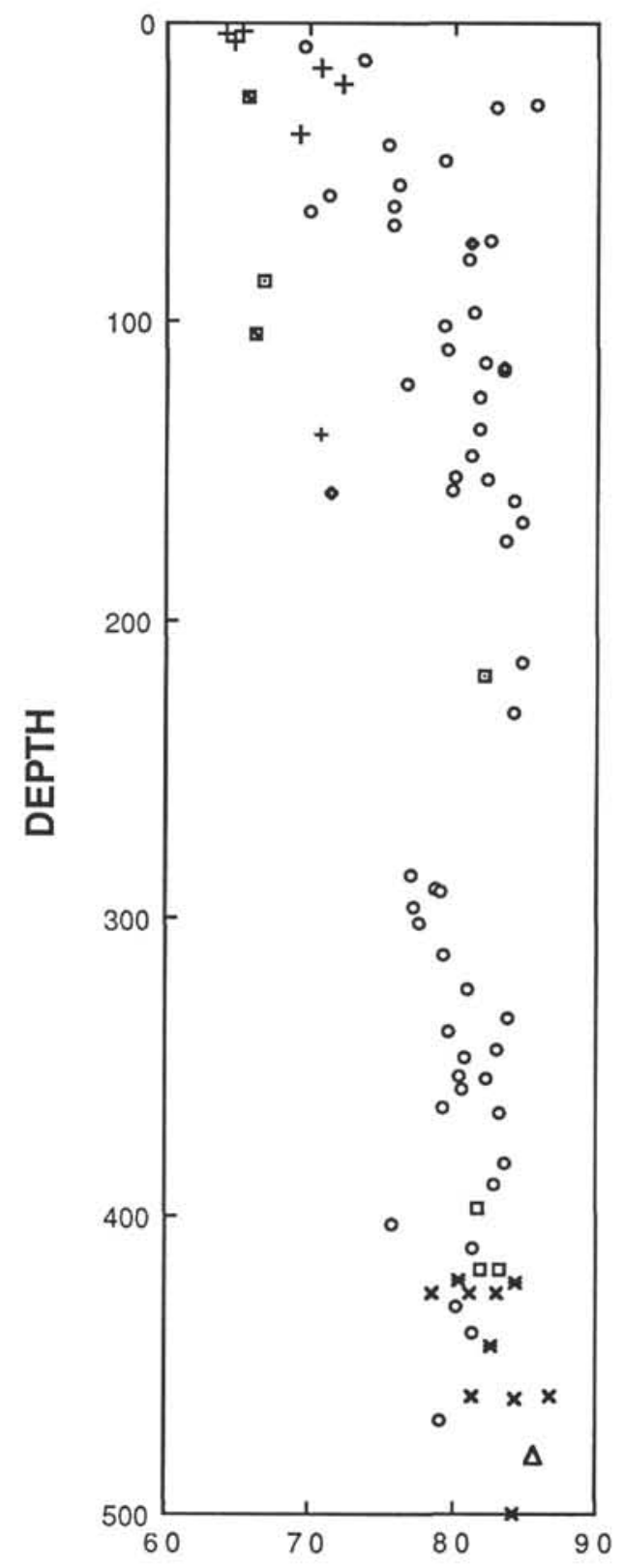

\section{WHOLE ROCK MG\#} All Gabbros

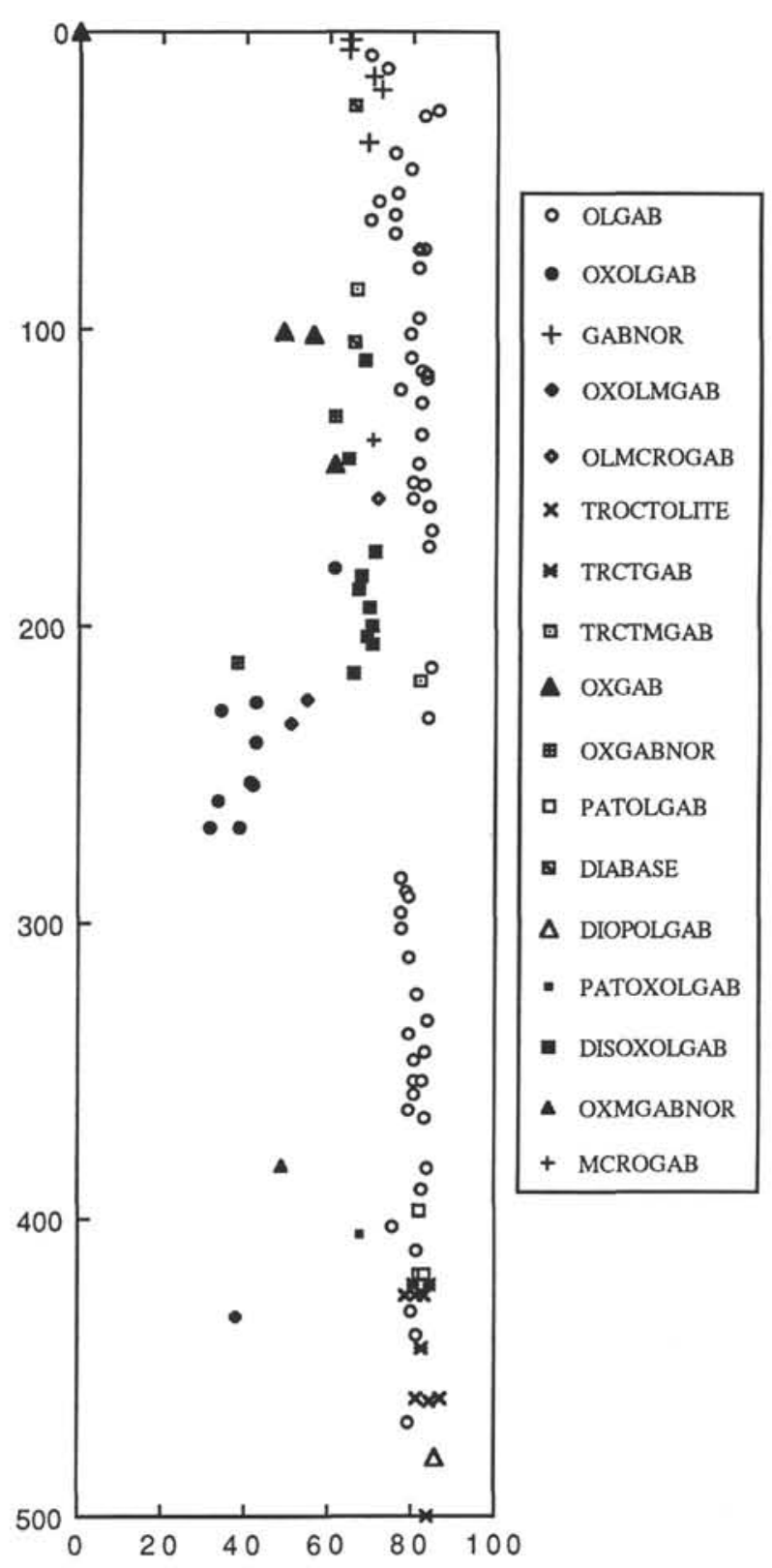

\section{Mg\#}

Figure 19. Plots of downhole whole-rock chemistry, sorted by lithology, for shipboard and post-cruise analyses of Hole $735 \mathrm{~B}$ gabbros and diabase, showing depth below seafloor

apparently complementary to the soda variation. When the olivine gabbros are considered separately from the troctolites at the bottom of the hole and the gabbronorites at the top, however, the overall trend is vertical, except perhaps for whole-rock $\mathrm{Mg} /(\mathrm{Mg}+\mathrm{Fe})$ and $\mathrm{Ca} /(\mathrm{Ca}+\mathrm{Na})$ in the upper $73 \mathrm{~m}$. In Unit $\mathrm{V}$, there is a slight upward decrease in $\mathrm{Mg} /(\mathrm{Mg}+\mathrm{Fe})$. Overall, at the scale examined here, there is little coherent stratigraphic variation in the bulk composition of the oxide- free gabbros. This indicates little gross chemical variation except at the very top of the hole, where olivine gabbros and gabbronorites interdigitate in Unit I and the top of Unit II, and a slight systematic increase in $\mathrm{Mg} /(\mathrm{Mg}+\mathrm{Fe})$ toward the top of Unit V.

The mineral composition plots show trends for the oxidefree gabbros similar to those shown by whole-rock chemistry. There may be a slight systematic decrease in anorthite content 


\section{WHOLE ROCK Ca\# Oxide-free Gabbros}

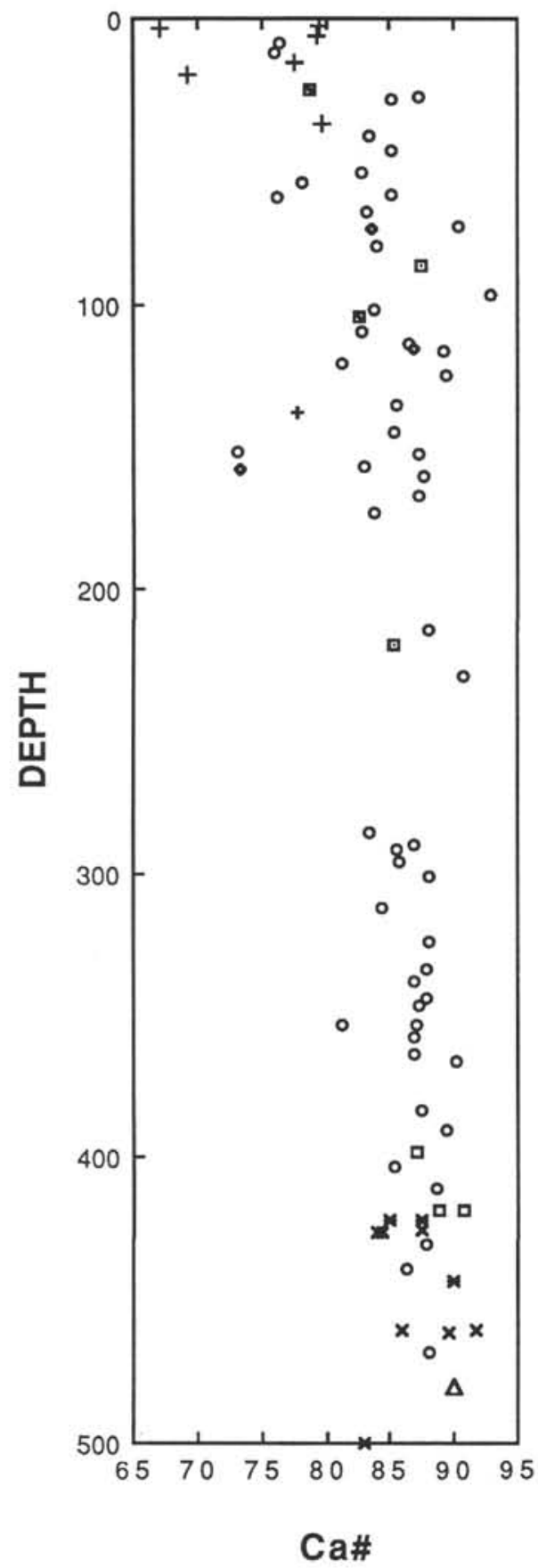

\section{WHOLE ROCK Ca\# All Gabbros}

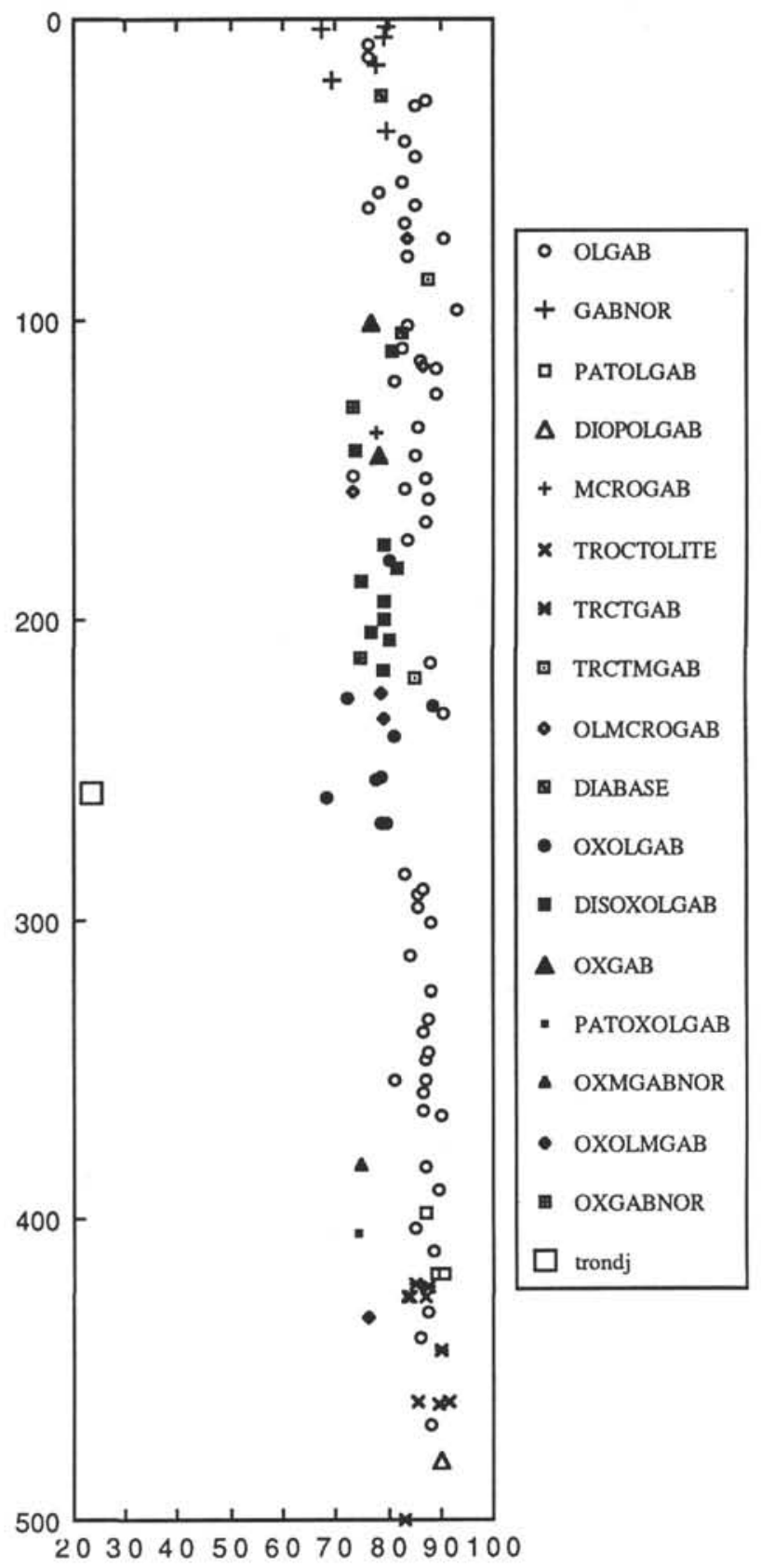

Figure 19 (continued).

of plagioclase in oxide-free olivine gabbros, complementary to the decrease in whole-rock $\mathrm{Ca} /(\mathrm{Ca}+\mathrm{Na})$, but there is little discernable variation in either olivine or pyroxene $\mathrm{Mg}$ / $(\mathrm{Mg}+\mathrm{Fe})$ or for $\mathrm{TiO}_{2}$ or $\mathrm{Na}_{2} \mathrm{O}$ in pyroxene. While there is considerable scatter, all of these trends have a best fit remarkably close to a vertical line for the olivine gabbro. The gabbronorites have a bimodal distribution of plagioclase and olivine compositions some plotting with the olivine gabbros, and some with the oxide gabbros. This may reflect the difficulty of discriminating between different gabbros in the heavily deformed and altered upper $100 \mathrm{~m}$ of the hole, and thus could represent errors in assigning of rock names.

Increasing modal plagioclase content can cause bulk-rock $\mathrm{Na}_{2} \mathrm{O}$ to increase and $\mathrm{Ca} /(\mathrm{Ca}+\mathrm{Na})$ to decrease with no change in mineral composition. Thus, the downhole uniformity of plagioclase composition suggests that much of the variation of whole-rock $\mathrm{Na}_{2} \mathrm{O}$ and $\mathrm{Ca} /(\mathrm{Ca}+\mathrm{Na})$ reflect differences in the relative proportions of modal plagioclase and 


\section{WHOLE ROCK Na2O Oxide-free Gabbros}

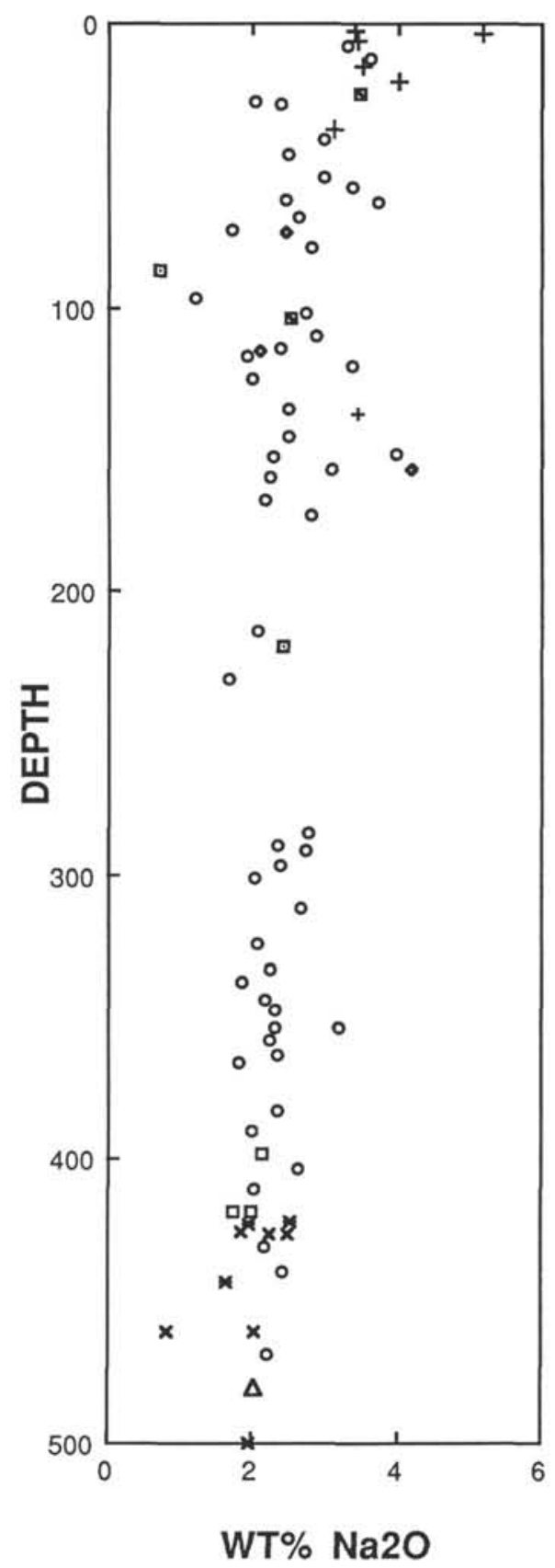

Figure 19 (continued).

\section{WHOLE ROCK Na2O \\ All Gabbros}

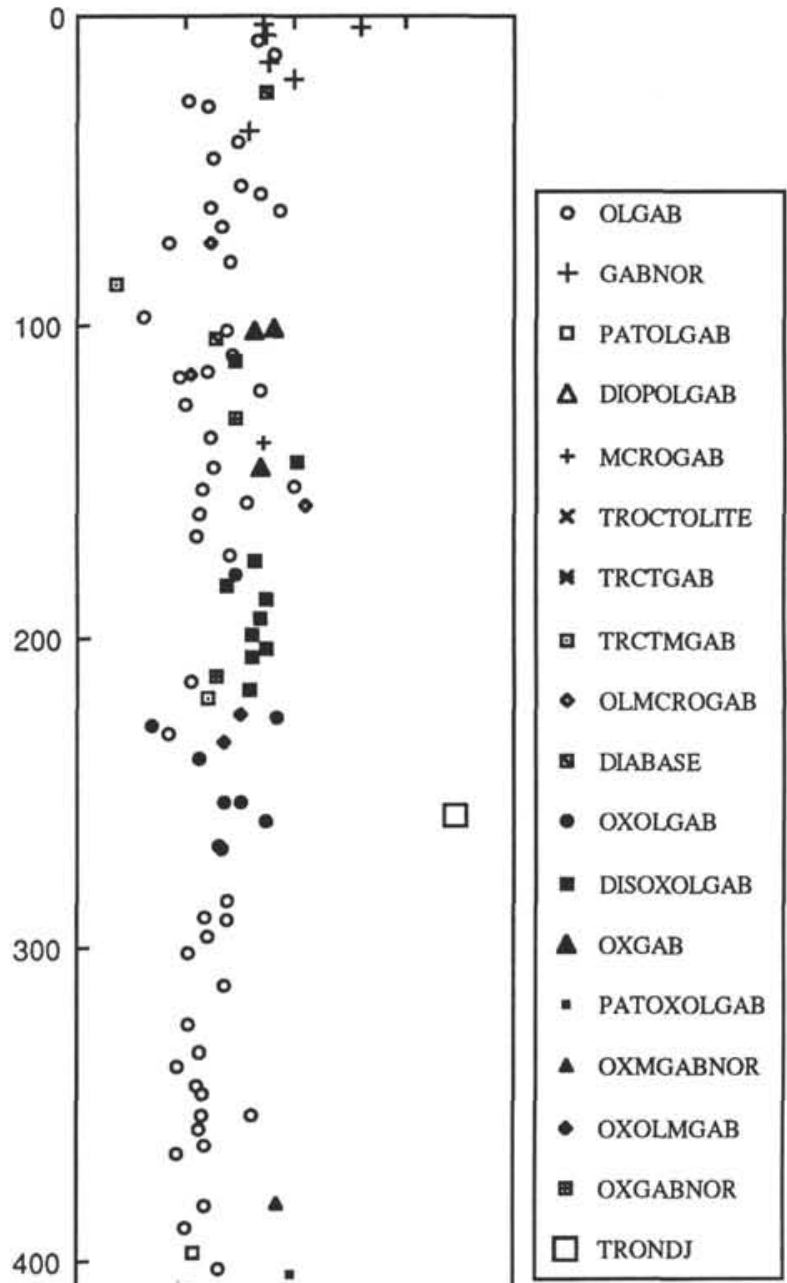

pyroxene, rather than any systematic change in the composition of the liquids from which the rocks crystallized. Only in Unit V is there a coherent mineral composition trend with a slight upward decrease of olivine $\mathrm{Mg} /(\mathrm{Mg}+\mathrm{Fe})$ to the oxide olivine gabbro at the base of Unit IV and somewhat statistically questionable complementary decreases in $\mathrm{Mg} /(\mathrm{Mg}+\mathrm{Fe})$ of pyroxene and $\mathrm{Ca} /(\mathrm{Ca}+\mathrm{Na})$ of plagioclase.

The least titaniferous, most magnesian, and most calcic of the gabbros are the intrusive troctolites and troctolitic gabbros at the base of the hole, and these provide evidence for the most primitive liquids in the section-in all probability a primitive magnesian MORB. The most titaniferous, least magnesian, and least calcic of the oxide-free gabbros are the gabbronorites at the top of the hole, which conversely provide evidence of the most evolved liquid of any of the oxide-free gabbros-probably a ferrobasalt. The rock and mineral data for gabbronorites appear to have systematically shifted in the downhole plots to more sodic, less calcic, more iron-rich, and less magnesian compositions than the olivine gabbros having consistently more titanium and much lower 


\section{WHOLE ROCK TiO2 Oxide-free Gabbros}

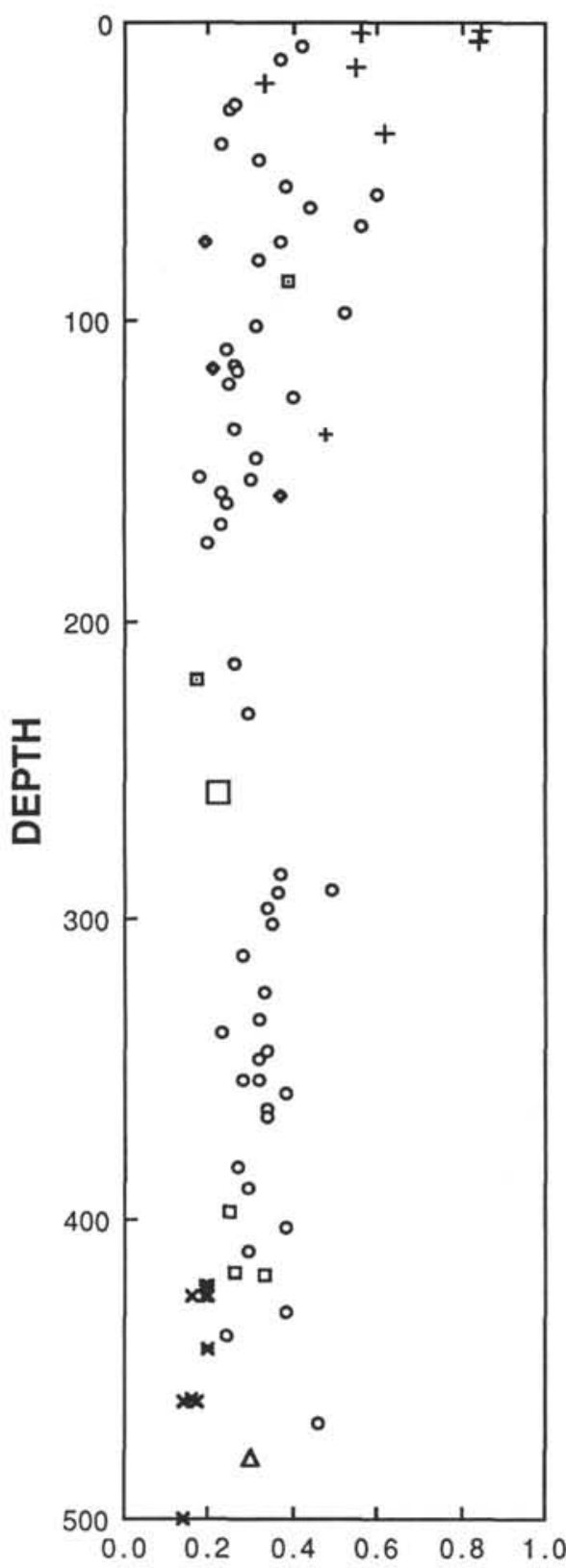

WT \% TiO2

\section{WHOLE ROCK TiO2}

All Gabbros

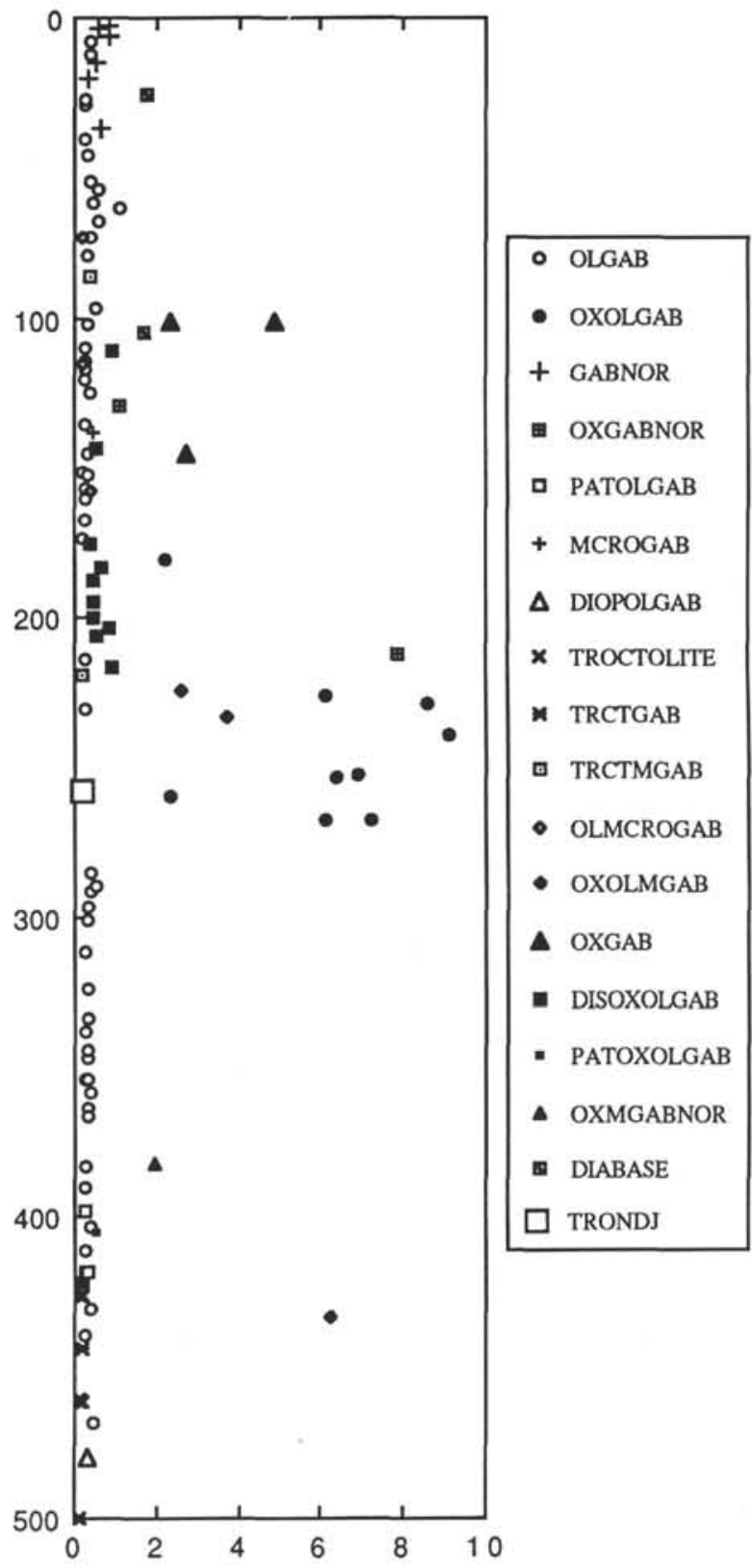

WT \% TiO2

Figure 19 (continued).

chromium contents. These differences are consistent with crystallization from different, though possibly related, magmas and with the proposed intrusive relationship between these two rock types.

\section{Oxide Gabbros}

The oxide gabbros show fairly uniform downhole bulk-rock $\mathrm{Ca} /(\mathrm{Ca}+\mathrm{Na})$ and soda contents. Whole-rock $\mathrm{TiO}_{2}$, by contrast, is extremely variable, reflecting large changes in modal ilmenite, though these variations do not appear systematic. There are systematic downward decreases in bulk rock, olivine, and pyroxene $\mathrm{Mg} /(\mathrm{Mg}+\mathrm{Fe})$ and plagioclase $\mathrm{Ca}$ $(\mathrm{Ca}+\mathrm{Na})$ through Unit IV. Unfortunately, oxide gabbros in the lower section of the core were systematically undersampled for shipboard whole-rock analysis, and little can be determined from the three analyses available below Unit IV, while the mineral data show little coherence, the scatter is greater in Unit VI than elsewhere, reflecting irregular alterna- 
735B DOWNHOLE WHOLE ROCK Cr

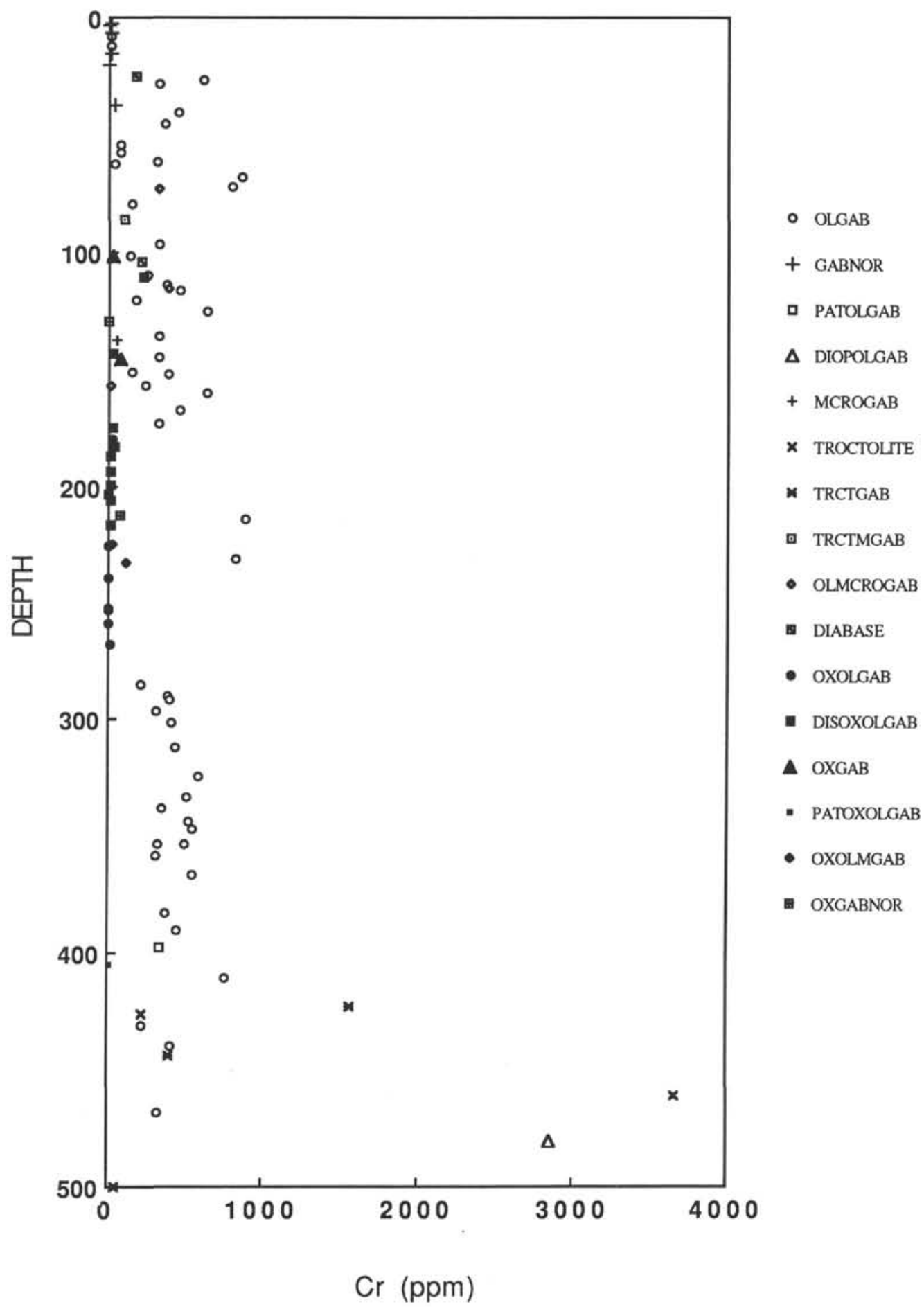

Figure 19 (continued).

tions of massive oxide olivine gabbro and disseminated oxide olivine gabbro, intercalated with the oxide-free gabbros.

There is a striking modal gap for rock and mineral analyses in the downhole stratigraphic plots that were not as clear in the simple chemical variation diagrams (Figs. 19 and 20). This gap is quite large, about $20 \%$ in plagioclase anorthite content $\left(\mathrm{An}_{38}\right.$ to $\left.\mathrm{An}_{58}\right)$, about $15 \%$ in olivine forsterite $\left(\mathrm{Fo}_{60}\right.$ to $\left.\mathrm{Fo}_{75}\right)$, and clinopyroxene $\mathrm{Mg} /(\mathrm{Mg}+\mathrm{Fe})$. The gap is not very clear, though there is still a bimodal distribution for titanium and sodium in clinopyroxene or bulk-rock $\mathrm{Ca} /(\mathrm{Ca}+\mathrm{Na})$, and sodium. Detailed studies of mineral compositions at the contacts between the oxide- 


\section{B DOWNHOLE OLIVINE}

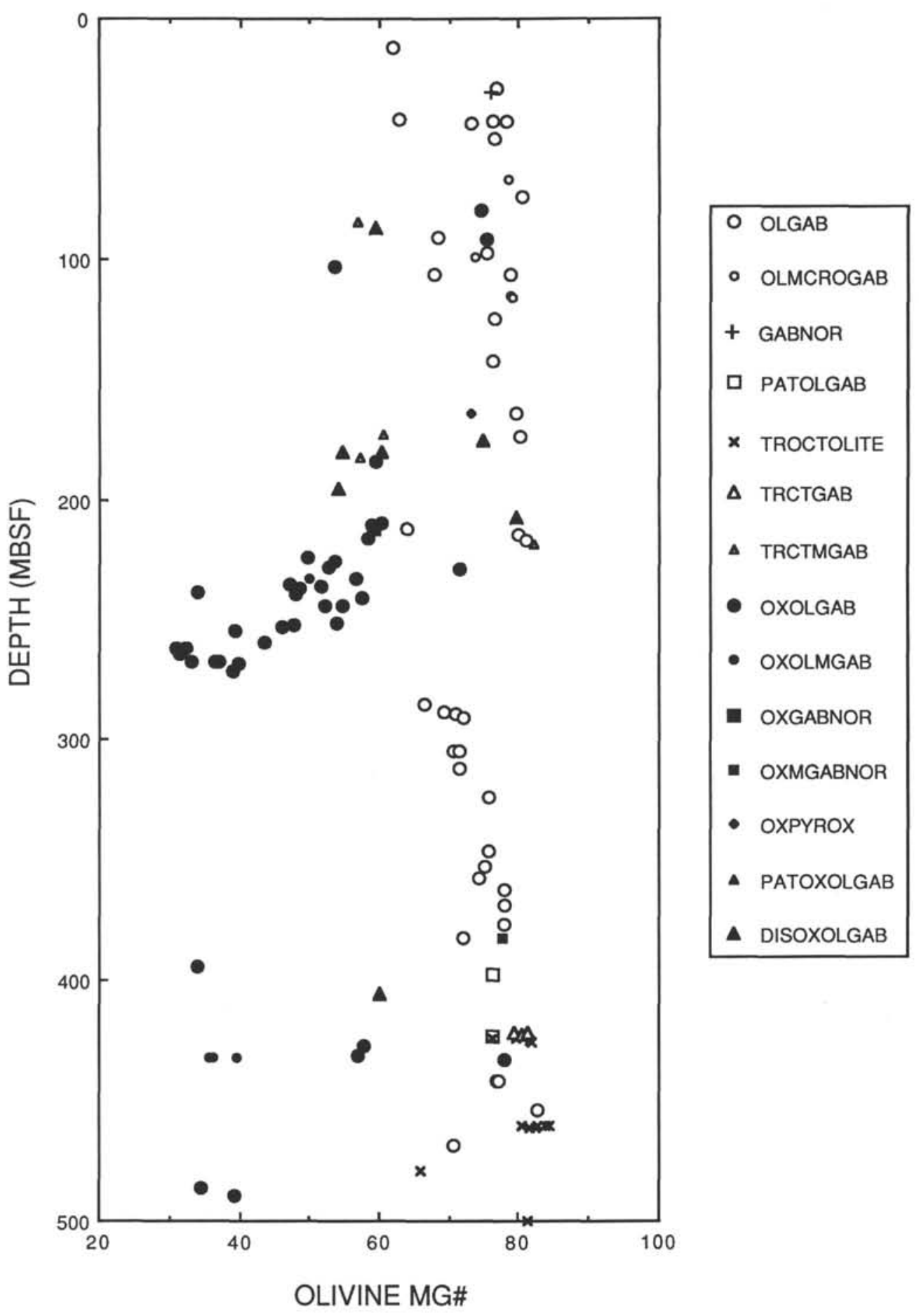

Figure 20. Downhole plot of mineral chemistry, sorted by rock type, for Hole 735B gabbros, showing depth below seafloor vs. olivine $\mathrm{Mg} /(\mathrm{Mg}+\mathrm{Fe})$, clinopyroxene $\mathrm{Mg} /(\mathrm{Mg}+\mathrm{Fe})$, and plagioclase anorthite content $(\mathrm{Ca} /\{\mathrm{Ca}+\mathrm{Na}\})$. Data from Ozawa et al. (this volume), Bloomer et al. (this volume), Dick and Angeloni (unpubl. data), and Meyer et al. (unpubl. data). 


\section{B DOWNHOLE CPX MG\#}

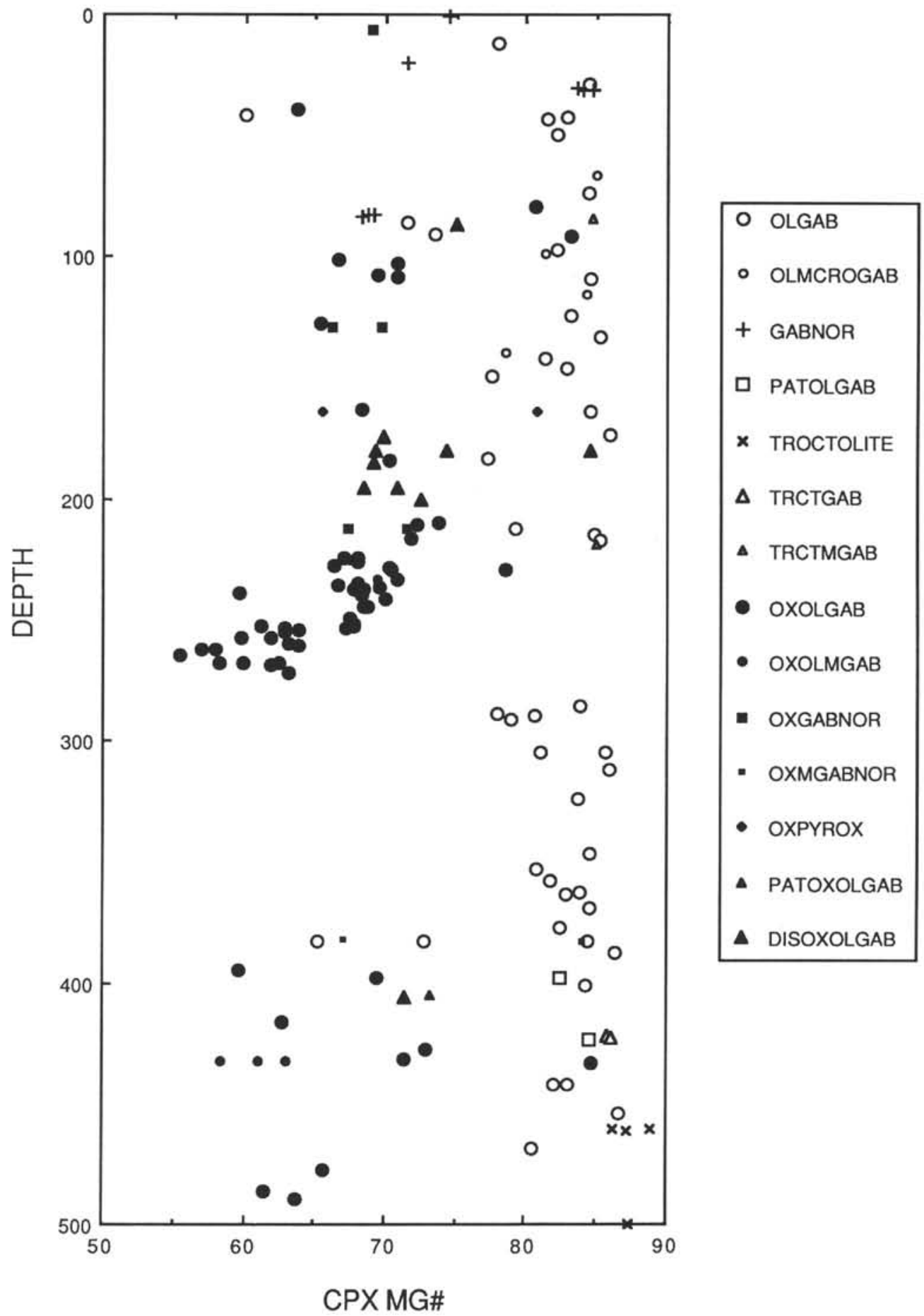

Figure 20 (continued).

bearing and oxide-free gabbros show that the chemical transition between the two is generally quite sharp. Thus, chemically they look like intrusive contacts between two unrelated igneous rock types. This is true, apparently, for small oxide-bearing shear zones a few millimeters thick in oxide-free olivine gabbro and for oxide layers tens of meters thick (Ozawa et al., this volume; Bloomer et al., this volume). This is surprising in light of the textural and structural evidence for a hybrid origin presented in the igneous lithostratigraphy section. One might have anticipated more gradational contacts, and large scale chemical zoning of plagioclase crystals from calcic cores with the same composition as the plagioclase in the olivine gabbro to sodic rims reflecting equilibrium with the late invasive 
735B DOWNHOLE PLAGIOCLASE

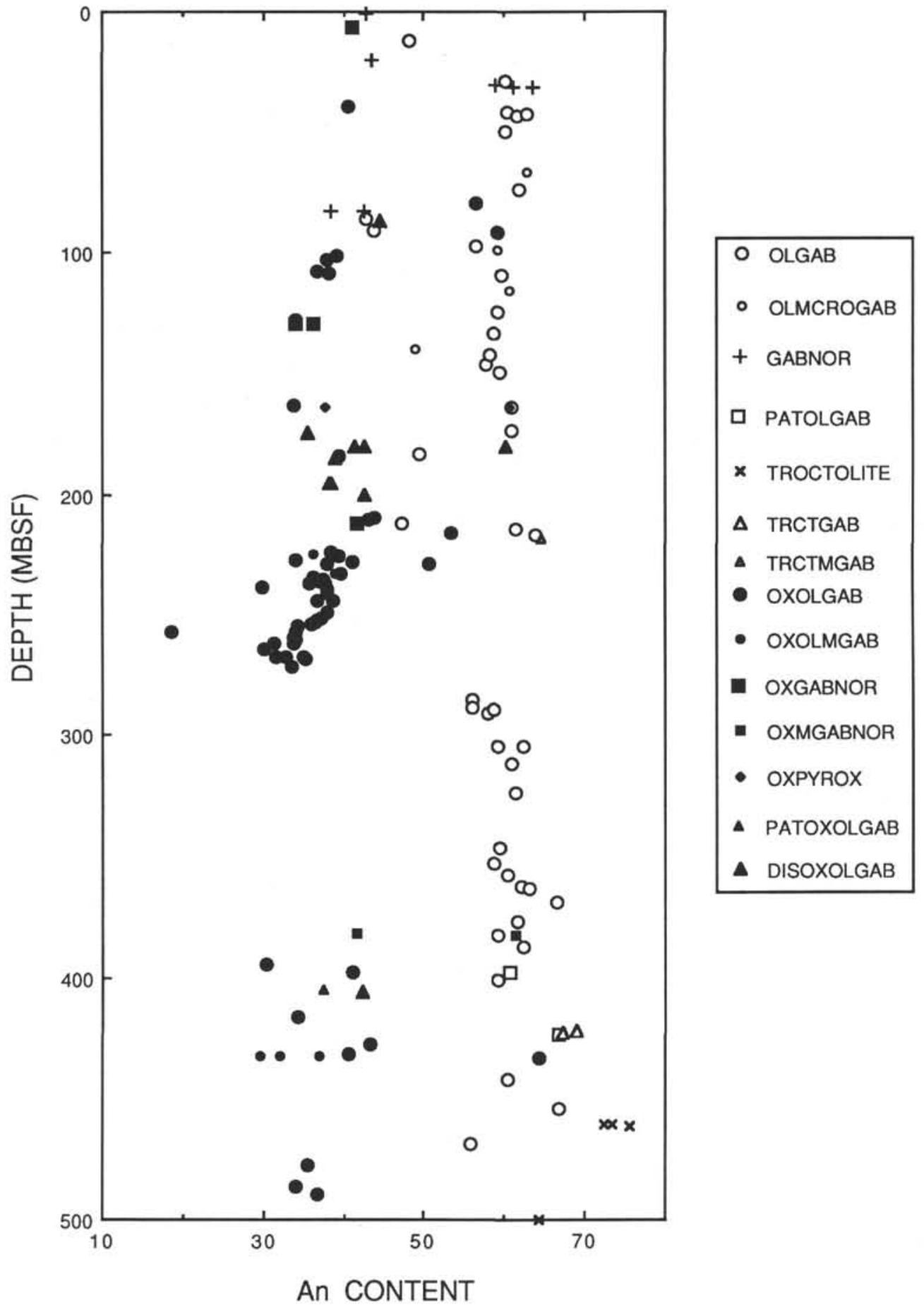

Figure 20 (continued).

magmatic liquid, which precipitated the interstitial ilmenite. Such zoning was generally not found.

A remarkable feature of the downhole chemical variation is the low chrome content of the oxide-bearing gabbro in Units III and IV. These include disseminated oxide olivine gabbros containing less than $2 \%$ ilmenite. This indicates that these rocks have equilibrated with very chrome-poor liquids.

\section{Bulk Hole Composition}

The bulk composition of the entire section is given in Table 2. Overall, the computed bulk composition of Hole $735 \mathrm{~B}$ is basaltic, with a high $\mathrm{Mg} /(\mathrm{Mg}+\mathrm{Fe})$ ratio, and is similar to the dredged and drilled diabases, plotting close to them in plots of $\mathrm{Mg} /(\mathrm{Mg}+\mathrm{Fe})$ vs. $\mathrm{Ca} /(\mathrm{Ca}+\mathrm{Na})$ and $\mathrm{TiO}_{2}$ vs. $\mathrm{Mg} /(\mathrm{Mg}+\mathrm{Fe})$ and 
H. J. B. DICK ET AL.

735B DOWNHOLE CPX TIO2

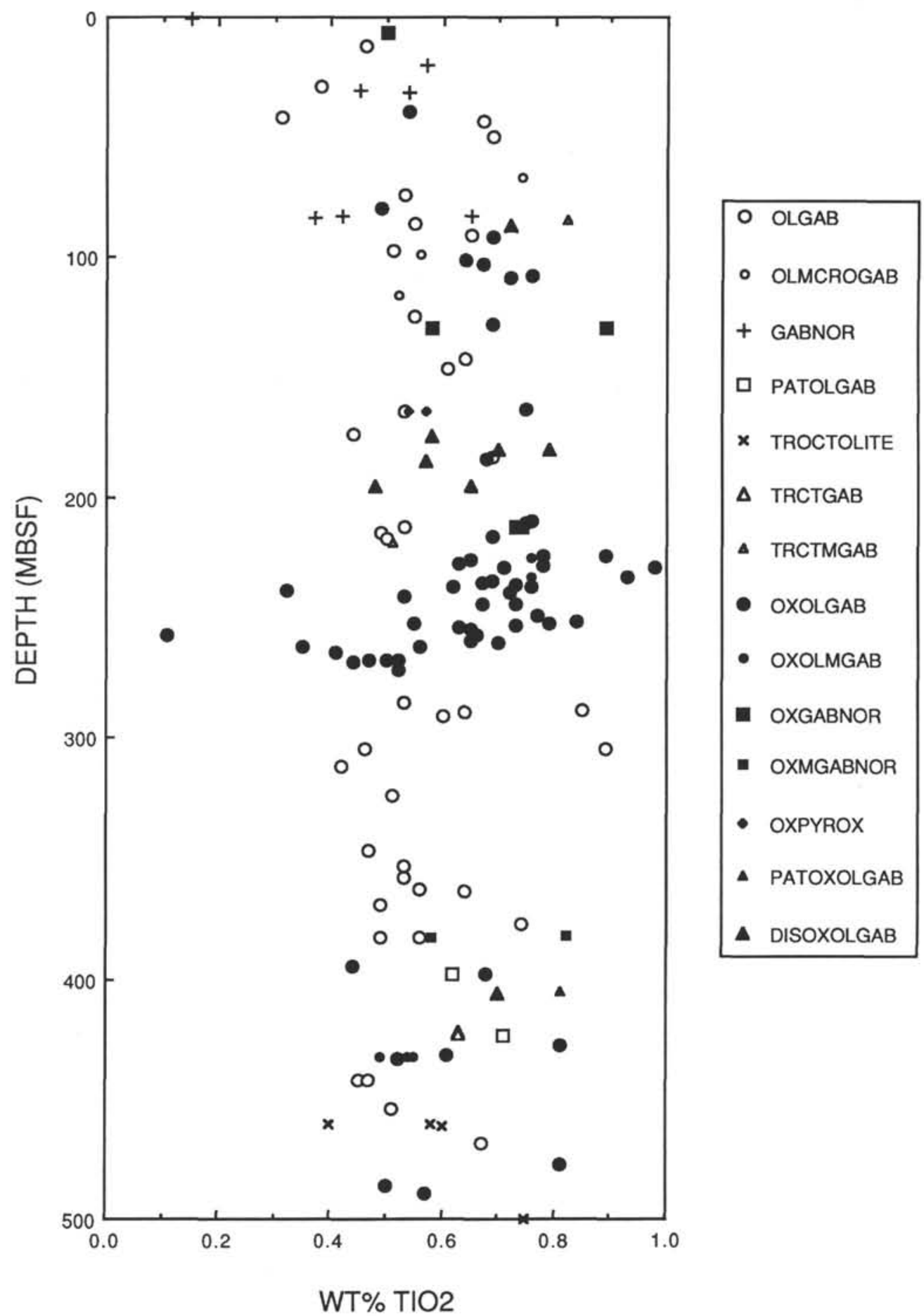

Figure 21. Downhole plot of mineral chemistry for Hole 735B gabbros using data from Ozawa et al. (this volume), Bloomer et al. (this volume), Dick and Angeloni (unpubl. data), and Meyer et al. (unpubl. data), sorted by rock type: clinopyroxene, titanium, and soda contents (in wt\%) vs. depth below seafloor.

colinear with them and the suite of dredged basalts, giving a relatively primitive bulk composition, close to that anticipated for equilibrium with mantle olivine, and therefore close to that anticipated for the bulk ocean crust.

We note, however, that the absolute concentrations of zirconium, yttrium, and phosphorous are lower by factors of
$3.8,2.9$, and 9.0, respectively, than in the diabase. Although part of this could be accounted for by the slightly less primitive composition of the diabase, the differences are far too great to explain by liquid fractionation considering the respective $\mathrm{Mg} /(\mathrm{Mg}+\mathrm{Fe})$ values of the bulk hole composition and the diabase. These three elements are the most incom- 
735B DOWNHOLE CPX NA2O

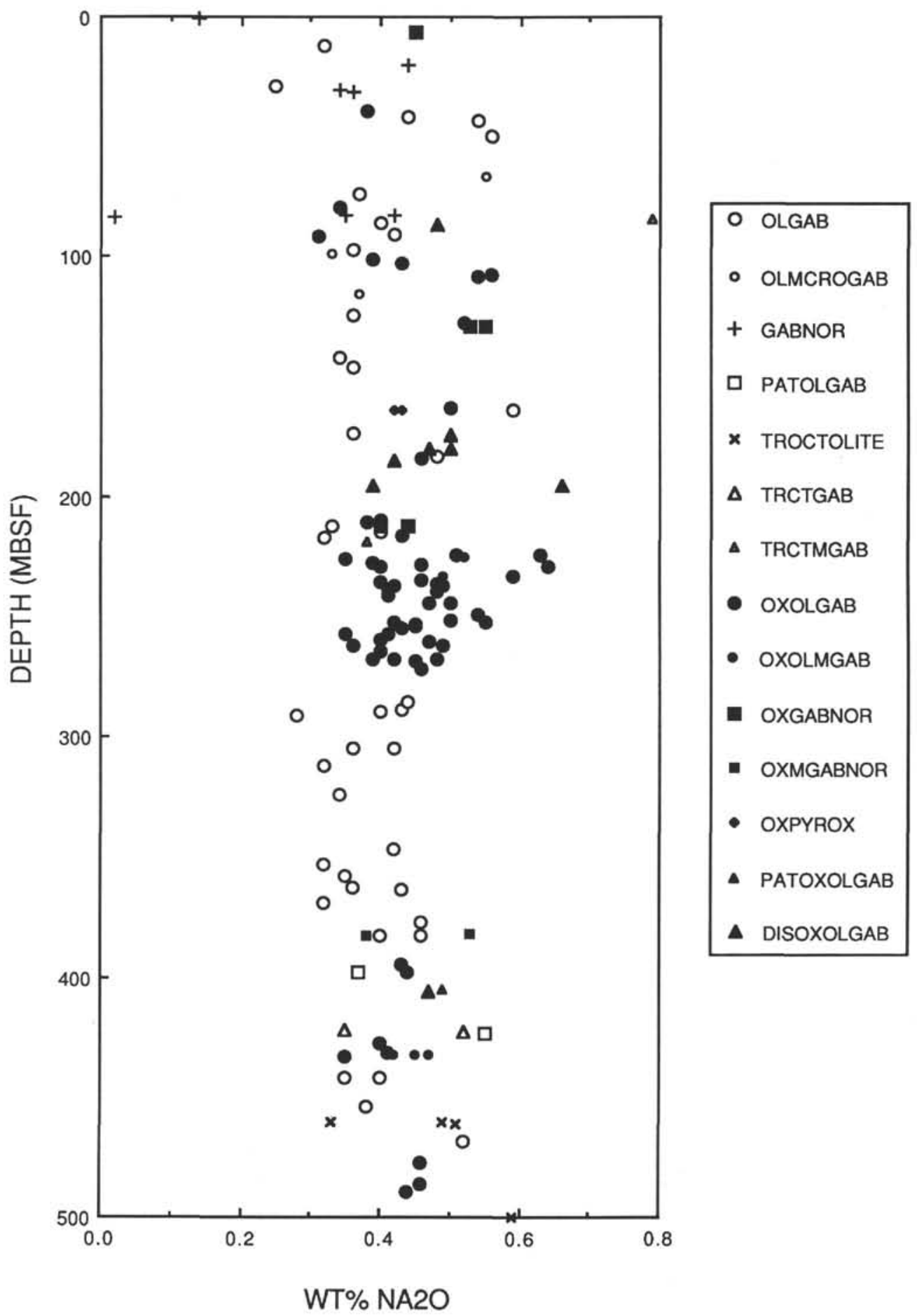

Figure 21 (continued).

patible of the elements analyzed, and are concentrated in the last fraction of melt during crystallization. The oxide-bearing gabbros, are depleted in zirconium, yttrium, and phosphorus by a factor of nearly two compared to the diabase, and thus, cannot account for the missing trace elements. Despite the close similarity of the bulk composition of Hole $735 \mathrm{~B}$ to a primitive MORB, a significant fraction of the last liquids must have escaped from the section. Conversely, however, the MORB-like composition of the section for even fairly incompatible elements like titanium, requires that the large majority of the liquid crystallized in situ (e.g., $80 \%$ to $90 \%$ ) and that the liquid containing the highly incompatible elements was expelled as a small late fraction of the original intrusion. 
The $\mathrm{Y} / \mathrm{Zr}$ ratios for the diabase dikes and the bulk hole, however, are similar, and we note that these highly incompatible elements could be concentrated in local pegmatites or be removed by alteration. Although a large number of pegmatitic, felsic, and trondhjemitic veins were encountered, only one trondhjemite was analyzed for major elements. Thus, the lack of highly incompatible elements in the bulk hole composition might disappear once the composition of these vein assemblages have been accounted for. Existing trace element analyses of trondhjemites from the Atlantic and Indian Oceans (Carol, unpubl. manuscript; Engel and Fisher, 1975), however, are inconsistent with this. The uppermost limit of zirconium in these trondhjemites is $1500 \mathrm{ppm}$. Given that there are $1.06 \%$ felsic and trondhjemitic veins in the entire section (see "Deformation and Alteration" section, this chapter), these veins might account for at most $15.9 \mathrm{ppm}$ zirconium-which, added to the value computed in Table 1 , gives a maximum of $51.5 \mathrm{ppm}$ for the bulk hole composition. This is approximately a factor of two too low for a primitive MORB. An additional $4 \%$ to $6 \%$ trondhjemite containing the maximum value of $1500 \mathrm{ppm}$ zirconium should then be required for the Hole $735 \mathrm{~B}$ bulk composition to match that of a primitive MORB. A similar problem exists for phosphorus and yttrium.

Therefore, two possibilities exist: (1) the percentage of trondhjemite encountered in Hole $735 \mathrm{~B}$ is not representative of the plutonic section as a hole-i.e., we may have missed drilling a large trondhjemite interval in the gabbro body by centimeters or meters, or (2) the system was open, with some of the last evolved liquids escaping out of the body, perhaps through the deformation zones.

The fact that the Hole 735B bulk hole composition is close to that of a primitive mid-ocean ridge basalt is intriguing. This argues that this section is not the partial remains of a large layered intrusion, rather it must represent near complete in-situ crystallization of a discrete magma body ( $80 \%$ plus). Fractional crystallization and magmatic sedimentation from an olivine-pyroxene-plagioclase saturated magma produces a sediment close to the composition of a basalt with the exception of elements such as titanium that are enriched in the liquid. In this case, the majority of the trace and major elements do add up to a basaltic composition. Simple magmatic sediments (cumulates) also do not generally lie along the regional liquid line of descent for MORB in chemical plots, though they may lie on some projections from them. A reasonable conclusion is that the Hole $735 \mathrm{~B}$ complex represents a relatively small, well-mixed, rapidly cooled intrusion, from which only about $10 \%$ to $20 \%$ of its mass escaped near the end of crystallization. This liquid formed either bodies of trondhjemite within the mass or was tapped off to a higher level in the crust. Such a small pluton, and the absence of a large, long-lived magma chamber, is consistent with the postulated low rates of magma supply at very slow-spreading ridges such as the Southwest Indian Ridge (e.g., Reid and Jackson, 1981; Dick, 1989),

\section{Synkinematic Differentiation}

The structural relationships reviewed in the lithostratigraphic section demonstrate that the oxide-bearing gabbros, with the exception of the oxide microgabbronorite intrusives, formed by some form of hybridization of the olivine gabbro by late magmatic liquids along high-temperature penetrative deformation and shear zones. Chemically, this process involved re-equilibration and chemical exchange with a migrating iron titanium-rich late-magmatic liquid, accompanied by extensive oxide precipitation. Such a process explains the near-random scatter of the analyses downhole, as the distribution of oxidebearing gabbros (there are 295 such intervals recorded in
Appendix A) is controlled by deformation, which has an irregular distribution down the hole. The extent of chemical exchange, precipitation of impregnating oxides, and the amount of melt trapped at the end of deformation all would depend directly on the local intensity and duration of deformation.

The striking gaps in bulk rock and mineral compositions between oxide-bearing and oxide-free gabbros indicates equilibration of the two with very different liquid compositions. If we presume, on structural grounds, that the oxide gabbros are formed by impregnation or invasion of an oxide-free protolith, then we must also postulate a remarkable degree of chemical exchange between the liquid and the invading melt to achieve the uniformity of plagioclase and olivine mineral compositions in the oxide gabbros and their systematic offset from plagioclase in oxide free gabbros. In essence, the chemical boundaries between the two rock types mimic intrusive contacts between chemically distinct magmas. Simple impregnation would not do this as it would create a spread of analyses between the composition of the original oxide-free gabbro, the invading melt, and the composition of intercumulus minerals that crystallize from that melt where some of it escapes. This is true regardless of the composition of the invasive melt.

The low concentration of chrome in the oxide-bearing gabbros presents an additional problem. For simple impregnation of a primitive olivine gabbro protolith by an irontitanium-rich silicate liquid, or by cumulus minerals precipitated from it, the chrome content of the resulting rock would reflect the respective proportions of protolith and invasive liquid or minerals precipitated from it. This is not the case here, as the near-zero chrome content of many of the disseminated oxide olivine gabbros is far less than that of the olivine gabbro protoliths. This indicates that the process by which the oxide-bearing gabbros formed was considerably more complex than simple impregnation of an earlier olivine gabbro cumulate by late magmatic liquid or by phases crystallized from a late magmatic liquid such as ilmenite.

An evolved chrome-poor liquid migrating in some quantity through a comparatively primitive chrome-rich matrix has the potential to react with and strip that matrix of chrome. A good example of this kind of elemental stripping and in-situ chemical exchange can be seen in the hortonolite pipes in the Bushveld Complex in South Africa, where the entire matrix of the layered gabbros, including forsteritic olivine, is replaced by hortonolite olivine $\left(\mathrm{Fo}_{30-50}\right)$ resulting from percolation and pipe-flow of late evolved melt up through the complex. That this has occurred here, and that a considerable portion of the late liquid escaped, seems unavoidable given the very low chrome contents of all the oxide bearing gabbros compared to that in the oxide-free gabbros.

The slow, intragranular diffusion rates measured for many silicates, particularly plagioclase (e.g., Grove et al., 1984; Yund and Snow, 1989) would appear to be a problem for the degree of chemical exchange we postulate to form the oxidebearing gabbros. One would normally expect an early formed calcic plagioclase crystal to show zonation, where it has reacted with a late magmatic liquid due to the amount of time it would require to completely homogonize a feldspar grain. Although some such zoning is seen (see Bloomer et al., this volume), there is surprisingly little in the oxide-bearing gabbros for the mode of origin we propose. While this lack of zonation would not be a major problem if the oxide-bearing gabbros simply crystallized from an evolved melt, the textural evidence reviewed appears to rule out such a simple origin for much of the oxide-bearing gabbro.

Isotropic gabbros showing little visible zonation of plagioclase grains under the microscope, however, are not an 
unusual feature of ocean ridge gabbros (e.g., Hodges and Papike, 1976). In theory, such rocks can be produced by adcumulate growth in a crystal mush with rapid diffusional or advective exchange of components, relative to crystal growth rates with a large nearby magma reservoir. In such a case, little zonation might be created in the adcumulate due to the slow change in liquid composition in the overlying magma chamber. However, ocean-ridge magma chambers are thought to be small and ephemeral, particularly along the Southwest Indian Ridge, and erupted pillow basalts typically contain radically zoned plagioclase crystals that indicate that fluid compositions in the source region are evolving rapidly with the growth of individual crystals.

Thus, the geologic evidence suggests that the rates and extent of postcumulus chemical exchange and re-equilibration between cumulus phases and intercumulus liquid may remain an open question, particularly in the light of recent studies of the Rhum Layered Intrusion. Bedard et al. (1988) showed that where layered troctolites are intruded by peridotite sills crystallized from picritic melts, the troctolites are locally transformed to gabbro. This occurred by chemical exchange and in-situ replacement of plagioclase and olivine by pyroxene and by reaction with liquid expelled from the intrusive into the troctolite. Original layering in the troctolites is pseudomorphed by the gabbros and can be followed texturally across gabbro/troctolite contacts. This process evidently occurred as the troctolite was still partially molten at the time of intrusion, and thus permeable to the intruding picritic melt. Significant to the discussion here, plagioclase in these replacement gabbros show no zoning. Thus, chemical exchange between an invaded protolith (the troctolite at Rhum, the olivine gabbros in Hole 735B) can be quite rapid and complete. The critical difference here, however, is that flow of the invasive magma at Rhum was controlled by preexisting permeability in a partially molten crystal mush, while that in the Hole $735 \mathrm{~B}$ gabbros was controlled by permeability created by faulting and penetrative deformation.

For the suite at hand, chemical exchange between an invasive silicate liquid and a ductily deforming crystal mush may be greatly enhanced by deformation. Exchange rates are dependant on the ratio of surface area to mass (grain size) and dislocation densities within phases. In a ductily deforming rigid crystal mush, continuous syntectonic recrystallization, grain boundary migration, pressure solution and intragranular dislocation propagation and growth all would promote rapid chemical re-equilibration. Annealing recrystallization, which can produce granular textures like those in many of the oxide gabbros is a very effective means of eliminating chemical zonation of individual mineral grains.

What is clear, however, is that the formation of the oxide-bearing gabbros is not a simple impregnation processes. Rather, there must be extensive reaction and re-equilibration between gabbro and liquid in the process.

\section{Source of the Late Magmatic Liquid}

The source of the invasive fluid that forms the oxidebearing gabbros from the oxide-free protoliths is a major question. We envisage three possibilities. One possible source is a melt injected or percolated up from an underlying or overlying magma chamber. A second source is late intercumulus melt in partially molten zones of the olivine gabbro, which may be expelled into the deformation zones by compaction from unsheared regions of the body. Finally, large ilmenite ore bodies in anorthositic complexes are thought to have formed in magma chambers by liquid immiscibility and the formation of an iron-titanium silicate liquid, which settles to the floor of the chamber. This fluid, then, by virtue of its high density, fills cracks and fissures and displaces the lighter silicate liquid in any unconsolidated permeable crystal mush at the bottom of the chamber (Eric Force, pers. comm., 1989; Herz, 1976). We think it unlikely, however, that a brittleductile shear zone would terminate upward into a magma chamber, or that fluid at hydrostatic pressure would seep downward from a magma chamber into a shear zone. Further, where oxide filled cracks or veins have been observed, they terminate upward, and appear to root downward, ending at brittle-ductile deformation zones. In addition, the absence of olivine in the oxide gabbros high in Hole 735B suggests that the late-magmatic liquid here was different than that intruded into the deformation zones deeper in the hole, which would require two different cycles of intrusion and simultaneous deformation, which would be rather coincidental. It also seems amazing that such a liquid would systematically impregnate every small high-temperature shear zone, including isolated shear zones less than a millimeter thick lying well within long sections of oxide-free olivine gabbro.

A better model, in view of the Hole 735B lithostratigraphy, is the proposal that the source of the invasive liquid is the olivine gabbro itself; in this case, trapped intercumulus liquid, which has differentiated by in-situ crystallization to an evolved iron-titanium-rich composition-ferrobasalt. This is permissible since the bulk composition of the hole, with the exception of the most highly incompatible elements, is basaltic. Thus, there is no requirement for a source exotic to the section for the late-magmatic liquid from which the oxide precipitated in the deformation zones. Despite the incredible local enrichment of ilmenite in Unit IV, overall there is only $1.78 \%$ iron-titanium oxide in the entire section.

Melt within the pluton should be at or near lithostatic pressure, and its flow should be controlled by local permeability and fairly slight pressure gradients. In a rigid grainsupported matrix, the density of the melt relative to the matrix is irrelevant. Brittle-ductile deformation creates permeability and porosity, and thus small pressure gradients, due to grain boundary sliding, cataclasis of mineral grains, and local inhomogeneous deformation (pressure shadows and pressure solution in gneisses are a graphic example of the later). Thus, where deformation and shearing occur in a rigid crystal mush, the intercumulus melt is likely to be expelled by compaction and cumulus crystal growth into the shear zones, which then control the flow of intercumulus liquid within the crystallizing pluton.

Brittle-ductile deformation and the formation of shear zones within partially molten rocks is likely to have a narrow stress-strain-melt volume percent window. A partially molten zone is likely to deform by simple plastic deformation and viscous flow at even fairly small melt percentages due to both the hydrostatic and lubricating effect of melt on rock rheology. At some point in its cooling history prior to complete solidification, however, a rock will become sufficiently rigid to support a shear stress, at which point brittle-ductile deformation zones can form. In the ordinary case, it would be fortuitous for an intrusion in a stable environment to undergo brittle-ductile shear at precisely this moment in its cooling history. In a sub-axial ocean ridge environment, however, brittle-ductile deformation accompanying lithospheric necking at the plate boundary is a steady-state process. Plutonic rocks in the ocean crust are likely to be subjected to such deformation once they have crystallized sufficiently to support a shear stress.

The narrow window for the formation of shear zones in the presence of melt in a solidifying pluton would also restrict the intercumulus melt composition to a fairly narrow range close to the end of solidification. Models for the crystallization of 
tholeiitic melt show that crystallization produces iron-titanium rich liquids after about $70 \%$ to $80 \%$ fractional crystallization (e.g., Carmichael, 1964; Clague and Buch, 1976; Natland, 1980; le Roex and Dick, 1981), and basalts of that composition are commonly erupted in many ocean ridge environments. Such liquids should become progressively enriched in iron and titanium until ilmenite or titanomagnetite appear on the liquidus. It is reasonable, therefore, that the trapped melt present in a crystallizing pluton would be consistently iron-titanium rich at the time it was sufficiently rigid for brittle-ductile shear zones to form. This might explain overall uniform composition of the oxide-bearing gabbros with respect to the major silicate phases throughout the Hole $735 \mathrm{~B}$ section. At the critical melt percentage for brittle-ductile deformation, at sub-axial strain rates, this melt composition may vary slightly in plutons of different composition. The inferred difference between the invasive liquid forming the oxide-bearing gabbros in the vicinity of the gabbronorites at the top of the hole and the invasive liquid forming oxide-bearing gabbros in the olivine gabbros lower down could be explained this way.

The large consistent gap between the composition of the oxide-bearing gabbros and the oxide-free gabbros remains a major problem, as it suggests that the invasive fluid was very different from the composition of the olivine gabbro, or any liquid in equilibrium with it at the time of deformation. Moreover, the existence of oxide-free shear polyhedra within the deformation zones suggests that the olivine gabbro was nearly impermeable to the invasive melt at the time of deformation. The presence of extension cracks filled with oxides in the olivine gabbro shear polyhedra within the penetratively deformed oxide gabbros show that they were under tension, and thus one would expect them to be at least partially invaded by the migrating liquid in the shear zone. In thin section, one can see that oxides enclose and partly invade the olivine gabbro (Fig. 21) at the contact for a few millimeters distance beyond the deformation zone, but no further, both along the walls of shear zones and the contacts of undeformed shear polyhedra within the ductile deformation zones. This and the overall absence of oxides within these undeformed shear polyhedra of olivine gabbro argue that much of the olivine gabbro was already impermeable at the time of formation of the oxide gabbros. Finally, the chemical relationships between these oxide-free and oxide-bearing gabbros are more consistent with an intrusive relationship. If melt were percolating through the matrix toward the shear zones, one would expect the percentage of oxide to increase systematically toward the deformation bands, rather than an abrupt appearance of oxide at the deformation band.

A plausible alternative, which is our preferred hypothesis, is that much of the invasive liquid is tapped by the deformation zones from an underlying partially molten zone. This possibility is illustrated in Figure 22. Here, a ductile deformation zone roots downward, as the end of a listric normal fault beneath the rift valley, into a crystal mush zone, which would be a logical locus for the brittle-ductile transition. Beneath this zone, the lower crust behaves ductily, above it there is a transition to purely brittle behavior. Melt from the rigid crystal mush is tapped, as we envisage for the case just discussed, and percolates upward along the deformation zone. As it ascends, the wall rocks become slowly cooler and the melt becomes saturated with oxides and reacts with the matrix, forming the oxide-bearing gabbros by replacement of the olivine gabbro matrix and by precipitation of ilmenite and titanomagnetite. The extensive chemical exchange, and in-situ replacement of the preexisting nearly or completely solidified olivine gabbro takes place due to the ongoing ductile deformation enhancing reaction rates, and because the migrating liquid, as in the case at Rhum (Bedard et al., 1988), is grossly out of equilibrium with the gabbros overlying the partially molten zone. In the process, some of the migrating melt may escape upward, resulting in removal of chromium from the magmatically altered rocks in the shear zone.

This process by which the late intercumulus melt in a uniform crystal mush is tectonically redistributed to form penetratively deformed oxide-rich gabbros in a dynamic environment beneath a rigid axis we term syntectonic differentiation to distinguish the layering so formed from other forms of magmatic layering. The process may or may not involve replacement of an earlier matrix, and may be a way of tapping off melt from long-lived crystal mush zones and transporting it to the upper levels of the ocean crust. It is possible that this mechanism could explain the aphyric nature of many evolved basalts erupted along ocean ridges, which chemically appear to have formed by fractional crystallization of a more primitive magma.

\section{DEFORMATION AND ALTERATION}

\section{Introduction}

The principal deformation and alteration events found in Hole 735B included (1) a prolonged period of extension and the formation of brittle-ductile shear zones accompanied by tectonically controlled and enhanced circulation of late intercumulus melt and subsequent hydrothermal alteration, and (2) the abrupt termination of extension in the middle amphibolite facies, block uplift, and static alteration down to ambient subseafloor conditions (Figs. 23 and 24).

Extensional deformation occurred both below the gabbro solidus. During the former, faulting apparently extended into partially molten rocks resulting in migration of late intercumulus melt up the shear zones. This late melt fundamentally altered the chemistry of the gabbros in the shear zones and greatly complicates the structural and igneous relationships in the hole. The most visible effect of this melt migration was local precipitation of magmatic oxide, often in large quantity in weakly to strongly deformed and foliated gabbro. Hypersolidus deformation was followed by the formation of trondhjemite veins and breccias. These trondhjemites represent the last significant magmatic event. They crosscut the late-magmatic foliation, and are generally unaffected or only very weakly deformed by the late-magmatic deformation. In contrast the trondhjemites are always deformed, where subsolidus deformation occurred.

Subsolidus brittle-ductile deformation was extensive at many levels in the core, and is reported by Stakes et al. (this volume) to have begun under granulite conditions $\left(700^{\circ}-\right.$ $1000^{\circ} \mathrm{C}$ ), with recrystallization and re-equilibration of the primary igneous phases, and to have continued down to mid-amphibolite grade $\left(450^{\circ}-500^{\circ} \mathrm{C}\right)$. Trondhjemite veins and breccias are deformed wherever this deformation phase occurred. Accompanying the subsolidus brittle-ductile deformation was pervasive amphibolite facies hydrothermal alteration. This tectonically enhanced alteration affected the entire core to some degree, both as dynamic alteration in the shear zones, and as tectonically enhanced static alteration in the undeformed sections of the core. The latter resulted from the imposition of the tensile stress existing throughout the section during the ductile deformation on the stored elastic thermal strain due to cooling, resulting in enhanced cracking, permeability to seawater, and alteration of groundmass minerals to amphibole. Amphibolitization is most extensive, however, within the dynamically recrystallized gabbros in the shear zones, particularly near the largest zone at the top of the core, 

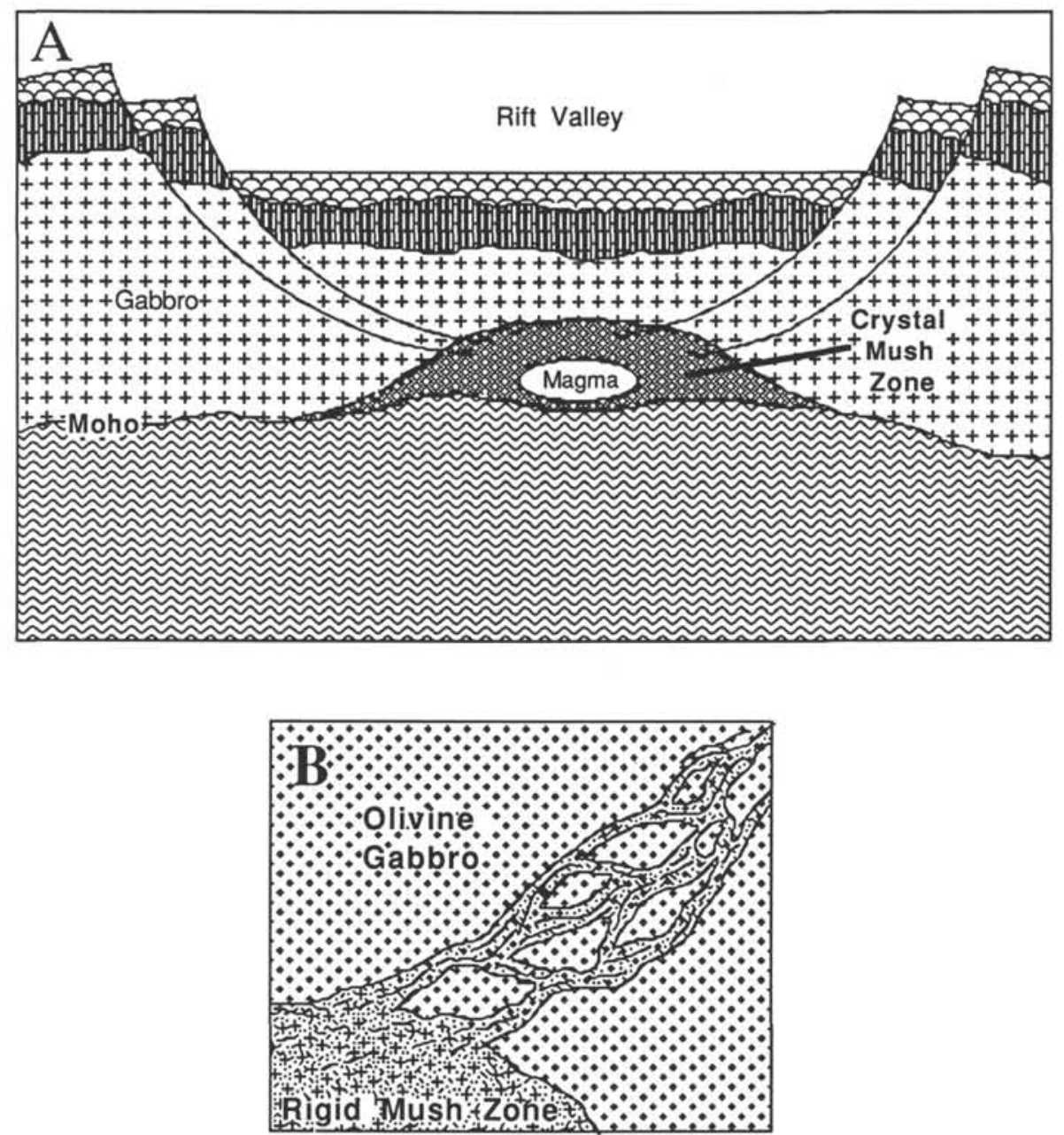

Figure 22. A. Cartoon showing an idealized version of listric normal faults penetrating the ocean crust and rooting in the brittle-ductile transition within a partially molten zone. A magma chamber may or may not be present below or nearby. The actual plutonic stratigraphy at the Southwest Indian Ridge is, of course, far more complex than the conceptual diagram show here. B. Detail, showing listric normal fault rooting into partially molten gabbro.

indicating that overall permeability was highest there during deformation.

Hydrothermal alteration continued at lower temperatures from the middle amphibolite facies under relatively static conditions. The effects of the purely static phase of alteration are confined largely to the less-deformed sections of the core, where stored elastic thermal strain was not relieved by dynamic recrystallization. Locally, on a scale of meters, extensive autoclastic hydrothermal breccias formed. The static alteration includes formation of numerous monomineralic and compound felsic, diopside, plagioclase, amphibole, and lower temperature veins, which are relatively scarce elsewhere in the core. This alteration differs significantly from that associated with the brittle-ductile deformation, and extends down from the middle amphibolite to the zeolite facies. Below the lower amphibolite facies, however, this "static" alteration produced relatively minor mineralization, providing evidence that permeability and/or reaction rates decreased as the gabbro massif as it cooled. This network of static hydrothermal veins and breccias is similar in extent and mineralogy to that formed accompanying circulation of water into large layered intrusions during subsolidus cooling and brittle deformation (Bird et al., 1986).
A major feature of the core is the near absence of greenschist facies alteration. This is also the case for the small gabbro sections drilled with sheared serpentinite near suspected fault scarps in the North Atlantic in DSDP Hole 334 near $37^{\circ} \mathrm{N}$ (Helmstaedt and Allen, 1977) and Hole 556 near $38^{\circ} \mathrm{N}$. While this is also true for some dredged gabbros, notably those from the Gorringe Bank (Mével, 1988), the majority of oceanic gabbros, and those dredged during the site survey of the Atlantis II Fracture Zone in particular, are moderately to heavily altered in the greenschist facies. Even where gneissic amphibolites have been dredged or sampled from scarps in fracture zones and ocean rift valleys, as at the Vema and Kane Fracture Zones, and the Cayman Trough, they often have a major retrograde greenschist facies alteration (e.g., Bonatti et al., 1975; Ito et al., 1983; Honnorez et al., 1984; Karson and Dick, 1983; Delaney et al., 1987). Numerous submersible dives have shown that these dredged gabbros come from talus slopes and debris from the foot walls of major low and high angle normal faults (Francheteau et al., 1976; CAYTROUGH, 1979; Fox and Stroup, 1981; Karson and Dick, 1983; OTTER, 1984). Thus, greenschist facies alteration seems to be associated with high level retrograde metamorphism along these fault zones, or with low-tempera- 
Deformation Zones

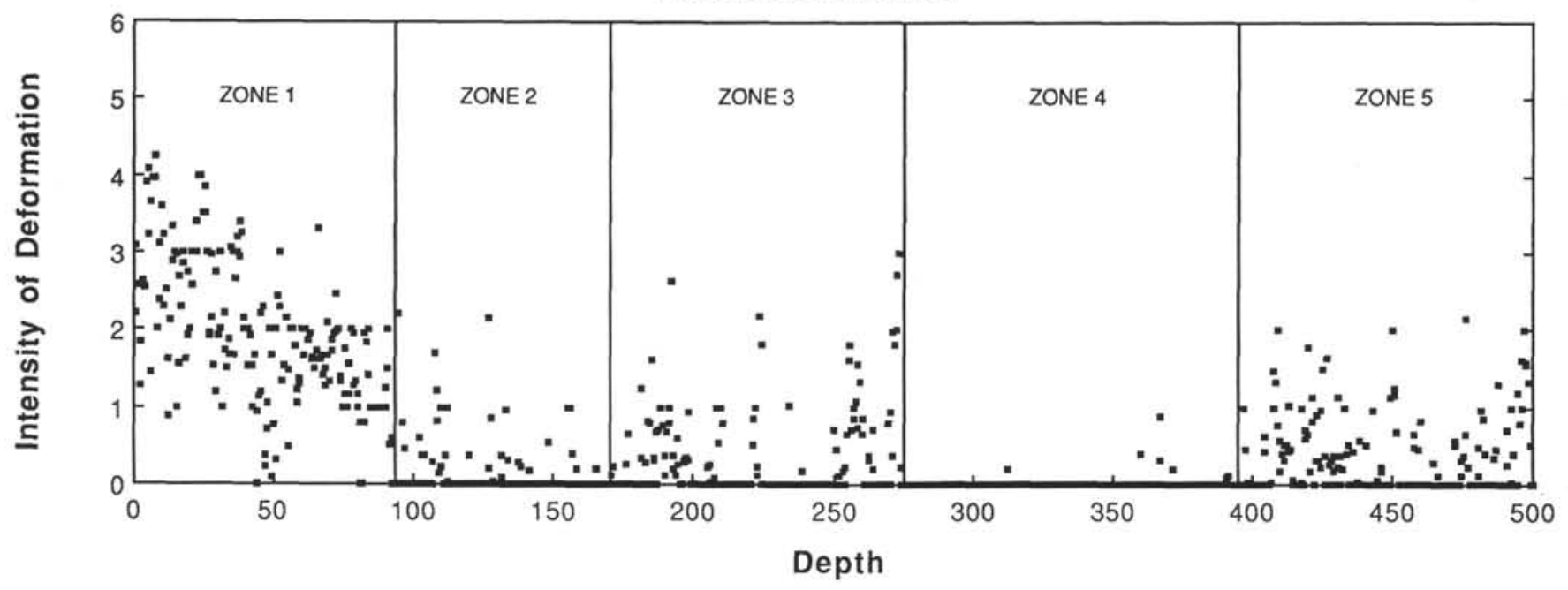

0.5M Average Degree of Deformation

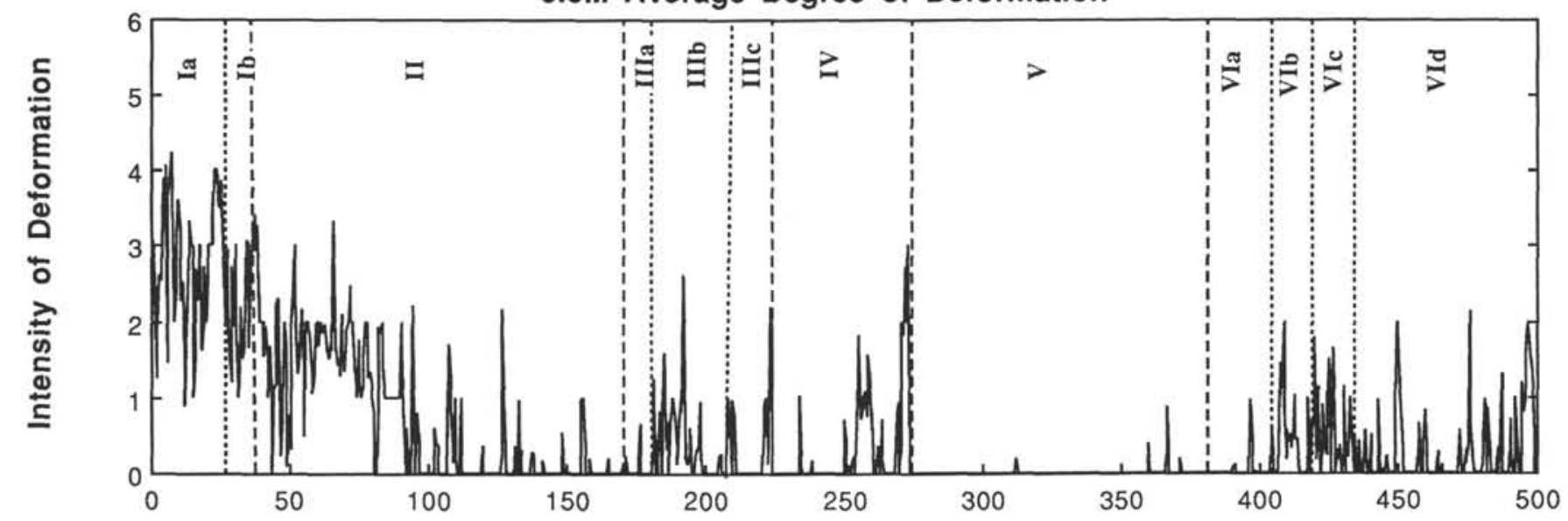

Dip of Late Magmatic Foliation

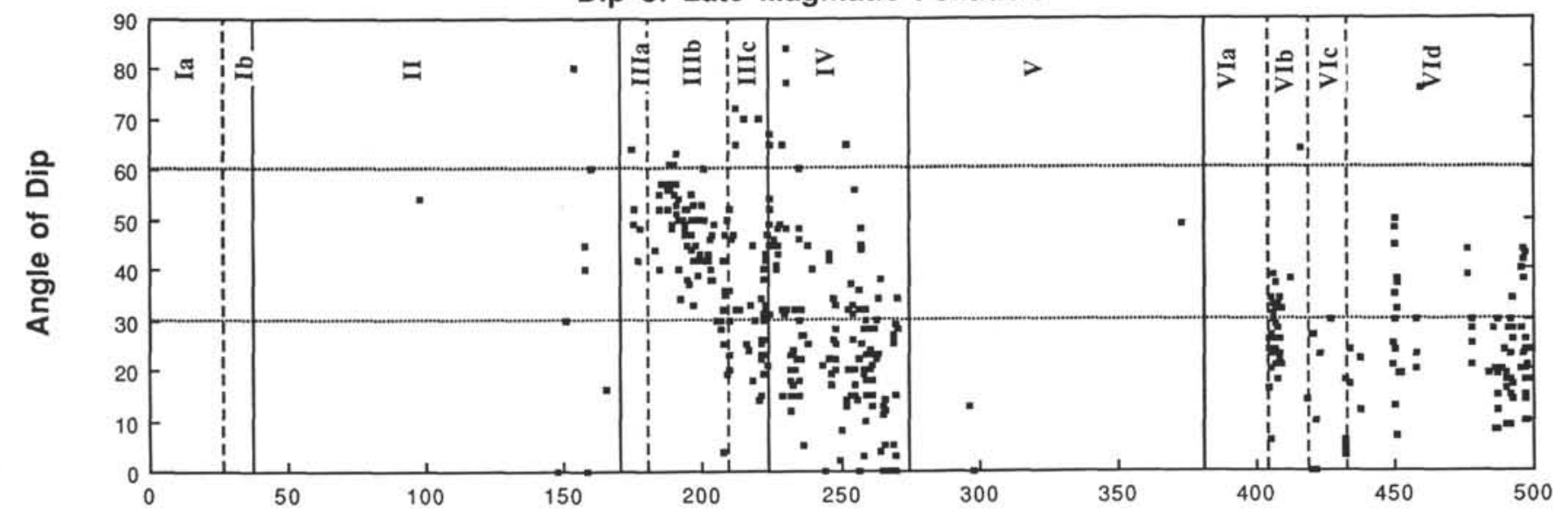

Figure 23. Downhole structural log showing averaged $0.5-\mathrm{m}$ deformation intensity and angle of dip (inclination from horizontal) of the principal foliations. Vertical lines show the divisions between the major deformation zones. 

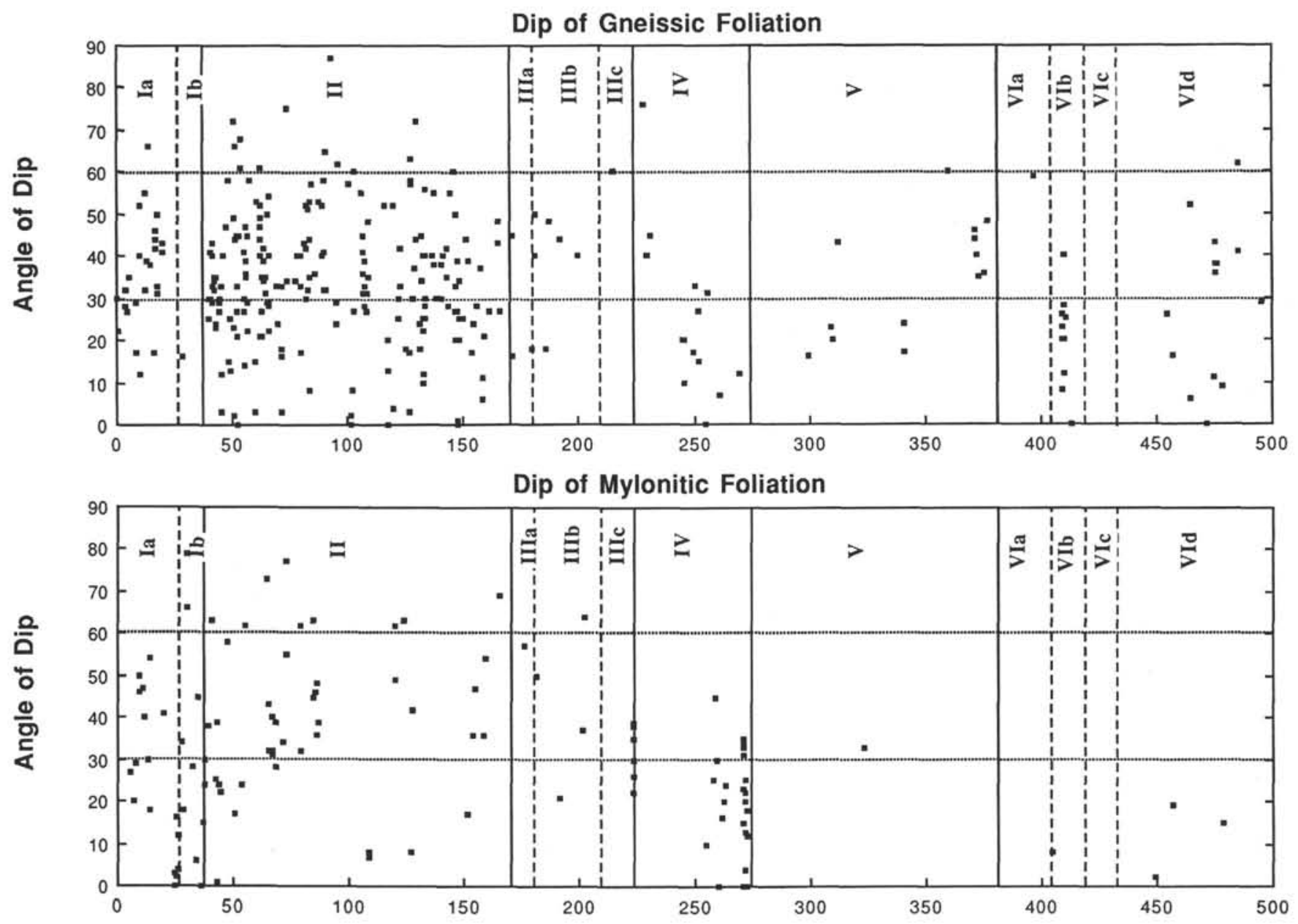

Figure 23 (continued).

ture hydrothermal upflow zones producing quartz, chlorite and epidote vein assemblages believed to represent the stockwork below black smokers and hydrothermal plumes localized near rift valley walls (Stakes and Vanko, 1986; Delaney et al., 1987), probably by these major fault systems. The more general character of alteration of the lower oceanic crust, away from these faults, as drilled in Hole 735B, would appear to be largely in the amphibolite facies alteration and higher, with only minor low temperature alteration.

\section{Brittle-Ductile Deformation}

Strictly speaking, both ductile and brittle-ductile deformation occurred during the high-temperature late-magmatic, and lower-temperature granulite and amphibolite facies deformations. Macroscopically, the deformation can often be treated as pure ductile shear, and as a result we often refer to the deformation as ductile. Microscopically, however, there is abundant evidence of cataclasis, cracking and stretching of grains, the formation of pressure shadows, local microfaulting and the like, which in general indicate that the deformation is not "pure" ductile deformation, and is locally heterogeneous. In hand specimen, the shear zones are often associated with extension cracks in adjacent undeformed gabbro. Locally, amphibole veins and crack networks may crosscut or be crosscut by the shear zones, indicating that both brittle and ductile deformation were occurring contemporaneously. As a result, the terms ductile, and brittle-ductile are sometimes used interchangeably. It is reasonable, on an outcrop scale, to treat the deformation as ductile, but on a petrographic scale as brittle-ductile. This distinction is important when discussing the permeability of the rock, as pure ductile deformation would not create permeability, which was clearly not the case here. The evidence shows that ductile deformation controlled and channeled flow of late intercumulus melt and later hydrothermal fluids through the massif.

The control and enhancement of the circulation of metamorphic fluids by ductile deformation and shear is well known to the geologic community (e.g., Beach, 1976; McCaig, 1984; Kerrich et al., 1984; Rutter and Brodie, 1985; Kerrich, 1986; Brodie and Rutter, 1987; Burkhard and Kerrich, 1988). This may be the first time, however, that ductile deformation along fault zones has been invoked to control the flow and distribution of intercumulus melt in a solidifying pluton. The role of melt was explored as an important phenomenon during deformation in the mantle by Dick and Sinton (1976), who think it has a role in the formation of metamorphic layering ("flowbanding") and enhancement of ductile flow by pressure solution creep. Both this geologic evidence and the experiments of Cooper and Kohlstedt (1986) showed that melt circulating along a shear zone will greatly reduce the effective viscosity and the activation energy for shear as well as enhance recrystallization of the deforming matrix. These are the same effects documented by the authors listed above for hydrothermal fluids and water in subsolidus shear zones in metamorphic rocks that range from carbonates to amphibolites. 


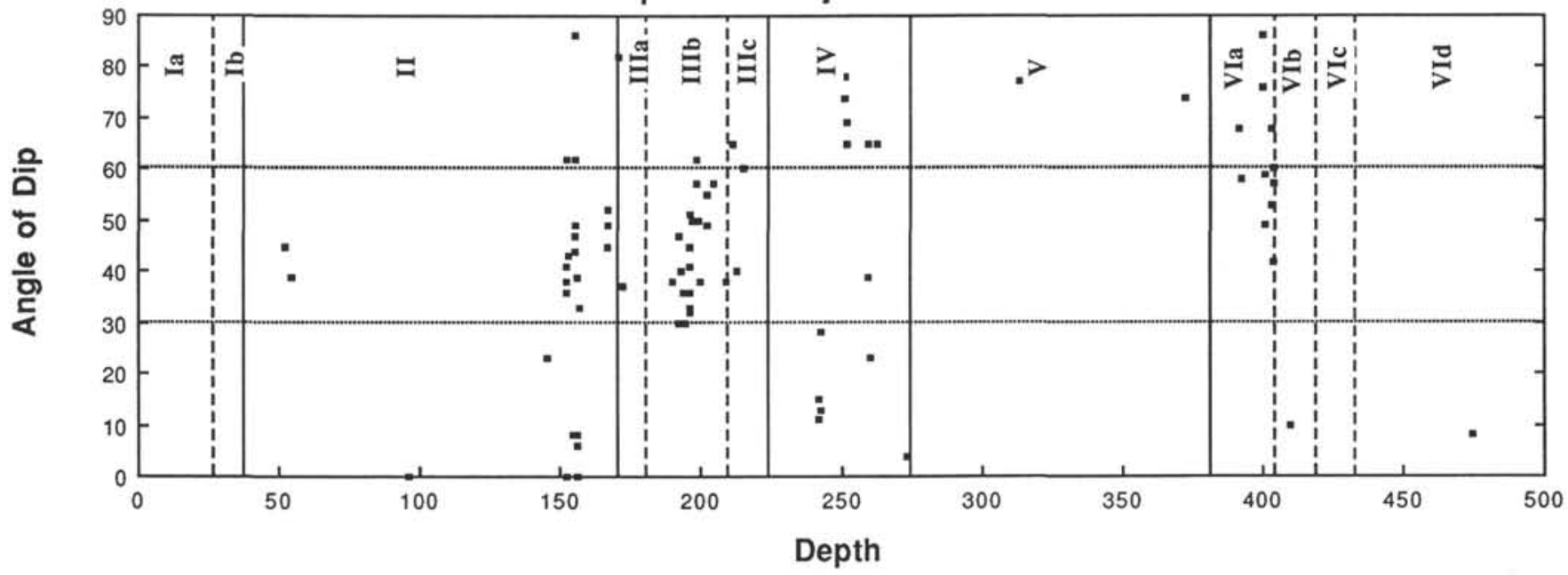

Dip of Felsic Veins
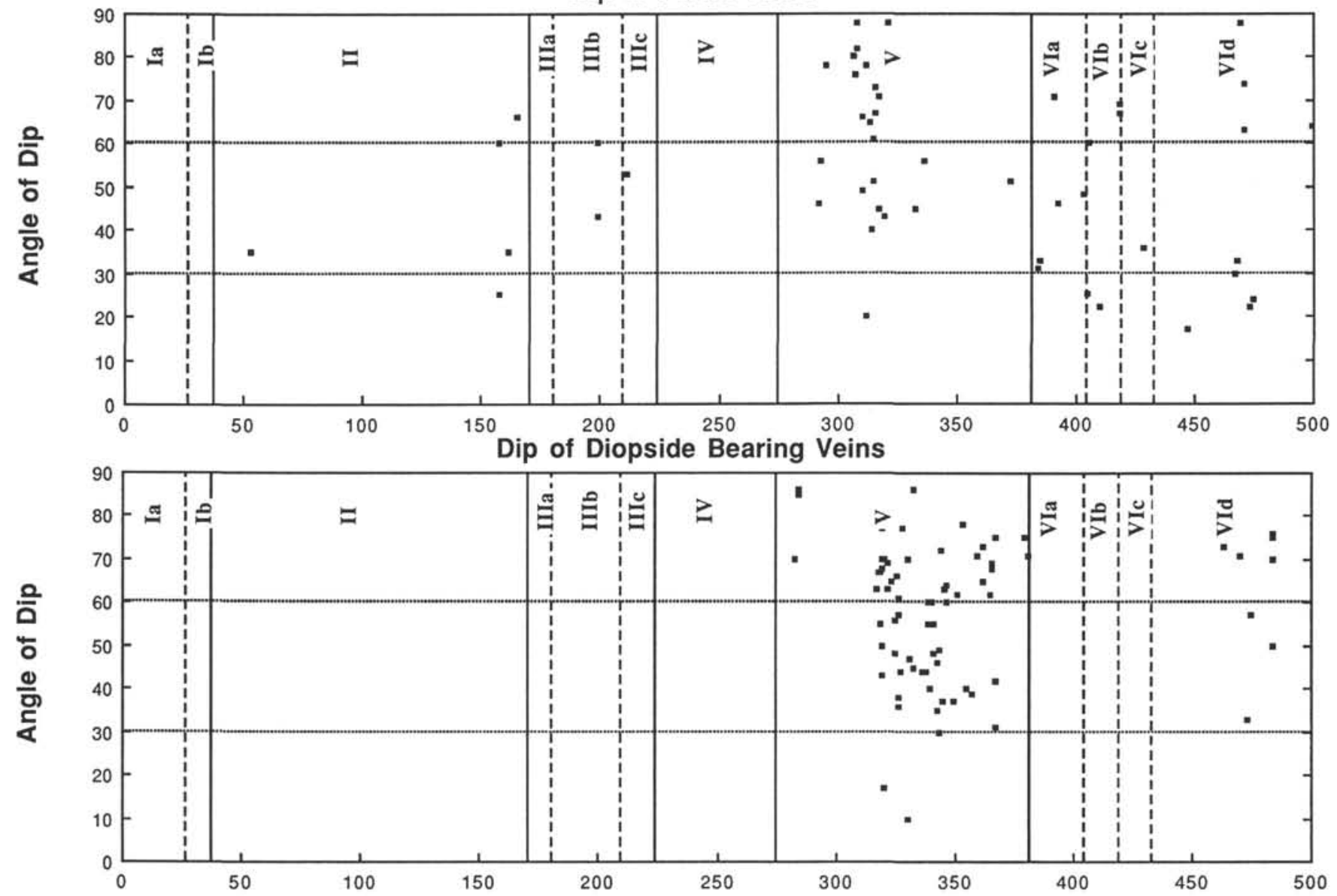

Figure 24. Downhole structural log showing the angle of dip (inclination from horizontal) for different veins in Hole 735B. Vertical lines show the divisions between the major lithostratigraphic units.

Ductile deformation in the large proportion of Hole $735 \mathrm{~B}$ gabbros is relatively weak, and they lack a clear penetrative foliation, and most show only slight granulation or recrystallization around grain margins and the formation of kink bands, or are totally undeformed. This differs somewhat from the statements in the Initial Reports volume of Leg 118, which probably overemphasized the total deformation. To determine with some precision the extent and location of deformation we reexamined every sample in the core and classified them on the basis of appearance in hand specimen on a six-point grade scale ranging from undeformed to ultramylonite (Plate 6) as follows:

0. Coarse-grained protolith: original igneous grain relations preserved, little or no grain shape anisotropy (0, plagioclase not obviously recrystallized.

1. Weakly foliated gabbro: Original igneous grain relations preserved, around 2:1 shape anisotropy, plagioclase partially recrystallized with clear coherent cores. 
Dip of Plagioclase-Amphibole Veins
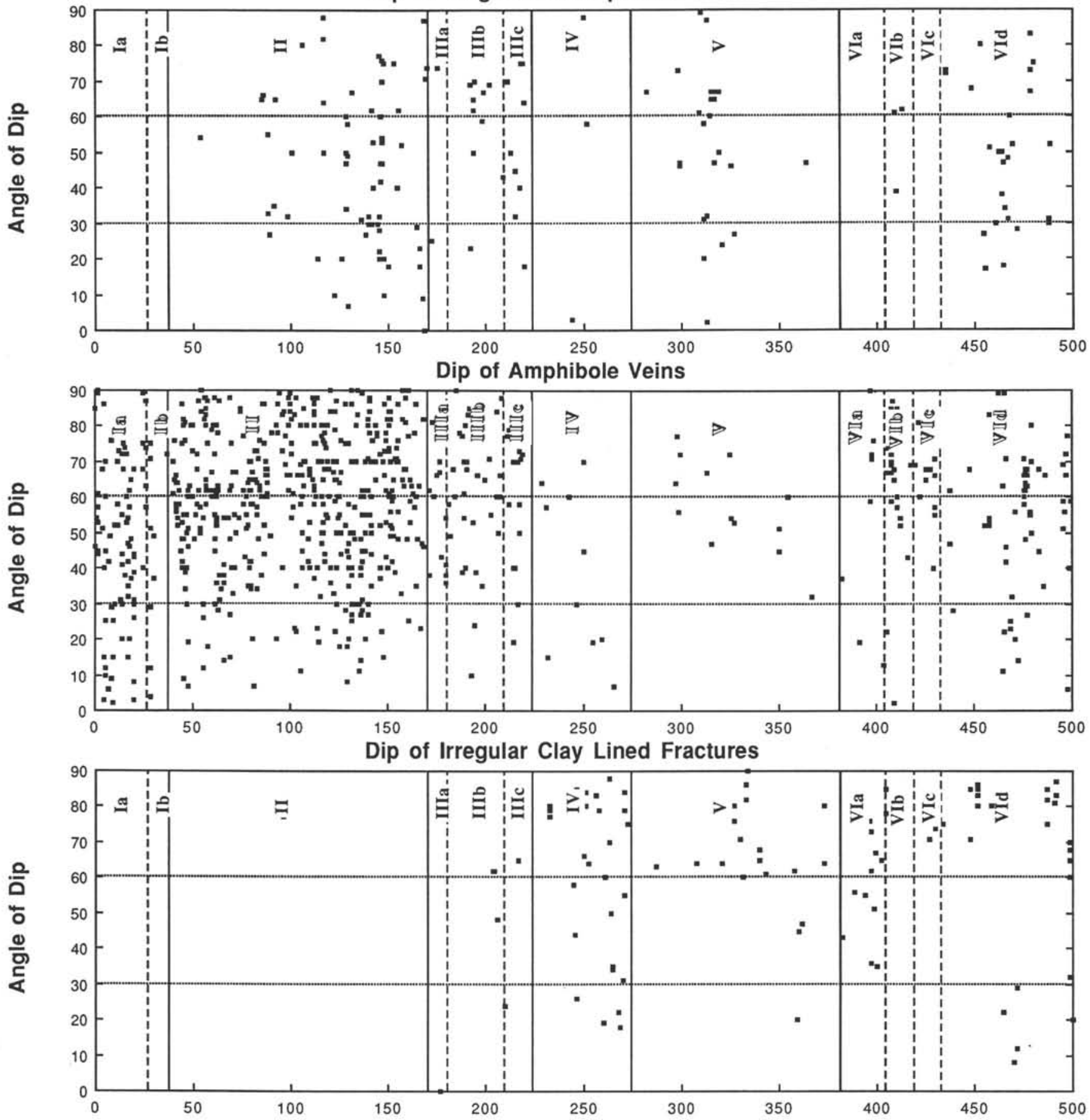

Figure 24 (continued).

2. Strongly foliated gabbro: Some original igneous grain relations preserved around clinopyroxene, around a 4 to $5: 1$ clinopyroxene shape anisotropy, some recrystallized tails on pyroxene porphyroclasts, plagioclase mostly recrystallized.

3. Porphyroclastic mylonite: No original grain relations preserved in clinopyroxene, 8:1 clinopyroxene shape anisotropy with long recrystallization tails, all plagioclase recrystallized.

4. Mylonite: No original grain relations preserved, most clinopyroxene recrystallized, very fine grained, parallel banding often present.
5. Ultramylonite: Extreme grain size reduction, few porphyroclasts present, not strongly foliated in hand specimen, dark color.

We note that this scale is not necessarily linear with respect to total strain, strain rate, or deviatoric stress. Rather, it is a reasonably simple textural progression readily discernable in hand specimen and reasonably reproducible by different observers. A thin ultramylonite, for example, where super plastic flow has occurred, might represent meters or kilome- 
ters of displacement. Our strain log is similar to that prepareon board ship and used by Cannat et al. (this volume).

The relative proportions of the different deformation grades are shown in Figure 25. Using this classification, 71\% of the Hole 735B gabbros are either slightly or weakly deformed, essentially retaining their primary igneous texture intact. A question of some interest, however is what propor- tion of the gabbro shows any evidence of deformation? A large number of grade 1 weakly foliated gabbros show grain boundary recrystallization, mortar texture, and kinking of mineral grains, and yet the original igneous texture is well-preserved. The cutoff point between undeformed and deformed gabbros in our scale, then, is arbitrary and many gabbros graded as 0 on our scale show weak deformation, though they lack a
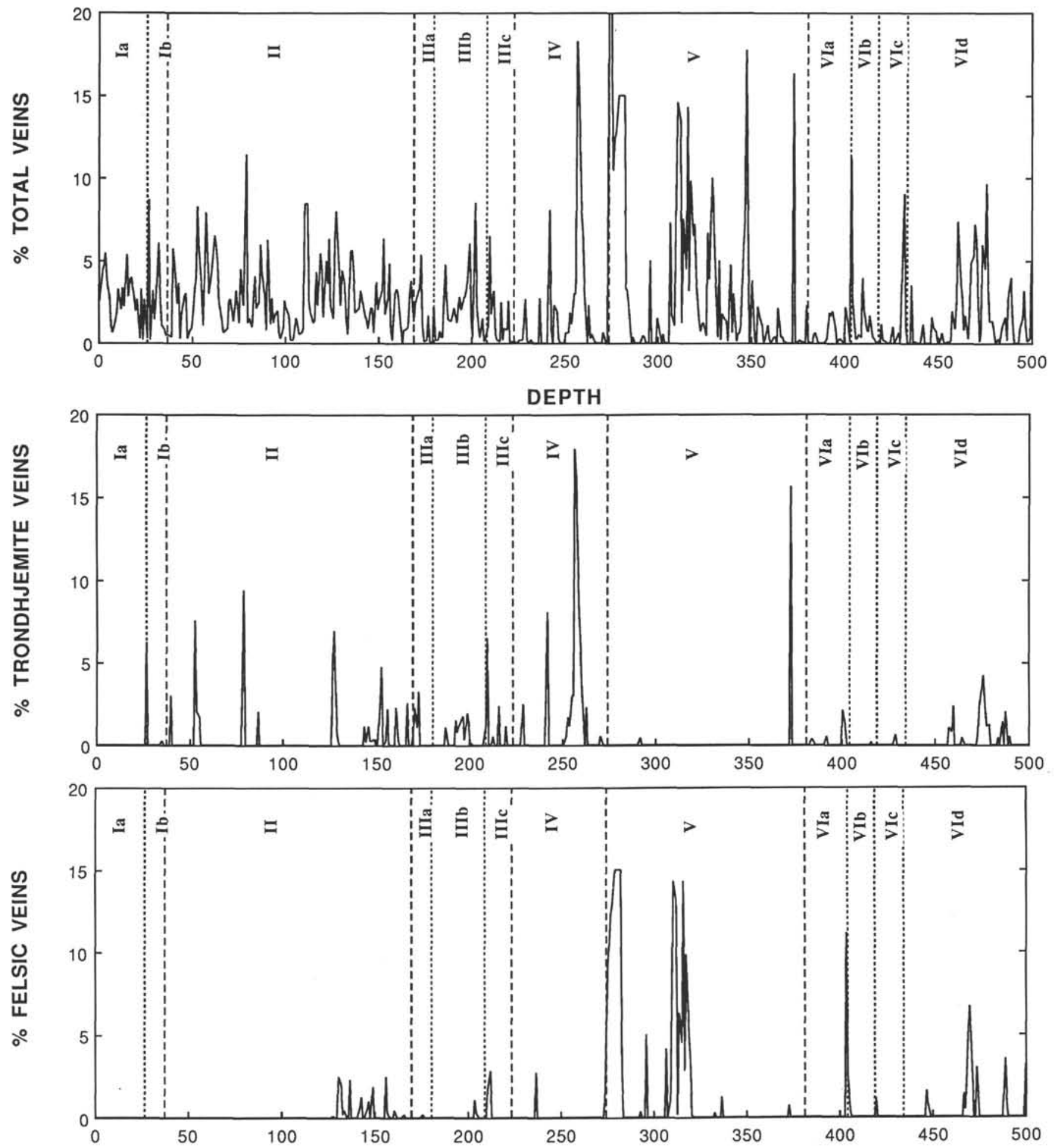

Figure 25. Downhole log of Hole 735B showing 1-m average density for Hole 735B vein assemblages and the 1-m running-average for deformation intensity. Vertical lines show the divisions between the major lithostratigraphic units. "Other" refers to low-temperature veins, including carbonate, clay, and zeolites. 
foliation. Without benefit of examining a continuous series of thin sections, it is extremely difficult to detect the often subtle evidence of deformation in a rock that has undergone relatively little deformation (Fig. 26). We note, however, that there is a fairly regular nonlinear progression from the most, to the least deformed gabbro in our scale. This progression can be curve-fit to yield an estimate of the proportion of the rocks remaining as the deformation goes to a vanishingly small degree at somewhere around $35 \%$. This is about the proportion one might guess from a general inspection of the core and shipboard thin sections: that roughly one-third exhibit no evidence of deformation visible to the naked eye.

Plotted in Figure 23 is the $0.5-\mathrm{m}$ running average of the deformation intensity down Hole 735B. The degree of deformation, however, varies greatly, even on a scale of centimeters. Thus, showing a running average in this manner lumps undeformed and deformed rocks together, reducing the estimate of the maximum intensity of deformation in an interval, while at the same time giving the impression that a higher percentage of rock has been deformed than actually is. The
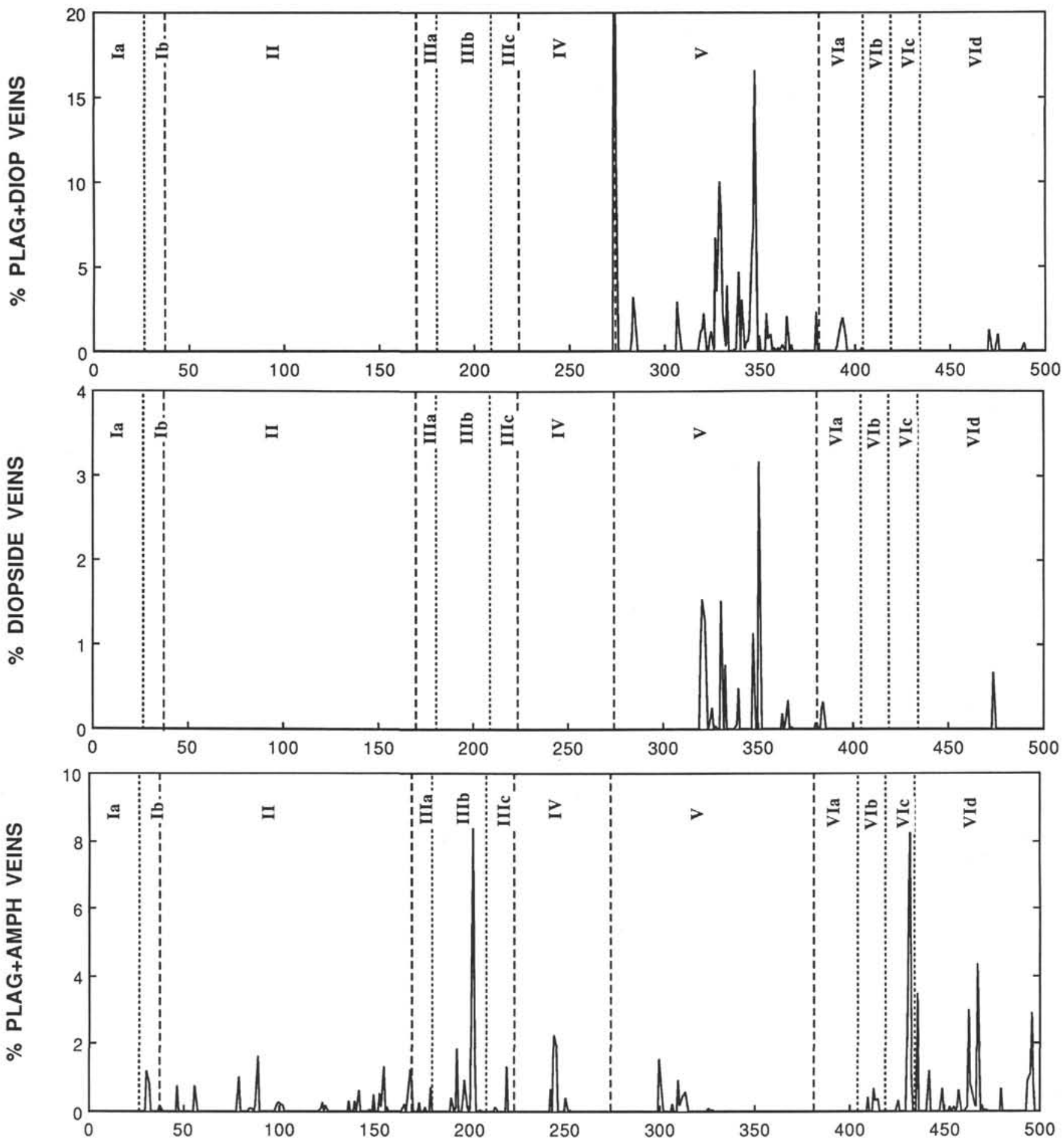

Figure 25 (continued). 
variability at even the $10-\mathrm{cm}$ scale is so great, however, that it would be difficult to show at a reasonable scale in a figure here. This heterogeneity may be characteristic of dynamically deformed ocean ridge gabbros, with mylonite bands and undeformed igneous textures commonly found together on a hand sample scale (e.g., Helmstaedt and Allen, 1977; Malcolm, 1980; Mével, 1988). Also plotted downhole in Figure 23 is the dip of the tectonic foliation. As can be seen, the dip, nature and character of the foliation varies considerably with depth.
Two principal varieties of brittle-ductile deformation are evident in the hole: a late-magmatic period associated with the formation of the oxide gabbros, and a subsolidus, amphibolite facies deformation. The late-magmatic deformation occurred locally throughout the core, but is most extensive in the Unit III and IV gabbros and in the Unit VI gabbros at the base of the hole. Late-magmatic deformation occurred at the top of the hole, as can be seen from the presence of oxide intervals compositionally identical to those lower in the core associated with the high temperature ductile deformation and shearing.
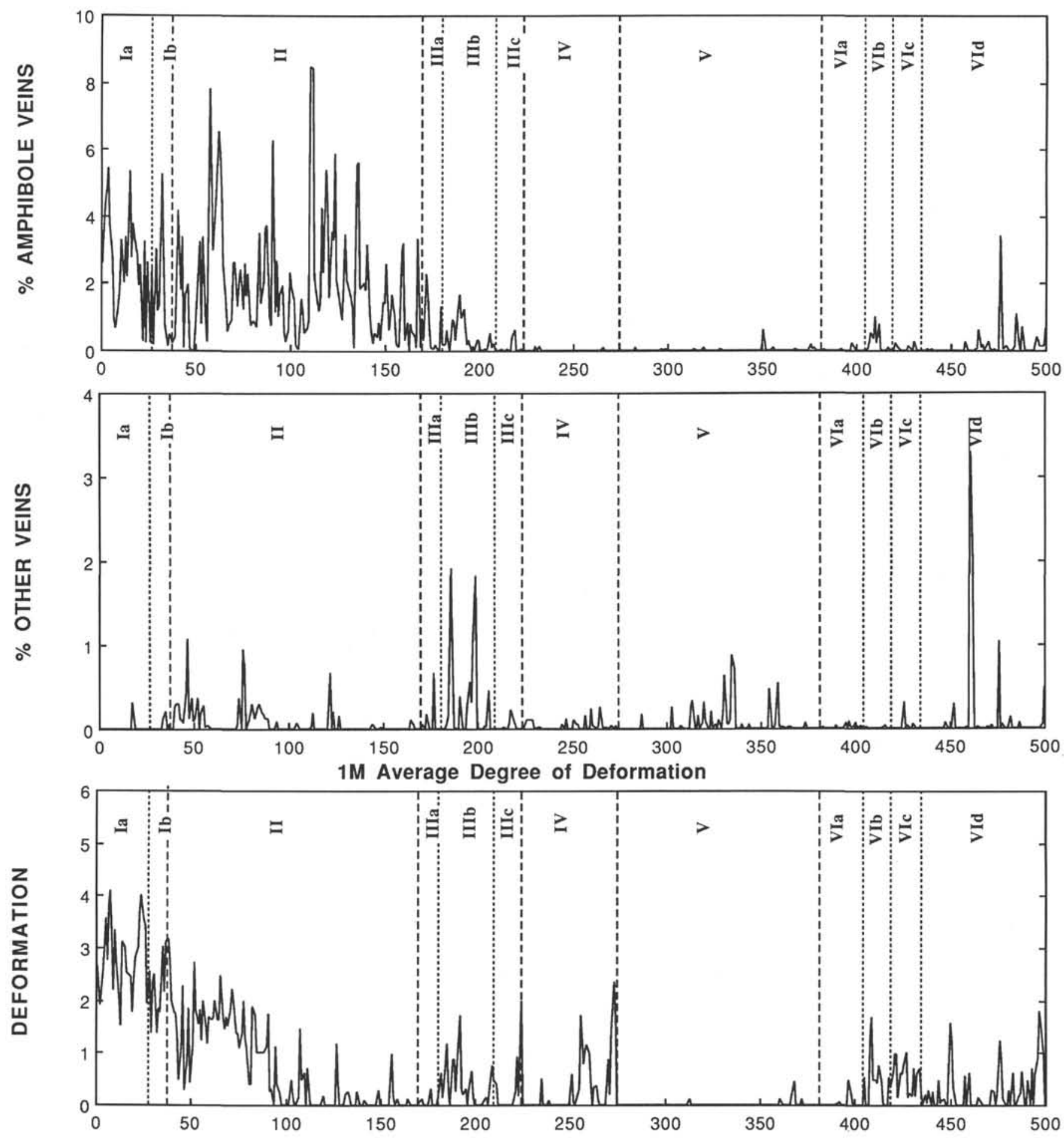

Figure 25 (continued). 


\section{Deformation Intensity in Hole 735B}

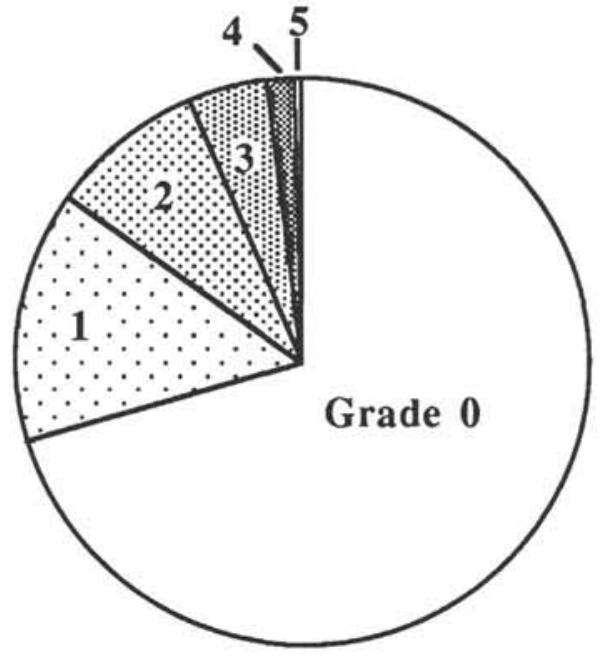

Figure 26. Relative proportion of deformed and undeformed gabbros in Hole 735B, estimated from a post-cruise inventory of the recovered rocks.
Generally, late magmatic ductile deformation is found along small intermittent shear bands from a few millimeters to tens of centimeters. The morphology of these shear zones suggest braided shear, similar to that seen in the lower-temperature amphibolite facies ductile deformation zones. Only in Units III, IV and VI are the late magmatic shear zones of any thickness, but there they have had dramatic effects on both fabric and rock chemistry. The high-temperature deformation zones are often heavily overprinted and often texturally obliterated by later amphibolitization and subsolidus brittleductile deformation. In Core 3, Pc. 2, a high-temperature foliation with ilmenite can be seen cross-foliated by the later subsolidus deformation.

There is a major zone of amphibolite facies brittle-ductile deformation, which has reduced most of Unit I and much of Unit II to an amphibolite gneiss at the top of the hole, and a much smaller zone at the base of the hole in Subunit VID. Through most of the rest of the core, scattered small brittleductile shear zones are common, except for a long interval beginning at the top of Unit IV (Fig. 27) and extending down to the base of Subunit VIB, where late subsolidus brittleductile deformation is almost absent. Unit V comprises a single 108 -m interval nearly devoid of brittle-ductile deformation of any kind. We examined all the brittle-ductile shear zones for rolled porphyroclasts with tails (fish and snails), microfaults and cross foliations from which we could determine a sense of shear. In all we were able to do this unambiguously at 24 locations and with some doubt at another 22. In 45 of these, the sense of shear was normal, and in one it was reversed.

The subsolidus deformation extends from low to high water/rock ratio deformation in the amphibolite facies (Stakes et al., this volume). At the low water/rock end, the "alteration" assemblage essentially consists of the igneous paragenesis, which has been partially or completely recrystallized in the amphibolite facies, with a consequent modification to lower pressure and temperature mineral compositions. At higher water/rock ratios conversion of clinopyroxene and olivine to amphibole is complete, and the rock is essentially an amphibolite gneiss. A characteristic feature of the subsolidus deformation is an often rapid change in degree of deformation on a scale of centimeters (Plate 6). Contacts between deformed and undeformed rock can be razor sharp, undeformed igneous textures abutting ultramylonite (Plate 6), or they may be gradational, going gradually from undeformed gabbro through weakly deformed to gneissic to mylonite over a scale of $50 \mathrm{~cm}$. Gneissic zones tend to be thicker than mylonitic zones, and we note that as the overall intensity of deformation drops, the deformation becomes less penetrative with the

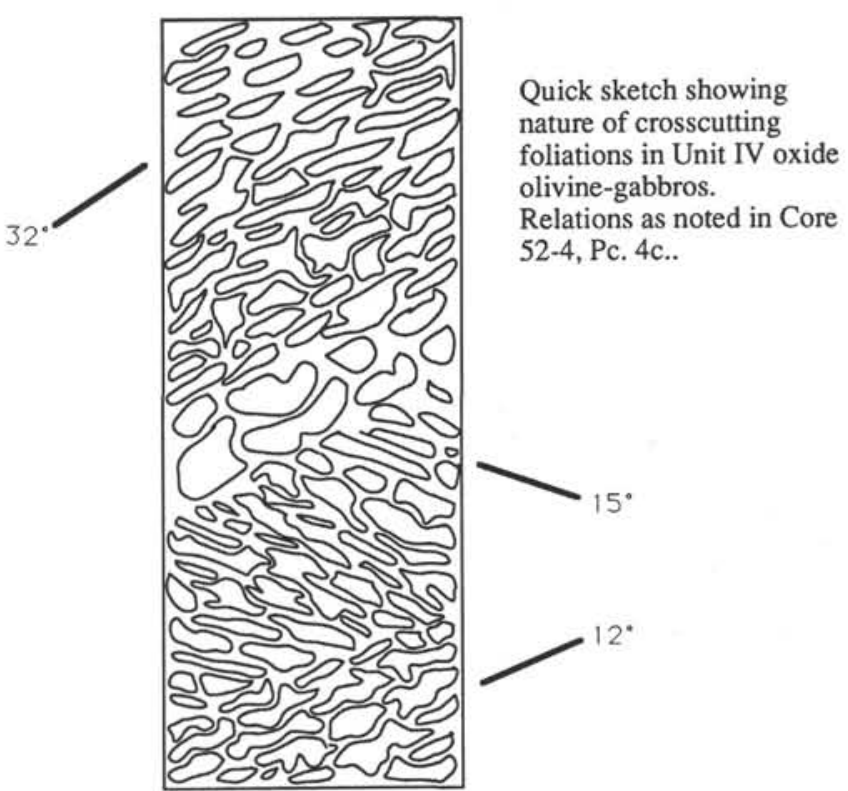

Figure 27. Oblique slip on sheared amphibole veins crosscutting Hole $735 \mathrm{~B}$ gabbros and gneisses. Plot shows the difference between the dip direction and the amphibole lineation $(\beta)$ on the ordinate, and the depth in the hole on the abscissa. Dashed lines represent the ratio of strike-slip to dip-slip motion, which is equal to the tangent of the angle $\beta$. 


\section{H. J. B. DICK ET AL.}

thickness and number of the deformed zones dropping sharply. At the same time, however, the intensity of deformation within the zones increases, with a higher percentage of mylonite.

Texturally, hypersolidus ductily deformed gabbros are significantly different from subsolidus ductily deformed gabbros. While coarse plagioclase and pyroxene grains in both exhibit local fracture and pull-apart texture, in the former case the cracks between grain fragments are filled by oxides, while in the later they are filled by amphibole. The hypersolidusdeformed, oxide-bearing gabbros also exhibit a uniform penetrative deformation over long intervals in Units III, IV, and VI, discussed extensively in the igneous stratigraphy section, which may extend tens of meters down the core. This is a striking contrast to the extreme variability of the subsolidus deformation fabrics, even where they are best developed in the upper $100 \mathrm{~m}$ of the hole. Perhaps most significant, however, is that the oxide-bearing gabbros frequently have an igneous texture, characterized by interlocking grain boundaries, unstrained grains, and sometimes subhedral mineral morphologies, which is attributed to post-tectonic crystallization of trapped intercumulus melt. These contrast sharply to the deformed mineral grains, cataclastic textures, and extensive polygonalized recrystallization fabrics that are far more abundant in subsolidus deformed gabbros (Fig. 28).

Although most oxide-bearing gabbros are texturally distinct from both the undeformed oxide-free igneous rocks and rocks having experienced subsolidus brittle-ductile deformation, as discussed earlier, a complete textural gradation exists. With increasing degree of deformation (probably reflecting increasing strain rate), hypersolidus and subsolidus mylonites are virtually indistinguishable in hand specimen. This similarity of texture can make separating foliations produced by the two deformation phases very difficult. Locally, in the massive oxide gabbro, there is a relatively simple igneous texture with complex interlocking grains and little evidence of a foliation at a hand-specimen scale. In such cases, it is only by looking at the unit as a whole and by examining the rock on a scale of meters, that one sees that this is a local textural extreme, in a fairly uniformly deformed unit. This may simply reflect high melt contents at the end of deformation, which produced a more typical igneous texture.

Many textural differences in the oxide-bearing gabbros are likely to reflect local variations of initial grain size before deformation and infiltration of late melt. Locally, where the protolith was a patchy olivine gabbro, the foliation in the finer-grained, impregnated oxide olivine gabbro may wrap around more competent, unimpregnated, coarse-grained patches (e.g., Core 77R-1, Pc. 4, Plate 7). Generally, the finer-grained oxide olivine gabbro has a uniform xenomorphic granular (aplitic) texture, whereas the coarser-grained, impregnated gabbro has a leopard-spot texture with coarse abraded pyroxene augen and pull-apart texture enclosed in a finer-grained matrix of feldspar. In the latter case, the finer grain size of the feldspar is probably due to dynamic recrystallization of the less competent feldspar, whereas the more competent pyroxene underwent local brittle deformation, abrasion, and cataclasis.

A striking feature of the foliated oxide gabbros, when closely examined in Units III and IV, is that there are sections

\section{Oblique-Slip Component on Late Lineated Amphibole Veins}
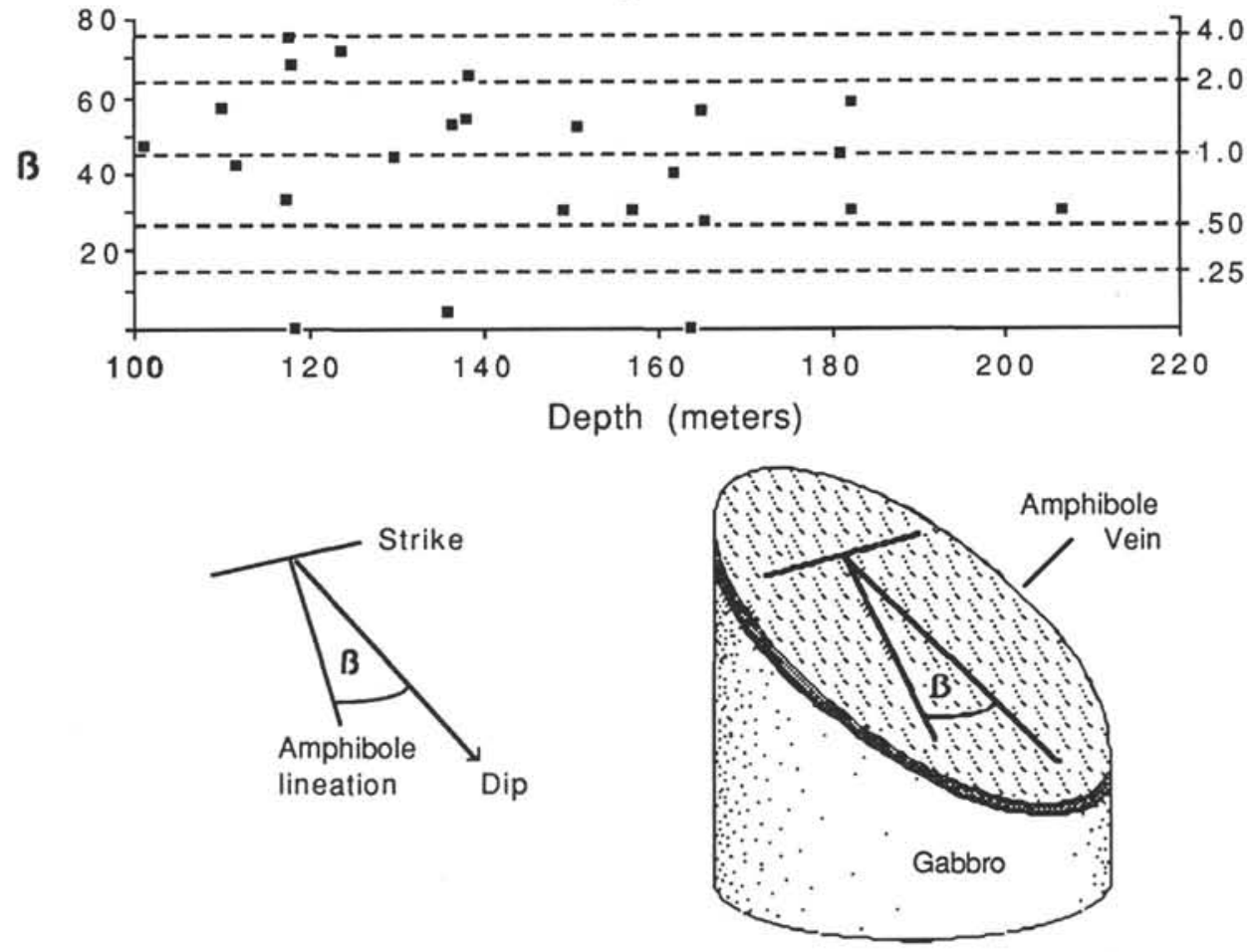

Figure 28. Hypothetical ridge-transform intersection showing fault surfaces oblique to the spreading direction and transform on which a strike-slip motion component creates oblique-slip (nondip-slip) on the fault surface itself. Present-day spreading axis lies along the neovolcanic zone. Nodal basin is shown by heavy shading, and the active transform fault is shown by the heavy line. 
of the core where the foliations appear to crosscut each other, implying a number of discrete episodes of microfaulting and impregnation. In Core $52 \mathrm{R}-4$, Pc. $4 \mathrm{c}$, there is an excellent example where a later foliation crosscuts an earlier one having a reverse dip (Fig. 29). These are not cross-foliations, but more like cross beds in appearance. Similar textures can be seen in the thick Oman Ophiolite gabbro section that Nicolas (pers. comm., 1990) attributed to late-magmatic deformation of layered gabbros. In this case, a late-magmatic foliation might be disrupted by subsequent slumping, microfaulting or deformation while the gabbro was still partially molten. Alternatively, these simply may be a consequence of inhomogeneous deformation, where different shear systems in a braided shear zone operate at different times during one deformation cycle, leading to local crosscutting relationships (Fig. 30C).

In Unit IV (and lower down in Unit VI), narrow bands of mylonite 1 to $3 \mathrm{~cm}$ wide representing microfaults, crosscut the late-magmatic foliation with opposing dip. These mylonites seem similar to those in the amphibolite gneisses, and all have normal shear sense. We placed several subunit contacts where different lithologic intervals are juxtaposed on either side of these microfaults. The net displacement on these mylonite bands must be small, as the rocks on either side are part of the same series. Their most striking feature is the opposite dip to the latemagmatic foliation. This might be explained in a number of ways, for example: (1) they are relatively late antithetic faults to the late-magmatic brittle-ductile deformation; (2) they may represent later subsolidus faulting during uplift of the gabbros from beneath the rift valley to the rift mountains-in which case the reversal of the dip implies that these may represent fault surfaces dipping away from the rift valley, complementary to the inward facing faults seen on rift valley walls in an uplifted horst block; and (3) a crustal block initially undergoing high temperature ductile deformation with southward-dipping listric faulting on the northern side of the paleo-rift valley may have been transferred to the southern side by a small ridge jump, thereby reversing the direction of dip for faulting.

\section{Brittle Deformation}

By brittle deformation, we mean cracking or rigid faulting where simple slip occurs between two opposing rock faces creating a discontinuous break. This is distinct from the ductile shear zones discussed previously, where the displacement across the deformation zone is continuous, and the total

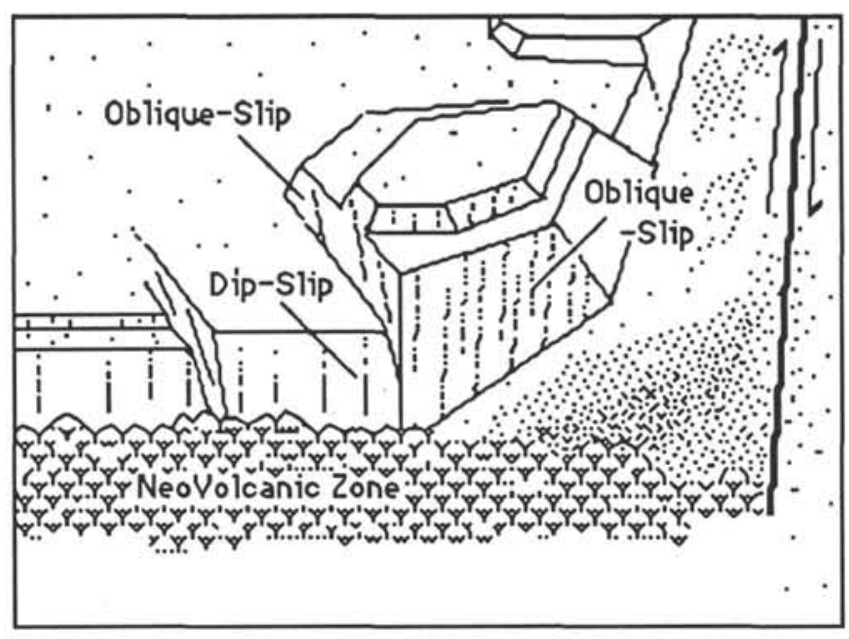

Figure 29. Quick, stylized sketch of texture of Core 52-4, Pc. 4c, from notes made at the Gulf Coast Repository showing crosscutting latemagmatic foliations. displacement at opposing sides of the fault zone is generally a direct function of the thickness of the mylonitic or gneissic shear zone. Brittle deformation was present as an ongoing process accompanying brittle-ductile deformation in the "brittle-ductile fault zones," producing innumerable amphibole filled cracks, crack networks, and veins. Thus, the brittleductile deformation zones do not represent pure ductile flow, but rather complex heterogeneous deformation in the brittleductile transition zone. Brittle deformation unaccompanied by ductile deformation is fairly limited in the Hole 735B core. Cracking and vein formation occurred in the relatively undeformed sections of the core as well during ductile deformation, though in lesser amounts. After deformation ceased in the middle amphibolite facies, however, vein formation virtually stopped in the ductily deformed gabbros, while it continued on down to progressively lower temperatures, though in steadily decreasing amount, to the zeolite facies in the relatively undeformed gabbros.

The orientations of all the vein assemblages down through lower amphibolite facies is highly variable, but on average they dip at $60^{\circ}$, opposite to the dip of the predominant foliation to which they are generally orthogonal (Fig. 24). Only the trondhjemites at the base of Units II and III have significantly different dip, which may reflect simple igneous intrusion, rather than formation as a result of hydrofracturing under an imposed extensional stress during and immediately following ductile deformation. The lowest temperature veins, containing smectite and zeolites, have a vertical orientation unrelated to the ductile deformation, as discussed later.

The most visible effects of brittle deformation are the numerous crosscutting amphibole veins, cataclastic trondhjemitic intrusion breccias, and the late hydrothermal breccias located at intervals in the core below Unit IV and an associated assemblage of veins and alteration minerals extending from high temperatures down to the zeolite facies. The latter are generally undeformed, whereas the trondhjemitic and related felsic veins rarely are slightly deformed in the foliated oxide olivine gabbros in Units III and IV, but are always deformed with the gabbro protolith by the subsolidus amphibolite facies brittle-ductile deformation. We define hydrother$\mathrm{mal}$ and intrusion breccia here as strictly referring to intervals of the core that contain rotated clasts in a secondary matrix. On this basis, the total amount of breccia we found is more limited than that reported by Stakes et al. (this volume), but there are still a number of significant intervals that crosscut the core, in particular a thick interval located immediately beneath Unit IV, which extends approximately $9 \mathrm{~m}$ from Core 56R-3, Pc. 3, to Core 57R-3, Pc. 5. We take these late hydrothermal breccias, and the associated vein networks, to represent local up-flow zones for seawater that has circulated into the gabbro.

Relatively pure amphibole vein linings occur locally on fracture or crack surfaces in the core, often with a coating of smectite, and sometimes with free vuggy spaces that have fractured or parted during drilling to reveal beautifully lineated black acicular hornblende crystals. These can be used locally to determine a sense of shear and slip-direction using slip surface roughness (shingle structure) and amphibole lineation. The shear sense so determined is somewhat ambiguous, though mostly normal. These veins crosscut gabbro and gneiss from 100 to $210 \mathrm{~m}$ and locally at $471 \mathrm{mbsf}$ near the lowest amphibolite facies brittle-ductile deformation zone. These veins crosscut mostly weakly to undeformed gabbro and, in some cases, the gneissic foliation. They are generally orthogonal to foliation where they crosscut it, clearly locally post-dating the last period of brittle-ductile deformation. 


\section{Late Magmatic Foliation in Units III and IV Deformation Zone 4}
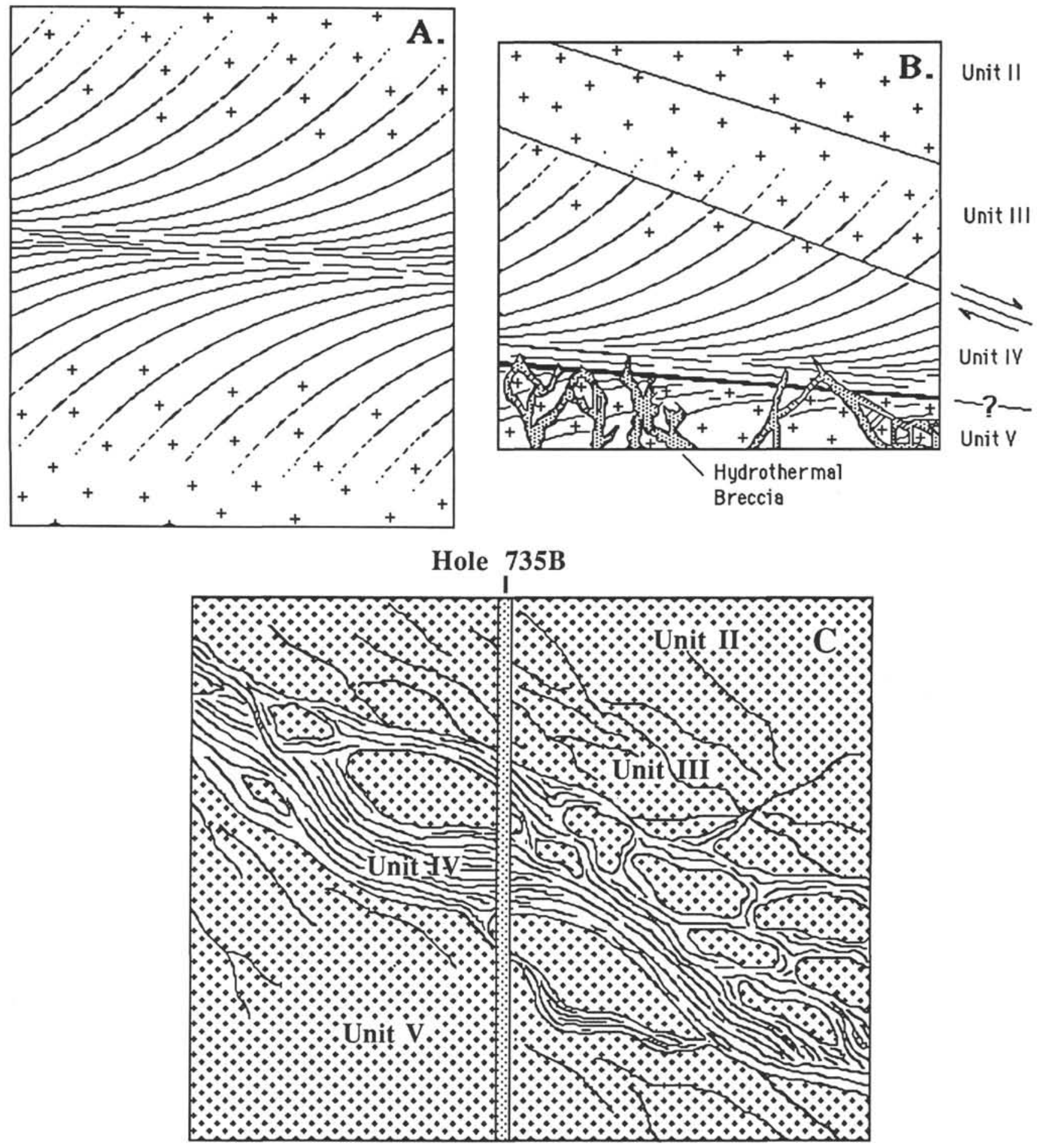

Figure 30. A. Symmetry of foliation in brittle-ductile shear zones in metagabbros and granites after Ramsay and Graham (1970). B. Possible simplified geometry for the decreasing dip of foliation with depth in Units III and IV and superimposed later brittle-ductile faulting and alteration. Thin, straight lines are mylonite zones at the base of Unit IV and narrow (e.g., $2 \mathrm{~cm})$ amphibolite facies porphyroclastic mylonites brittle-ductile shear zones, which locally offset the igneous stratigraphy (see Plate 2) with normal shear sense. The actual sense of shear at the base of Unit IV and its dip cannot be determined because the contact zone is brecciated in the core. C. Possible more realistic original structure for Units III/IV shear zone. Note the crosscutting foliations resulting from periodic locking of one shear system and activation of another during shear. The latter is a common phenomenon observed in subsolidus shear zones over a wide range of metamorphic grades. 
The slip direction indicated by the vein lineations in Figure 27 is generally not dip-slip, but at an angle to it. There is a bimodal distribution of slip direction, with a few lineations parallel, but the majority oblique to the dip direction. The latter make an average angle of $48.5^{\circ} \pm 14.7^{\circ}$ on the slip plane from the dip-slip direction ( $\beta$ in Fig. 27). Nondip-slip lineations occur on fault surfaces when both strike-slip and dip-slip motions are associated with faulting. This might have arisen during uplift of a tectonic block into the rift mountains, where a bounding fault on the wall of the median valley is oriented at an angle to the strike of the rift valley, such that the fault motion is nondip-slip. Alternatively, nondip-slip motion can occur locally on bounding rift valley faults, where they approach the ridge-transform intersection. Near the intersection, their orientation may rotate with the stress field as the principle fault motion changes from normal to strike-slip (e.g., Fig. 28). At the eastern intersection of the Mid-Atlantic Ridge rift valley with the Kane Fracture Zone, for example, Karson and Dick (1983) reported oblique normal faults where gabbroic crust is exposed and uplifted to the transverse ridge bordering the transform.

The oblique-slip component (indicated by the lineated amphibole) is likely too great to be a perturbation of extensional rifting far from a transform. The ratio of strike-slip to dip-slip component for these shears can be determined from the angle of the lineation from the dip direction. As can be seen from Figure 27, the amount of strike-slip component is generally slightly greater than the dip-slip component of motion and is locally four times as much as the dip-slip. Thus, these late veins reflect a stress field different from that for simple extensional faulting and flow beneath the rift valley floor-one where the principal stress directions must have rotated. We suggest that these lineations may have formed at the end of brittle-ductile flow, when the gabbros were being transferred from the zone of ductile flow and lithospheric necking beneath the rift valley into a zone of block uplift near the ridge-transform intersection. The oblique slip indicated by the amphibole lineations is direct evidence that the brittleductile deformation was terminated abruptly due to tectonic stresses related to uplift and formation of the transverse ridge.

An alternative explanation is that the nondip-slip component of the amphibole lineations results from late block rotation of originally dip-slip lineations. This might have been produced by listric normal faulting on an axis orthogonal to the ridge and parallel to the transform during formation of the transverse ridge. However, the steep, eastward-facing slopes of the transverse ridge at Site 735 indicate that the block drilled is a horst bounded by steep conjugate normal faults and thus is unlikely to have been tilted away from the transform the minimum of $49^{\circ}$ required to explain the average nondipslip component of the amphibole lineations.

\section{Tectonic Stratigraphy}

To assess the structural evolution of the core, we measured the orientation of foliations and veins through the core and estimated the volume percent of veins on a fragment by fragment basis. Our estimates of vein percentages were done visually, calibrated against a measured scale, while our identification of the individual veins were done in hand sample. As a consequence, the identification of the mineral assemblage in many veins is preliminary. Structural measurements were done using a protractor. Measuring the dip of the foliation or vein was not done on the cut surface, as was done for the Initial Reports volume of Leg 118, but rather after the sample had been rotated, so that the vein or foliation was in the vertical plane, to determine true dip. Plotted in Figure 23 are deformation intensity and the dip of the foliation, divided into three categories: late-magmatic, gneissic, and mylonitic. The section drilled at
Hole 735B can be divided into five major deformation zones based on variations in the intensity and character of deformation. These zones include one major and one minor interval of subsolidus brittle-ductile deformation and two minor and one major interval of late-magmatic brittle-ductile deformation.

\section{Zone 1}

Zone 1 coincides with the principal subsolidus brittle-ductile deformation zone and ranges from 0 to 90 mbsf (meters below seafloor), averaging close to grade 2 on the deformation scale. In zone $\mathrm{I}$, the most intense deformation, averaging grade 2.5 , is in Subunits IA and IB. The variability of the deformation is large on all scales, and in Figure 23 we plot the intensity based on a $0.5 \mathrm{~m}$ running-average. As noted earlier, this averages out the higher grade deformation, since these zones are generally narrower than the averaging interval. Given the intensity of brittle-ductile deformation, the upper deformation zone can be taken as a zone of fault displacement. The igneous stratigraphy shows, however, that this is a ductile fault with a lithologic gradation across it, such that the stratigraphy is thinned without an abrupt discontinuity. The total amount of displacement of the undeformed rocks below the zone relative to the now-missing overburden cannot be determined here; however, the rocks at the top of the deformation zone are petrologically related to those at its base, suggesting that displacement is probably much less than a kilometer given the small magma chamber dimensions believed to exist here.

The dip of the gneissic and mylonitic foliations in Zone 1 average about $35^{\circ}$, but show tremendous variability. The numerous amphibole veins in this section generally have the same strike as the foliation, and generally dip orthogonal to it. These veins also show highly variable dips, but average close to $60^{\circ}$, dipping opposite the foliation. This indicates that the brittle-ductile deformation and the veins are directly related. Inspection of the core shows that the dip of the foliation and veins varies on the hand-specimen scale, often wrapping around "shear" polyhedra of undeformed or relatively undeformed gabbro, suggesting braided brittle-ductile deformation zones similar in morphology to that suggested by Mével (1987, 1988) for North Atlantic and Gorringe Bank abyssal gabbros.

Numerous oxide-bearing horizons showing evidence of late magmatic ductile deformation are overprinted in the first brittle-ductile deformation zone. These horizons, where original textures are preserved, are identical to the late-magmatic foliated oxide gabbros lower in the core. As a proportion of the total deformation in the upper $90 \mathrm{~m}$, the overprinted late-magmatic foliation, represented by the oxide-bearing redeformed gabbros, appears to be minor.

\section{Zone 2}

At 90 mbsf, the intensity of deformation decreases abruptly, with only intermittent narrow shear zones criss-crossing weakly to undeformed olivine gabbro for the next $80 \mathrm{~m}$ down to the top of Subunit IIIA (170 mbsf). Both late-magmatic oxide-impregnated $\left(\mathrm{S}_{2}\right)$ and later amphibolitized shear zones $\left(\mathrm{S}_{3}\right)$ occur, although the latter are much more frequent. The dip of the foliation in the gneissic sheared intervals, like that in Zone 1, is highly variable, again averaging close to $35^{\circ}$. Numerous amphibole-filled veins also have highly variable dip and are predominantly oriented orthogonal to the foliation, with an average dip similar to, but perhaps slightly steeper than, the average dip of the Zone 1 amphibole veins.

\section{Zone 3}

Deformation Zone 3 coincides with Units III and IV and largely reflects late-magmatic brittle-ductile deformation and oxide impregnation of an olivine gabbro protolith. Although 
large intervals in this zone are shown as undeformed, in reality the entire section exhibits a weak, penetrative deformation, lamination, and lineation, which would be intermediate between deformation grades 0 and 1 . Locally, more intense deformation is seen, notably at the base of Subunit IIIC and Unit IV. These may reflect late-magmatic deformation concentrating at the base of an individual shear zone. Where the deformation is most intense, the fabric becomes mylonitic, and the deformation was sometimes classified as mylonitic or gneissic. However, the foliation plane of the mylonitic gneissic zones is the same as that for the foliation classified as late-magmatic and probably reflects the same deformation episode where stain rates were relatively high and granulation and recrystallization driven by dislocation propagation and nucleation predominated locally over pressure-solution creep and melt-lubricated sliding as the principle deformation process.

One of the most interesting features of Zone 3 is the relatively uniform dip of the late magmatic foliation, $\mathrm{S}_{2}$, and its systematic flattening downhole compared with that for $\mathrm{S}_{3}$. The systematic decrease in inclination goes from an average of $50^{\circ}$ at the top of Unit III to $15^{\circ}$ at the base of Unit IV over an interval of $53 \mathrm{~m}$. As noted in the section on igneous stratigraphy, this correlates with a downward change in chemistry, which was interpreted as reflecting a greater degree of melt transport, chemical exchange, and late magnatic impregnation.

The decrease in the dip of the foliation with depth may have several explanations. This change in dip does not represent simple curvature of a single fault surface, but rather a fanning of the foliation. This is shown in a simplistic rendition in Figure 30. When analyzing this feature, it is important to note that we may not have the entire original section. The transition from intensely sheared oxide olivine gabbros to undeformed olivine gabbros is abrupt, with a zone of intense hydrothermal alteration and brecciation crossing the contact (Fig. 30B). The actual contact is physically absent, along with approximately $20 \%$ of the rock drilled in this interval. The missing material and the hydrothermal brecciation might well obscure a late, mylonitic, brittle-ductile fault that may have foreshortened the section, similar to those that foreshortened Units II, III, and IV in numerous locations (e.g., Fig. 30B). The actual contact between Units IV and V is not drawn at the base of the mylonite, but more than $1 \mathrm{~m}$ below it, where somewhat less deformed and oxide-rich gabbro clasts occur intermittently with undeformed olivine gabbro in the hydrothermal breccia. Thus, the fanning of the foliation seen in this zone cannot be treated as a complete intact structure, but rather as part of a structure, the lower portion of which has been obscured by alteration and brecciation, such as that illustrated in Figure 30C.

Fanning of the foliation might occur in a number of ways. The simplest is rotation of a pre-existing foliation by simple shear due to drag against a later crosscutting low-angle fault. In this particular case, the preexisting late-magmatic foliation would be crosscut by a subsolidus, relatively narrow, brittleductile deformation zone. This seems unlikely, here, as it requires drag and rotation to occur evenly over a $50-\mathrm{m}$ interval above the basal crosscutting fault to explain the progressive rotation of the foliation, while the gabbros below the fault remain unsheared. None of the numerous subsolidus microfaults elsewhere in the core have had such an affect. In addition, this scenario provides no explanation for the curious correlation of chemical composition with dip of the foliation.

An alternative scenario is that the foliation initially formed at an angle to the maximum resolved shear stress, and with ongoing shear, this foliation was rotated into the principal plane of displacement at the center of the deformation zone by progressive shear and displacement across it (Fig. 30A). Thus, as a major shear zone is approached, one should encounter a weak foliation inclined to that zone, which, with increasing intensity of deformation, should gradually turn into the plane of the shear zone. Ramsay and Graham (1970) described shear zones in ductily deformed metagabbros and granites with precisely this geometry (cf., Ramsay et al., 1970, Figs. 13, 24): "The schistosity planes appearing at the margin of the shear zone are oriented at an angle of $45^{\circ}$ to the walls of the zone and as the schistosity becomes progressively stronger in the center of the zone, the angle it makes with the walls decreases." This is consistent with the greater intensity of the deformation in the last $1.5 \mathrm{~m}$ of Unit IV, where the dip of the foliation is shallowest. In addition, because permeability and fluid flow are enhanced by ductile deformation and shear, the center of such a zone (where deformation was most intense) should also have the greatest permeability. Thus, the zone where the dip is steepest (in Unit III, where the permeability presumably was the lowest) has the smallest amount of oxide and the smallest change in chemistry from the postulated gabbro protolith, while the zone at the base, which may have been the locus of principle shear (where enhanced permeability and impregnation were most prolonged and extensive) has the greatest change in chemistry.

\section{Zone 4}

Deformation Zone 4 extends approximately $116 \mathrm{~m}$ from the Unit IV/Unit V contact into the upper half of Subunit VIA. It is characterized by the near absence of brittle-ductile deformation, either late or post-magmatic. At the few places where the late foliation could be measured, the dip is similar to foliations in Zones 1 and 2, with considerable scatter. The most prominent deformation in this horizon is the thick hydrothermal breccia. The breccia starts $1.5 \mathrm{~m}$ above the Unit IV/Unit V contact, where it has brecciated the bottom of the Zone 3 basal mylonite and extends down for another $7.5 \mathrm{~m}$ into Unit V. This breccia locally has clasts in excess of $10 \mathrm{~cm}$ and is cemented by a felsic hydrothermal cement consisting mostly of plagioclase with some diopside, and an assortment of lower-temperature later hydrothermal phases (see Stakes et al., this volume).

A particular characteristic of Zone 4 are the numerous hydrothermal veins, starting with an assortment of felsic veins that extend into (or from) the hydrothermal breccia at the top of the zone, and including a whole series of apparently related compound plagioclase-diopside and diopside veins, and less abundant greenschist to zeolite facies assemblages associated with the higher-temperature breccias and veins. The dips of the diopside-bearing and felsic veins in Zone 4 are varied but typically about $65^{\circ}$. These are noticeably steeper than those of the trondhjemitic veins (discussed below) concentrated in the Units III and IV oxide olivine gabbros. The latter have an average dip of about $45^{\circ}$, complementary to the average dip of the late-magmatic foliation, suggesting that the development of these veins occurred under a different stress field than the felsic and related veins in Zone 4, and therefore at a different time. This interpretation is consistent with the general scarcity of diopside-bearing and lower-temperature hydrothermal assemblages associated with the clearly intrusive magmatic trondhjemites in Units III and IV.

\section{Zone 5}

This is a fairly complex zone exhibiting subsolidus and late magmatic phases of ductile deformation, one superimposed, but not entirely overlapping the other. Intervals with latemagmatic brittle-ductile deformation start midway through 
Subunit VIA, increasing in number and extent into Subunit VIB, decrease slightly in VIC, and become relatively few in Subunit VIC at the base of the hole. At the same time, intervals having amphibolite facies subsolidus deformation increase from a few, relatively minor, shear zones in Subunits VIA and VIB, to locally abundant in Subunit VID, overprinting and transposing the earlier late-magmatic foliation. The late deformation becomes sufficiently intense in the lower portion of Zone 5 to constitute a secondary ductile fault, which must significantly thin the local igneous stratigraphy. The dip of the subsolidus gneissic and mylonitic foliation in Zone V is highly variable and similar to that in Zones 1 and 2, averaging about $30^{\circ}$, though the scatter is large. In contrast, the late-magmatic foliation has a more uniform, relatively gentle dip, averaging about $25^{\circ}$.

\section{Alteration Stratigraphy}

Summing the percentages of visible veins and filled crack networks seen in hand sample through the entire core gives a total of $2.4 \%$ hydrothermal veins of various kinds in the Hole 735B (Fig. 31). With the exception of the extremely brecciated zone immediately below Unit IV, these veins are fairly evenly distributed down the core. The individual vein assemblages, however, are not distributed randomly, and vary in a geologically significant manner as discussed below.

\section{Trondhjemites}

Trondhjemite veins and intrusion breccias are common at many levels in the core, constituting about $0.43 \%$ of the section. They represent the last phase of igneous activity in Hole $735 \mathrm{~B}$, largely post-date the late magmatic ductile deformation, and may have overlapped early subsolidus deformation. The trondhjemites and felsic veins tend to occur in discrete zones of crisscrossing veins up to 1 to $2 \mathrm{~cm}$ thick. The igneous origin of many of these veins is clear, not only from both their petrography and chemistry, but from their textural relationships to the enclosing rocks as well. In Unit IV, for example, trondhjemite often networks the oxide gabbros or forms intrusion breccias with angular to rounded, very-coarse- to medium-grained gabbro clasts. Some of the clasts are penetratively foliated and are rotated with respect

\section{Relative Vein Proportions, Hole 735B}

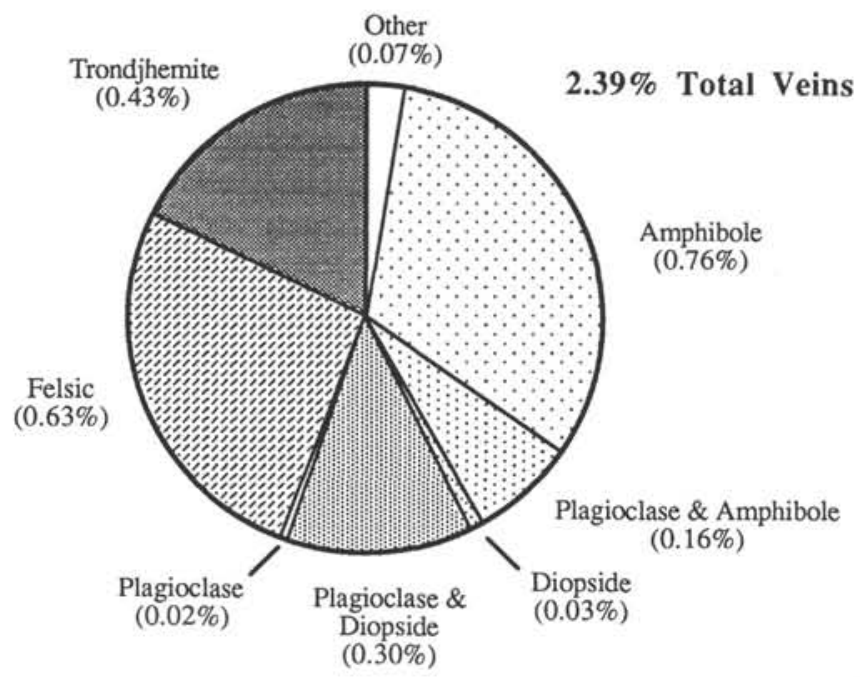

Figure 31. Relative vein proportions, Hole 735B, estimated on a sample-by-sample basis visually for the entire core and then summed. to each other and look partially assimilated by the trondhjemite. A fairly spectacular example of a partially digested wall rock xenolith occurs in Core 53R-4, Pc. 7a. Albitization of recrystallized plagioclase can sometimes be seen in the oxide gabbro in the vicinity of the trondhjemites. Locally, the trondhjemites in the oxide-bearing gabbros are deformed with both the enclosing oxide-bearing and adjacent oxidefree gabbros by the subsolidus amphibolite facies brittleductile deformation. The trondhjemitic intrusion breccias, however, sharply crosscut the foliation associated with the ubiquitous late magmatic in the oxide-bearing gabbros (Plate 5, Fig. A). This deformation demonstrates that from Unit III on down, they formed and were locally intruded after late-magmatic ductile deformation and formation of the oxide-bearing gabbro, but prior to the subsolidus deformation.

Trondhjemite and trondhjemitic intrusion breccias, seen in the amphibolite gneiss zone in the upper $100 \mathrm{~m}$, have a strikingly different appearance than the trondhjemites in the oxide-bearing gabbros. In part this could be due to the lack of hydrothermal alteration, but it could also reflect intrusion at a different point in time, and different chemistry. Although all trondhjemites are deformed where amphibolite facies ductile deformation occurs, in some cases they are complexly ptygmatically folded with the amphibole gneiss, suggesting that intrusion occurred during deformation (Plate 5, Fig. B) or that they may even have formed due to local anatexis, perhaps due to heating by a nearby intrusive body. Though some are unmistakably igneous, trondhjemitic veins in Units I and II are locally deformed by the late subsolidus deformation, with intrusive contacts generally transposed into or subparallel to the foliation, remaking these into felsic layers difficult to distinguish from leucocratic plagioclase bands and schlieren of recrystallized primary plagioclase in the gabbro gneisses. The possibility that there were several episodes of trondhjemite intrusion is also supported by the strikingly shallower dip of the trondhjemite and related felsic veins measured from the base of Unit II and through Unit III from the remaining trondhjemites in the hole.

Sorting trondhjemite veins by the rock type in which they occur, $47 \%$ are found in oxide-bearing gabbros. As oxidebearing gabbros amount to only $20 \%$ of the section, a disproportionate amount of trondhjemite would appear to be associated with the oxide-bearing gabbro. This might be taken as evidence that the trondhjemites formed in-situ by fractional crystallization of intercumulus melt, and that they are most abundant in the oxide bearing gabbros because the late melt was concentrated there during late magmatic deformation. However, one should note that unambiguous trondhjemites are concentrated in high- and low-temperature ductily deformed gabbros. Sorting the felsic veins by the lithology in which they occur, $92 \%$ are in oxide-free olivine gabbro. Comparing the deformation $\log$ to the downhole log for felsic veins in Figure 25, one can also seen that the felsic veins largely occur in undeformed sections of the olivine gabbro. As discussed earlier, the felsic veins have ambiguous paragenesis and often appear to have been originally igneous. If we assume (as discussed below) that hydrothermal alteration after ductile deformation was largely limited to undeformed sections of the core, then the felsic veins may be nearly all altered trondhjemite. Lumping them with the trondhjemites, there is no statistically significant difference in distribution between oxide-free and oxide-bearing gabbros, with $24 \%$ of all felsic and trondhjemitic veins situated in the oxide-bearing gabbro. This argues that most of the felsic veins were originally trondhjemite prior to alteration. 


\section{Amphibole Veins}

The most abundant vein assemblage in Hole 735B is nearly monomineralic amphibole veins $(0.75 \%$ of the total). These veins are generally less than a few millimeters thick, often quite straight, and tend to be orthogonal to the foliation. Most common are long thin hairline cracks, though veins as much as $0.5 \mathrm{~cm}$ thick do occur. Also abundant are complex, randomly oriented, amphibole-filled, hairline crack networks, which in some cases have been penetratively deformed. The clear relationship between these and the subsolidus ductile deformation can be clearly seen by comparing the deformation and amphibole vein logs in Figure 24. Amphibole veins are most abundant in Units I and II where the most extensive subsolidus deformation has occurred, and are important in Unit VI where significant subsolidus ductile deformation reoccurs. In contrast, amphibole veins are nearly absent between 200 and $400 \mathrm{~m}$ in Units IV, V, and Subunit VIA, where the only ductile deformation was largely late magmatic, and little subsolidus deformation has occurred. It is important to note that by far the greatest volume of secondary amphibole in the core is not in the veins, but is present as replacement of the igneous mineralogy and is a pervasive alteration phase throughout the core. Stakes et al. (this volume), based on shipboard thin section descriptions (Init. Repts., Vol. 118), estimate that there has been approximately $25 \%$ replacement of the primary mafic minerals in the gabbro. This "matrix" amphibole is seen throughout the core, including much of the undeformed gabbro. Overall, secondary matrix amphibole is least abundant in the lower half of the core and highest in the upper $50 \mathrm{~m}$, where the most intense subsolidus brittle-ductile deformation has occurred, correlating well with the overall abundance of veins and the deformation log.

Amphibole veins, orthogonal to the foliation, both crosscut and are crosscut by the gneissic and mylonitic foliation (Plates 9 and 10), indicating that related brittle and ductile deformation occurred penecontemporaneously. In braided shear zones, different shear planes can be operative at different times. Where one shear zone becomes inactive (or locked) as a result of cross-faulting on another shear plane (e.g., Fig. $30 \mathrm{C})$, the deformed gabbro in it will reasonably exhibit brittle behavior and crack formation, just as adjacent unsheared gabbro does, due to unrelieved tensional forces on it. The forces causing this are the same as those causing cracking and boudinage of a resistant layer in ductily deformed shales. In the intense deformation zone in the upper $40 \mathrm{~m}$, amphibole veins are generally crosscut by gneissic and mylonitic shear zones, whereas deeper down the reverse is true. Thus, in the upper $40 \mathrm{~m}$, many early amphibole veins have been transposed into the foliation plane, where they are schliered into the matrix, accounting for the somewhat lower than expected abundance of veins there, which is no greater than in the less deformed gabbro immediately below.

The complete range of vein assemblages associated with the subsolidus amphibolite facies ductile deformation includes plagioclase-amphibole veins and plagioclase-pyroxene veins; the latter essentially identical to the original igneous mineralogy. Mineral chemistry shows that the vein amphibole, and that replacing igneous pyroxene in the gabbro, formed over a temperature range of $500^{\circ}$ to $700^{\circ} \mathrm{C}$, while the anhydrous assemblages represent crystallization up into the granulite facies (Stakes et al., this volume). The hydrous and anhydrous assemblages reasonably reflect varying water rock ratios during ductile deformation and vein formation (Stakes et al., this volume) and reflect an early onset of ductile deformation at temperatures close to the solidus and continuing down to the middle amphibolite facies. This would appear to be typical of deformed gabbros elsewhere in the oceans as well, and similar relationships are reported for both North Atlantic and Gorringe Bank gabbro gneisses (Helmstaedt and Allen, 1977; Mével, 1987, 1988).

The distribution of secondary amphibole in Hole 735B clearly demonstrates that fluid permeability, flow, and reaction rates are greatly enhanced by the combination of brittleductile deformation and syntectonic recrystallization occurring in these shear zones. This is also the case in many other metamorphic environments on land (Beach, 1976; McCaig, 1984; Kerrich et al., 1984; Rutter and Brodie, 1985; Kerrich, 1986; Brodie and Rutter, 1987; Burkhard and Kerrich, 1988) and has been postulated for gneissic amphibolites in the oceans as well (Helmstaedt and Allan, 1976; Vanko and Batiza, 1982; Honnorez et al., 1984; Ito and Anderson, 1983; Mævel, 1987, 1988). Disruption of the oxygen isotope profile, associated with hydrothermal alteration, reported by Stakes et al. (this volume) in the upper $40 \mathrm{~m}$ is due to a relatively unaltered fine-grained diabasic dike, which is weakly foliated and lies in the foliation plane. As discussed earlier, this horizon was misidentified in the original core descriptions as hydrothermally altered mylonitic gabbro.

\section{Felsic and Related Veins}

Felsic veins and related diopside, plagioclase, plagioclasediopside, and plagioclase-amphibole compound veins make up a little more than one-third of the total vein assemblage in the core. This group of veins is largely concentrated in the oxide-free and relatively undeformed olivine gabbro below the Unit IV/Unit V contact, but also occur in other relatively undeformed sections of the core. In particular diopsidebearing veins are concentrated in Unit V. This latter assemblage is similar to that reported by Bird et al. (1986) in the Skaergaard Intrusion in East Greenland, which formed during the subsolidus cooling and deformation of the intrusion. Bird et al. (1986) reported that diopside occurring with aluminous diopside in early veins in the Skaergaard Intrusion equilibrated at minimum temperatures of $500^{\circ}$ to $750^{\circ} \mathrm{C}$ and that hydrothermal calcic pyroxenes equilibrated to $<500^{\circ} \mathrm{C}$. The Skaergaard veins are thought to have been the result of large-scale fluid circulation and water/rock reactions occurring at static subsolidus conditions. This flow is required to explain the oxygen isotopic composition of what often at first sight appear to be relatively unaltered rocks in the intrusion (Norton and Taylor, 1979).

There are numerous felsic, trondhjemitic-appearing veins, which are of problematic origin. They typically contain lowtemperature minerals, including epidote, sphene, and chlorite. Some of the felsic veins are unambiguously hydrothermal, such as pure plagioclase veins, but many are morphologically similar to more clearly igneous trondhjemites and may well be deuterically, or post-intrusion, hydrothermally altered intrusives (see also Stakes et al., this volume). Felsic veins are most abundant in those sections of the core that do not exhibit extensive ductile deformation. Lower-temperature greenschist minerals occur as late alteration phases in these felsic veins, but generally not in the trondhjemites in the deformed gabbros. We think that trondhjemite was intruded throughout the core, but as hydrothermal alteration below middle amphibolite facies was largely limited to the undeformed sections of the core, the trondhjemites there were preferentially altered to form felsic veins. Presumably, initial intrusion of the late-magmatic trondhjemites provided a marked lithologic contrast and zones of weakness where cracking and alteration of the original trondhjemite and further precipitation of hydrothermal minerals occurred.

Zones containing epidote, chlorite, and actinolite are present sporadically from Core 18 down to the upper part of Unit 
VI (Stakes et al., this volume). The total amount of greenschist facies alteration is volumetrically insignificant (lumped with "other"' in Fig. 31), and greenschist facies minerals occur in abundance only in the hydrothermal breccias low in the core (Stakes et al., this volume). Zeolite facies alteration is indicated by analcite prehnite or thomsonite, and is present in veins from Core 18 downward. This phase of alteration is locally pronounced in a number of the hydrothermal breccias. A detailed description of the various assemblages, their mineralogy, and the isotopic variability of the core can be found in Stakes et al. (this volume).

Locally in the core, a number of zones where pinkish mixed smectite-carbonate veins occur (Fig.31) evidently reflect late fracture and seawater circulation. We do not have enough of these veins to present statistically significant data about these dips, but where they do occur, they may have formed on late conjugate joints.

\section{Late Subvertical Fractures}

The last brittle deformation event was the formation of a suite of subvertical irregular clay lined fractures, often extending $1 \mathrm{~m}$ or more down through the core. These fractures differ from all the other alteration veins in that they generally have highly irregular walls, breaking around mineral grains rather than through them. This is unlike the smooth, straight walls that characterize the greenschist facies and higher-temperature veins, where cracks have propagated through the rock without much interference from individual grain boundaries. The orientation of these veins is significantly different than for the higher-temperature veins, with a mean dip close to $70^{\circ}$, whereas the amphibole veins have a less steep dip, around $59^{\circ}$ (Fig. 24). Because the chances of hitting a vein in a vertical drill hole are statistically greatly reduced as the dip approaches $90^{\circ}$ (vertical), and yet the distribution of the irregular smectite lined cracks shown in Figure 24 is greatly skewed towards $90^{\circ}$, the majority of these cracks are probably oriented vertically. These cracks were likely initiated due to cracking along grain boundaries that accompanied simple unloading and release of stored elastic thermal strain, perhaps due to erosion of the massif to sea level after uplift. Interestingly, these cracks are not distributed uniformly down the hole, but are absent from the more gneissic intervals and are concentrated in areas where amphibole veins are scarce and the rock is relatively undeformed and coarsely crystalline.

\section{IN-SITU STRESS STATE AND SEAWATER CIRCULATION}

The high state of internal stress in the Hole 735B gabbros is dramatically demonstrated by the spontaneous bending of sections of the core when cut (Plate 8). In the case illustrated, the rock is a Unit IV oxide olivine gabbro with a well-developed, late-magmatic foliation. On close inspection, the acicular minerals are weakly to strongly lineated in the foliation plane, dipping $18^{\circ}$ from horizontal. The spontaneous bending of the core during sawing jammed the saw blade and required the technician to saw backward out of the sample. Thus, the kerf (material removed by sawing) is nearly twice the normal thickness at the end of the clothespin structure, where the two halves of the core have bent together. This high in-situ stress state is thought to result from unrelieved stored elastic thermal strain produced by cooling under relatively static conditions from the solidus to ambient temperature. The bending observed during cutting, not seen in more isotropic gabbros, likely reflects the strong preferred mineral orientation that gives the rock a strong physical anisotropy. The lamination was produced at relatively high temperatures due to late-magmatic deformation that accompanied impregnation of the rock by late intercumulus melt. Subsequent cooling from the solidus to ambient temperature then created a deviatoric internal stress state due to the preferred mineral orientation present in the rock: reflecting the dependence of the thermal expansion coefficient with crystallographic orientation.

Such a deviatoric internal stress should not occur in isotropic undeformed gabbros (where minerals are oriented more or less randomly), as it requires a nonuniform stored elastic strain. Isotropic gabbros, however, should have similar or greater stored net elastic thermal strain, unless it was relieved by recrystallization or cataclasis accompanying brittle-ductile deformation, or by spontaneous cracking during cooling. In so far as simple unloading and decompaction of core drilled from $247 \mathrm{mbsf}$ is able or unable to account for the spontaneous deformation seen in the oxide gabbro, Plate 8 can be taken as direct evidence that a significant component of the elastic thermal strain can survive down to room temperature in the deep ocean crust: even surviving the dramatic tectonic event that produced the unroofing of the complex and emplacement to sea level.

The internal stress state of oceanic gabbros is critical to understanding the circulation of seawater into the ocean crust. Lister (1974) introduced the concept of a cracking front in hot rock as the principal mechanism by which seawater penetrates the ocean crust: the cracking front is thought to separate the convective regime, where cooling occurs largely by the circulation of seawater in cracked porous rock from the conductive boundary layer below it. Rock in the boundary layer beneath the cracking front cools, shrinks and builds up horizontal tensile stress as resistance to creep rises. Cracking occurs when the tensile stress slightly exceeds the internal cohesive strength of the rock and the overburden pressure and results in the stable downward propagation of a polygonal pattern of subvertical cracks. Further cooling shrinkage opens these cracks to the percolation of water so that the effective bulk permeability is a strong function of both crack spacing and temperature.

The vertically oriented crack network described by Bird et al. (1986) for high-temperature hydrothermal veins in the Skaergaard Intrusion may be an excellent example of the process envisaged by Lister (1974). Bird et al. (1986) reported that the fractures along which the veins formed are expressions of simple brittle deformation and mineralization associated with the subsolidus cooling. Unlike the veins reported on here, the predominant orientation of veins in the Skaergaard Intrusion is vertical, reflecting the relatively simple geologic history and relatively static conditions under which it cooled, where the principal stress was oriented horizontally and was equal to the lithostatic stress.

The Skaergaard fracture network has a vein density and mineralogy similar to the 'static' alteration assemblage drilled in Hole 735B. In one sense, however, the vein assemblage in the less deformed portions of Hole $735 \mathrm{~B}$ is very different from the Skaergaard assemblage, while their orientation shows considerable scatter, they are predominantly oriented at $60^{\circ}$, rather than vertically (Fig. 24). Clearly, the Hole 735B assemblage did not develop under a simple lithostatic stress field. The Hole 735B stress field was rotated with respect to vertical, probably reflecting rotation in the vicinity of the brittle-ductile fault zones. Simple block rotation of an originally vertical vein set, however, cannot be entirely ruled out. This latter explanation, however, requires that the orthogonal gneissic foliations were originally horizontal, and produced by pure rather than simple shear in the necking lithosphere beneath the ocean ridge-which seems unlikely.

Little difference exists between the orientation of the amphibole veins in the brittle-ductile deformation zones and those regions exhibiting little macroscopic deformation. In 
both cases, the veins are predominantly situated orthogonal to the gneissic foliation. Obviously, this is because the imposed stress field during brittle-ductile deformation existed throughout the section, not only within the shear zones, where mechanical failure and accompanying cataclasis and recrystallization occurred. The inclined orientation of the lower amphibolite and greenschist facies static vein assemblages in the relatively undeformed sections of the core, however, we attribute to the inherited effects of compaction and stored elastic mechanical strain produced by the ductile deformation throughout the Hole 735 section.

Another difference between the Skaergaard alteration and that at Hole 735B is the pervasive amphibolite facies matrix alteration. The Skaergaard Intrusion is reportedly free of such extensive mineralization, with secondary matrix amphibole in the intrusion relatively scarce. In contrast, approximately one-quarter of the matrix pyroxene in the Hole 735B gabbros has been altered to amphibole and other secondary phases. This suggests that there was more circulation of seawater into the gabbro than is normally the case for the simple static cooling. This would likely be the result of the extra component of tensile stress created by lithospheric necking that drove brittle-ductile deformation and formation of the brittle-ductile shear zones and should have greatly enhanced cracking and hydrothermal circulation during cooling.

Interestingly, therefore, the distribution of veins is not uniform through the Hole 735B section (Fig. 25). Whereas amphibole veins predominate in the sections where brittle-ductile deformation has been most extensive, they are virtually absent in large sections of the core, where little or no subsolidus brittleductile deformation occurred. In contrast, later hydrothermal veins, plagioclase-diopside veins, and lower temperature greenschist and zeolite facies alteration are nearly absent in the deformed rocks. It may be that alteration stopped in the amphibolite facies in the deformed zones, as has been previously noted for other oceanic gabbro amphibolite gneisses; however, in Hole $735 \mathrm{~B}$, we find that it continued down to low temperatures in the undeformed rock and followed a new pattern similar to that of the Skaergaard Intrusion.

The explanation for this is that the stored elastic strain in the gneisses and mylonites available for cracking was far less than in the undeformed gabbros. While it was occurring, the brittle-ductile fault zones were also the loci of extensive grain boundary sliding, tensile cracking, cataclasis, and granulation-all of which created enhanced local permeability. As long as the deformation was an ongoing process, these deformation zones were the loci of enhanced fluid flow. Hence, the total alteration, as evidenced by the amphibole percentage reported in the shipboard thin section descriptions, is the highest in the deformed regions. Once this deformation stopped, however, these zones immediately became the most impermeable in the entire Hole 735B section.

Because elastic strain is continuously created as the rock cools, the net elastic strain available for cracking is equal to the thermal expansion coefficient times the cooling interval, less the relieved thermal strain. Thermal and mechanical strain can be relieved by cracking, cataclasis, or by recrystallization. The most pervasive alteration process in the deformed zones is actually syntectonic recrystallization, whereby intracrystalline deformation and strain is relieved by dislocation climb, the formation of new subgrain boundaries to form neoblasts of unstrained material, and grain boundary migration. This is an ongoing process during and at the end of high-temperature deformation which will continually relieve accumulated elastic strain within the rock. These deformed gabbros consist of augen or porphyroclasts of cracked and resistant pyroxene in a matrix of recrystallized plagioclase, olivine and pyroxene. Thus, the internal stress-state of the deformed gabbros has been reset by recrystallization to the cessation of the brittle-ductile deformation at around $575^{\circ}$ to $600^{\circ} \mathrm{C}$. The stored internal elastic strain, and therefore the stress available for cracking in the undeformed rocks, is far greater: equal to that stored from their solidus temperature (about $1100^{\circ} \mathrm{C}$ ) down to the cracking temperature. Thus, cracking, circulation of seawater, and vein formation continued without a break in the undeformed sections of the Hole $735 \mathrm{~B}$ core after brittle-ductile deformation; albeit at a reduced permeability, following the Skaergaard model down into the zeolite facies. The formation of the diopside-plagioclase veins, and the secondary alteration of the trondhjemites and formation of felsic veins in the undeformed gabbros, formation of hydrothermal breccias all continued because there was plenty of internal strain. Thus, as cooling proceeded and added to the existing thermal strain, cracking proceeded apace, whereas in the ductily deformed rocks the renewed stress buildup due strain produced by cooling through the lower amphibolite and greenschist facies was generally insufficient to overcome the internal strength of the rocks and the confining pressure to produce cracks: no cracks-no permeability-no seawater circulation-no veins.

The temperature of formation of the plagioclase-diopside veins is estimated to be about $510^{\circ} \mathrm{C}$ (Vanko and Stakes, 1986), slightly lower than the cutoff for the brittle-ductile deformation. These veins also do not appear to have been cut by the subsolidus brittle-ductile deformation. Fluid inclusion studies show that they formed under relatively low temperatures, but high water/rock ratios compared to comparatively high temperatures and lower water/rock ratios implied from fluid inclusion studies of the amphibole and amphibole veins in the deformed gabbros. This is consistent with the large-scale ongoing fluid circulation we propose for the undeformed gabbros. Similarly, at the end of brittle-ductile deformation, any seawater in the brittle-ductile deformation zones should be effectively trapped and totally consumed, producing the high salinities and low water/rock ratios calculated from the fluid inclusions there (Vanko and Stakes, this volume).

The replacement of amphibole by diopside and diopsideplagioclase as the principal vein assemblage in the undeformed gabbros can be attributed to the differences in fluid flow and internal stress states of the deformed and undeformed gabbros. Bird et al. (1988) showed that the mineral assemblage that precipitates during cooling of a layered intrusion under static conditions is highly dependent on fluid composition and reaction progress. Where the $\mathrm{Ca} / \mathrm{Mg}$ ratio of the fluid is low, amphibole will be the principal phase to precipitate; where it is high, diopside will precipitate. Initially, the fluids in the Skaergaard Intrusion had a fairly low $\mathrm{Ca} / \mathrm{Mg}$ ratio and precipitated amphibole. As the reaction proceeded, however, precipitation of amphibole, which has five moles of magnesium for every mole of calcium, rapidly changes the solution chemistry. Thus, due to local precipitation of matrix amphibole in the country rock, by the time the fluids escape into the vein network, diopside, not amphibole becomes the stable precipitating phase. At the lowered permeabilities (due to the decline in tensile stress at the end of brittle-ductile deformation) under which the static alteration of the Hole $735 \mathrm{~B}$ gabbros proceeded, these conditions were reproduced. In addition, alteration of plagioclase to more sodic compositions at lower temperatures during the static alteration also would raise the $\mathrm{Ca} / \mathrm{Mg}$ ratio of the fluids, further promoting diopside precipitation (Vanko, pers. comm., 1989). During the enhanced fluid flow and higher temperatures present throughout the Hole 735B section during the brittle-ductile deformation, reaction progress should have been less important as the 
fluid composition should have been continuously renewed and the composition of the secondary plagioclase should be more calcic, reducing the rate at which $\mathrm{Ca} / \mathrm{Mg}$ increased in the fluid during reaction.

\section{DENSITY VARIATIONS AND SEISMIC REFLECTORS}

We suggest that Hole 735B was drilled into rocks representing a particular tectonic environment in the ocean crust-a zone of active faulting and brittle-ductile deformation in a semiconsolidated partially molten plutonic crust beneath the median valley. This faulting accompanied lithospheric necking and extension at the ridge axis. Ferrogabbros (the common informal name for oxide-bearing gabbros) have been commonly dredged from oceanic fracture zones, and thus the Hole 735B suite is not anomalous, but is probably representative of a fairly common phenomenon in the ocean crust. The chances of drilling such a suite then might be likened to the spacing of major ridge parallel deformation zones in the lower ocean crust.

Shown in Table 2 are the average densities for the different rock types listed in Table 1 . These were calculated by sorting the shipboard density measurements using Appendix A and then averaging the measurements by rock type. No correction was made for density affects due to alteration, and therefore the densities are not for pristine gabbro, but for the gabbros as they are currently. The average bulk density for the hole (2.984) was calculated using the proportion of each rock type drilled and differs slightly from the simple average for the lithologies (3.009).

The maximum density difference between rock types is $14.6 \%$ for troctolitic gabbro (2.906) and oxide gabbro (3.331), which is large. Both of these lithologies are minor, however, and the density difference between the two most abundant rock types, olivine gabbro (2.953) and oxide olivine gabbro (3.114) is only $5.5 \%$. A very sharp, almost razor-edged contact exists between two fairly thick intervals at $274 \mathrm{~m}$, almost coincidental with the Unit IV/Unit V boundary, where a 50.5 $\mathrm{m}$ unit of oxide olivine gabbro overlies a $108.3 \mathrm{~m}$ thick unit of olivine gabbro. These two units physically are the two most uniform in the entire section. In addition to the density contrast, the Unit IV gabbros have a moderately well-developed, late-magmatic lamination, with an average dip of about $35^{\circ}$, where plagioclase has been locally recrystallized and generally realigned into the foliation plane, which may produce an additional physical anisotropy. It is possible, therefore, that these effects may be additive and provide sufficient contrast in physical properties to produce a seismic reflector.

Recent seismic work in the North Atlantic (McCarthy et al., 1988; NAT Study Group, 1985; White et al., 1990) located numerous low-angle dipping reflectors in the deep crust. Some of these break the surface, where noticeable inflections in the bathymetry or in the rock sediment interface occur; others lie entirely within layer 3 . One can reasonably presume that the brittle-ductile shear zones we have documented in Hole 735B are candidates for explaining many of these reflectors. Both the Unit IV/Unit V boundary, with its sharp density contrast, and the gneissic zone in the upper $100-\mathrm{m}$ of the hole, with its pronounced fabric and metamorphic anisotropy are reasonable candidates. In addition to the offset of contrasting lithologic units, ductile shear zones can be large, as in the upper $100 \mathrm{~m}$ gneissic zone in Hole 735B. Ductile shear zones, extending from the late-magmatic stage into the subsolidus amphibolite facies localize and control fluid circulation from the late-magmatic stage to amphibolite facies hydrothermal alteration. Late-magmatic impregnation, amphibolitization accompanying circulation of hydrothermal fluids, dynamic recrystallization, and reorientation of mineral grains to produce fabric anisotropies can all combine to produce pronounced physical contrast between rocks within the deformation zone and those outside it.

Swift et al. (this volume) report the results of a vertical downhole seismic experiment conducted at Hole 735B. They note reflectors in the upper $100 \mathrm{~m}$, which would correspond to the thick amphibolitized mylonite zone there; and a reflector at the base of Unit IV which would correspond to the density contrast between the massive oxide olivine gabbro of Unit IV and the massive olivine gabbro of Unit V. Thus, one might be able to estimate the abundance of rocks similar to the Hole $735 \mathrm{~B}$ oxide-bearing gabbros in the ocean crust from the number of suitable reflectors in multichannel seismic profiles.

The seismic reflectors of interest here are those that can be seen on profiles run parallel to a lithospheric spreading line, which would emphasize ridge parallel structures. Such lines typically show 4.9 reflectors per $100 \mathrm{~km}$ in the North Atlantic (J. Mutter, pers. comm., 1989). These reflectors may have a near-random spacing and may occur in bunches with spacing as little as $0.5 \mathrm{~km}$ or may occur $30 \mathrm{~km}$ apart. Apparently, the characteristic signal is that anticipated more for a band of reflecting material than a simple interface-the crisp return indicating a temporally short band width of the order of 50 to $100 \mathrm{~m}$ on the scale of a single seismic pulse width (J. Mutter, pers. comm., 1989). This suggests a structure on the order of 50 to $100 \mathrm{~m}$ thick, but no larger than about $200 \mathrm{~m}$, which is entirely consistent with the brittle-ductile deformation zones found in Hole 735B. Assuming that spacing of these seismic reflectors is that of brittle-ductile deformation zones in the lower ocean crust, it is reasonable that oxide-rich gabbros (produced by synkinematic late-magmatic differentiation) and subsolidus shear zones might be a ubiquitous, but fortuitously sampled component of the lower ocean crust.

\section{LATE INTRUSIVE ACTIVITY}

Although volumetrically minor, ubiquitous small fine- to medium-grained intrusives crosscutting the coarse-grained olivine gabbro demonstrate that upward migration of small batches of melt was an ongoing process throughout the course of its solidification (Fig. 32). These include oxide gabbronorite, microgabbro, olivine gabbro, troctolitic gabbro, and troctolite, representing products of crystallization of magmas ranging from highly evolved ferrobasalt to primitive olivine tholeiite, with compositions ranging from intrusive liquids to adcumulates produced by fractional crystallization. Despite this chemical diversity, they all have similar textures and contact relationships with the gabbro. The contacts are highly irregular and sharply sutured with individual mineral grains interlocking across them. There is scattered evidence of partially assimilated wall rock xenoliths or pegmatitic patches in the intrusives near olivine gabbro contacts. The contacts are often crosscut by or transposed into the foliation plane by both the high-temperature and late subsolidus ductile deformations, giving an erroneous impression of magmatic sedimentary layering. Locally, however, the high-temperature penetrative foliation is crosscut by microgabbro intrusives, indicating that the high-temperature deformation, and microgabbro intrusion were concurrent processes.

There is a continuous textural gradation from these clearly intrusive rocks to the patchy olivine gabbros, where one sees both pegmatitic olivine gabbro patches in olivine microgabbro and olivine microgabbro patches in coarse olivine gabbro. As discussed earlier, these patchy olivine gabbros are thought to represent late magma influx into a highly viscous crystal mush late in its solidification history. We interpret this progression of texture and intrusive contact relationships, as illustrated in Figure 33 , as due to periodic influxes of magma into a 


\section{B Carbonate Veins}

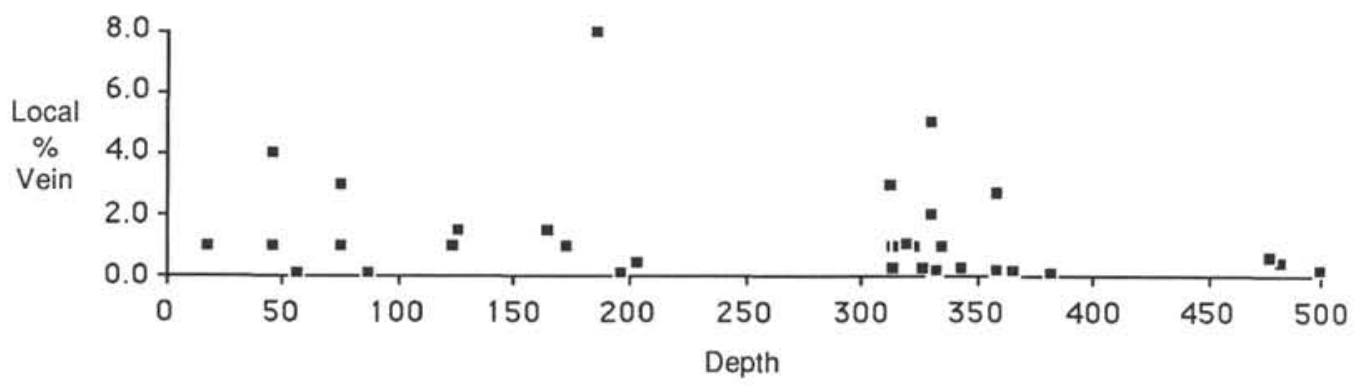

Figure 32. Location and volume percent mixed smectite-carbonate veins averaged over 1-m interval.

Intrusive Relationships In Hole 735B

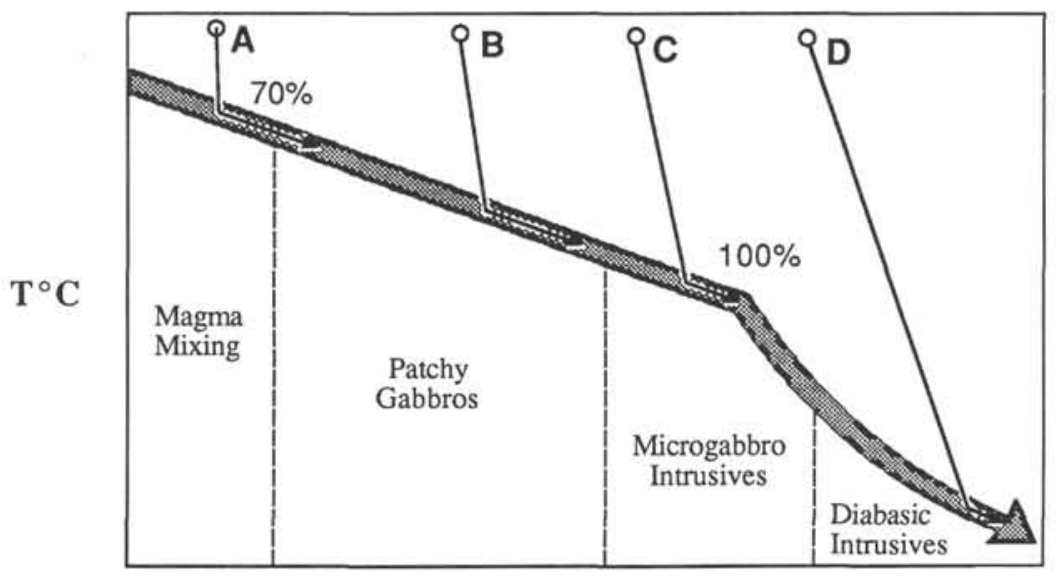

Time

Figure 33. Cartoon showing possible textural relationships in Hole 735B gabbros due to the periodic intrusion of new melt into a solidifying gabbro body. Shown are four batches of melt, each intruded at roughly the same initial temperature into a slowly crystallizing pluton. Each melt batch underwent a period of rapid cooling and nucleation of new crystals until it reached the temperature of the crystallizing pluton, at which point it solidified with the pluton. Shaded arrow shows the cooling curve for the pluton, with an inflection at the point at which it solidified, and hydrofracing and the circulation of seawater enhanced the rate of cooling (the point at which the cooling curve was dominated by advective, rather than conductive heat transfer). The boundary between different textural fields is only generally indicated, with the boundary between microgabbros and diabase intrusives taken to be the point at which undercooling was sufficient to form intrusive chilled margins (presumably at a temperature close to the solidus of the pluton).

solidifying magma chamber over the entire range of its crystallization history and post-solidification cooling.

Early in the history of the magma body, when it contained a large liquid fraction, new inputs of magma simply mixed with the preexisting melt body (path "A" in Fig. 33). The principal effect should be a change in nucleation rate and the composition and proportions of the phases crystallizing in the magma. Evidence for such magma mixing is seen in many mid-ocean ridge basalts (e.g., Rhodes et al., 1978; Dungan et al., 1978), in reverse zoning of phenocrysts, and in chemical variations falling on mixing lines. We see evidence for perturbation of the crystallization history of the Hole 735B olivine gabbros in variations in grain size and modal proportions, which we think represent local perturbations in the cooling and nucleation rate due to convective processes or new magma influxes. Examples would be changes in the modal proportion of olivine or changes in average grain size, which are the principal form of primary igneous layering seen in Unit V. Some local scale variability in mineral and bulk-rock chemistry can also be reasonably explained by magma mixing early in the solidification history of the Hole 735B gabbros.

As the gabbro cooled and the proportion of crystals increased, so did its viscosity, making magma mixing less efficient (path "B" in Fig. 33). Thus, new melt influxes into the crystallizing gabbro should mix heterogeneously with the crystal mush and would tend to produce local patches in the gabbro representing rapid nucleation due to supercooling of the new melt by the cooler surrounding crystal mush. As the 
new melt approached the temperature of the enclosing viscous magma, nucleation and crystal growth would slow to the same rate as in the mush. In a magma body that contains a moderate proportion of crystals, the numerous small nuclei and interstitial liquid of the new melt should eventually mix with the rest of the melt, leaving little trace. In a body having sufficient crystals to prevent such mixing (e.g., 60\%-70\%), where crystals are in grain-to-grain contact, the patches of numerous small nuclei would persist. Continued grain growth should coarsen these nuclei somewhat, but is unlikely to catch up with the coarser crystals in the surrounding magma body because the number of crystals growing per unit area is so great. As a result, a fine-grained quasi-intrusive patch of microgabbro is produced at the end of solidification in the coarser olivine gabbro. Because these patches undergo a proportion of their crystallization history with the crystal mush, chemical exchange between the mush and the intrusive patch will occur due to intragranular melt flow and chemical diffusion across the boundary between the two. This can eliminate or diminish initial differences in chemistry between the preexisting mush and the quasi-intrusive patches.

As solidification continued, grain-to-grain contacts should increase and weld together, producing a rigid crystal mush capable of supporting a shear stress. At this point, intrusion of new batches of melt might occur either through permeable flow or by intrusion and brittle fracture. Abundant evidence exists for the latter in the many small intrusive microgabbros that crosscut the olivine gabbro. In this case, crystallization of the intrusive bodies should initially be rapid, but then would slow considerably and eventually would follow the temperature path of the olivine gabbro massif. As long as the temperature of the wall rock exceeds the solidus temperature of the intrusive, it is unlikely that a chilled margin would develop against it. Thus, there might be little or no evidence of a chilled margin, though some fining of the average grain size of the microgabbro might occur due to enhanced initial nucleation of grains near the contact. Disaggregation and assimilation of the adjoining wall rock should be common as melt and wall rock of different composition and initial temperature, both above their solidus, interacted, producing highly irregular assimilative contacts between the two. The intrusive liquid might crystallize in its entirety locally or, as the olivine gabbro is a rigid mass, crystallization of the intruding melt might be incomplete, and it might continue to migrate through the pile for a considerable distance or migrate out of it, leaving behind an adcumulate residue. Alternatively, liquid might leak from the intrusion into the adjoining semi-solidified olivine gabbro if permeability remains, producing, for example, a hybrid olivine gabbro, such as the olivine gabbro with bright green chrome diopside patches that occurs adjacent to the troctolites in Unit VI. As the olivine gabbro cooled and reached its solidus, the amount of assimilation should rapidly drop off, and chilled margins should appear due to undercooling at the edges of the intrusion, and eventually diabase, rather than a microgabbro, should form.

\section{CONCLUSIONS}

Gabbros similar to those from Hole 735B have been widely reported on from dredge collections from oceanic transforms and rift valley walls (e.g., Melson and Thompson, 1970; Bonatti and Honnorez, 1976; Engel and Fisher, 1976; Hodges and Papike, 1976; Miyashiro and Shido, 1980; Tiezzi and Scott, 1980). In general, the close similarity of the chemical trends for these rocks. those for many layered intrusions, as well as the presence of phase and modal layering in hand specimen, led most investigators to conclude that these rocks were the remains of large subsea layered intrusions. Problems with this interpretation arose, however, as the extreme iron- enrichment of many of these gabbros seemed to require large long-lived magma chambers beneath slow-spreading ridges (e.g., Miyashiro and Shido, 1980) which have not been seen in seismic profiles specifically targeted to find them. An additional problem is presented by the rarity of ferrobasalts, the eruptive equivalents of the evolved ferrogabbros, along slowspreading ridges (e.g., Bloomer et al., 1989, Dick, 1989). The lack of ferrobasalts at the Atlantis II Fracture Zone, in particular, is notable in light of the abundance of ferrogabbros in both dredge hauls and drill hole. Our study resolves this apparent contradiction by demonstrating that large magma chambers are not required to generate extreme iron enrichment in plutonic rocks. It also explains why erupted basalts of this composition are not found, as the process occurs largely within intercumulus liquid along fault zones, where melts largely freeze without escaping to the surface.

The often abundant ferrobasalt magmatism at fast-spreading ridges, where long-lived magma chambers are believed to exist, show that Miyashiro and Shido's (1980) arguments for large slow-spreading ridge magma chambers based on ferrogabbros were internally chemically consistent. Our results demonstrate the danger, however, of interpreting the chemistry of plutonic rocks without the context of stratigraphic relationships and point out the necessity of drilling the lower ocean crust if we are to ever fully understand its evolution.

While no section like that found at Hole $735 \mathrm{~B}$ has been described in an ophiolite that we are aware of, many of its gross stratigraphic features are similar to those encountered at some ophiolites, such as the Troodos Complex of Cyprus (e.g., Moores and Vine, 1970; Xenophontas, pers. comm., 1989), which are thought to have formed at slow-spreading ridges. These features include those associated with small ephemeral intrusions, discontinuous small magma chambers, and episodic volcanism. These features are unlike those we have seen in ophiolites, such as the Oman Ophiolite, which are thought to have formed at fast-spreading ridges and contain abundant evidence for well-developed, long-lived magma chambers (e.g., Hopson et al., 1981; Smewing, 1981; Nicolas et al., 1990; Juteau et al., 1990). In neither case, however, do the deformation and alteration features documented the Hole 735B section appear to predominate.

Shown in Figure 34 is a synoptic cartoon of the evolution of layer 3 at Hole $735 \mathrm{~B}$ based on the data and discussion presented in this study. The time scale shown is arbitrary, but the time elapsed from the first section, shortly after intrusion of the basal troctolites, to the last section, at the end of brittle-ductile deformation and the initiation of block uplift, is limited by the period for seafloor spreading to move a crustal block from the zone of active magmatism to the rift mountains. The inner rift valley floor at the southern and northern ridge axes is about $8 \mathrm{~km}$ wide, measured across the axial high and the flanking axial depressions to the points at which the valley walls begin. The valley walls presumably are the location of the master faults bounding the zone of brittleductile extension and lithospheric necking. For a $1 \mathrm{~cm} / \mathrm{yr}$ half rate, the time to move a crustal block from the valley to the rift mountains might take on the order of $400,000 \mathrm{yr}$. In the cartoon we assume that formation of the section was not instantaneous, and that from emplacement of the upper gabbronorite interval to intrusion of the basal troctolitic gabbro considerable time elapsed.

The first section (Fig. 34, 0 yr) shows our best estimate of the initial primary igneous relationships in Hole 735B. The main body of the section is an olivine gabbro that has intruded upward into a medium- to coarse-grained gabbronorite, and while still in the partially molten state, has been intruded in turn from below by a troctolitic gabbro. The intrusive relationship between the olivine gabbro and the gabbronorite is 


\section{Evolution of the Layer 3 Section at Site 735B}
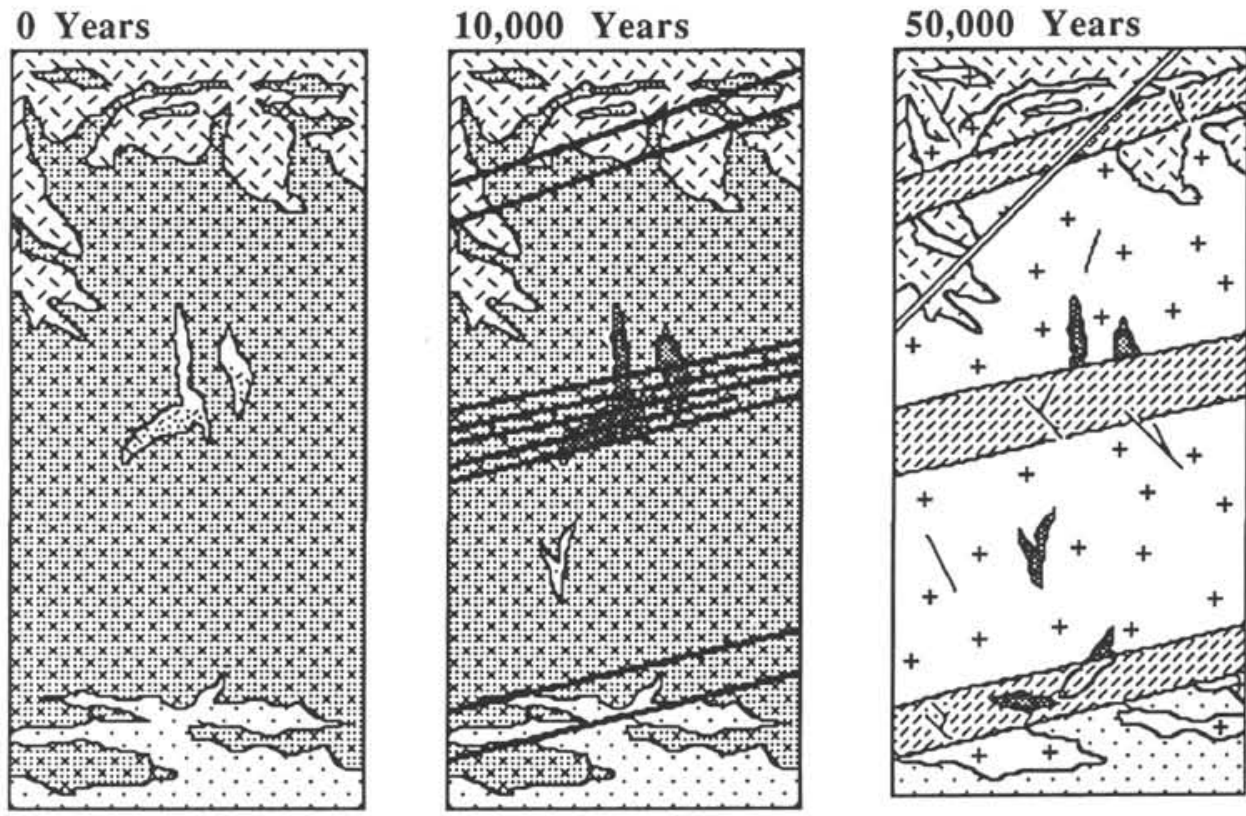

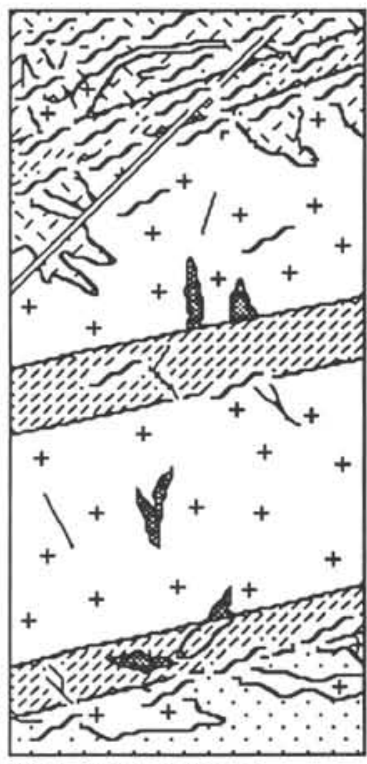

100,000 Years

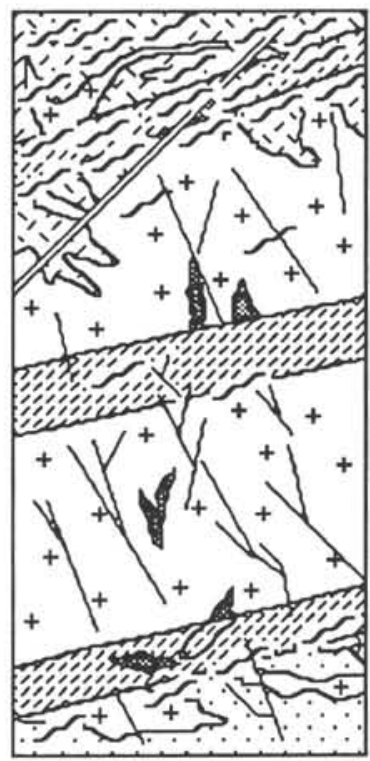

$1,000,000$ Years

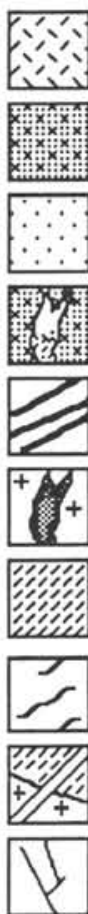

Coarse Grained

Gabbro Norite

Olivine Gabbro Rigid

Crystal Mush

Troctolitic Gabbro

Late Intrusive \&

Cumulate Crystals

Late Magmatic Ductile

Deformation Zone

Intrusive Microgabbro

Oxide-Bearing Foliated

Gabbro \& Olivine Gabbro

Sub-solidus Ductile

Deformation Zone

Diabase Dike

Felsic \& Related Veins \&

Hydrothermal Breccia

Figure 34. Sequential cross sections showing the geologic evolution of Hole 735B. Time scale is arbitrary, broadly constrained by the spreading and crustal formation rates along the Southwest Indian Ridge.

implied from the coarse grain size of the gabbronorite and its interdigitation with the olivine gabbro, which closely resembles that of the troctolitic gabbros and olivine gabbro at the base of the hole. The chemical uniformity through the $450-\mathrm{m}$ section of olivine gabbro implies that this is not part of a layered intrusion, as one would anticipate an upward cryptic chemical variation in the section, leading to formation of the gabbronorite due to fractional crystallization and differentiation of a parent magma body. That instead there is an abrupt chemical and mineralogic discontinuity between the gabbronorite and the olivine gabbro implies an intrusive relationship. The uniform composition of the olivine gabbro suggests that it is a small intrusive body, which crystallized fairly rapidly to a crystal mush. The alternative, that it is part of a layered intrusion, might require a truly enormous parent magma body to crystallize a $450-\mathrm{m}$ section of such chemical uniformity. In a layered intrusion, where cooling occurs over a long time period, nucleation of crystals is likely to be slow, 
and mineral grains are likely to grow and sink before there are sufficient numbers to create a grain-supported crystal mush. In a slow-spreading ridge environment, where magma chambers are short-lived, cooling will be fairly rapid when a batch of magma is intruded into the crust. Thus, rapid nucleation may occur from initial undercooling, and a crystal mush may form before much crystal settling can occur.

A large troctolitic intrusion below the base of the hole is implied from the intercalation of troctolite and troctolitic gabbro microintrusions with olivine gabbro at the base of the hole, and form the progressive downward coarsening of these troctolitic gabbros. The abrupt appearance of this rock type at the base of the hole, rather than it being scattered throughout the section, suggests that we stopped drilling in the middle of a transition zone similar to Subunit IB, between the gabbronorite and the olivine gabbro. Supporting this is the presence of a shallow seismic reflector about $60 \mathrm{~m}$ below the base of the hole that could easily be a such an intrusive body.

Also shown in the 0 -yr section are podiform microgabbro intrusives, still largely molten, that represent the passage of melts toward the surface through the solidifying olivine gabbro. These melts produced rock types ranging from troctolitic microgabbro, olivine microgabbro, and microgabbro, to oxide microgabbronorite due to a combination of fractional crystallization of the migrating melt and wall rock assimilation. In most cases, the microgabbros are cumulates, rather than simple intrusives, as the melt from which they crystallized has either continued migrating to higher levels or has dispersed into the still partially molten olivine gabbro.

The second section (at $10,000 \mathrm{yr}$ ) shows initiation of brittle-ductile shear due to the ongoing process of extension and lithospheric necking beneath the plate boundary once the partially molten gabbro became sufficiently rigid to support a shear stress. These shear zones do not represent simple ductile deformation as cracking, fragmentation of coarse pyroxenes and grain boundary sliding occurred on a handspecimen scale, as well as shear around locally resistant blocks. Strictly speaking, deformation is heterogeneous, rather than purely ductile: a critical difference, as perfect plastic or ductile flow would not create permeability. Intrusion from below is ongoing, as melt continues to migrate locally upward through the olivine gabbro, leaving behind small fineto medium-grained bodies of residual cumulate crystals and trapped melt. The source of the melts might be the troctolitic intrusion, where fractionation of a more primitive melt body might produce a range of magmas, either interstitially in a crystal mush, or within a small magma chamber.

Major late-magmatic brittle-ductile deformation zones tend to coincide locally with the migration paths of late intrusives as these represent zones of preferential weakness. Thus, the intrusive boundary between the troctolitic gabbro and the olivine gabbro was also a preferred locus for deformation as the troctolitic gabbro crystallized.

By $50,000 \mathrm{yr}$, the entire section had solidified, cooled into the upper amphibolite facies, and was crosscut by a few diabase dikes with chilled margins. In the intervening time, the olivine gabbro underwent "synkinematic differentiation" into two distinctive rock types. This process expelled intercumulus melt from the olivine gabbro by permeable flow, compaction and adcumulus mineral growth into shear zones penetrating partially molten regions of the gabbro. This dynamic intergranular intrusion of late intercumulus melt along deep faults replaced the gabbro in the shear zones with ferrogabbro formed by chemical exchange between migrating melt and deforming matrix, local precipitation of iron oxide, and crystallization of trapped melt at the end of deformation. Locally within these late-magmatic deformation zones, mutu- ally crosscutting relationships exist between different microgabbros and the foliated oxide-bearing gabbros as microgabbro intrusion, high-temperature deformation, and infiltration of melt along ductile shear zones overlapped. It is not unreasonable that this would be a common phenomenon beneath ocean ridges, as back tilting on large faults bounding rift valleys indicate that they curve and flatten with depth, where they root into a brittle ductile transition (e.g. Karson and Dick, 1984; Karson et al., 1987). A logical locus for this transition would be the boundary between partially molten and solidified gabbro in the deep ocean crust.

As the section solidified, trondhjemites formed by fractionation of intercumulus liquid and possibly by wall rock anatexis. Given the episodic ephemeral nature of magmatism along the Southwest Indian Ridge and the overlap of ductile deformation and igneous activity, it is reasonable that some trondhjemite originated by melting of earlier formed amphibolites into which the olivine gabbro was intruded. Trondhjemites distributed throughout the section appear to have been back-intruded from larger trondhjemite bodies during several different episodes and to have overlapped with early upper amphibolite facies alteration. This is consistent with the morphology of the veins and the bulk composition of the hole, which suggests that some late liquid escaped toward the end of the crystallization, possibly to form a nearby trondhjemite plug.

By $100,000 \mathrm{yr}$, extensive tectonically enhanced circulation of seawater, formation of brittle-ductile shear zones accompanied extension in the now rapidly cooling gabbro. In addition, a zone of detachment faulting formed around this time, unroofing the plutonic section (Fig. 35B). These various shear zones represent "ductile faults" (Ramsay and Graham, 1970) because the differential movement between the bounding walls occurred without rupture. Thus, they differ from the classic "fault," which is a special instance of a shear zone where the zone is narrow and displacement across it is discontinuous. Although numerous small microfaults occur, the primary igneous relationships can be traced through all the brittle-ductile deformation zones, and therefore the section can be viewed as thinned, but not radically disrupted by the subsolidus brittle-ductile deformation. Alteration continued throughout the deformation, with veins and crack networks forming continuously not only within the fault zones, but throughout the entire section, to a lesser degree accompanied by extensive formation of matrix amphibole. We note that we do not know whether there is more than one class of "ductile fault" in Hole 735B because all are inclined at low-angles, they might represent the root zone of a high-angle listric normal fault or a low-angle detachment fault (a special class of normal fault).

After about one million years, the Hole 735B section became part of a tectonic block that was uplifted into the Atlantis II transverse ridge. This occurred as a result of a narrowing of the zone of active extension and lithospheric necking beneath the rift valley by an inward jump of the bounding master faults (Fig. 35C). This brought an end to brittle-ductile deformation; rendering the subsolidus shear zones impermeable to further hydrothermal circulation. Somewhat slower circulation continued in the undeformed gabbro section due to continued release of stored elastic thermal strain by continuing hydrofracture following the static Skaergaard model. The orientation of the late vein sets is similar to that of the early formed veins caused by the influence of unrelieved elastic mechanical strain from the earlier ductile extension, and because inherited microcracks and veins were preferred zones of weakness for continued cracking and vein formation. 

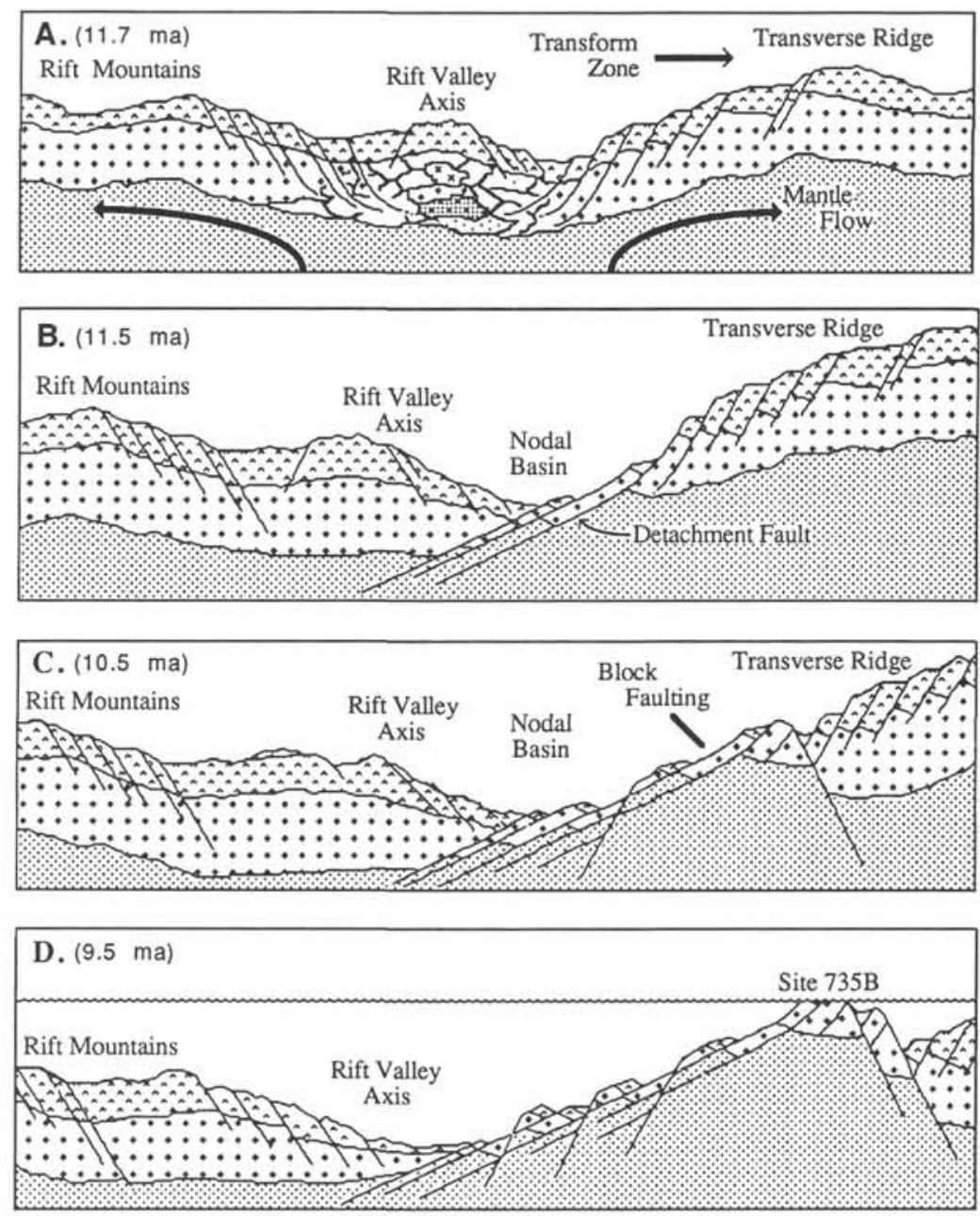

Figure 35. Temporal cross sections across the Southwest Indian Ridge rift valley drawn parallel to the spreading direction (not across the fracture zone, but parallel to it) showing the postulated tectonic evolution of the transverse ridge and Hole 735B from Dick et al. (this volume). Sequential sections are drawn at about $18 \mathrm{~km}$ from the transform fault. Crust spreading to the right passes into the transverse ridge and spreads parallel to the transform valley. Crust spreading to the left spreads into the rift mountains of the Southwest Indian Ridge parallel to the inactive extension of the Atlantis II Fracture Zone. A. Initial symmetric spreading, possibly at the end of a magmatic pulse: late-magmatic brittle-ductile faulting occurring due to lithospheric necking above and in the vicinity of whatever passes for a magma chamber at these spreading rates; hydrothermal alteration at high temperatures accompanies necking and ductile flow in subsolidus regions. B. At some point, the shallow crust is welded to the old cold lithosphere to which the ridge axis abuts, causing formation of a detachment fault and nodal basin: initiation of low-angle faulting, continued brittleductile faulting, and amphibolite facies alteration of rocks drilled at Hole 735B. C., D. Enhanced block uplift of the rift mountains at the ridge-transform corner forms a transverse ridge: initiation of the block uplift terminates extension and drastically reduces permeability and alteration of the Hole $735 \mathrm{~B}$ rocks, effectively terminating most circulation of seawater and alteration in the ductily deformed rocks. Greenschist facies retrograde alteration continues along the faults on which the block is uplifted to account for the greenschist facies alteration predominating in dredged gabbros.

The paradigm for the formation of ocean crust commonly accepted in the 1970 s following the advent of plate tectonics, was based on the simple scenario of a large, layered intrusion underlain by a residual mantle pediment, from which the magma had been squeezed. The intrusion was overlain by a zone of sheeted dikes that fed a carapace of extrusive volcanics. The sheeted dikes represented the only major expression of rifting in the magmatic process and modification of the simple layered intrusion model for the primary igneous stratigraphy of the ocean crust. This basic igneous stratigraphy was then modified by 
subsequent faulting, tectonism, and uplift into the rift mountains. This was envisaged as a steady-state process in which the magma chamber was viewed as the core of an infinite onion (Cann, 1970), generating successive layers of crystalline plutonic rock under a continuously renewed zone of sheeted dikes and pillow lavas, creating a layer-cake ocean crust.

In the 1980 s, this simple paradigm was substantially modified as a result of detailed bathymetric, petrologic, and geophysical observation and modeling. The layer-cake model, with an essentially continuous elongate magma chamber underlying the global ridge system, was replaced by a model of segmented volcanism, with discontinuous magma chambers fed intermittently from below at regularly spaced points (e.g., Francheteau and Ballard, 1983; Whitehead et al., 1984; Crane, 1985). Whereas something approaching a steady-state magma chamber is thought to exist locally beneath the fastest spreading ridges, such as the EPR, where the rate of magma supply required to form crust at $140-180 \mathrm{~mm} / \mathrm{yr}$ is large (Detrick et al., 1987), this is not likely to be the case for the large proportion of ocean ridges. At the slow end of the spectrum, represented by the Southwest Indian Ridge and Hole 735B, where crust is created at only $16 \mathrm{~mm} / \mathrm{yr}$, it is thought that magmatism is ephemeral and that a steady-state magma chamber could not possibly be maintained. In this case, formation of the ocean crust is viewed as similar to the volcanism in island arcs, with the critical difference of a vanishingly thin lithosphere and continuous extension. This results in the formation of ribbons of crust formed at episodic, but regularly spaced, magma chambers, rather than the construction of volcanic edifices as in an arc setting (Dick, 1989).

The scenario drawn here fits well with the new ocean crust paradigms. Here, we envisage layer 3 as the product of sequential crystallization of relatively small intrusive bodies, successively working their way up through the crust. It is interesting to note that the succession we see in Hole 735B is of more primitive intrusive bodies intruding less primitive: troctolitic gabbro intruding olivine gabbro, in turn intruding gabbronorite. In the simple layered intrusion model, where a large magma body evolves by fractional crystallization, the intrusive sequence is reversed-with melts tapped off the main body crosscutting more primitive earlier crystallized cumulates.

The results from Hole 735B produce a new modification of the ocean crust paradigm. We have documented the formation of a new form of primary igneous layering due to "syntectonic differentiation," due to the interaction of ductile extension and magmatism. This tectonic/magmatic process is unique to extensional tectonic settings in the same way as sheeted dike complexes. Because brittle-ductile deformation and lithospheric necking are perhaps the only truly continuous processes occurring beneath ocean ridges and should occur throughout and at all levels during solidification of magma bodies in the lower ocean crust, one can reasonably assume that the formation of impregnated meso- and orthocumulates in late-magmatic brittle-ductile shear zones should be a common process during formation of layer 3 .

At a slow-spreading ridge, with ephemeral magma chambers, the brittle-ductile transition would be likely to migrate up and down through the crust with time (even into the shallow mantle) as magmatism waxes and wanes. In contrast, at a fast-spreading ridge, such as the East Pacific Rise, where long-lived or steady-state magma chambers might exist, the brittle-ductile transition would be fixed near the roof of the magma chamber. This is strongly supported by the finding that the maximum centroid depths of large earthquakes at ocean ridges show a large systematic decrease with increasing spreading rate $-\mathrm{a}$ likely response to a shallower and more uniform brittle-ductile transition (Huang and Solomon, 1988). These earthquakes are all associated with normal faulting and are located beneath the median valley floors. Thus, the master faults bounding the zone of extension are likely to root at a fairly constant, shallow, depth, and to be much shorter-lived than at slow-spreading ridges. This is consistent with the much lower relief in the rift mountains of fast-spreading ridges compared to slower spreading ridges, as the total vertical throw on a fault should be related to its longevity and the depth to which it penetrates. Thus, synkinematic differentiation and the formation of ferrogabbros along fault zones, as well as tectonically enhanced high-temperature alteration are likely to be more important and effect broader regions of the ocean crust at slow-spreading ridges.

\section{ACKNOWLEDGMENTS}

We are particularly grateful to Captain Ed Oonk of the JOIDES Resolution, Drilling Superintendent Ken Horne, and Drilling Engineers Barry Harding, Steve Howard, and Charles Hansen: an exceptional group; few have had such fun and drilled such rock. Numerous conversations and exchange of data with James Natland, Kaz Ozawa, Dave Vanko, Dennis Bird, and Hugh Taylor were a great aid for understanding the core and for preparing this manuscript. Technical assistance and data processing were admirably done by Linda Angeloni. We thank R. L. Fisher for introducing a number of the authors to the rocks and geology of the Indian Ocean, without which none of this would have happened. Steve DeLong and one anonymous reviewer attempted to improve the manuscript, for which the authors are grateful. Jeff Fox, our editor for this study, went to truly heroic efforts on its behalf, which greatly improved an originally even more cumbersome and wieldy manuscript than the present one.

\section{REFERENCES}

Beach, A., 1976, The interrelations of fluid transport, deformation, geochemistry and heat flow in early Proterozoic shear zones in the Lewissian Complex. Royal Soc. London Phil. Trans., Ser. A, 280:569-604.

Bedard, J. H., Sparks, R.S.J., Renner, R., Cheadle, M. J., and Hallworth, M. A., 1988. Peridotite sills and measomatic gabbros in the Eastern Layered Series of the Rhum complex. J. Geol. Soc., D 145:207-224.

Bird, D. K., Rogers, R. D., and Manning, C. E., 1986. Mineralized fracture systems of the Skaergaard intrusion, East Greenland. Meddelelser om Grønland.nland Geoscience, 16:1-68.

Bird, D. K., Manning, S. and Rose, N., 1988. Hydrothermal alteration of Tertiary layered gabbros. Am. J. Sci., 288:405-457.

Bonatti, E., Honnorez, J., Kirst, P., and Radicati, F., 1975. Metagabbros from the Mid-Atlantic Ridge at $06^{\circ} \mathrm{N}$ : contact-hydrothermaldynamic metamorphism beneath the axial valley. J. Geol., 83:6178.

Bonatti, E., and Honnorez, J., 1976, Sections of the earth's crust in the equatorial Atlantic. J. Geophys. Res., 81:4104-4116.

Cann, J. R., 1970. New model for the structure of the ocean crust. Nature, 226:928-930.

Carmichael, I.S.E., 1964. The petrology of Thingmuli, a Tertiary volcano in eastern Iceland. J. Petrol., 5:435-460.

Carter, K. E., and Dworkin, S. I., in press. Channelized fluid flow through shear zones during fluid-enhanced dynamic recrystallization, Northern Apennines, Italy. Geology.

CATROUGH, 1979. Geological and geophysical investigation of the Mid-Cayman Rise Spreading Center: initial results and observations. In Talwani, M., Harrison, C. J., and Hays, D. E. (Eds.), Deep Drilling Results in the Atlantic Ocean: Ocean Crust. Am. Geophys. Union Maurice Ewing Ser., 2:66-93.

Clague, D. A., and Bunch, T. E., 1976. Formation of ferrobasalt at East Pacific midocean spreading centers. J. Geophys. Res., $81: 4247-4256$. 
Cooper, R. F., and Kohlstedt, D. L., 1986. Rheology and structure of olivine-basalt partial melts. J. Geophys. Res., 91:9315-9323.

Crane, K., 1985. The spacing of rift axis highs: dependence upon diapiric processes in the underlying asthenosphere. Earth Planet. Sci. Lett., 72:405-414.

Detrick, R. S., Buhl, P., Vera, E., Mutter, J., Orcutt, J., Madsen, J., and Brocher, T., 1987. Multichannel seismic imaging along the East Pacific Rise. Nature, 326:35-41.

Dick, H.J.B., 1977. Evidence of partial melting in the Josephine Peridotie. In Dick, H.J.B. (Ed.), Magma Genesis. Oregon Dept. Geol. Mineral. Ind. Bull., 96:59-62.

1989. Abyssal peridotites, very slow-spreading ridges and ocean ridge magmatism. In Saunders, A. D., and Norry, M. J. (Eds.), Magmatism in the Ocean Basins, Geol. Soc. Spec. Publ., 42:71-105.

Dick, H.J.B., Bryan, W. B., and Thompson, G., 1981. Low-angle faulting and steady-state emplacement of plutonic rocks at ridgetransform intersections. Eos, Trans. Am. Geophys. Union, 62:406.

Dixon, S., and Rutherford, M. J., 1979. Plagiogranites as late-stage immiscible liquids in ophiolitic and mid-ocean ridge suites: an experimental study. Earth Planet. Sci Lett., 45:45-60.

Dunyan, M. A., Rhodes, J. M., Long, P. E., Blanchard, D. P., Brannon, J. C. and Rodgers, K. V., 1978. The petrology and geochemistry of basalts from Site 396 Legs 45 and 46 of the Deep Sea Drilling Project. In Melson, W. G., Rabinowitz, P. D., Init. Repts. DSDP, 46:84-114.

Engel, C. G., and Fisher, R. L., 1975. Granitic to ultramafic rock complexes of the Indian Ocean Ridge system, western Indian Ocean. Geol. Soc. Am. Bull., 96:1553-1578.

Fisher, R. L., Dick, H.J.B., Natland, J. H., and Meyer, P. S., 1986. Mafic/ultramafic suites of the slowly spreading Southwest Indian Ridge: Protea exploration of the Antarctic Plate Boundary, $24^{\circ} \mathrm{E}-$ $47^{\circ}$ E. Ophioliti, 11:147-178.

Fox, P. J., and Stroup, J. B., 1981. The plutonic foundation of the oceanic crust.In Emiliani, C. (Ed.), The Sea, Vol. 7: New York (Wiley), 119-218.

Francheteau, J., and Ballard, R. D., 1983. The East Pacific Rise near $21^{\circ} \mathrm{N}, 13^{\circ} \mathrm{N}$, and $20^{\circ} \mathrm{S}$; inferences for along strike variability of axial processes. Earth Planet. Sci. Lett., 64:93-116.

Francheteau, J., Choukroune, P., Hekinian, R., Le Pichon, X., and Needham, H. D., 1976. Oceanic fractures do not provide deep sections in the crust. Can. J. Earth Sci., 13:1223-1235.

Gerlach, D. C., 1981. An investigation of dioritic to trondhjemitic rocks from mid-oceanic ridges and fracture zones. [Unpubl. manuscript]. MIT Graduate Education Program, Dept. Earth Atm. and Planet. Sci. M.I.T., Cambridge, MA.

Grove, T. L., Baker, M. B., and Kinzler, R. J., 1984. Coupled $\mathrm{CaAl}-\mathrm{NaSi}$ diffusion in plagioclase feldspar: experiments and applications to cooling rate speedometry. Geochim. Cosmochim. Acta, 48:2113-2121.

Hekinian, R., and Thompson, G., 1976. Comparative geochemistry of volcanics and rift valleys, transform faults and aseismic ridges. Contrib. Mineral. Petrol., 57:145-162.

Helmstaedt, H., and Allen, J. M., 1977. Metagabbronorites from DSDP Hole 334, an example of high temperature deformation and recrystallization near the Mid-Atlantic Ridge. Can. J. Earth Sci., 14:886-898.

Herz, N., 1976. Titanium deposits in anorthosite massifs. In Force, E. R. (Ed.), Geology and Resources of Titanium. Geol. Surv. Prof. Pap., 959:D1-D6.

Hodges, F. N., and Papike, J. J., 1976. Magmatic cumulates from oceanic layer 3. J. Geophys. Res., 81:4135-4151.

Honnorez, J., Mével, C., and Montigny, R., 1984. Geotectonic significance of gneissic amphibolites from the Vema Fracture Zone, Equatorial Mid-Atlantic Ridge. J. Geophys Res., 89:11379-11400.

Hopson, C. A., Coleman, R. G., Gregory, R. T., Pallister, J. S., and Bailey, E. H., 1981. Geologic section through the Samail ophiolite and associated rocks along a Muscat-Ibra transect, southeastern Oman Mountains. J. Geophys. Res., 86:2527-2544.

Huang, P. Y., and Solomon, S. C., 1988. Centroid depths of midocean ridge earthquakes: dependence on spreading rate. J. Geophys. Res., 93:13445-13477.
Hunter, R. H., and Sparks, R.S.J., 1987. The differentiation of the Skaergaard Intrusion. Contrib. Mineral. Petrol., 95:451-461.

Ito, E., and Anderson, A. T., Jr., 1983. Submarine metamorphism of gabbros from the Mid-Cayman Rise: Petrographic and mineralogic constraints on hydrothermal processes at slow-spreading ridges. Contrib. Mineral. Petrol., 82:371-388.

Juteau, T., Beurrier, M., and Nehlig, P., 1990. The ophiolited of the Central Oman Mountains; interaction between magmatic, tectonic, and hydrothermal processes in a crustal section. Trans. Symp. Symp. Ophiolite Genesis and Evolution of Oceanic Lithosphere:Muscat, Sultanate of Oman (Ministry of Petroleum and Minerals).

Karson, J. A., and Dick, H.J.B., 1983. Tectonics of ridge-transform intersections at the Kane Fracture Zone. Mar. Geophys. Res., 6:51-98.

1984. Deformed and metamorphosed oceanic crust on the Mid-Atlantic Ridge. Ophioliti, 9:279-302.

Karson, J. A., Thompson, G., Humphris, S. E., Edmond, J. N., Bryan, W. B., Brown, J. R., Winters, A. T., Pockalny, R. A., Casey, J. F., Campbell, A. C., Klinkhammer, G., Palmer, M. R., Kinsler, R. J., and Sulanowska, M. M., 1987. Along-axis variations in seafloor spreading in the MARK area. Nature, 328:681685 .

Kerrich, R., 1986. Fluid infiltration into fault zones: Chemical, isotopic, and mechanical effects. Pure and Applied Geophys., 124:225-268.

Kerrich, R., LaTour, T. E., and Willmore, L., 1984. Fluid participation in deep fault zones: evidence from geological, geochemical, and ${ }^{18} \mathrm{O} /{ }^{16} \mathrm{O}$ relations. J. Geophys. Res., 89:4331-4343.

Langmuir, C. E., Bender, M., and Batiza, R., 1986. Petrological and tectonic segmentation of the East Pacific Rise, $5^{\circ} 30^{\prime}-14^{\circ} 30^{\prime} \mathrm{N}$. Nature, 332:422-429.

le Roex, A. P., and Dick, H.J.B., 1981. Petrography and geochemistry of basaltic rocks from the Conrad fracture zone on the AmericaAntarctic Ridge. Earth Planet. Sci. Lett., 54:117-138.

le Roex, A. P., Dick, H.J.B., Erlank, A. J., Reid, A. M., Frey, F. A., and Hart, S. R., 1983. Geochemistry, mineralogy and petrogenesis of lavas erupted along the Southwest Indian Ridge between the Bouvet Triple Junction and $11^{\circ}$ East. J. Petrol., 24:267-318.

le Roex, A. P., Dick, H.J.B., Reid, A. M., Frey, F. A., Erlank, A. J., and Hart, S. R., 1985. Petrology and geochemistry of basalts from the American-Antarctic Ridge, southern ocean: implications for the westward influence of the Bouvet mantle plume. Contrib. Mineral. Petrol., 90:367-380.

le Roex, A. P., Dick, H.J.B., and Fisher, R. L., 1989. Petrology and geochemistry of MORB from $25^{\circ} \mathrm{E}$ to $46^{\circ} \mathrm{E}$ along the Southwest Indian Ridge: evidence for contrasting styles of mantle enrichment. J. Petrol., 30:947-986.

Lister , C.R.B., 1974. On the penetration of water into hot rock. Geophys. J. Royal Astron. Soc., 39:465-509.

McCaig, A. M., 1984. Fluid-rock interaction in some shear zones from the Pyrenees. J. Metamorph. Geol., 2:129-141.

McCarthy, J., Mutter, J. C., Morton, J. L., Sleep, N. H., and Thompson, G. A., 1988. Relic magma chamber structures preserved within the Mesozoic North Atlantic crust. Geol. Soc. Am. Bull., 100:1423-1436.

Malcolm, F. L., 1981. Microstructures of the Cayman Trough gabbros. J. Geol., 89:675-688.

Melson, W. G., and Thompson, G., 1970. Layered basic complex in oceanic crust, Romanche fracture, equatorial Atlantic Ocean. Science, 168:817-820.

Meyer, P. S., Dick, H.J.B., and Thompson, G., 1989. Cumulate gabbros from the Southwest Indian Ridge, $54^{\circ} \mathrm{S}-7^{\circ} 16^{\prime} \mathrm{E}$ : implications for magmatic processes at a slow spreading ridge. Contrib. Mineral. Petrol., 103:44-63.

Mével, C., 1988. Metamorphism in oceanic layer 3, Gorringe Bank, Eastern Atlantic. Contrib. Mineral. Petrol., 100:496-509.

1987. Evolution of oceanic gabbros from DSDP Leg 82: influence of the fluid phase on metamorphic crystallizations. Earth Planet. Sci. Lett., 83:67-79.

Miyashiro, A., and Shido, F., 1980. Differentiation of gabbros in the Mid-Atlantic Ridge near $24^{\circ} \mathrm{N}$. Geochem. J., 14:145-154. 
Morse, S.A., Moores, E. M., and Vine, F. J., 1971. The Troodos Massif, Cyprus and other ophiolites as oceanic crust: Evaluation and implications. Phils. Trans. Royal Soc. London, A268:443466.

Melson, W. G., Hart, S. R., and Thompson, G., 1972. St Paul's Rocks, equatorial Atlantic: petrogenesis, radiometric ages and implications on seafloor spreading. Geol. Soc. Am. Mem., 132:241-272.

Natland, J., and Melson, W. G., 1980. Compositions of basaltic glasses from the East Pacific Rise and Siqueiros Fracture Zone, near $9^{\circ}$ N. In Rosendahl, B. R., Hekinian, R., et al., Init. Repts. DSDP, 15: Washington (U.S. Govt. Printing Office), 705-723.

NAT Study Group, 1985. North Atlantic Transect: A wide aperture, two-ship Multichannel seismic investigation of the oceanic crust. J. Geophys. Res., 90:10321-10341.

Nicolas, A., Pallister, J., and Ceuleneer, G., 1990. Field excursion in the Oman ophiolite, Sumail and Wadi Tayin Massifs, southeastern Oman mountains. Excursion C Field Guide, Symp. on Ophiolite Genesis and Evolution of Oceanic Lithosphere: Muscat, Oman (Ministry of Petroleum and Minerals), UNESCO-Sultan Qaboos Univ.

Norton, D., and Taylor, H. P., 1979. Quantitative simulation of the hydrothermal systems crystallizing magmas on the basis of transport theory and oxygen isotope data: an analysis of the Skaergaard Intrusion. J. Petrol., 20:421-486.

OTTER, 1984. The geology of the Oceanographer Transform: the transform domain. Mar. Geophys. Res., 7:329-358.

Ramsay, J. G., and Graham, R. H., 1970. Strain variation in shear belts. Can. J. Earth Sci., 7:786-813.

Reid, I., and Jackson, H. R., 1981. Oceanic spreading rate and crustal thickness. Mar. Geophys. Res., 5:165-172.

Rhodes, J. M., Blanchard, D. P., Dungan, M. A., Rodgers, K. V., and Brannon, J. C., 1978. Chemistry of Leg 45 basalts. In Melson, W. G., Rabinowitz, P. D., et al., Init. Repts. DSDP, 45: Washington (U.S. Govt. Printing Office), 447-460.

Rutter, E. H., and Brodie, K. H., 1985. The permeation of water into hydrating shear zones. In Thompson, A. B. (Ed.), Metamorphic
Reactions, Kinetics, Textures and Deformation: New York (Springer-Verlag), Advances in Geochemistry, 4:242-250.

Sclater, J. G., Dick, H.J.B., Norton, I., and Woodroffe, D., 1978. Tectonic structure and petrology of the Antarctic Plate boundary near the Bouvet Triple Junction. Earth Planet. Sci. Lett., 36:393400.

Smewing, J. D., 1981. Mixing characteristics and compositional differences in mantle-derived melts beneath spreading axes: evidence from cyclically layered rocks in the ophiolite of North Oman. J. Geophys. Res., 86:2645-2661.

Stakes, D., and Vanko, D. A., 1986. Multistage hydrothermal alteration of gabbroic rocks from the failed Mathematician Ridge. Earth Planet. Sci. Lett., 79:75-92.

Tiezzi, L. J., and Scott, R. B., 1980. Crystal fractionation in a cumulate gabbro, Mid-Atlantic Ridge, $26^{\circ}$ N. J. Geophys. Res., 85:5438-5454.

Vanko, D., and Batiza, R., 1982. Gabbroic rocks from the Mathematician Ridge failed rift. Nature, 300:742-744.

Wager, L. R., and Brown, G. M., 1967. Layered Igneous Rocks: San Francisco (Freeman).

White, R. S., Detrick, R. S., Mutter, J. C., Buhl, P., Minshull, T. A., and Morris, E., 1990. New seismic images of oceanic crustal structure. Geology, 18:462-465.

Whitehead, J. A., Jr, Dick, H.J.B., and Schouten, H., 1984. A mechanism for magmatic accretion under spreading centers. $\mathrm{Na}$ ture, 312:146-148.

Yund, R. A., and Snow, E., 1989. Effects of hydrogen fugacity and confining pressure on the interdiffusion rate of $\mathrm{NaSi}-\mathrm{CaAl}$ in plagioclase. J. Geophys. Res., 94:10662-10668.

Date of initial receipt: 18 December 1989

Date of acceptance: 4 September 1990

Ms 118B-128 


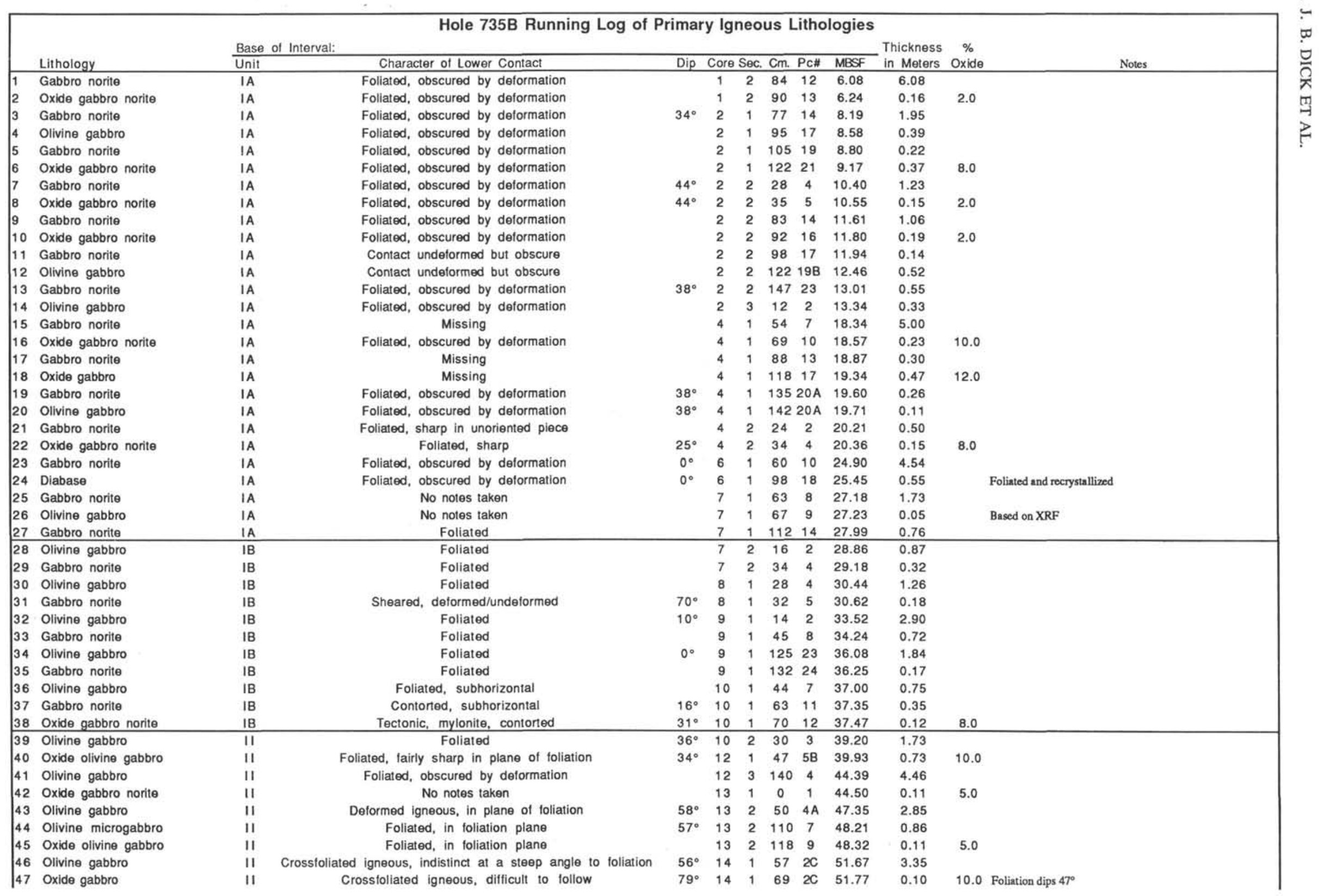


Appendix A (continued).

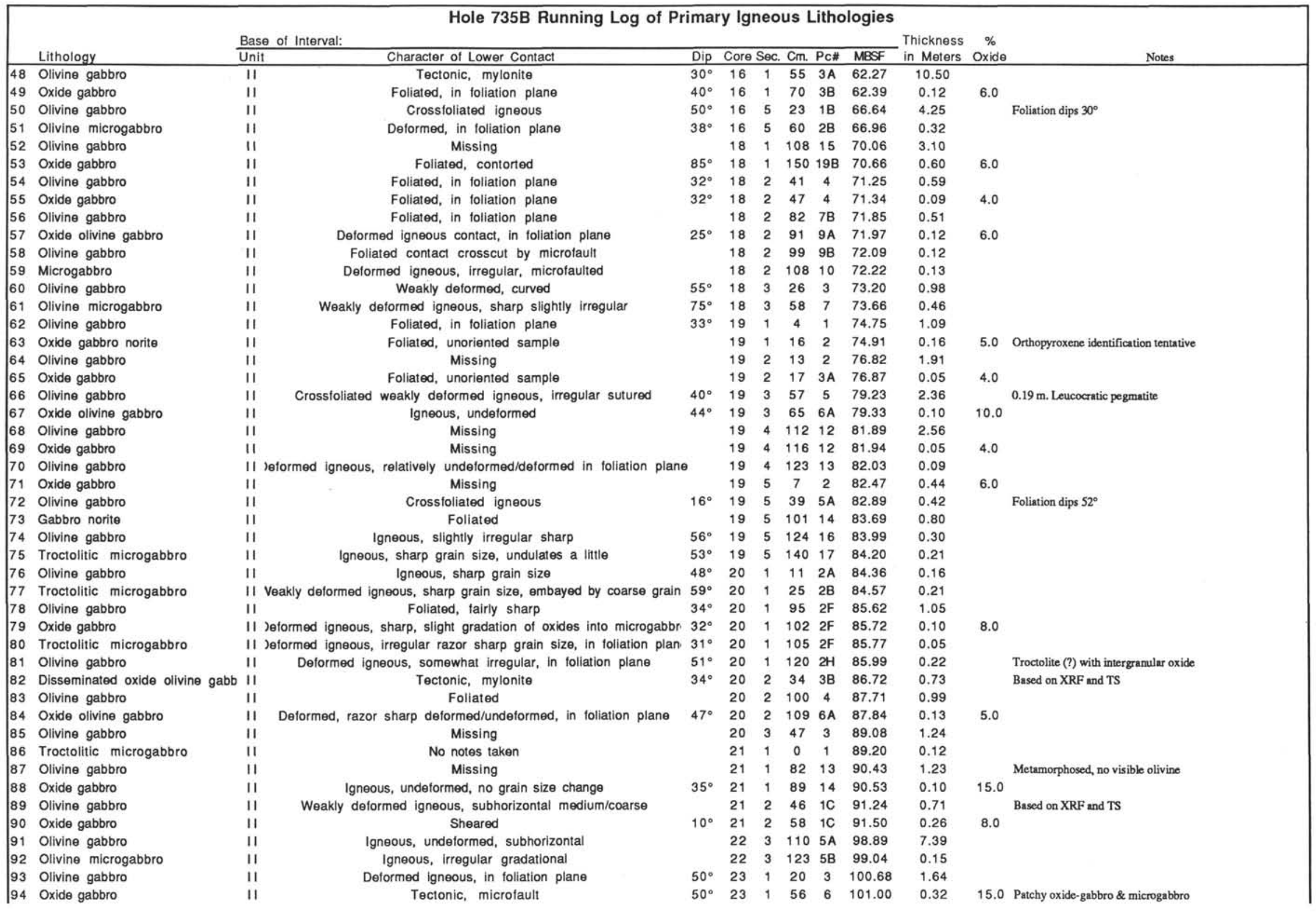




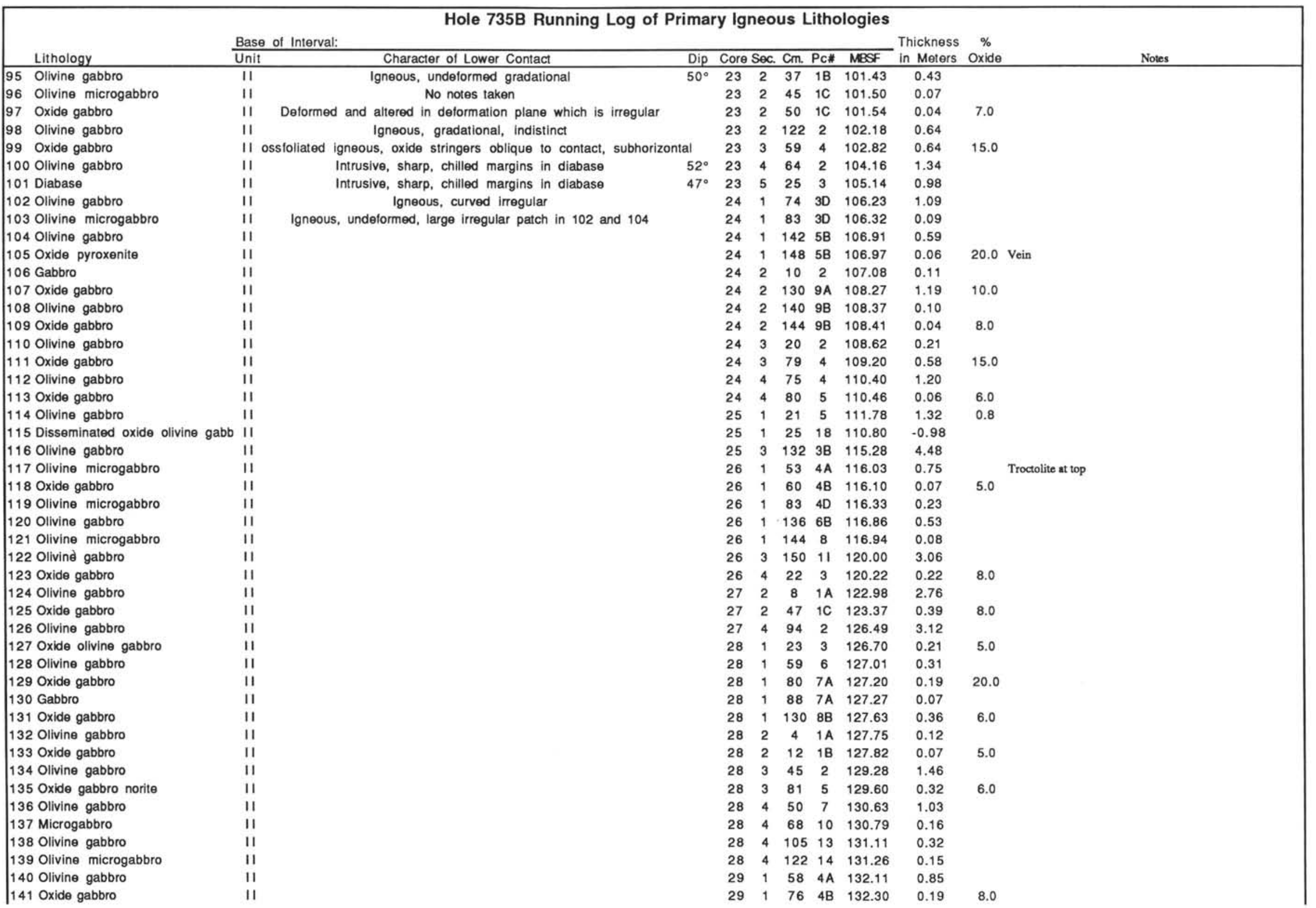


Appendix A (continued).

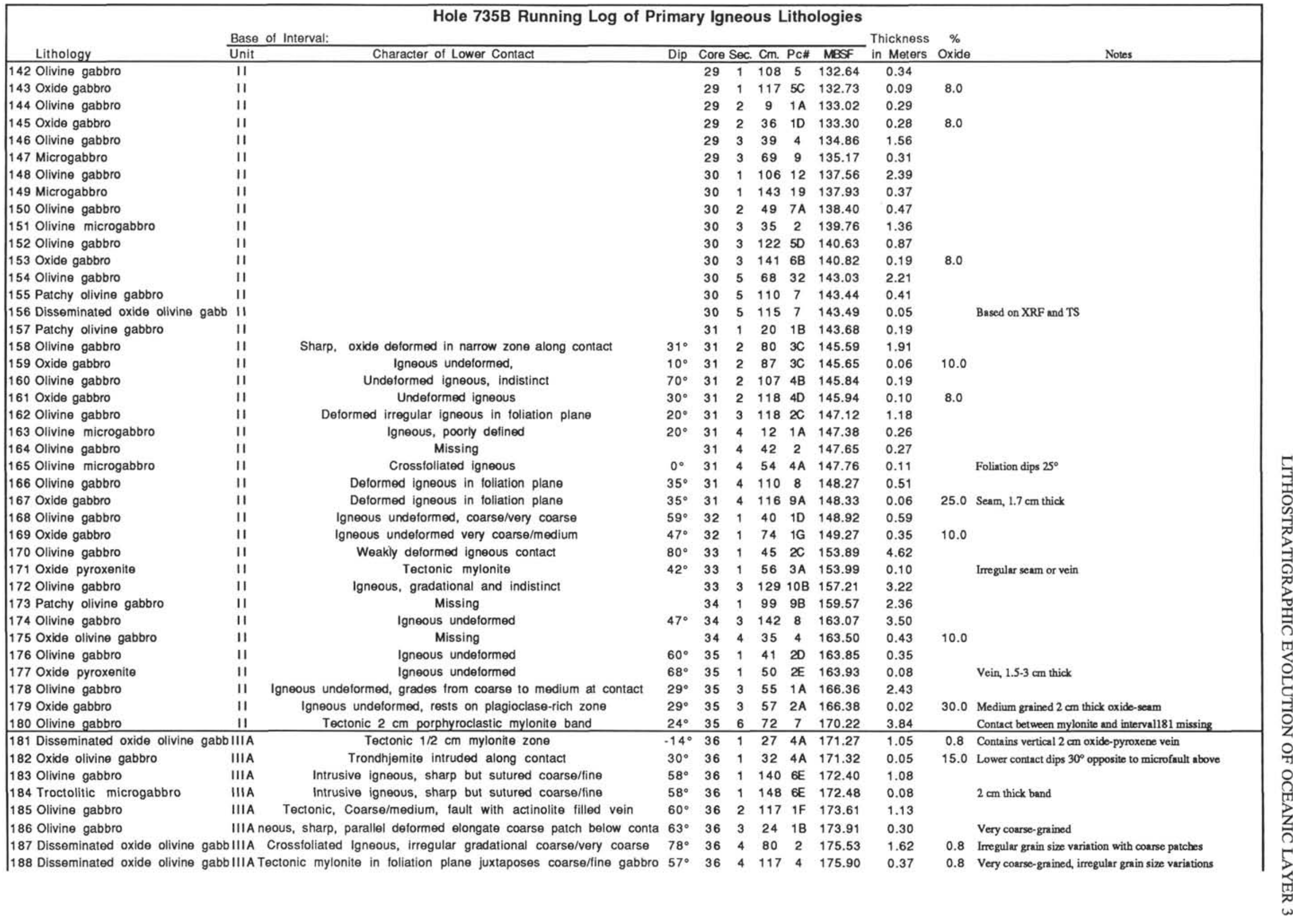




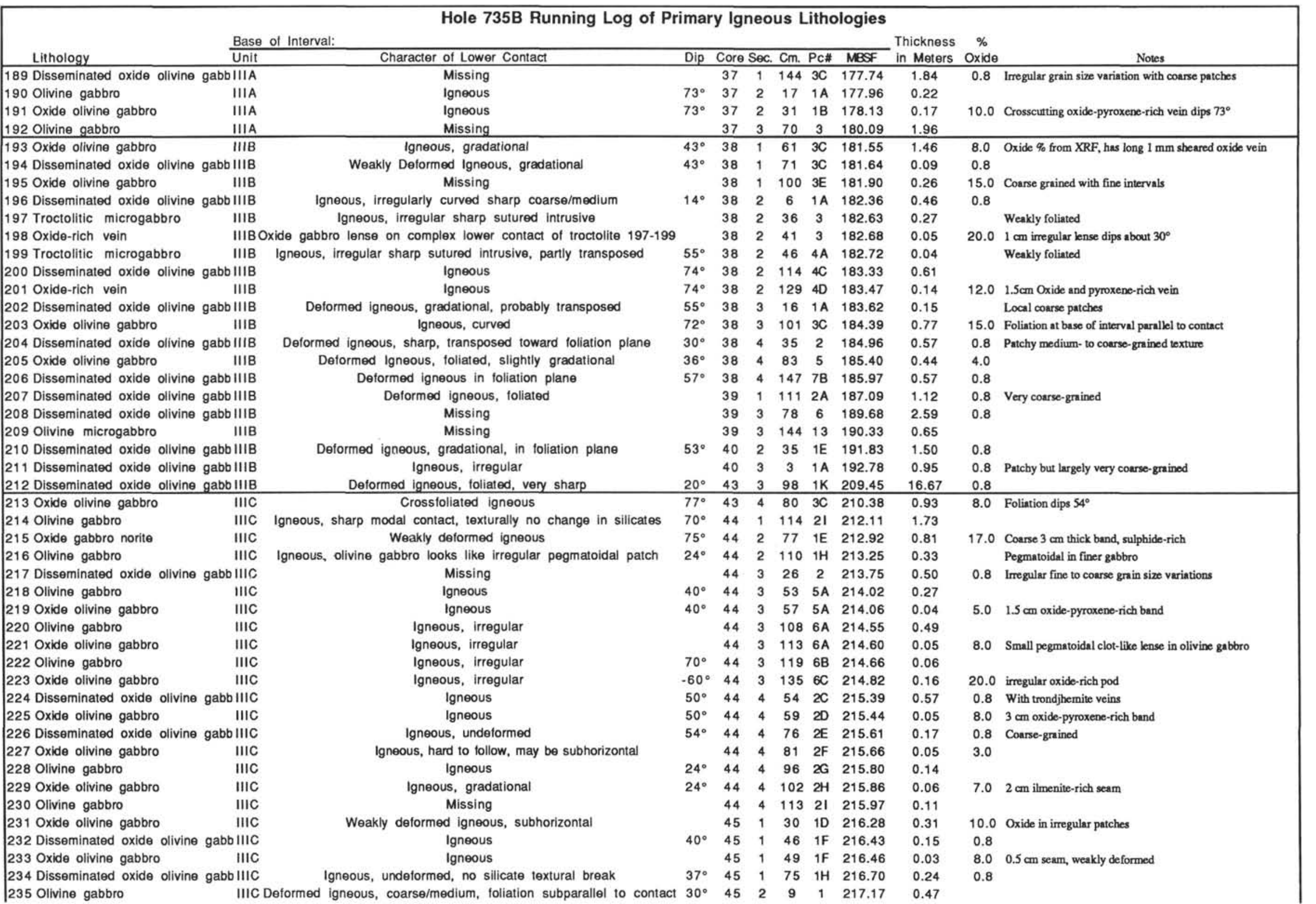




\begin{tabular}{|c|c|c|c|c|c|c|c|c|c|c|c|}
\hline \multicolumn{12}{|c|}{$\begin{array}{ll}\text { Hole 735B Running Log of Primary Igneous Lithologies } \\
\end{array}$} \\
\hline \multirow[b]{2}{*}{ Lithology } & \multicolumn{2}{|c|}{ Base of Interval: } & \multirow[b]{2}{*}{ Dip } & \multirow{2}{*}{\multicolumn{2}{|c|}{ Core Sec }} & \multirow[b]{2}{*}{$\mathrm{Cm}$. } & \multirow{3}{*}{$\frac{P C \#}{4 B}$} & \multirow{3}{*}{$\frac{\text { MBSF }}{218.23}$} & \multirow{2}{*}{$\begin{array}{l}\text { Thickness } \\
\text { in Meters }\end{array}$} & \multirow{2}{*}{$\begin{array}{c}\% \\
\text { Oxide }\end{array}$} & \multirow[b]{2}{*}{ Notes } \\
\hline & Unit & Character of Lower Contact & & & & & & & & & \\
\hline 236 Disseminated oxide olivine g & gabb IIIC & Igneous, irregular pegmatoidal coarse band lying along contact & $45^{\circ}$ & 45 & 2 & 122 & & & 1.06 & 0.8 & \\
\hline 237 Microgabbro & IIIC & Igneous, undeformed sharp & $40^{\circ}$ & 45 & 3 & 7 & 1 & 218.36 & 0.13 & & \\
\hline 238 Olivine gabbro & IIIC & Intrusive igneous, very sharp sutured coarse/medium & $43^{\circ}$ & 45 & 3 & 64 & $2 A$ & 218.90 & 0.54 & & \\
\hline 239 Troctolitic microgabbro & IIIC & Intrusive igneous, undeformed, sharp medium/coarse & $-56^{\circ}$ & 45 & 3 & 99 & 20 & 219.22 & 0.32 & & \\
\hline 240 Olivine gabbro & IIIC & Igneous, no silicate textural break & $63^{\circ}$ & 45 & 4 & 59 & $4 \mathrm{~A}$ & 220.15 & 0.93 & & \\
\hline 241 Disseminated oxide olivine g & gabb IIIC & Igneous, undeformed & $32^{\circ}$ & 45 & 4 & 80 & $4 \mathrm{~B}$ & 220.35 & 0.20 & 0.8 & Coarse-gnined \\
\hline 242 Olivine gabbro & IIIC & Igneous, undeformed & $32^{\circ}$ & 45 & 4 & 85 & 4B & 220.39 & 0.04 & & Very course-grained \\
\hline 243 Olivine gabbro & IIIC & Weakly deformed igneous, foliated & & 45 & 4 & 92 & $5 \mathrm{~A}$ & 220.46 & 0.07 & & \\
\hline 244 Disseminated oxide olivine $g$ & gabb IIIC & Crossfoliated Igneous, gradational coarse/fine & $23^{\circ}$ & 45 & 4 & 107 & $5 \mathrm{~B}$ & 220.60 & 0.14 & 0.8 & Coarse grained, olivine-rich \\
\hline 245 Disseminated oxide olivine g & gabb IIIC & Igneous, undeformed, irregular, no real textural break & & 45 & 4 & 117 & $5 \mathrm{C}$ & 220.69 & 0.09 & 0.8 & \\
\hline 246 Oxide olivine gabbro & IIIC & Igneous, undeformed & $76^{\circ}$ & 45 & 4 & 144 & 72 & 220.94 & 0.25 & 8.0 & Oxide irregularly distributed in gabbro \\
\hline 247 Olivine gabbro & IIIC & Igneous, curved, oxide-tree gabbro patch & & 46 & 1 & 2 & $1 \mathrm{~A}$ & 221.02 & 0.08 & & Oxide-free patch with curved contacts \\
\hline 248 Disseminated oxide olivine g & gabb IIIC & Deformed igneous, medium/coarse, in foliation plane & $35^{\circ}$ & 46 & 1 & 130 & $6 \mathrm{~A}$ & 222.15 & 1.13 & 0.8 & \\
\hline 249 Disseminated oxide olivine $g$ & gabb IIIC & Deformed igneous, in foliation plane & $41^{\circ}$ & 46 & 2 & 5 & $1 \mathrm{~A}$ & 222.30 & 0.15 & 0.8 & Very coarse-grained \\
\hline 250 Disseminated oxide olivine g & gabb IIIC & Deformed igneous, transposed close to foliation plane & $32^{\circ}$ & 46 & 2 & 33 & $2 A$ & 222.54 & 0.24 & 0.8 & \\
\hline 251 Disseminated oxide olivine g & gabb IIIC & Deformed igneous, in foliation plane & $43^{\circ}$ & 46 & 2 & 61 & 20 & 222.79 & 0.25 & 0.8 & Very course-grained \\
\hline 252 Disseminated oxide olivine $g$ & gabb IIIC & Crossfoliated igneous, & $43^{\circ}$ & 46 & 2 & 98 & $6 \mathrm{~B}$ & 223.12 & 0.33 & 0.8 & \\
\hline 253 Disseminated oxide olivine $g$ & gabb IIIC & Deformed igneous & $43^{\circ}$ & 46 & 2 & 105 & $6 \mathrm{~B}$ & 223.18 & 0.06 & 0.8 & Coarse-grained patch, nice rotated pyroxene augen \\
\hline 254 Disseminated oxide olivine g & gabb IIIC & Tectonic, mylonite & $-38^{\circ}$ & 46 & 2 & 109 & $6 \mathrm{~B}$ & 223.21 & 0.03 & 0.8 & Folinted gabbro crosscut by mylonite @ contact \\
\hline 255 Oxide olivine gabbro & IIIC & Deformed igneous, in foliation plane & $27^{\circ}$ & 46 & 2 & 136 & 7B & 223.45 & 0.24 & 8.0 & Foliated gabbro crosscut by mylonite @ contact \\
\hline 256 Olivine gabbro & IIIC & Tectonic $2 \mathrm{~cm}$ mylonite band & $-18^{\circ}$ & 46 & 2 & 150 & $7 \mathrm{C}$ & 223.57 & 0.12 & & Folinted Babbro crosscut by mylonite@ contact \\
\hline 257 Oxide olivine gabbro & IV & Weakly crossfoliated gradational igneous & $32^{\circ}$ & 46 & 3 & 40 & 3В & 223.93 & 0.36 & 15.0 & Lower contact cross folinted \\
\hline 258 Oxide olivine gabbro & IV & Foliated gradational igneous & $53^{\circ}$ & 46 & 3 & 49 & $3 \mathrm{C}$ & 224.01 & 0.08 & 20.0 & Coarse-grained, crosscutting mylonite band \\
\hline 259 Oxide olivine gabbro & IV & Foliated igneous & $65^{\circ}$ & 46 & 3 & 80 & $6 B$ & 224.28 & 0.27 & 15.0 & \\
\hline 260 Oxide olivine gabbro & IV & Foliated sharp irregular intrusive igneous & & 46 & 3 & 113 & 9 & 224.57 & 0.29 & 12.0 & Very coarse-grained \\
\hline 261 Oxide olivine microgabbro & IV & Sharp sutured igneous & $50^{\circ}$ & 46 & 3 & 129 & 10 & 224.71 & 0.14 & 2.0 & Olivine-rich \\
\hline 262 Oxide olivine gabbro & IV & Undeformed igneous & $72^{\circ}$ & 47 & 2 & 136 & 10 & 228.65 & 3.94 & 15.0 & \\
\hline 263 Olivine gabbro & IV & Undeformed igneous & $32^{\circ}$ & 47 & 3 & 42 & 1D & 229.11 & 0.46 & & Contains $5 \mathrm{~mm}$ vertical oxide and pyroxene vein \\
\hline 264 Oxide olivine gabbro & IV & Irregular gradational igneous & & 47 & 3 & 149 & $6 \mathrm{~B}$ & 230.13 & 1.02 & 15.0 & Coarse-grained, vein above roots here \\
\hline 265 Olivine gabbro & IV & Weakly foliated igneous & $31^{\circ}$ & 47 & 4 & 8 & 12 & 230.22 & 0.09 & & \\
\hline 266 Oxide olivine gabbro & IV & Subvertical, igneous undeformed & $77^{\circ}$ & 47 & 4 & 48 & 3 & 230.60 & 0.38 & 8.0 & Probably a subvertical oxide-rich vein \\
\hline 267 Olivine gabbro & IV & Deformed foliated & $40^{\circ}$ & 48 & 1 & 34 & $2 B$ & 231.32 & 0.72 & & \\
\hline 268 Oxide ollvine gabbro & IV & Somewhat irregular sharp foliated igneous & & 48 & 2 & 90 & 6 & 233.09 & 1.77 & 10.0 & \\
\hline 269 Oxide olivine microgabbro & IV & Crossfoliated igneous sharp coarse/medium grain size & $-32^{\circ}$ & 48 & 2 & 117 & $10 \mathrm{~A}$ & 233.34 & 0.25 & 15.0 & Troctolitic patch, folintion dip opposite to contact \\
\hline 270 Oxide olivine gabbro & IV & Crossfoliated sharp, somewhat irregular & $18^{\circ}$ & 51 & 4 & 79 & 10 & 247.56 & 14.22 & 10.0 & \\
\hline 271 Oxide olivine microgabbro & IV & Sharp igneous grain size & $-12^{\circ}$ & 51 & 4 & 85 & 10 & 247.62 & 0.06 & 8.0 & \\
\hline 272 Oxide ollivine gabbro & IV & crossfoliated igneous, Irregular & & 51 & 4 & 110 & $1 \mathrm{E}$ & 247.89 & 0.27 & 8.0 & \\
\hline 273 Oxide olivine microgabbro & IV & Irregular subparallel to foliation & & 51 & 4 & 117 & $1 \mathrm{E}$ & 247.97 & 0.08 & 10.0 & \\
\hline 274 Oxide olivine gabbro & IV & Deformed igneous in foliation plane & $23^{\circ}$ & 52 & 3 & 132 & $2 \mathrm{~F}$ & 251.70 & 3.73 & 10.0 & \\
\hline 275 Oxide olivine microgabbro & IV & Deformed igneous in foliation plane & $32^{\circ}$ & 52 & 3 & 135 & $2 \mathrm{G}$ & 251.73 & 0.03 & 2.0 & Olivine-rich \\
\hline 276 Oxide olivine gabbro & IV & Foliated subhorizontal igneous subparallel to foliation & & 52 & 4 & 74 & 4B & 252.50 & 0.77 & 8.0 & \\
\hline 277 Oxide olivine gabbro & IV & Foliated subhorizontal igneous subparallel to foliation & & 52 & 4 & 78 & $4 \mathrm{~B}$ & 252.54 & 0.04 & 8.0 & Olivine-rich \\
\hline 278 Oxide olivine gabbro & IV & Igneous & $30^{\circ}$ & 52 & 4 & 105 & $4 \mathrm{C}$ & 252.80 & 0.26 & 8.0 & \\
\hline 279 Oxide olivine gabbro & IV & Igneous & $30^{\circ}$ & 52 & 4 & 113 & $4 \mathrm{C}$ & 252.88 & 0.08 & 6.0 & Olivine-rich, coarse-grained \\
\hline 280 Oxide olivine gabbro & IV & Igneous in foliation plane & $30^{\circ}$ & 53 & 1 & 24 & $2 \mathrm{~A}$ & 253.22 & 0.34 & 12.0 & \\
\hline 281 Oxide olivine gabbro & IV & Igneous in foliation plane & $34^{\circ}$ & 53 & 1 & 46 & 28 & 253.41 & 0.19 & 8.0 & Olivine-rich \\
\hline 282 Oxide olivine gabbro & IV & Tectonic mylonite & $51^{\circ}$ & 54 & 1 & 111 & $8 \mathrm{~A}$ & 259.03 & 5.62 & 12.0 & \\
\hline
\end{tabular}




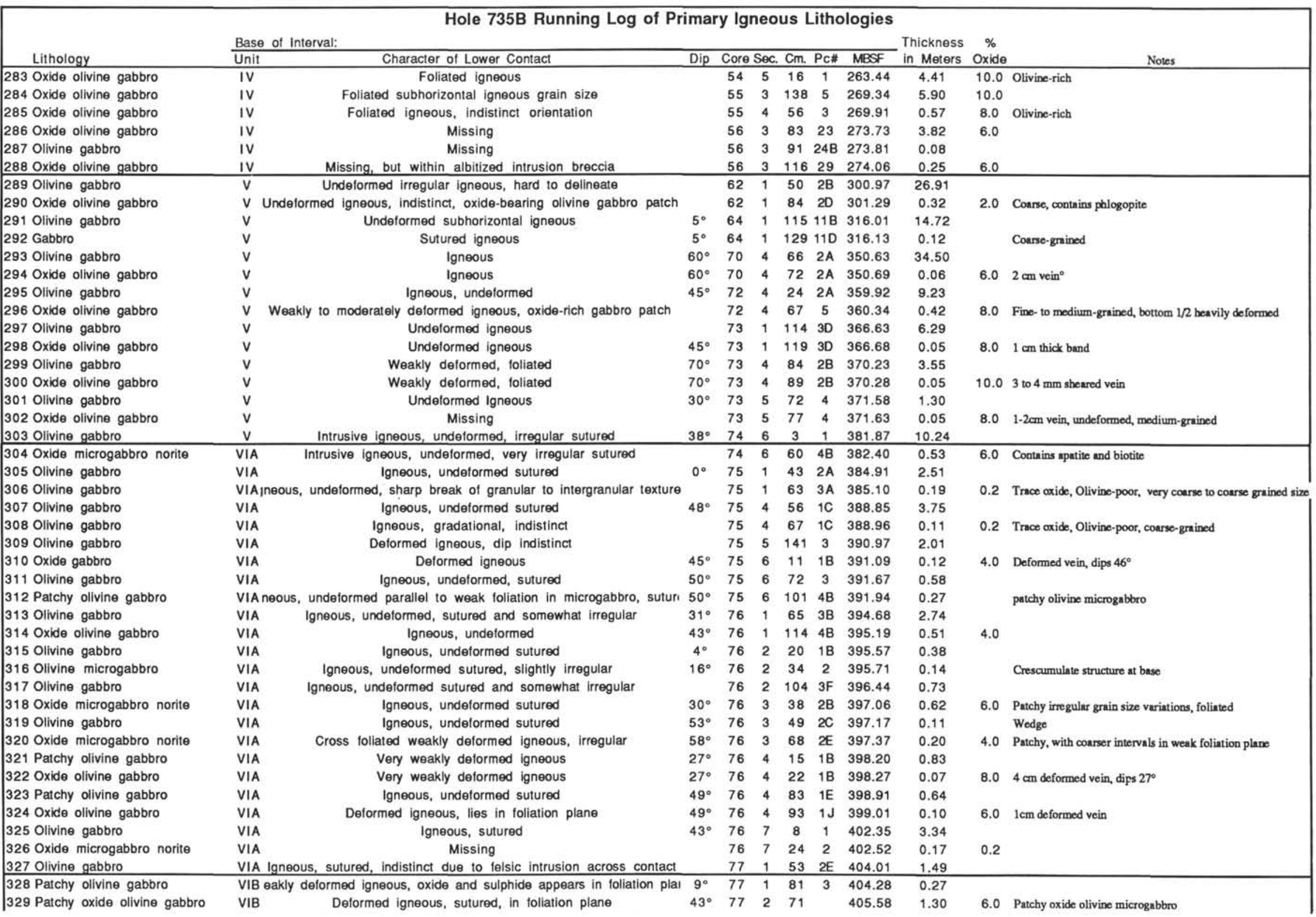




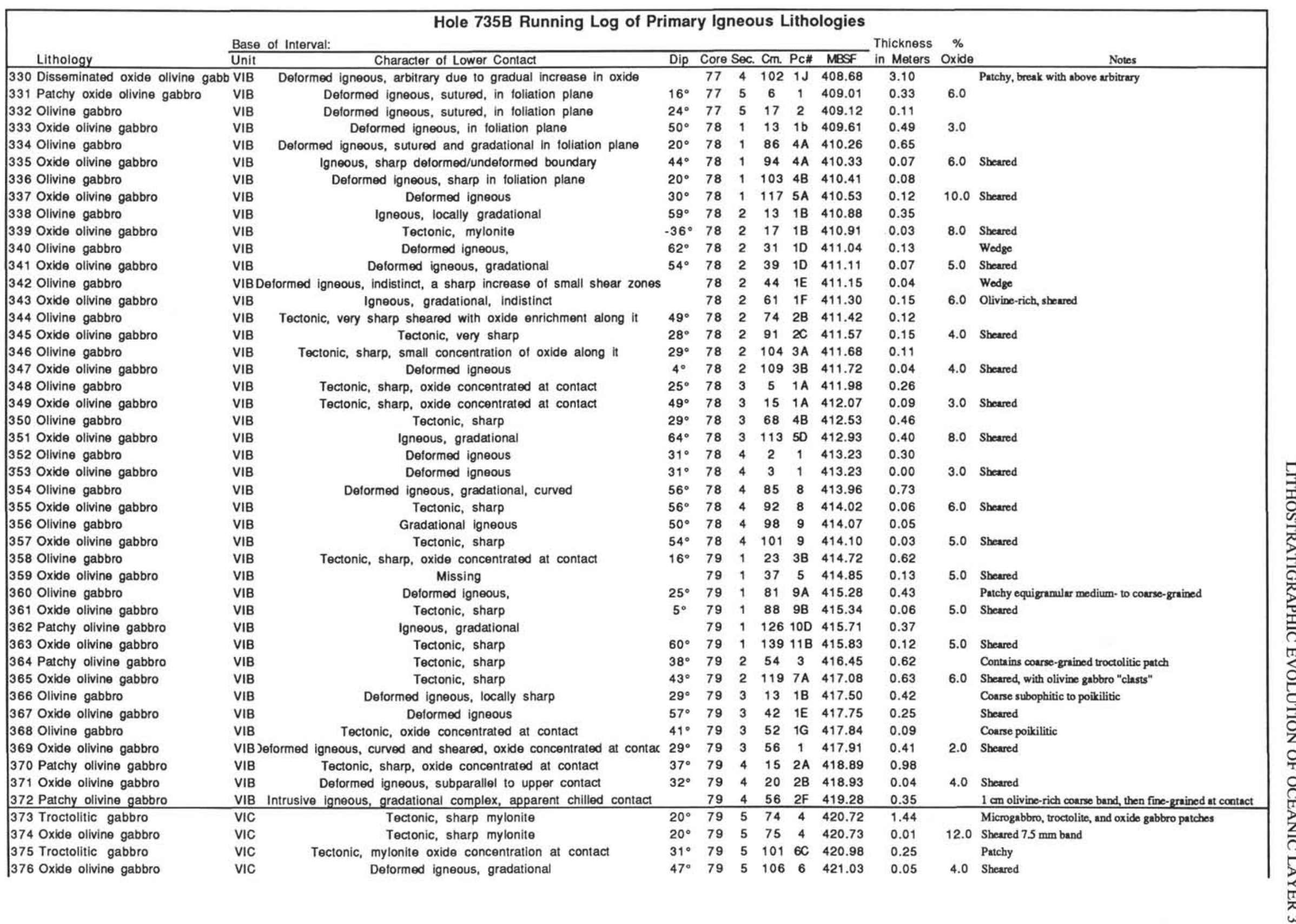




\begin{tabular}{|c|c|c|c|c|c|c|c|c|c|c|c|}
\hline \multicolumn{12}{|c|}{ Hole 735B Running Log of Primary Igneous Lithologies } \\
\hline \multirow[b]{2}{*}{ Lithology } & \multicolumn{8}{|c|}{ Base of Interval: } & \multirow{2}{*}{$\begin{array}{l}\text { Thickness } \\
\text { in Meters }\end{array}$} & \multirow{2}{*}{$\begin{array}{c}\% \\
\text { Oxide } \\
\end{array}$} & \multirow[b]{2}{*}{ Notes } \\
\hline & Unit & Character of Lower Contact & Dip & Core & Sec. & $\mathrm{Cm}$. & Pc\# & MBSF & & & \\
\hline 377 Patchy olivine gabbro & VIC & Deformed igneous, gradational sutured, sheared & $25^{\circ}$ & 79 & 5 & 129 & $7 \mathrm{C}$ & 421.25 & 0.22 & & \\
\hline 378 Oxide olivine gabbro & VIC & Deformed igneous, oxide concentrated at contact, sheared & $26^{\circ}$ & 79 & 5 & 138 & 8 & 421.34 & 0.09 & 4.0 & Sheared \\
\hline 379 Patchy olivine gabbro & VIC & No notes taken & $18^{\circ}$ & 79 & 6 & 8 & $1 \mathrm{~A}$ & 421.46 & 0.12 & & \\
\hline 380 Oxide olivine gabbro & VIC & Tecionic, mylonite & $23^{\circ}$ & 79 & 6 & 21 & $1 \mathrm{~B}$ & 421.59 & 0.13 & 6.0 & Sheared, olivine-rich \\
\hline 381 Olivine gabbro & VIC & Deformed igneous, gradational & $39^{\circ}$ & 79 & 6 & 25 & 1B & 421.62 & 0.03 & & \\
\hline 382 Oxide olivine gabbro & VIC & Tectonic, mylonite, oxide concentrated at contact & $23^{\circ}$ & 79 & 6 & 45 & $2 B$ & 421.82 & 0.20 & 6.0 & Sheared, olivine-rich \\
\hline 383 Troctolitic gabbro & VIC & Deformed igneous, gradational & $18^{\circ}$ & 79 & 7 & 68 & 7 & 423.43 & 1.61 & & Sheared oxide olivine and troctolite patches \\
\hline 384 Patchy olivine gabbro & VIC $n t$ & trusive olivine microgabbro against deformed oxide gabbro, suture & $47^{\circ}$ & 79 & 7 & 114 & 10 & 423.87 & 0.44 & & Oxide zone crosses microgabbro/gabbro contact in interval \\
\hline 385 Oxide olivine gabbro & VIC & Missing & & 80 & 1 & 3 & 1 & 424.03 & 0.16 & 10.0 & Sheared oxide-bearing troctolitic gabbro \\
\hline 386 Troctolitic gabbro & VIC & No notes taken & $20^{\circ}$ & 80 & 1 & 14 & 4 & 424.13 & 0.10 & & \\
\hline 387 Oxide olivine gabbro & VIC & Deformed igneous, sheared, oxide concentration at contact & $20^{\circ}$ & 80 & 1 & 16 & 4 & 424.15 & 0.02 & 2.0 & Sheared \\
\hline 388 Troctolitic gabbro & VIC & Igneous, sharp grain size change over $5 \mathrm{~cm}$, irregular & $83^{\circ}$ & 80 & 1 & 49 & $6 C$ & 424.46 & 0.31 & & \\
\hline 389 Troctolite & VIC & Deformed igneous, oxide concentrated near contact & $75^{\circ}$ & 80 & 1 & 74 & $7 \mathrm{~B}$ & 424.69 & 0.23 & & \\
\hline 390 Oxide olivine microgabbro & VICT & Tectonic, highly contorted mylonite with oxide concentration belou & $55^{\circ}$ & 80 & 1 & 101 & 10 & 424.94 & 0.25 & 4.0 & Sheared, olivine-rich \\
\hline 391 Troctolitic gabbro & VIC & Tectonic, & $16^{\circ}$ & 80 & 1 & 130 & $13 \mathrm{~A}$ & 425.21 & 0.27 & & Troctolite present \\
\hline 392 Oxide olivine microgabbro & VIC & Deformed igneous, fine-/medium-grained, deformed/undeformed & $18^{\circ}$ & 80 & 1 & 137 & 13B & 425.28 & 0.07 & 5.0 & Sheared, olivine-rich \\
\hline 393 Troctolitic gabbro & VIC & Igneous, irregular troctolitic gabbro patch & & 80 & 2 & 10 & $1 \mathrm{~B}$ & 425.45 & 0.17 & & \\
\hline 394 Troctolite & VIC & Igneous, undeformed sutured & $9^{\circ}$ & 80 & 2 & 58 & $5 B$ & 425.89 & 0.44 & & \\
\hline 395 Olivine gabbro & VIC & Tectonic, undeformed olivine gabbro against deformed rock below & $26^{\circ}$ & 80 & 2 & 111 & $7 \mathrm{~B}$ & 426.39 & 0.50 & & Fine-grained troctolite patch near top \\
\hline 396 Oxide olivine gabbro & VIC & Missing & & 80 & 2 & 119 & $7 \mathrm{C}$ & 426.46 & 0.07 & 6.0 & Sheared \\
\hline 397 Olivine gabbro & VIC D & Deformed igneous, mega-augen at contact in sheared gabbro below & $54^{\circ}$ & 80 & 2 & 140 & $9 \mathrm{~B}$ & 426.66 & 0.20 & & \\
\hline 398 Patchy oxide olivine gabbro & VIC & Detormed igneous, gradational & $50^{\circ}$ & 80 & 3 & 74 & $10 \mathrm{~A}$ & 427.40 & 0.74 & 8.0 & Sheared, olivine-rich possible oxide-bearing troctolite? \\
\hline 399 Olivine gabbro & VIC & Deformed igneous, gradational & $36^{\circ}$ & 80 & 3 & 114 & $11 \mathrm{~B}$ & 427.77 & 0.37 & & \\
\hline 400 Oxide olivine gabbro & VIC & Igneous, gradational sutured, not very distinct & $9^{\circ}$ & 80 & 3 & 127 & $12 \mathrm{~A}$ & 427.89 & 0.12 & 8.0 & Sheared, olivine-rich \\
\hline 401 Olivine gabbro & VIC & Weakly deformed igneous, sutured & $12^{\circ}$ & 80 & 4 & 6 & 1 & 428.12 & 0.23 & & \\
\hline 402 Oxide olivine gabbro & VIC & Missing & & 80 & 4 & 29 & 3 & 428.33 & 0.21 & 8.0 & Sheared, coarse olivine gabbro "clasts" \\
\hline 403 Troctolitic microgabbro & VIC & Missing & & 80 & 4 & 42 & 4 & 428.45 & 0.12 & & \\
\hline 404 Olivine gabbro & VIC & Delormed igneous, irregular and curved & $6^{\circ}$ & 80 & 4 & 71 & $6 C$ & 428.72 & 0.27 & & Olivine-rich, diopside patches \\
\hline 405 Oxide olivine gabbro & VIC & Deformed igneous, gradational & $8^{\circ}$ & 80 & 4 & 74 & $6 C$ & 428.75 & 0.03 & 8.0 & Sheared, olivine-rich \\
\hline 406 Olivine gabbro & VIC & Tectonic & $18^{\circ}$ & 80 & 4 & 139 & $9 \mathrm{~B}$ & 429.36 & 0.61 & & Olivine-rich, diopside patches \\
\hline 407 Oxide ollvine gabbro & VIC & Deformed igneous, very irregular and steep & & 80 & $\mathbf{5}$ & 3 & 1 & 429.38 & 0.02 & 4.0 & Sheared \\
\hline 408 Olivine gabbro & VIC & Missing & & 80 & $\mathbf{5}$ & 38 & 4 & 429.70 & 0.32 & & Local diopsidic patches \\
\hline 409 Oxide olivine microgabbro & VIC & Deformed igneous, fine and coarse contact within oxide-rich band & $19^{\circ}$ & 80 & 5 & 41 & 5 & 429.73 & 0.03 & 6.0 & Sheared \\
\hline 410 Olivine gabbro & VIC & Missing & & 80 & 6 & 19 & 2 & 430.92 & 1.19 & & Local oxide bearing shear zones \\
\hline 411 Oxide ollvine gabbro & VIC & Deformed igneous, gradational & $36^{\circ}$ & 80 & 6 & 113 & 13 & 431.80 & 0.88 & 6.0 & Sheared \\
\hline 412 Oxide olivine gabbro & VIC F & Penetratively deformed igneous, sutured, deformed across contact & $26^{\circ}$ & 80 & 6 & 145 & 16 & 432.10 & 0.30 & 10.0 & Olivine-rich \\
\hline 413 Oxide olivine microgabbro & VIC'e & eakly penetratively deformed lgneous, indistinct gradational suturec & & 80 & 7 & 79 & $6 \mathrm{~A}$ & 432.84 & 0.74 & & \\
\hline 414 Oxide olivine gabbro & VIC & Penetratively deformed igneous, gradational sutured & $60^{\circ}$ & 80 & 7 & 93 & 8 & 432.97 & 0.13 & 8.0 & \\
\hline 415 Olivine gabbro & VIC & Igneous, undeformed & $45^{\circ}$ & 80 & 7 & 150 & 11 & 433.50 & 0.53 & & local oxide bearing shear zones \\
\hline 416 Oxide ollivine gabbro & VIC & Weakly deformed igneous, sutured sharp irregular contact & $35^{\circ}$ & 81 & 1 & 26 & $1 \mathrm{~B}$ & 433.77 & 0.27 & 5.0 & Olivine-rich, contact undeformed in embayments \\
\hline 417 Olivine gabbro & VID & Weakly deformed igneous, undeformed against deformed & $50^{\circ}$ & 81 & 1 & 46 & $1 \mathrm{D}$ & 433.97 & 0.20 & & \\
\hline 418 Oxide olivine gabbro & VID & Igneous, very sharp deformed against undeformed, oxide sutured & $65^{\circ}$ & 81 & 2 & 115 & $2 \mathrm{C}$ & 434.70 & 0.73 & & Oxide impregnates olivine gabbro across contact \\
\hline 419 Olivine gabbro & VID & No notes taken & & 81 & 2 & 128 & $5 \mathrm{C}$ & 436.26 & 1.56 & & \\
\hline 420 Oxide olivine gabbro & VID & No notes taken & & 81 & 2 & 133 & 50 & 436.31 & 0.05 & 3.0 & Sheared mylonite \\
\hline 421 Olivine gabbro & VID & Deformed igneous, indistinct, foliated oxide impregnates contact & $45^{\circ}$ & 81 & 3 & 47 & 3 & 436.84 & 0.53 & & $2.3 \mathrm{~mm}$ oxide bearing ductile deformation band dips $23^{\circ}$ \\
\hline 422 Oxide olivine gabbro & VID & Irregular & $35^{\circ}$ & 81 & 3 & 59 & $4 \mathrm{~A}$ & 436.96 & 0.12 & 8.0 & Sheared \\
\hline 423 Olivine gabbro & VID & Deformed igneous, sutured & $56^{\circ}$ & 81 & 3 & 123 & $5 \mathrm{~F}$ & 437.62 & 0.66 & & \\
\hline
\end{tabular}




\begin{tabular}{|c|c|c|c|c|c|c|c|c|c|c|c|}
\hline \multicolumn{12}{|c|}{ Hole 735B Running Log of Primary Igneous Lithologies } \\
\hline \multirow[b]{2}{*}{ Lithology } & \multicolumn{8}{|c|}{ Base of Interval: } & \multirow{2}{*}{$\begin{array}{l}\text { Thickness } \\
\text { in Meters }\end{array}$} & \multirow{2}{*}{$\begin{array}{c}\% \\
\text { Oxide }\end{array}$} & \multirow[b]{2}{*}{ Notes } \\
\hline & Unit & Character of Lower Contact & Dip & Core & Sec. & $\mathrm{Cm}$. & Pc\# & MBSF & & & \\
\hline 424 Oxide olivine gabbro & VID & No notes taken & $43^{\circ}$ & 81 & 4 & 68 & $6 C$ & 438.60 & 0.98 & 2.0 & Olivine-rich, sheared \\
\hline 425 Olivine gabbro & VID & Tectonic & $29^{\circ}$ & 81 & 5 & 67 & $4 \mathrm{D}$ & 440.01 & 1.41 & & \\
\hline 426 Oxide-rich vein & VID & Deformed igneous, & $37^{\circ}$ & 81 & 5 & 68 & $4 \mathrm{E}$ & 440.02 & 0.01 & & $5 \mathrm{~mm}$ sheared vein dips $37^{\circ}$ \\
\hline 427 Olivine gabbro & VID & Weakly delormed igneous, & $41^{\circ}$ & 81 & 6 & 56 & 3в & 441.11 & 1.09 & & \\
\hline 428 Oxide olivine gabbro & VID & Weakly deformed igneous & $58^{\circ}$ & 81 & 6 & 77 & $4 \mathrm{~A}$ & 441.32 & 0.21 & 6.0 & sheared with olivine gabtro "clasts" \\
\hline 429 Olivine gabbro & VID & Igneous undeformed, steep but hard to measure, oxide at contact & & 81 & 7 & 123 & 11 & 442.93 & 1.61 & & Long sheared oxide-rich vein, dips $69^{\circ}$ \\
\hline 430 Oxide olivine gabbro & VID & Igneous, sutured, oxide extends into undeformed gabbro $1 / 2 \mathrm{~cm}$ & $76^{\circ}$ & 82 & 1 & 25 & $2 B$ & 443.26 & 0.33 & 8.0 & Sheared, up to $50 \%$ oxide locally \\
\hline 431 Olivine gabbro & VID 9 & gneous, undeformed irregular moderately sharp modal and grain size & & 82 & 1 & 50 & 3 & 443.53 & 0.27 & & \\
\hline 432 Troctolitic gabbro & VID & Weakly deformed igneous, sutured & $11^{\circ}$ & 82 & 1 & 63 & $4 \mathrm{~A}$ & 443.67 & 0.14 & & \\
\hline 433 Oxide olivine gabbro & VID & Coarse $2.5 \mathrm{~cm}$ pegmatoidal band & & 82 & 1 & 65 & $4 \mathrm{~A}$ & 443.69 & 0.02 & 9.0 & Sheared, local pegmatoidal band \\
\hline 434 Troctolitic gabbro & VID & Igneous, sutured undelormed/detormed & & 82 & 2 & 27 & 2 & 444.87 & 1.18 & & Microgabbro/gabbro contact crosscut by oxide gabbro \\
\hline 435 Oxide olivine gabbro & VID & Igneous, undeformed pegmatitic & $63^{\circ}$ & 82 & 2 & 61 & $6 \mathrm{~B}$ & 445.23 & 0.36 & 6.0 & Coarse primary homblende patch? \\
\hline 436 Olivine gabbro & VID & Contact with sheared oxide rich vein & $41^{\circ}$ & 82 & 2 & 94 & $7 \mathrm{~B}$ & 445.58 & 0.35 & & \\
\hline 437 Oxide olivine gabbro & VID & Starts as inclined $2.5 \mathrm{~cm}$ shear band, and cuts down into $1 \mathrm{~m}$ vein & $90^{\circ}$ & 82 & 2 & 96 & 7B & 445.60 & 0.02 & 20.0 & Subvertical $2.5 \mathrm{~cm}$ sheared $1 \mathrm{~m}$ long vein, \\
\hline 438 Olivine gabbro & VID & Tectonic, sharp & $2^{\circ}$ & 82 & 5 & 37 & 4 & 449.24 & 3.64 & & \\
\hline 439 Oxide olivine gabbro & VID & Missing & & 82 & 6 & 90 & $5 F$ & 451.30 & 2.06 & 8.0 & Sheared, locally up to $30 \%$ oxide \\
\hline 440 Olivine gabbro & VID & Missing & & 82 & 7 & 69 & 6 & 452.51 & 1.21 & & \\
\hline 441 Oxide olivine gabbro & VID & Missing & & 83 & 1 & 11 & 1 & 452.60 & 0.09 & 4.0 & Olivine-rich, sheared \\
\hline 442 Olivine gabbro & VID & Missing & & 83 & 3 & 58 & $3 \mathrm{~B}$ & 455.63 & 3.03 & & \\
\hline 443 Oxide olivine gabbro & VID & Contact crosscut by miarolitic cavities, a mess & & 83 & 3 & 63 & $4 \mathrm{~A}$ & 455.68 & 0.05 & 15.0 & Oxide-rich patch in olivine gabbro \\
\hline 444 Olivine gabbro & VID & No notes taken & & 83 & 4 & 73 & 2 & 456.97 & 1.29 & & \\
\hline 445 Oxide olivine gabbro & VID & Tectonic, mylonite & $25^{\circ}$ & 83 & 4 & 87 & 4 & 457.10 & 0.13 & & Sheared \\
\hline 446 Olivine gabbro & VID & Tectonic & $53^{\circ}$ & 83 & 4 & 136 & SE & 457.53 & 0.43 & & \\
\hline 447 Oxide olivine gabbro & VID & Tectonic, microfault juxtaposing detormed/undetormed & $36^{\circ}$ & 83 & 5 & 60 & $6 \mathrm{~A}$ & 458.18 & 0.65 & 8.0 & Sheared \\
\hline 448 Olivine gabbro & VID & Igneous, indistinct steeply dipping undeformed/deformed contact & & 83 & 6 & 2 & $1 \mathrm{~A}$ & 458.84 & 0.66 & & \\
\hline 449 Oxide olivine gabbro & VID & Missing & & 83 & 6 & 45 & 2 & 459.22 & 0.38 & & Sheared \\
\hline 450 Olivine gabbro & VID & Deformed igneous, sheared & $19^{\circ}$ & 83 & 6 & 62 & 4 & 459.37 & 0.15 & & Olivine-rich \\
\hline 451 Oxide olivine gabbro & VID & Missing & & 83 & 6 & 101 & 78 & 459.71 & 0.34 & 8.0 & Sheared, olivine-rich \\
\hline 452 Troctolite & VID & Missing & & 83 & 8 & 32 & 4 & 461.73 & 2.02 & & Coarse-\& fine-grained intervals \\
\hline 453 Olivine gabbro & VID & Missing & & 84 & 5 & 4 & 1 & 467.81 & 6.08 & & \\
\hline 454 Oxide olivine gabbro & VID & Missing & & 84 & 5 & 12 & 2 & 467.89 & 0.08 & 10.0 & Sheared \\
\hline 455 Olivine gabbro & VIDie & eformed igneous, oxide extends across contact into undeformed roc & $30^{\circ}$ & 85 & 1 & 80 & $8 \mathrm{C}$ & 472.25 & 4.36 & & \\
\hline 456 Oxide olivine gabbro & VIDI & eformed igneous, oxide extends across contact into undeformed roc & $30^{\circ}$ & 85 & 1 & 84 & 80 & 472.29 & 0.04 & 12.0 & Sheared \\
\hline 457 Olivine gabbro & VID & No notes taken & & 85 & 3 & 39 & $1 \mathrm{E}$ & 474.58 & 2.29 & & Three $1 \mathrm{~cm}$ oxide-bearing shear zones \\
\hline 458 Oxide olivine gabbro & VID & Crossfollated igneous, very sharp & $45^{\circ}$ & 85 & 3 & 59 & $2 \mathrm{~A}$ & 474.77 & 0.19 & 12.0 & Sheared \\
\hline 459 Olivine gabbro & VID & No notes taken & & 85 & 3 & 78 & $2 B$ & 474.95 & 0.18 & & \\
\hline 460 Oxide olivine gabbro & VID & Deformed igneous, deformed twice - once in amphibolite facies & $41^{\circ}$ & 85 & 3 & 97 & $3 \mathrm{~A}$ & 475.13 & 0.18 & 6.0 & Sheared, oxide shear zone cut by oblique strike microfautt \\
\hline 461 Olivine gabbro & VID & Deformed igneous, sharp in unoriented core fragment & & 85 & 5 & 66 & $4 A$ & 477.40 & 2.27 & & With oxide olivine gabbro veins \\
\hline 462 Oxide olivine gabbro & VID & Missing & & 85 & 5 & 124 & $4 G$ & 477.95 & 0.55 & 12.0 & Sheared \\
\hline 463 Olivine gabbro & VID & Igneous, obscured by amphibolite facies deformation & $35^{\circ}$ & 85 & 6 & 24 & $1 \mathrm{C}$ & 478.21 & 0.26 & & Band \\
\hline 464 Oxide gabbro & VID & Igneous, obscured by amphibolite facies deformation & $35^{\circ}$ & 85 & 6 & 26 & 1C & 478.23 & 0.02 & 8.0 & Sheared $5 \mathrm{~mm}$ vein dips $35^{\circ}$ \\
\hline 465 Diopsidic olivine gabbro & VID & Igneous, coarse patches at irregular contact & $21^{\circ}$ & 85 & 6 & 42 & $2 \mathrm{C}$ & 478.38 & 0.15 & & Diopsidic patches \\
\hline 466 Troctolite & VID & Tectonic, located in redeformed amphibolitized gabbro & $15^{\circ}$ & 85 & 7 & 42 & $3 A$ & 479.70 & 1.32 & & Diopsidic olivine gabbro patches \\
\hline 467 Diopsidic olivine gabbro & VID & Tectonic, sheared & $17^{\circ}$ & 85 & 8 & 7 & 1 & 480.50 & 0.80 & & Diopsidic patches \\
\hline 468 Troctolite & VID & Igneous, amphibolitized, hard to follow & $15^{\circ}$ & 85 & 8 & 24 & 3 & 480.66 & 0.16 & & \\
\hline 469 Diopsidic olivine gabbro & VID & Amphibolitized, dip estimated & $20^{\circ}$ & 86 & 1 & 90 & 7 & 481.89 & 1.23 & & Diopsidic patches \\
\hline 470 Oxide olivine gabbro & VID & Amphibolitized, contact not seen & & 86 & 1 & 132 & 11 & 482.31 & 0.42 & 11.0 & Sheared \\
\hline
\end{tabular}




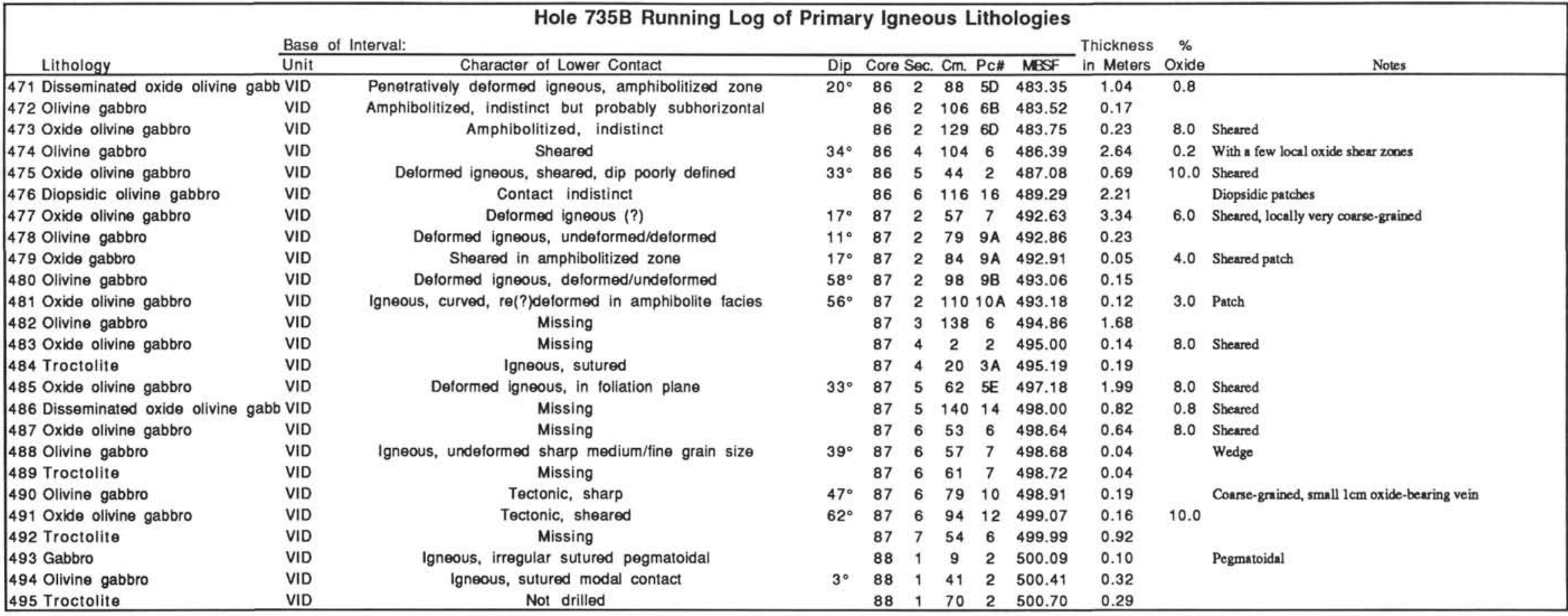




\section{Hole 735B XRF Whole Rock Analyses}

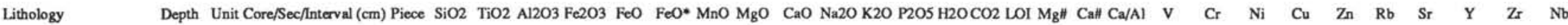

Diabase

Diabase

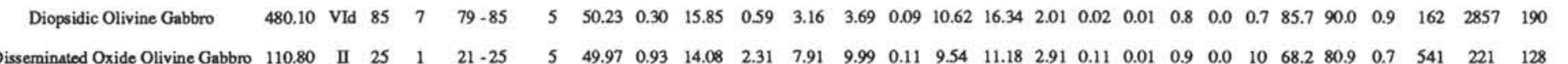
$\begin{array}{lllllll}25.10 & \text { la } & \ldots . . . . & 1 & 71-74\end{array}$ $\begin{array}{lllll}104.35 & \text { II } & 23 & 4 & 83-86\end{array}$

$\begin{array}{lllll}49.97 & 1.78 & 14.65 & 2.15 & 7.06\end{array}$

$\begin{array}{llllllllllllllllllllllllll}5 & 49.71 & 1.67 & 15.17 & 2.61 & 7.29 & 9.64 & 0.19 & 7.96 & 10.91 & 2.53 & 0.05 & 0.17 & 1.8 & 0.0 & 1.7 & 66.1 & 82.7 & 0.7 & 273 & 212\end{array}$

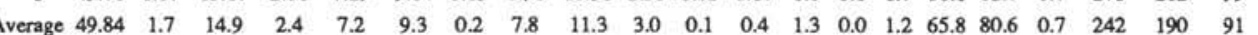
$\begin{array}{llllllllllllllllllllllllllllll}\text { Disseminated Oxide Olivine Gabbro } & 143.50 & \text { II } & 30 & 5 & 110-115 & 7 & 53.13 & 0.49 & 17.22 & 1.09 & 6.47 & 7.45 & 0.15 & 6.55 & 10.30 & 4.01 & 0.07 & 0.04 & 0.5 & 0.0 & 0.2 & 64.3 & 74.0 & 0.5 & 155 & 24 & 52 & 79\end{array}$

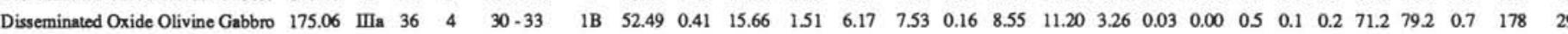
$\begin{array}{lllllllllllllllllllllllllll}\text { Disseminated Oxide Olivine Gabbro } & 183.06 & \mathrm{Imb} & 38 & 2 & 78-84 & \text { 4B } & 50.92 & 0.65 & 12.95 & 1.63 & 8.66 & 10.13 & 0.22 & 10.14 & 11.28 & 2.76 & 0.07 & 0.01 & 0.7 & 0.0 & 0.4 & 67.6 & 81.9 & 0.8 & 216 & 43\end{array}$

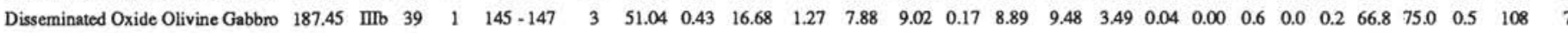

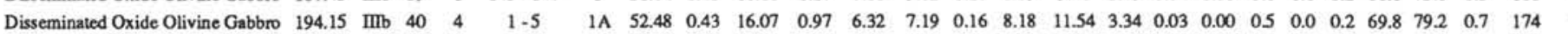
$\begin{array}{lllllllllllllllllllllllllll}\text { Disseminated Oxide Olivine Gabbro } & 199.73 & \mathrm{IIb} & 41 & 4 & 22-27 & 1 \mathrm{~A} & 52.26 & 0.47 & 15.85 & 1.73 & 6.26 & 7.82 & 0.16 & 8.23 & 11.29 & 3.21 & 0.03 & 0.00 & 0.4 & 0.1 & 0.2 & 70.1 & 79.5 & 0.6 & 178 & 15\end{array}$ Disseminated Oxide Olivine Gabbro 203.77 IIIb $\begin{array}{cccc}42 & 3 & 9-14\end{array}$ $\begin{array}{llllll}\text { Disseminated Oxide Olivine Gabbro } 206.29 & \mathrm{IIb} & 43 & 1 & 22-29\end{array}$ Disseminated Oxide Olivine Gabbro 216.50 Illc $45 \quad 1 \quad 48-54$

$\begin{array}{llllllllllllllllllllllll}\text { 1B } & 51.66 & 0.83 & 17.04 & 2.84 & 5.53 & 8.09 & 0.16 & 6.93 & 10.38 & 3.48 & 0.05 & 0.01 & 0.6 & 0.5 & 0.9 & 69.1 & 76.7 & 0.6 & 216 & 3\end{array}$

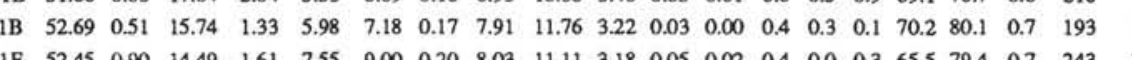

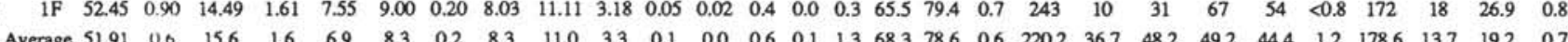
$\begin{array}{lllllllllllllllllllllllllllll}\text { Standard Deviation } & 0.99 & 0.2 & 1.4 & 0.6 & 1.0 & 1.1 & 0.0 & 1.1 & 0.7 & 0.3 & 0.0 & 0.0 & 0.2 & 0.2 & 3.1 & 2.2 & 2.6 & 0.1 & 118.7 & 65.9 & 29.0 & 22.9 & 11.8 & 22.7 & 3.3 & 9.8 & 0.2\end{array}$

Gabbro Norite Gabbro Norite Gabbro Norite Gabbro Norite Gabbro Norite Gabbro Norite

Microgabbro

Olivine Gabbro Olivine Gabbro Olivine Gabbro Olivine Gabbro Olivine Gabbro Olivine Gabbro Olivine Gabbro Olivine Gabbro Olivine Gabbro Olivine Gabbro Olivine Gabbro Olivine Gabbro Olivine Gabbro Olivine Gabbro Olivine Gabbro Olivine Gabbro Olivine Gabbro Olivine Gabbro Olivine Gabbro
2.39 Ia 11 1 90.92 3.12 Ia 1 l $117-120$ 6.34 Ia $120.91-94$ $\begin{array}{llllll}15.34 & \text { Ia } & 3 & 1 & 46-49\end{array}$ $\begin{array}{lllll}20.08 & \text { Ia } & 4 & 2 & 10-16\end{array}$ $\begin{array}{llllll}37.09 & \text { Ib } & 10 & 1 & 46-49\end{array}$

$\begin{array}{llllllllllllllllllllllll}14 & 51.66 & 0.85 & 14.90 & 2.05 & 6.64 & 8.49 & 0.17 & 6.98 & 11.98 & 3.40 & 0.16 & 0.02 & 1.2 & 0.1 & 1 & 65.2 & 79.6 & 0.7 & 243 & 9\end{array}$ $\begin{array}{lllllllllllllllllllll}19 & 54.21 & 0.56 & 20.93 & 1.15 & 3.80 & 4.84 & 0.10 & 3.82 & 9.64 & 5.19 & 0.09 & 0.02 & 0.4 & 0.1 & 0.3 & 64.2 & 67.2 & 0.4 & 152 & 1\end{array}$ $\begin{array}{lllllllllllllllllllll}14 & 51.87 & 0.84 & 15.01 & 1.91 & 6.74 & 8.46 & 0.16 & 6.89 & 11.99 & 3.46 & 0.16 & 0.03 & 0.9 & 0.0 & 0.7 & 64.6 & 79.3 & 0.7 & 254\end{array}$ $\begin{array}{lllllllllllllllllllll}9 & 53.93 & 0.55 & 15.64 & 1.64 & 5.96 & 7.44 & 0.16 & 8.05 & 11.07 & 3.53 & 0.16 & 0.07 & 1.2 & 0.0 & 1.1 & 70.6 & 7.6 & 0.6 & 165 & 18\end{array}$ $\begin{array}{llllllllllllllllllll}7 & 52.69 & 0.33 & 16.30 & 2.96 & 5.51 & 8.17 & 0.20 & 8.03 & 8.15 & 4.00 & 0.13 & 0.13 & 1.3 & 0.3 & 1.3 & 72.2 & 69.2 & 0.5 & 88\end{array}$ $\begin{array}{lllllllllllllllllll}52.64 & 0.62 & 14.97 & 2.19 & 6.19 & 8.16 & 0.19 & 7.80 & 11.13 & 3.14 & 0.12 & 0.01 & 1 & 0.0 & 0.8 & 69.2 & 79.7 & 0.7 & 238\end{array}$ $\begin{array}{llllllllllllllllllllll}52.83 & 0.6 & 16.3 & 2.0 & 5.8 & 7.6 & 0.2 & 6.9 & 10.7 & 3.8 & 0.1 & 0.0 & 1.0 & 0.1 & 0.8 & 68.0 & 75.7 & 0.6 & 190 & 13\end{array}$ $\begin{array}{llllllllllllllllllll}1.05 & 0.2 & 2.3 & 0.6 & 1.1 & 1.4 & 0.0 & 1.6 & 1.5 & 0.7 & 0.0 & 0.0 & 0.3 & 0.1 & 0.3 & 72.6 & 69.1 & 0.6 & 66\end{array}$

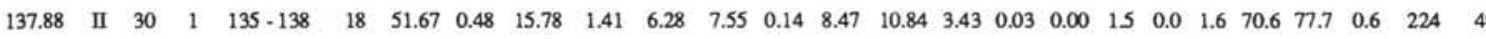

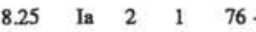

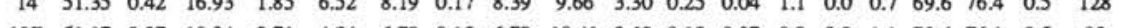

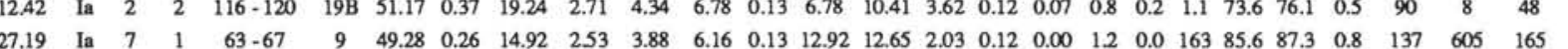

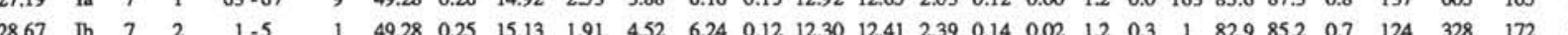

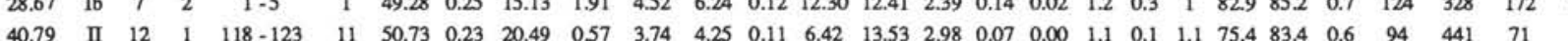

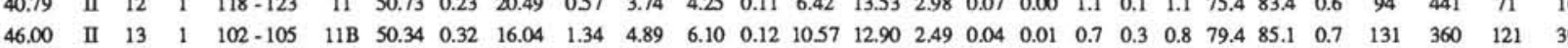
$\begin{array}{cccccccccccccccccccccccccccc}46.00 & \text { II } & 13 & 1 & 122-105 & 11 \text { B } & 50.34 & 0.32 & 16.04 & 1.34 & 4.89 & 6.10 & 0.12 & 10.57 & 12.90 & 2.49 & 0.04 & 0.01 & 0.7 & 0.3 & 0.8 & 79.4 & 85.1 & 0.7 & 131 & 360 & 121 & 39 \\ 54.40 & \text { II } & 14 & 3 & 136-141 & 10 & 51.71 & 0.38 & 17.20 & 1.10 & 4.42 & 5.41 & 0.11 & 7.95 & 13.04 & 2.99 & 0.04 & 0.01 & 0.8 & 0.3 & 0.7 & 76.2 & 82.8 & 0.7 & 171 & 76 & 59 & 18\end{array}$ $\begin{array}{llllllllllllllllllllllllllll}57.50 & \text { II } & 15 & 1 & 90 & -93 & 7 \text { B } & 51.40 & 0.60 & 16.39 & 1.44 & 6.12 & 7.42 & 0.12 & 8.54 & 10.93 & 3.37 & 0.07 & 0.04 & 1 & 0.0 & 0.9 & 71.3 & 78.2 & 0.6 & 179 & 72 & 68\end{array}$ $\begin{array}{llllllllllllllllllllllllllllll}61.74 & \text { II } & 15 & 3 & 92-96 & 8 & 50.25 & 0.44 & 14.06 & 1.55 & 6.27 & 7.67 & 0.13 & 10.94 & 12.58 & 2.44 & 0.07 & 0.02 & 1.1 & 0.2 & 0.8 & 75.7 & 85.1 & 0.8 & 173 & 308 & 122 & 12\end{array}$ $\begin{array}{cccccccccccccccccccccccccccc}62.99 & \text { II } & 16 & 1 & 139-141 & 3 \mathrm{H} & 51.56 & 1.13 & 16.56 & 1.37 & 5.85 & 7.08 & 0.10 & 7.67 & 10.86 & 3.73 & 0.07 & 0.20 & 0.9 & 0.0 & 0.9 & 70.0 & 76.3 & 0.6 & 169 & 36 & 76 & 9 \\ 68.01 & \text { II } & 17 & 1 & 22-27 & 5 & 50.74 & 0.56 & 15.34 & 1.23 & 5.91 & 7.02 & 0.13 & 10.37 & 11.76 & 2.64 & 0.08 & 0.04 & 1.2 & 0.0 & 1.1 & 75.8 & 83.1 & 0.7 & 122 & 854 & 179 & 55\end{array}$

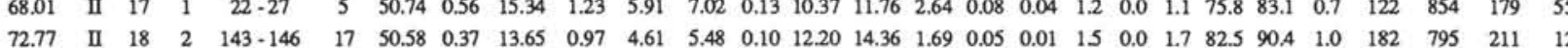
$\begin{array}{ccccccccccccccccccccccccccccc}72.77 & \text { II } & 18 & 2 & 143-146 & 17 & 50.58 & 0.37 & 13.65 & 0.97 & 4.61 & 5.48 & 0.10 & 12.20 & 14.36 & 1.69 & 0.05 & 0.01 & 1.5 & 0.0 & 1.7 & 82.5 & 90.4 & 1.0 & 182 & 795 & 211 \\ 79.46 & \text { II } & 19 & 3 & 73-75 & 6 \text { A } & 51.07 & 0.32 & 18.47 & 0.83 & 3.53 & 4.28 & 0.09 & 8.46 & 13.26 & 2.82 & 0.03 & 0.01 & 1.1 & 0.0 & 1 & 81.0 & 83.9 & 0.7 & 117 & 148 & 92\end{array}$ $\begin{array}{llllllllllllllllllllllllllll}93.51 & \text { II } & 21 & 2 & 53.56 & \text { 1B } & 52.06 & 0.31 & 19.60 & 3.77 & 0.00 & 3.39 & 0.08 & 7.03 & 14.19 & 2.94 & 0.03 & 0.01 & 0 & 0.0 & 1 & - & 84.2 & 0.7 & 124 & 165 & 79 & 10\end{array}$ $\begin{array}{lllllllllllllllllllllllllllllllll}967 & \text { II } & 22 & 2 & 86-91 & 3 \text { B } & 49.23 & 0.52 & 9.26 & 0.64 & 6.91 & 7.49 & 0.16 & 16.98 & 14.26 & 1.21 & 0.02 & 0.01 & 0.8 & 0.0 & 0.3 & 81.4 & 92.9 & 1.4 & 219 & 324 & 172 & 63\end{array}$

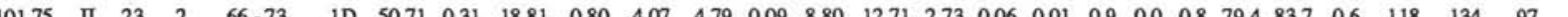
$\begin{array}{lllllllllllllllllllllllllllllll}109.72 & \text { II } & 24 & 4 & 1-6 & 1 \mathrm{~A} & 50.60 & 0.24 & 19.08 & 0.52 & 4.21 & 4.68 & 0.09 & 9.19 & 12.51 & 2.87 & 0.06 & 0.06 & 0.6 & 0.0 & 0.5 & 79.5 & 82.8 & 0.6 & 88 & 251 & 113 & 15 \\ 1\end{array}$ $\begin{array}{lllllllllllllllllllllllllllllll}109.72 & \text { II } & 24 & 4 & 1.6 & \text { 1A } & 50.60 & 0.24 & 19.08 & 0.52 & 4.21 & 4.68 & 0.09 & 9.19 & 12.51 & 2.87 & 0.06 & 0.06 & 0.6 & 0.0 & 0.5 & 79.5 & 82.8 & 0.6 & 88 & 251 & 113 \\ 114.27 & \text { II } & 25 & 3 & 43-48 & \text { 2B } & 50.48 & 0.26 & 17.86 & 0.43 & 3.97 & 4.36 & 0.09 & 10.22 & 13.65 & 2.37 & 0.02 & 0.00 & 0.5 & 0.1 & 0.4 & 82.1 & 86.4 & 0.7 & 122 & 368 & 125\end{array}$ $\begin{array}{lllllllllllllllllllllllllllll}114.27 & \text { II } & 25 & 3 & 43-48 & \text { 2B } & 50.48 & 0.26 & 17.86 & 0.43 & 3.97 & 4.36 & 0.09 & 10.22 & 13.65 & 2.37 & 0.02 & 0.00 & 0.5 & 0.1 & 0.4 & 82.1 & 86.4 & 0.7 & 122 & 368 & 125 \\ 116.84 & \text { II } & 26 & 1 & 131-134 & \text { 6A } & 49.82 & 0.27 & 15.70 & 0.59 & 4.18 & 4.71 & 0.11 & 11.90 & 14.22 & 1.91 & 0.04 & 0.01 & 1.3 & 0.0 & 0.5 & 83.5 & 89.2 & 0.8 & 130 & 459 & 171\end{array}$

$\begin{array}{cccccccc}32 & 42 & 60 & 3.3 & 157 & 19 & 26.0 & 0.7 \\ 16 & 9 & 35 & <0.8 & 259 & 11 & 17.0 & 0.0 \\ 30 & 42 & 62 & 3.2 & 158 & 21 & 27.0 & 0.5 \\ 51 & 22 & 56 & 1.8 & 157 & 36 & 37.0 & 2.4 \\ 89 & 18 & 45 & 1.4 & 199 & 28 & 969.0 & 1.3 \\ 50 & 68 & 58 & 1.5 & 170 & 17 & 39.0 & <0.5 \\ 45 & 34 & 53 & 2.2 & 183 & 22 & 185.8 & 1.0 \\ 25 & 21 & 11 & 0.9 & 40 & 9 & 383.8 & 0.9 \\ 47 & 9 & 30 & <0.8 & 168 & 13 & 12.9 & <0.5 \\ 53 & 25 & 56 & 3.0 & 176 & 12 & 26.0 & 0.6 \\ 48 & 22 & 42 & <0.8 & 220 & 7 & 15.0 & 0.6 \\ 165 & 35 & 28 & <0.8 & 141 & 9 & 8.3 & <0.5 \\ 172 & 20 & 35 & <0.8 & 125 & 12 & 24.0 & <0.5 \\ 71 & 16 & 35 & <0.8 & 194 & 8 & 12.1 & <0.5 \\ 121 & 39 & 38 & 1.0 & 159 & 12 & 25.2 & 0.6 \\ 59 & 18 & 27 & <0.8 & 175 & 14 & 18.7 & <0.5 \\ 68 & 12 & 31 & <0.8 & 163 & 28 & 110.0 & 1.2 \\ 122 & 12 & 27 & <0.8 & 134 & 14 & 23.9 & <0.5 \\ 76 & 9 & 17 & <0.8 & 187 & 41 & 187.0 & 2.1 \\ 179 & 55 & 40 & <0.8 & 153 & 31 & 89.0 & 1.8 \\ 211 & 12 & 26 & <0.8 & 111 & 12 & 15.9 & <0.5 \\ 92 & 12 & 21 & <0.8 & 177 & 8 & 18.6 & <0.5 \\ 79 & 10 & 18 & <0.8 & 185 & 8 & 15.5 & <0.5 \\ 172 & 63 & 48 & <0.8 & 84 & 15 & 27.1 & <0.5 \\ 97 & 10 & 24 & <0.8 & 176 & 8 & 11.6 & <0.5 \\ 113 & 15 & 22 & <0.8 & 172 & 7 & 13.2 & 0.5 \\ 125 & 21 & 23 & <0.8 & 162 & 6 & 6.5 & <0.5 \\ 171 & 43 & 29 & <0.8 & 135 & 7 & 9.7 & <0.5\end{array}$


Appendix B (continued).

\section{Hole 735B XRF Whole Rock Analyses}

Lithology Olivine Gabbro Olivine Gabbro Olivine Gabbro Olivine Gabbro Olivine Gabbro Olivine Gabbro Olivine Gabbro Olivine Gabbro Olivine Gabbro Olivine Gabbro Olivine Gabbr Olivine Gabbro Olivine Gabbro Olivine Gabbro Olivine Gabbro Olivine Gabbro Olivine Gabbro Olivine Gabbro Olivine Gabbro Olivine Gabbro Olivine Gabbro Olivine Gabbro Olivine Gabbro Olivine Gabbro Olivine Gabbro Olivine Gabbro Olivine Gabbro Olivine Gabbro Olivine Gabbro Olivine Gabbro Olivine Gabbro Olivine Gabbro Olivine Gabbro Olivine Gabbro

Olivine Microgabbro Olivine Microgabbro Olivine Microgabbro

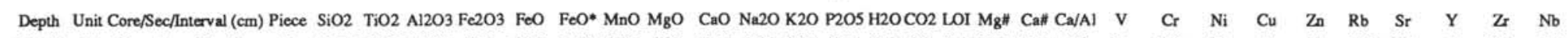
$\begin{array}{llllllllllllllllllllllllllllllllll}120.92 & \text { II } & 26 & 4 & 91-92 & 5 & 51.74 & 0.25 & 22.90 & 0.14 & 2.67 & 2.80 & 0.06 & 4.92 & 13.14 & 3.36 & 0.04 & 0.01 & 0.6 & 0.2 & 0.6 & 76.7 & 81.2 & 0.5 & 81 & 180 & 62 & 9 & 17 & <0.8 & 214 & 6 & 9.2 & <0.5\end{array}$ $\begin{array}{lllllllllllllllllllllllllllllllllllll}125.01 & \text { II } & 27 & 3 & 73-81 & \text { 1D } & 50.27 & 0.40 & 14.08 & 0.59 & 4.83 & 5.36 & 0.12 & 12.14 & 14.92 & 1.98 & 0.02 & 0.00 & 0.5 & 0.1 & 0.6 & 81.7 & 89.3 & 1.0 & 185 & 633 & 145 & 70 & 32 & <0.8 & 125 & 12 & 14.5 & <0.5\end{array}$ $\begin{array}{lllllllllllllllllllllllllllllllllllll}135.82 & \text { II } & 29 & 3 & 124-130 & 14 C & 49.93 & 0.26 & 17.78 & 0.93 & 4.00 & 4.84 & 0.10 & 10.04 & 13.32 & 2.47 & 0.05 & 0.00 & 1.1 & 0.0 & 1.4 & 81.7 & 85.6 & 0.7 & 116 & 327 & 117 & 11 & 25 & <0.8 & 159 & 8 & 7.3 & <0.5\end{array}$ $\begin{array}{llllllllllllllllllllllllllllllllllllll}145.27 & \text { II } & 31 & 2 & 40-45 & 2 \mathrm{~B} & 51.47 & 0.31 & 16.19 & 0.54 & 4.32 & 4.81 & 0.11 & 10.38 & 13.15 & 2.50 & 0.09 & 0.01 & 0.9 & 0.0 & 0.9 & 81.1 & 85.3 & 0.7 & 131 & 323 & 131 & 34 & 29 & 0.8 & 147 & 14 & 25.3 & <0.5\end{array}$ $\begin{array}{llllllllllllllllllllllllllllllllllll}145.27 & \text { II } & 31 & 2 & 40-45 & 2 B & 51.47 & 0.31 & 16.19 & 0.54 & 4.32 & 4.81 & 0.11 & 10.38 & 13.15 & 2.50 & 0.09 & 0.01 & 0.9 & 0.0 & 0.9 & 81.1 & 85.3 & 0.7 & 131 & 323 & 131 & 34 & 29 & 0.8 & 147 & 14 & 25.3 & <0.5 \\ 151.83 & \text { II } & 32 & 3 & 54-60 & \text { 1E } & 53.00 & 0.18 & 18.88 & 0.30 & 3.79 & 4.06 & 0.08 & 8.54 & 9.84 & 3.98 & 0.08 & 0.00 & 1.2 & 0.1 & 1.5 & 80.1 & 73.2 & 0.5 & 68 & 147 & 118 & 9 & 19 & <0.8 & 182 & 24 & 53.8 & 1.1\end{array}$

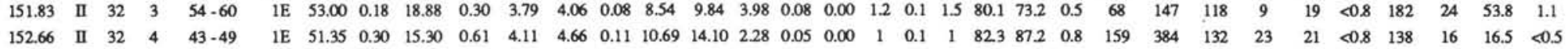
$\begin{array}{lllllllllllllllllllllllllllllllllll}156.86 & \text { II } & 33 & 3 & 85-89 & 7 & 51.56 & 0.23 & 21.19 & 0.27 & 2.82 & 3.06 & 0.07 & 6.24 & 13.66 & 3.10 & 0.05 & 0.00 & 0.8 & 0.0 & 0.9 & 79.8 & 83.0 & 0.6 & 87 & 240 & 64 & 9 & 15 & <0.8 & 193 & 6 & 7.2 & <0.5\end{array}$ $\begin{array}{lllllllllllllllllllllllllllllllllllllll}160.15 & \text { II } & 34 & 2 & 18 & -22 & \text { 1C } & 49.96 & 0.24 & 18.62 & 0.41 & 3.37 & 3.74 & 0.08 & 9.99 & 14.32 & 2.22 & 0.02 & 0.01 & 0.8 & 0.0 & 0.8 & 84.1 & 87.7 & 0.7 & 104 & 633 & 181 & 74 & 21 & 0.9 & 170 & 6 & 7.1 & <0.5 & \end{array}$ $\begin{array}{lllllllllllllllllllllllllllllllllllll}167.58 & \text { II } & 35 & 4 & 43-46 & 2 \text { A } & 49.53 & 0.23 & 16.41 & 0.85 & 4.05 & 4.82 & 0.10 & 12.60 & 13.33 & 2.17 & 0.04 & 0.00 & 0.7 & 0.0 & 0.6 & 84.7 & 872 & 0.7 & 107 & 464 & 239 & 47 & 25 & <0.8 & 152 & 8 & 8.7 & <0.5\end{array}$ $\begin{array}{llllllllllllllllllllllllllllllllllllll}173.47 & \text { Ia } & 36 & 2 & 98-102 & 1 E & 49.91 & 0.20 & 21.29 & 0.65 & 2.92 & 3.51 & 0.07 & 8.41 & 13.00 & 2.80 & 0.04 & 0.01 & 0.6 & 0.1 & 0.7 & 83.7 & 83.7 & 0.6 & 69 & 320 & 125 & 35 & 21 & <0.8 & 198 & 5 & 17.3 & <0.5\end{array}$ $\begin{array}{lllllllllllllllllllllllllllllllllllll}214.29 \text { IIIc } & 44 & 3 & 78-81 & \text { 5D } & 49.63 & 0.26 & 17.89 & 0.76 & 3.55 & 4.23 & 0.09 & 11.04 & 13.88 & 2.07 & 0.03 & 0.00 & 0.7 & 0.1 & 0.8 & 84.7 & 88.1 & 0.7 & 114 & 885 & 161 & 39 & 26 & <0.8 & 163 & 7 & 8.5 & <0.5\end{array}$ $\begin{array}{llllllllllllllllllllllllllllllllllll}230.96 & \text { IV } & 47 & 4 & 80-86 & 5 & 49.82 & 0.29 & 14.65 & 0.27 & 4.46 & 4.70 & 0.11 & 13.24 & 14.66 & 1.66 & 0.00 & 0.03 & 0.8 & 0.0 & 0.7 & 84.1 & 90.7 & 0.9 & 149 & 822 & 206 & 40 & 24 & <.8 & 134 & 7 & 7.2 & 0.8\end{array}$ $\begin{array}{lllllllllllllllllllllllllllllllllll}285.19 & \mathrm{~V} & 58 & 3 & 107-114 & \text { IF } & 50.26 & 0.37 & 16.37 & 1.39 & 5.46 & 6.71 & 0.13 & 10.32 & 12.51 & 2.76 & 0.04 & 0.00 & 0.4 & 0.0 & 0.4 & 77.1 & 83.4 & 0.7 & 128 & 212 & 115 & 37 & 38 & <0.8 & 172 & 8 & 11.0 & <0.5\end{array}$

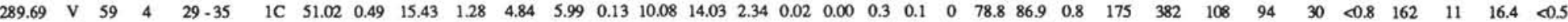
$\begin{array}{llllllllllllllllllllllllllllllllllll}291.30 & \mathrm{~V} & 60 & 1 & 80-83 & 1 \mathrm{E} & 51.85 & 0.36 & 18.04 & 0.41 & 3.57 & 3.94 & 0.10 & 7.61 & 14.72 & 2.75 & 0.03 & 0.00 & 0.6 & 0.0 & 0.8 & 79.2 & 85.5 & 0.7 & 139 & 397 & 70 & 50 & 22 & <0.8 & 180 & 10 & 13.5 & <0.5\end{array}$ $\begin{array}{lllllllllllllllllllllllllllllllllllllll}296.27 & \mathrm{~V} & 61 & 1 & 81-85 & 3 \mathrm{~A} & 49.74 & 0.34 & 16.53 & 1.04 & 5.62 & 6.56 & 0.13 & 10.66 & 12.93 & 2.37 & 0.01 & 0.01 & 0.7 & 0.0 & 0.2 & 77.2 & 85.8 & 0.7 & 126 & 305 & 139 & 95 & 35 & <0.8 & 159 & 8 & 11.6 & <0.5\end{array}$ $\begin{array}{llllllllllllllllllllllllllllllllllll}301.39 & \mathrm{~V} & 62 & 1 & 91-94 & 3 & 50.06 & 0.35 & 14.83 & 1.28 & 5.82 & 6.97 & 0.14 & 11.33 & 13.62 & 2.03 & 0.01 & 0.00 & 0.5 & 0.0 & 0.1 & 77.6 & 88.1 & 0.8 & 152 & 404 & 125 & 122 & 37 & <0.8 & 148 & 10 & 9.8 & <0.5\end{array}$ $\begin{array}{lllllllllllllllllllllllllllllllllllll}312.04 & \mathrm{~V} & 63 & 5 & 126-130 & 5 \mathrm{~A} & 51.05 & 0.28 & 17.45 & 0.53 & 4.41 & 4.89 & 0.10 & 9.53 & 13.10 & 2.68 & 0.03 & 0.00 & 0.8 & 0.0 & 0.7 & 79.4 & 84.4 & 0.7 & 120 & 433 & -123 & 20 & 31 & <0.8 & 165 & 22 & 17.5 & 0.8\end{array}$ $\begin{array}{llllllllllllllllllllllllllllllllllll}324.14 & \mathrm{~V} & 65 & 3 & 54-58 & \text { ID } & 49.83 & 0.33 & 16.39 & 0.67 & 4.78 & 5.38 & 0.11 & 11.41 & 13.72 & 2.05 & 0.02 & 0.00 & 0.7 & 0.0 & 0.5 & 81.0 & 88.1 & 0.8 & 123 & 584 & 196 & 91 & 30 & <0.8 & 153 & 8 & 12.7 & <0.5\end{array}$ $\begin{array}{llllllllllllllllllllllllllllllllllll}333.43 & \mathrm{~V} & 67 & 3 & 74-78 & 1 \mathrm{H} & 50.91 & 0.32 & 17.74 & 0.96 & 3.05 & 3.91 & 0.09 & 8.95 & 14.84 & 2.25 & 0.01 & 0.00 & 0.8 & 0.1 & 0.9 & 83.9 & 87.9 & 0.8 & 146 & 504 & 114 & 20 & 21 & <0.8 & 164 & 8 & 10.8 & <0.5 & \end{array}$ $\begin{array}{lllllllllllllllllllllllllllllllllllll}337.84 & \mathrm{~V} & 68 & 2 & 16-21 & 1 \mathrm{~B} & 47.40 & 0.23 & 14.87 & 0.59 & 7.29 & 7.82 & 0.14 & 15.98 & 10.97 & 1.84 & 0.01 & 0.00 & 0.7 & 0.0 & 0.1 & 79.6 & 86.8 & 0.7 & 88 & 353 & 260 & 117 & 45 & <0.8 & 146 & 6 & 8.3 & <0.5\end{array}$ $\begin{array}{llllllllllllllllllllllllllllllllllllll}343.97 & \mathrm{~V} & 69 & 3 & 86.92 & 5 \mathrm{C} & 50.30 & 0.34 & 16.80 & 1.23 & 3.80 & 4.91 & 0.10 & 10.52 & 14.17 & 2.17 & 0.02 & 0.00 & 0.5 & 0.1 & 0.3 & 83.1 & 87.8 & 0.8 & 134 & 519 & 149 & 56 & 25 & <0.8 & 161 & 9 & 12.9 & <0.5\end{array}$

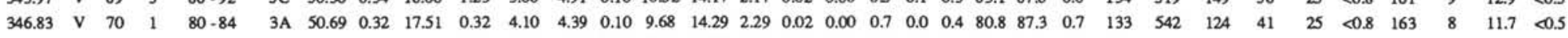
$\begin{array}{llllllllllllllllllllllllllllllllllllllll}353.46 & \mathrm{~V} & 71 & 2 & 129-131 & 3 \mathrm{C} & 48.29 & 0.28 & 19.26 & 0.73 & 3.44 & 4.10 & 0.12 & 7.92 & 12.58 & 3.21 & 0.02 & 0.00 & 4.2 & 0.0 & 0.4 & 80.4 & 81.2 & 0.6 & 88 & 317 & 109 & 22 & 37 & <0.8 & 235 & 17 & 59.0 & 1.4\end{array}$ $\begin{array}{lllllllllllllllllllllllllllllllllll}353.68 & \mathrm{~V} & 71 & 3 & 0.5 & 1 \mathrm{~A} & 50.43 & 0.32 & 17.59 & 0.94 & 3.80 & 4.65 & 0.10 & 9.96 & 14.03 & 2.29 & 0.02 & 0.00 & 0.4 & 0.1 & 0.5 & 82.4 & 87.1 & 0.7 & 112 & 496 & 134 & 88 & 27 & <0.8 & 164 & 8 & 11.3 & <0.5\end{array}$ $\begin{array}{lllllllllllllllllllllllllllllllllllll}357.99 & \mathrm{~V} & 72 & 2 & 56-62 & 1 \mathrm{D} & 49.89 & 0.38 & 17.56 & 1.05 & 4.45 & 5.40 & 0.11 & 10.45 & 13.43 & 2.25 & 0.02 & 0.01 & 0.3 & 0.1 & 0.1 & 80.7 & 86.8 & 0.7 & 116 & 315 & 124 & 60 & 31 & <0.8 & 164 & 9 & 15.1 & <05 & 0.5\end{array}$ $\begin{array}{lllllllllllllllllllll}363.59 & \mathrm{~V} & 72 & 6 & 126-136 & 50.27 & 0.34 & 16.98 & & 4.85 & 4.85 & 0.10 & 1051 & 14.06 & 2.35 & 0.03 & 0.02 & 79.4 & 86.9 & 0.8\end{array}$

$\begin{array}{lllllllllllllllllllllllllllllllllll}366.06 & \mathrm{~V} & 73 & 1 & 54-57 & 3 \mathrm{~B} & 50.46 & 0.34 & 15.13 & 0.83 & 4.14 & 4.89 & 0.11 & 11.53 & 15.14 & 1.81 & 0.01 & 0.00 & 0.4 & 0.1 & 0.4 & 83.2 & 90.2 & 0.9 & 166 & 544 & 165 & 117 & 26 & <0.8 & 132 & 9 & 11.0 & <0.5\end{array}$ $\begin{array}{lllllllllllllllllllllllllllllllllll}382.96 & \text { Vla } & 74 & 6 & 115-119 & \text { SB } & 50.70 & 0.27 & 18.00 & 0.69 & 3.27 & 3.89 & 0.09 & 9.37 & 14.64 & 2.33 & 0.01 & 0.00 & 0.4 & 0.1 & 0.6 & 83.6 & 87.4 & 0.7 & 119 & 375 & 114 & 76 & 21 & <0.8 & 167 & 8 & 9.3 & <0.5\end{array}$ $\begin{array}{llllllllllllllllllllllllllllllllll}389.91 & \text { VIa } & 75 & 5 & 27-30 & 1 \text { A } & 51.00 & 0.29 & 16.48 & 0.43 & 3.74 & 4.13 & 0.10 & 10.10 & 15.33 & 2.00 & 0.01 & 0.00 & 0.5 & 0.0 & 0.3 & 82.8 & 89.4 & 0.8 & 139 & 441 & 126 & 100 & 21 & <0.8 & 152 & 8 & 8.4 & <0.5\end{array}$ $\begin{array}{lllllllllllllllllll}402.80 & \text { Vla } & 76 & 6 & 44-54 & 50.92 & 0.38 & 17.35 & 5.35 & 5.35 & 0.11 & 9.38 & 13.74 & 2.61 & 0.04 & 0.03 & 75.8 & 85.3 & 0.7\end{array}$

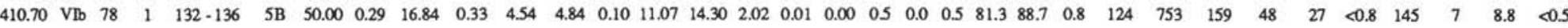
$\begin{array}{lllllllllllllllllllllllllllllllllll}430.83 & \text { VIc } & 80 & 6 & 6.9 & 1 & 50.66 & 0.38 & 15.04 & 0.21 & 5.03 & 5.22 & 0.12 & 11.54 & 14.28 & 2.18 & 0.01 & 0.00 & 0.6 & 0.0 & 0.4 & 80.3 & 87.9 & 0.9 & 159 & 227 & 135 & 47 & 28 & <0.8 & 129 & 10 & 14.0 & <0.5\end{array}$ $\begin{array}{lllllllllllllllllllllllllllllllllll}439.39 & \text { VId } 81 & 5 & 1.7 & 1 & 50.81 & 0.24 & 18.17 & 0.22 & 4.02 & 4.22 & 0.09 & 9.83 & 13.65 & 2.41 & 0.02 & 0.00 & 0.5 & 0.0 & 0.4 & 81.3 & 86.2 & 0.7 & 92 & 410 & 1.45 & 90 & 24 & <0.8 & 146 & 9 & 11.8 & <0.5\end{array}$ $\begin{array}{lllllllllllllllllllllllllllllllll}468.59 & \text { VId } 84 & 5 & 80-82 & 9 & 50.86 & 0.46 & 15.09 & 0.61 & 4.87 & 5.42 & 0.12 & 10.40 & 14.69 & 2.20 & 0.02 & 0.02 & 0.7 & 0.0 & 0.5 & 79.2 & 88.1 & 0.9 & 184 & 318 & 102 & 83 & 31 & <0.8 & 152 & 13 & 22.7 & 0.7\end{array}$ $\begin{array}{lllllllllllllllllllllllllllllll}\text { Average } 50.52 & 0.3 & 17.0 & 0.9 & 4.4 & 5.2 & 0.1 & 10.1 & 13.3 & 2.5 & 0.0 & 0.0 & 0.8 & 0.1 & 3.8 & 80.3 & 85.4 & 0.7 & 129.8 & 383.3 & 129.1 & 44.7 & 28.3 & 1.4 & 160.8 & 11.2 & 22.1 & 1.0\end{array}$ $\begin{array}{llllllllllllllllllllllllllllll}\text { Standard Deviation. } & 0.93 & 0.1 & 2.2 & 0.7 & 1.2 & 1.3 & 0.0 & 2.2 & 1.3 & 0.5 & 0.0 & 0.0 & 0.6 & 0.1 & 4.5 & 3.9 & 0.1 & 32.8 & 212.2 & 46.4 & 33.0 & 8.3 & 1.1 & 26.6 & 6.9 & 30.2 & 0.5\end{array}$

$\begin{array}{lllllllllllllllllllllllllllllllllll}73.40 & \text { II } & 18 & 3 & 37.40 & 4 & 48.00 & 0.19 & 17.32 & 1.42 & 4.86 & 6.14 & 0.09 & 11.71 & 11.34 & 2.46 & 0.18 & 0.01 & 2.3 & 0.2 & 2.3 & 81.1 & 83.6 & 0.6 & 76 & 327 & 233 & 5 & 17 & <0.8 & 157 & 5 & 11.8 & <0.5\end{array}$ $\begin{array}{lllllllllllllllllllllllllllllllllll}115.45 & \text { II } & 25 & 3 & 144-146 & 3 \text { B } & 48.30 & 0.21 & 16.01 & 0.80 & 4.93 & 5.65 & 0.12 & 13.85 & 12.67 & 2.11 & 0.07 & 0.00 & 1 & 0.0 & 0.9 & 83.4 & 86.9 & 0.7 & 92 & 383 & 220 & 103 & 35 & <0.8 & 145 & 6 & 4.5 & <0.5\end{array}$ $\begin{array}{llllllllllllllllllllllllllllllllllll}157.51 & \text { II } & 33 & 4 & 27-29 & 2 B & 53.90 & 0.37 & 17.54 & 1.35 & 4.71 & 5.93 & 0.12 & 6.60 & 10.44 & 4.19 & 0.05 & 0.00 & 0.7 & 0.0 & 0.6 & 71.4 & 73.4 & 0.5 & 145 & 12 & 31 & 15 & 29 & <0.8 & 202 & 16 & 14.0 & 0.7\end{array}$ $\begin{array}{lllllllllllllllllllllllllllll}\text { Average } 50.07 & 0.3 & 17.0 & 1.2 & 4.8 & 5.9 & 0.1 & 10.7 & 11.5 & 2.9 & 0.1 & 0.0 & 1.3 & 0.1 & 1.2 & 78.6 & 81.3 & 0.6 & 104 & 241 & 161 & 41 & 27 & <0.8 & 168 & 9 & 10.1 & 0.7\end{array}$

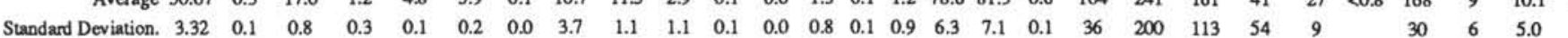


Appendix B (continued).

\section{Hole 735B XRF Whole Rock Analyses}

Lithology

Oxide Gabbro

Oxide Gabbro

Oxide Gabbro

Oxide Gabbro Norite Oxide Gabbro Norite

Oxide Microgabbro Norite

Oxide Olivine Gabbro Oxide Olivine Gabbro Oxide Olivine Gabbro Oxide Olivine Gabbro Oxide Olivine Gabbro Oxide Olivine Gabbro Oxide Olivine Gabbro Oxide Olivine Gabbro Oxide Olivine Gabbro

Oxide Olivine Microgabbro Oxide Olivine Microgabbro Oxide Olivine Microgabbro

Patchy Olivine Gabbro Patchy Olivine Gabbro Patchy Olivine Gabbro

Patchy Oxide Olivine Gabbro

Troctolite

Troctolite

Troctolite

Troctolite

Troctolite

Troctolite

Troctolite

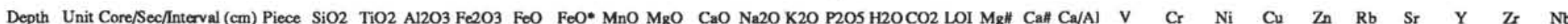

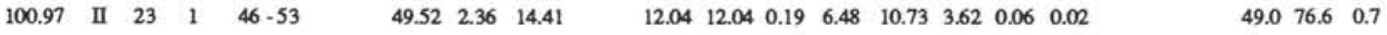

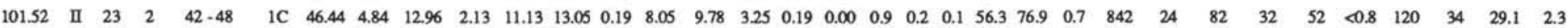
$\begin{array}{lllllllllllllllllllllllllllllllllll}145.60 & \text { II } & 31 & 2 & 77.81 & 3 \text { C } & 48.91 & 2.70 & 15.73 & 1.78 & 8.07 & 9.67 & 0.17 & 7.22 & 10.91 & 3.37 & 0.06 & 0.03 & 1 & 0.1 & 0.8 & 61.5 & 78.2 & 0.6 & 388 & 79 & 132 & 157 & 36 & <0.8 & 169 & 30 & 34.7 & 2.0\end{array}$ $\begin{array}{llllllllllllllllllllllllllllllllll}\text { Average } 48.29 & 3.3 & 14.4 & 2.0 & 10.4 & 11.6 & 0.2 & 7.3 & 10.5 & 3.4 & 0.1 & 0.0 & 0.9 & 0.1 & 0.5 & 55.6 & 77.2 & 0.7 & 615 & 52 & 107 & 95 & 44 & <0.8 & 145 & 32 & 31.9 & 2.2\end{array}$ $\begin{array}{lllllllllllllllllllllllllllll}\text { Standard Deviation. } & 1.63 & 1.3 & 1.4 & 0.2 & 2.1 & 1.7 & 0.0 & 0.8 & 0.6 & 0.2 & 0.1 & 0.0 & 0.0 & 0.0 & 0.5 & 6.3 & 0.8 & 0.0 & 321 & 39 & 35 & 88 & 11 & & 35 & 3 & 4.0 & 0.2\end{array}$ $\begin{array}{lllllllllllllllllllllllllllllllllll}129.49 & \text { II } & 28 & 3 & 63-69 & 4 & 51.88 & 1.13 & 11.66 & 3.00 & 11.19 & 13.89 & 0.33 & 9.88 & 7.14 & 2.91 & 0.05 & 0.05 & 0.8 & 0.0 & 0.2 & 61.1 & 73.1 & 0.6 & 165 & 2 & 34 & 44 & 117 & <0.8 & 153 & 19 & 27.8 & 1.2\end{array}$

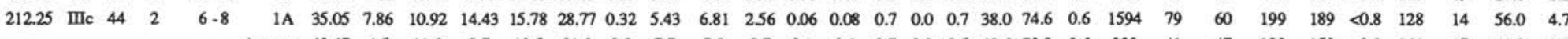

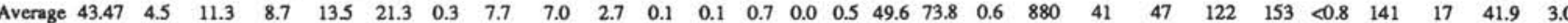
$50.301 .95 \quad 14.66$

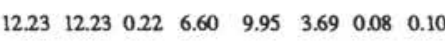
49.074 .90 .6

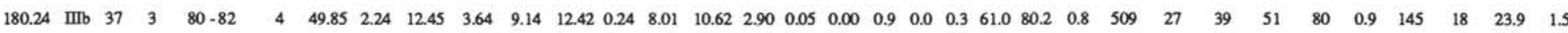
$\begin{array}{llllllllllllllllllllllllllllllllll}225.85 & \text { IV } & 46 & 4 & 109-113 & 11 & 45.62 & 6.10 & 14.92 & 5.55 & 10.27 & 15.27 & 0.20 & 4.27 & 8.74 & 3.68 & 0.05 & 0.01 & 0.6 & 0.0 & 0.1 & 42.6 & 72.4 & 0.5 & 77 & 5 & 31 & 71 & 82 & 0.9 & 200 & 13 & 45.0 & 2.8\end{array}$ $\begin{array}{lllllllllllllllllllll}228.57 & \text { IV } & 47 & 2 & 117-127 & 36.44 & 8.57 & 6.71 & 28.42 & 28.42 & 0.32 & 8.28 & 10.00 & 1.39 & 0.03 & 0.02 & 34.2 & 88.8 & 1.4\end{array}$

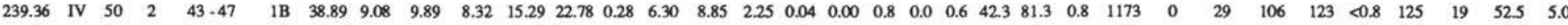

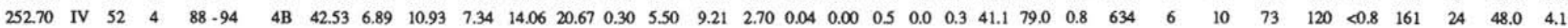
$\begin{array}{llllllllllllllllllllllllllllllllllll}253.49 & \text { IV } & 53 & 1 & 47-54 & 2 \mathrm{C} & 44.66 & 6.34 & 11.41 & 5.15 & 13.51 & 18.15 & 0.28 & 5.48 & 9.52 & 3.02 & 0.04 & 0.00 & 0.6 & 0.0 & 0.3 & 42.0 & 77.7 & 0.8 & 542 & 3 & 8 & 62 & 109 & <0.8 & 153 & 23 & 48.6 & 4.0\end{array}$ $\begin{array}{llllllllllllllllllllllllllllllllllll}259.26 & \text { IV } & 54 & 1 & 131 & -136 & 8 \mathrm{~B} & 44.86 & 2.33 & 12.02 & 5.35 & 17.69 & 22.51 & 0.42 & 5.03 & 6.72 & 3.47 & 0.17 & 1.20 & 0.8 & 0.0 & 0.8 & 33.6 & 68.2 & 0.5 & 70 & 0 & 10 & 57 & 170 & <0.8 & 193 & 69 & 59.2 & 5.6\end{array}$ $\begin{array}{llllllllllllllllllllllllllllllllll}267.52 & \text { IV } & 55 & 2 & 101-105 & 4 & 41.69 & 7.23 & 10.66 & 7.33 & 15.13 & 21.73 & 0.30 & 5.29 & 9.15 & 259 & 0.05 & 0.03 & 0.6 & 0.0 & 0.4 & 38.4 & 79.6 & 0.8 & 628 & 11 & 19 & 86 & 133 & 0.8 & 155 & 32 & 104.1 & 6.5\end{array}$ $\begin{array}{llllllllllllllllllll}267.67 & \text { IV } & 55 & 2 & 110-120 & 41.24 & 6.12 & 9.61 & 24.69 & 24.69 & 0.33 & 6.46 & 8.85 & 2.63 & 0.06 & 0.05 & 31.8 & 78.8 & 0.8\end{array}$

$\begin{array}{lllllllllllllllllllllllllllll}\text { Average } 42.86 & 6.1 & 11.0 & 6.1 & 16.5 & 20.7 & 0.3 & 6.1 & 9.1 & 2.7 & 0.1 & 0.1 & 0.7 & 0.0 & 0.4 & 40.8 & 78.4 & 0.8 & 619.0 & 7.4 & 20.9 & 72.3 & 116.7 & 0.9 & 161.7 & 28.3 & 54.5 & 4.2\end{array}$ $\begin{array}{lllllllllllllllllllllllllllll}\text { Standard Deviation. } & 3.95 & 2.4 & 2.2 & 1.6 & 6.3 & 4.9 & 0.1 & 1.3 & 1.1 & 0.7 & 0.0 & 0.4 & 0.1 & 0.0 & 0.2 & 8.6 & 5.7 & 0.2 & 329.5 & 9.4 & 12.3 & 18.8 & 31.0 & 0.1 & 26.4 & 18.9 & 24.5 & 1.7\end{array}$

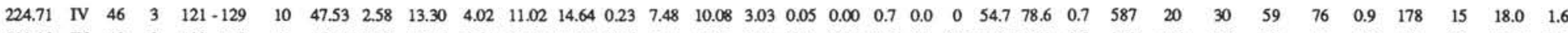
233.30 IV $48 \begin{array}{lllllllllllllllllllllllllllllllll} & 2 & 109-113 & 9 & 45.41 & 3.73 & 12.13 & 5.51 & 12.76 & 17.72 & 0.25 & 7.36 & 9.37 & 2.72 & 0.04 & 0.00 & 0.6 & 0.1 & 0.3 & 50.7 & 79.2 & 0.7 & 712 & 110 & 39 & 84 & 94 & <0.8 & 155 & 16 & 21.0 & 1.8\end{array}$

$$
\begin{array}{llllllllllllllllllllllllllll}
\text { VIc } & 80 & 7 & 56-65 & 43.98 & 6.23 & 12.26 & 18.15 & 18.15 & 0.25 & 6.25 & 9.36 & 3.17 & 0.04 & 0.01 & 38.0 & 76.5 & 0.7
\end{array}
$$

$\begin{array}{lllllllllllllllllllllllllllll}\text { Average } 45.64 & 4.2 & 12.6 & 4.8 & 14.0 & 16.8 & 0.2 & 7.0 & 9.6 & 3.0 & 0.0 & 0.0 & 0.6 & 0.1 & 0.2 & 47.3 & 78.1 & 0.7 & 650 & 65 & 35 & 72 & 85 & 0.9 & 167 & 16 & 19.5 & 1.7\end{array}$ $\begin{array}{lllllllllllllllllllllllllllll}\text { Standard Deviation. } & 1.79 & 1.9 & 0.6 & 1.1 & 3.7 & 1.9 & 0.0 & 0.7 & 0.4 & 0.2 & 0.0 & 0.0 & 0.1 & 0.1 & 0.2 & 24.5 & 665 & 0.6 & 88 & 64 & 6 & 18 & 13 & & 16 & 1 & 2.1 & 0.1\end{array}$

$\begin{array}{lllllllllllllllllllllllllllllllllllll}397.67 & \text { VIa } & 76 & 3 & 93-97 & 2 \mathrm{H} & 49.49 & 0.25 & 17.56 & 0.94 & 4.53 & 5.38 & 0.10 & 11.41 & 13.04 & 2.13 & 0.00 & 0.00 & 0.5 & 0.1 & 0.6 & 81.8 & 87.1 & 0.7 & 108 & 335 & 137 & 108 & 29 & <0.8 & 161 & 6 & 7.5 & <0.5\end{array}$

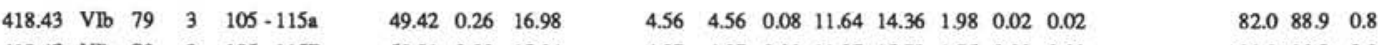
$\begin{array}{lllllllllllllllllll}418.47 & \mathrm{Vlb} & 79 & 3 & 105-115 \mathrm{~B} & 50.21 & 0.33 & 15.04 & 4.27 & 4.27 & 0.09 & 11.87 & 15.72 & 1.75 & 0.02 & 0.02 & 83.2 & 90.8 & 0.9\end{array}$

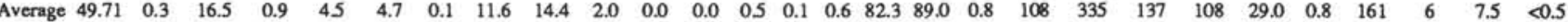
Standard Devintion. $\begin{array}{llllllllllllll}0.43 & 0.0 & 1.3 & 0.3 & 0.6 & 0.0 & 0.2 & 1.3 & 0.2 & 0.0 & 0.0\end{array}$ 
Appendix B (continued).

\section{Hole 735B XRF Whole Rock Analyses}

Lithology

Troctolitic Gabbro Troctolitic Gabbro Troctolitic Gabbro

Troctolitic Microgabbro Troctolitic Microgabbro

Trondjhenite

Depth Unit Core/Sec/Interval (cm) Piece $\mathrm{SiO}_{2} \mathrm{TiO}_{2} \mathrm{Al}_{2} \mathrm{O}_{3} \mathrm{Fe}_{2} \mathrm{O} 3 \mathrm{FeO} \quad \mathrm{FeO} * \mathrm{MnO} \mathrm{MgO} \quad \mathrm{CaO} \mathrm{Na} 2 \mathrm{O} \mathrm{K}_{2} \mathrm{O} \mathrm{P} 2 \mathrm{O} 5 \mathrm{H} 2 \mathrm{OCC}$

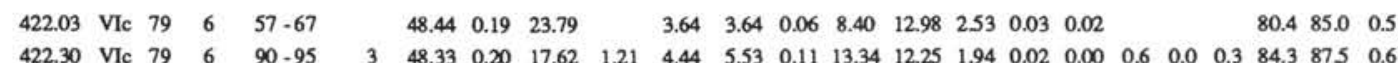
422.30 VIc 7926 $\begin{array}{llllllllllllllllllllllll}443.57 & \text { VId } & 82 & 1 & 49-54 & 3 & 49.36 & 0.20 & 19.04 & 0.00 & 4.88 & 4.88 & 0.09 & 13.07 & 12.99 & 1.62 & 0.01 & 0.01 & 0.7 & 0.0 & 0.9 & 82.7 & 89.9 & 0.6\end{array}$

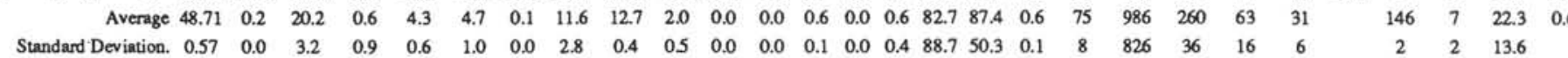

$\begin{array}{lllllllll}1570 & 285 & 51 & 26 & <0.8 & 144 & 5 & 12.7 & <0.5\end{array}$ $\begin{array}{lllllllllllllllllllllllllllllllllll}86.62 & \text { II } & 20 & 2 & 23-27 & 2 & 41.03 & 0.39 & 5.01 & 5.45 & 19.62 & 24.53 & 0.41 & 22.01 & 4.50 & 0.71 & 0.12 & 0.01 & 0.7 & 0.0 & 0.1 & 66.7 & 875 & 0.8 & 102 & 96 & 318 & 93 & 128 & 2.2 & 47 & 11 & 18.3 & 2.8\end{array}$ $\begin{array}{llllllllllllllllllll}219.16 \text { IIIc } & 45 & 3 & 78-92 & 48.68 & 0.17 & 20.33 & 4.14 & 4.14 & 0.07 & 10.72 & 12.70 & 2.41 & 0.02 & 0.02 & 82.2 & 85.3 & 0.6\end{array}$

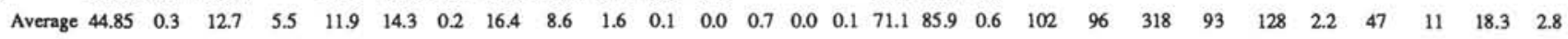

$\begin{array}{lllllllllllllllllllllllllllllllllll}257.89 & \text { IV } & 53 & 5 & 40-43 & 3 & 70.82 & 0.22 & 17.28 & 1.24 & 0.00 & 1.12 & 0.02 & 0.17 & 1.93 & 6.95 & 1.48 & 0.01 & 0 & 0.0 & 0.4 & - & 235 & 0.1 & 0 & 0 & 0 & 0 & 0 & 0.0 & 0 & 0 & 0.0 & 0.0\end{array}$ 


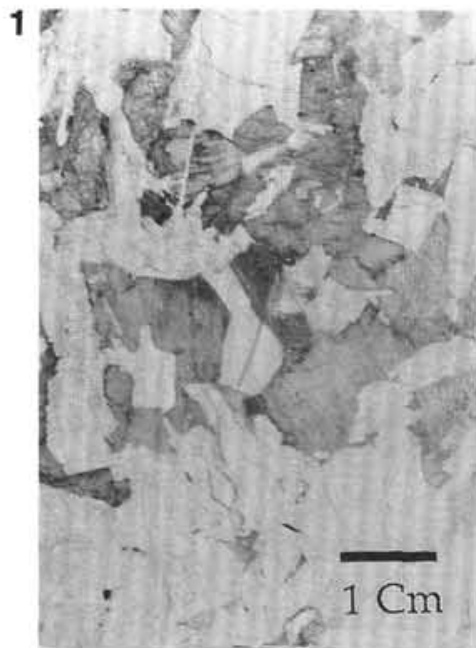

OLIVINE GABBRO

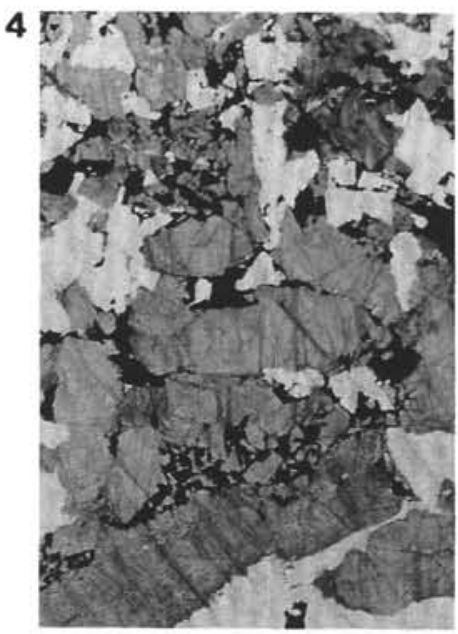

OXIDE OLIVINE GABBRO
2

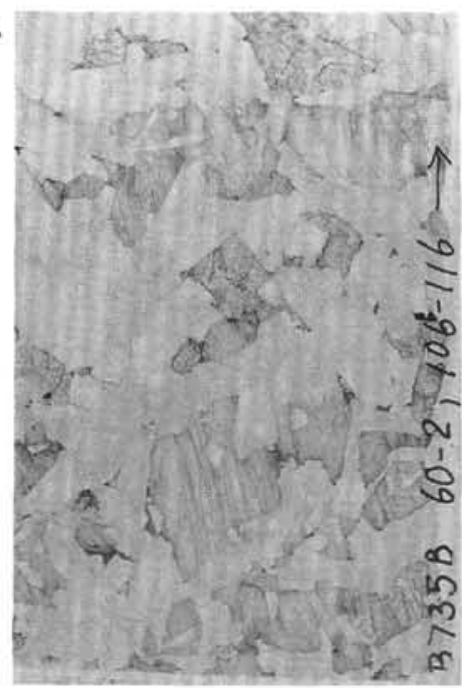

OLIVINE GABBRO

5

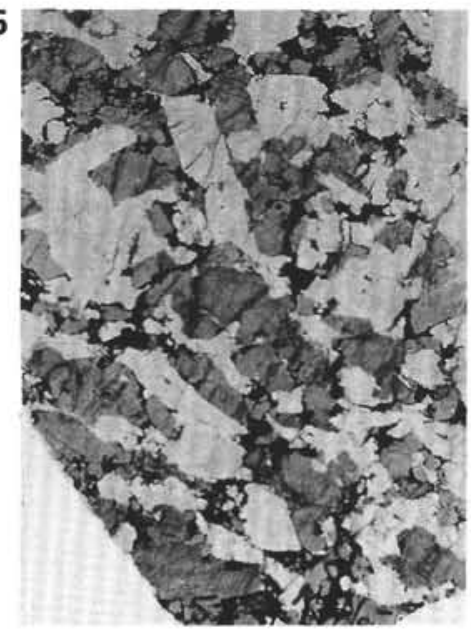

OXIDE OLIVINE GABBRO
3

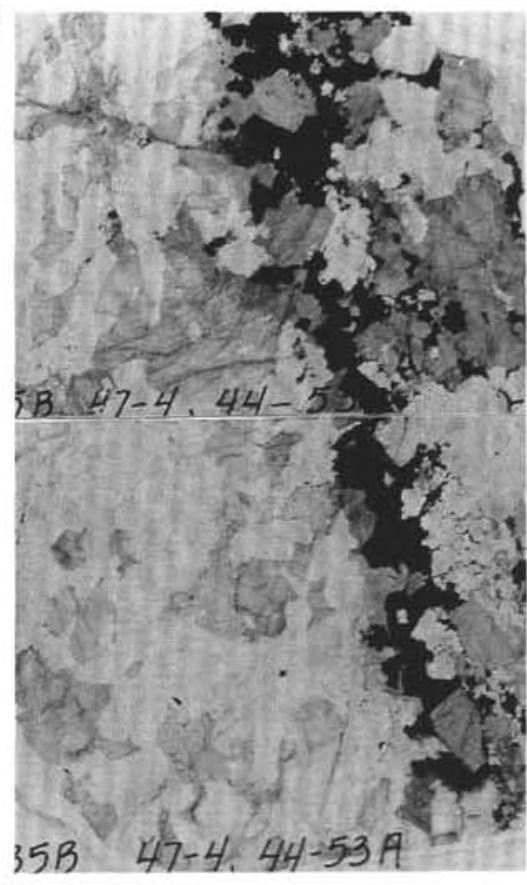

OXIDE/PX-RICH VEIN IN OLIVINE GABBRO

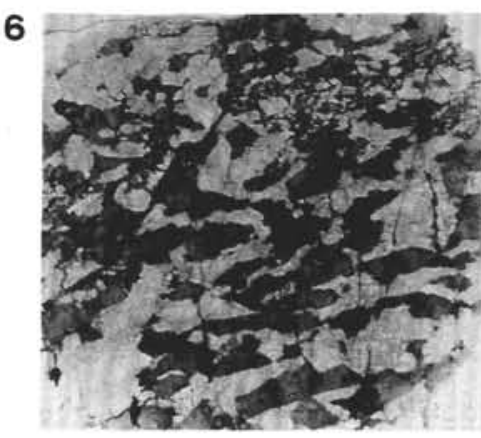

OXIDE OLIVINE GABBRO

Plate 1. Photomicrographs in plane light of Hole 735B gabbros showing contrasting pyroxene morphologies and textures in oxide-free and oxide-bearing olivine gabbros. 1. Core $67 \mathrm{R}-3,11-22 \mathrm{~cm}$, Unit V olivine gabbro with subophitic olivine and pyroxene partially enclosing subhedral plagioclase. 2. Core $60 \mathrm{R}-2,106-116 \mathrm{~cm}$, Unit V olivine gabbro. 3. Core 47R-4, 44-53 cm, Unit IV olivine gabbro with crosscutting subvertical pyroxene and iron-titanium oxide-rich vein. 4. Core $50 \mathrm{R}-3,40-50 \mathrm{~cm}$, Unit IV weakly deformed oxide-olivine gabbro. 5. Core 52R-1, 46-56 cm, Unit IV weakly foliated oxide-olivine gabbro containing stretched pyroxene with interstitial iron-titanium oxide in pull-apart cracks. 6. Core 53R-1, 127-137 cm, Unit IV foliated oxide-olivine gabbro containing extensively recrystallized plagioclase with interstitial iron-titanium oxide. All photomicrographs are at the same scale. $1-\mathrm{cm}$ scale bar is shown for reference. 

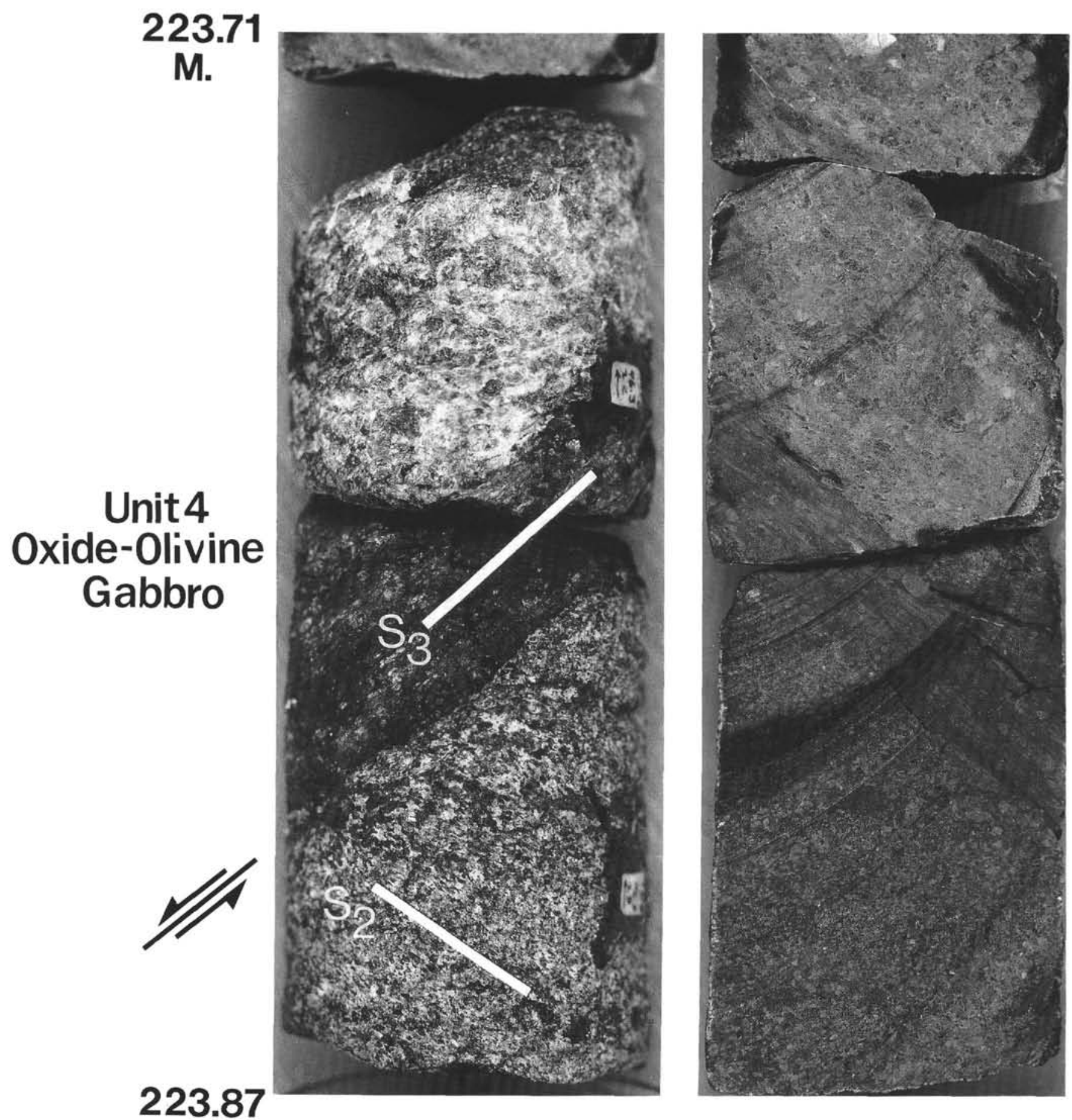

Plate 2. Back surface and cut surface of Core 46R-3 just below the Unit III/Unit IV contact showing a mylonite zone ( $\left.\mathrm{S}_{3}\right)$ crosscutting foliated oxide olivine gabbro. Curvature of the $\mathrm{S}_{2}$ foliation in the foliated oxide olivine gabbro immediately below the mylonite gives a clear normal shear sense. The mylonite zone juxtaposes texturally distinct Unit IV oxide olivine gabbros in Core $46 \mathrm{R}-3$. The mylonite zone and the foliation have approximately the same strike, but opposing dip. Core diameter is about $6 \mathrm{~cm}$. Note that $\mathrm{S}_{1}$ would refer to any primary cumulate layering in the core. 


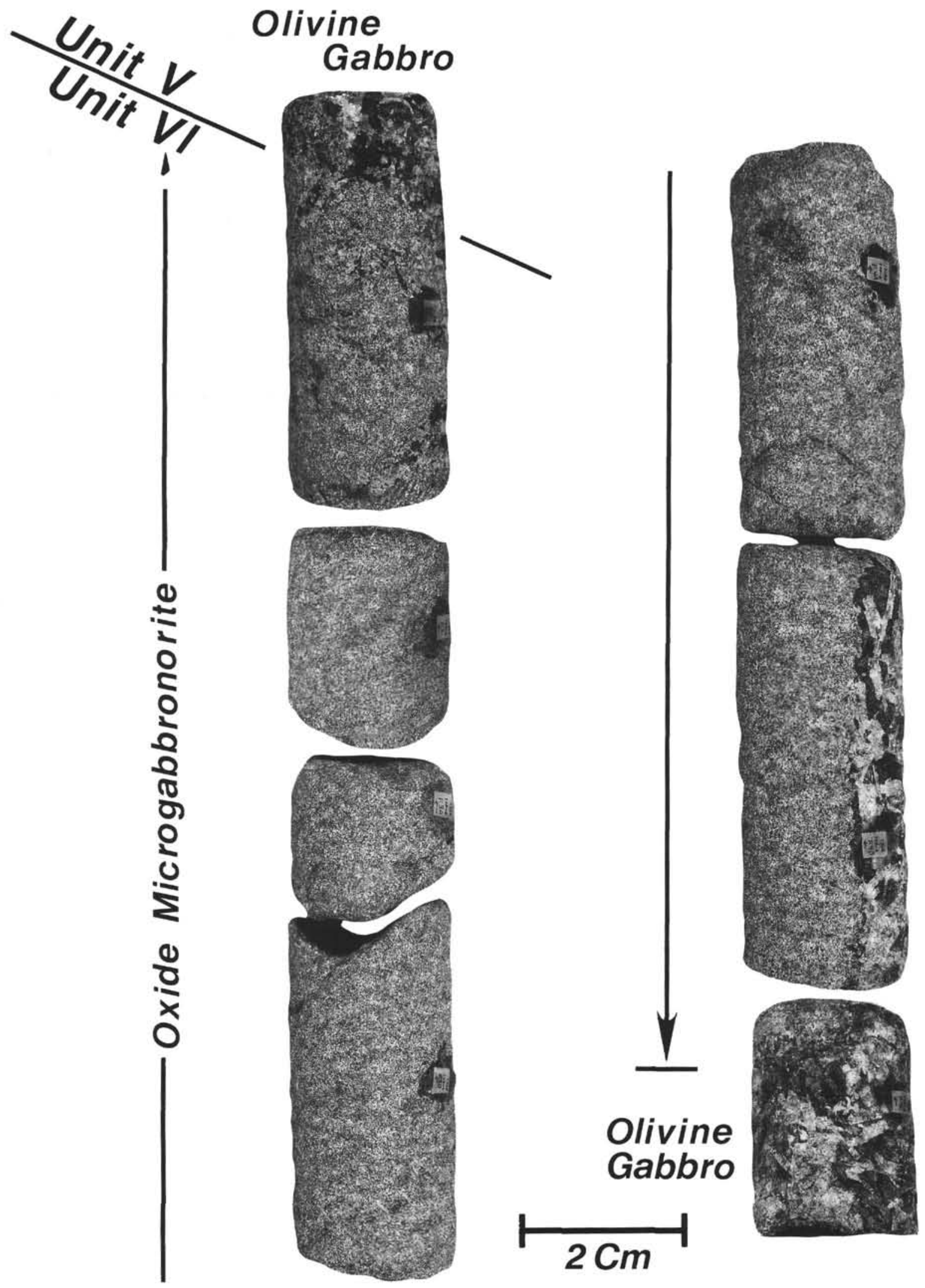

Plate 3. Unit V/Unit VI boundary at top of oxide microgabbronorite intruding olivine gabbro in Core 74R-6. Note that the upper and lower contacts of the oxide microgabbronorite are highly irregular with different dips and that there is no clear chill zone. Core diameter is about $6 \mathrm{~cm}$. 


\title{
Troctolitic Gabbro
}

\section{Oxide-rich}

\author{
Troctolitic
}

Microgabbro Boudins

Fold-nose with recrystallized plagioclase and olivine

\section{Sheared}

Oxide-rich

Troctolitic

Gabbro
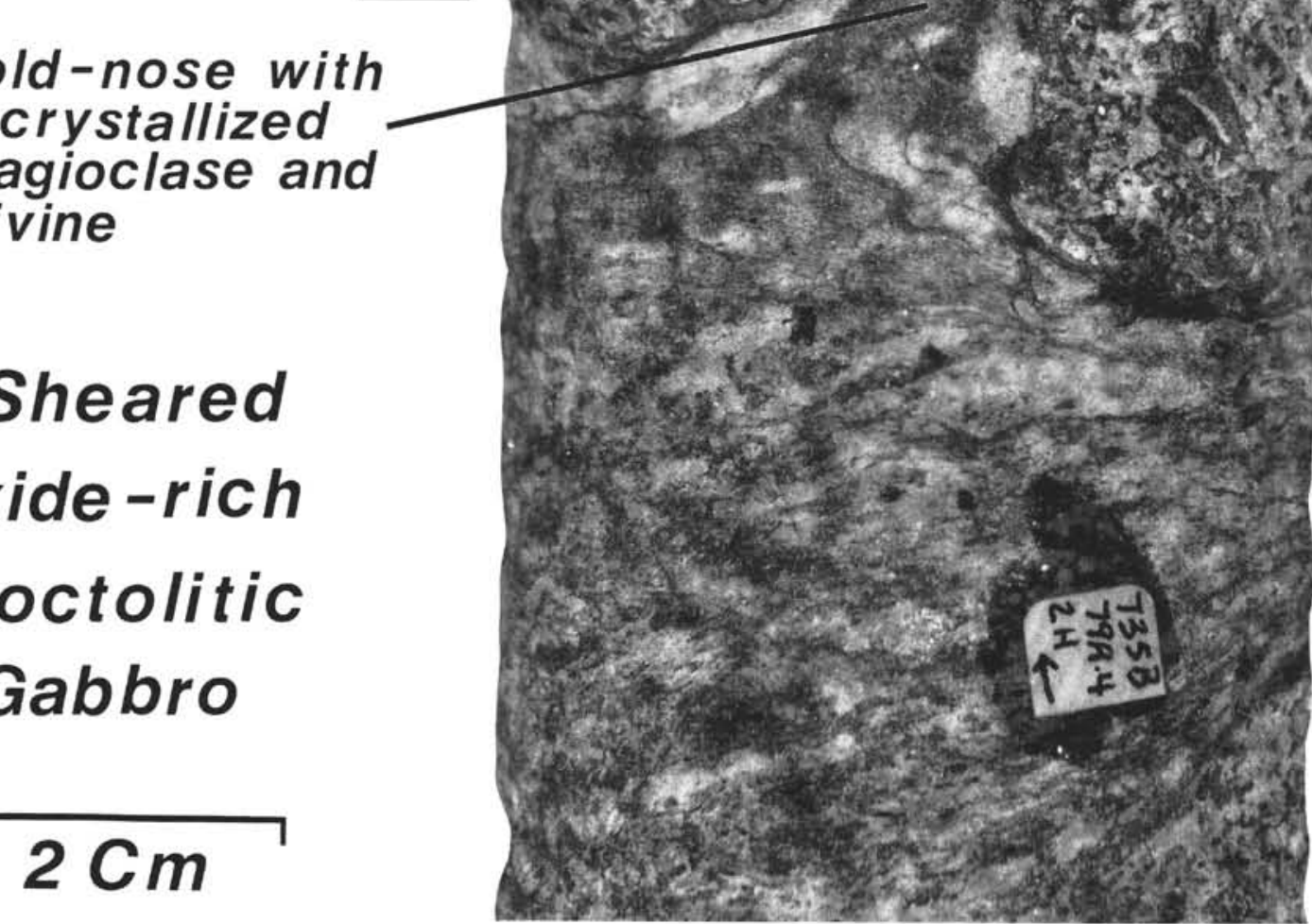

Plate 4. Similar folding of ductily deformed olivine and plagioclase between resistant olivine gabbro boudins in Core 79R-4, Pc. 2H. Plagioclase in fold is lighter mineral, olivine is darker mineral, while black mineral may be either pyroxene or iron-titanium oxide. Note that oxide is concentrated locally along the edge of the shear zone at contact with boudins. Upper oxide-rich shear zone, about $0.5 \mathrm{~cm}$ thick, separates coarse oxide-free troctolitic gabbro from troctolitic microgabbro boudins. 
1

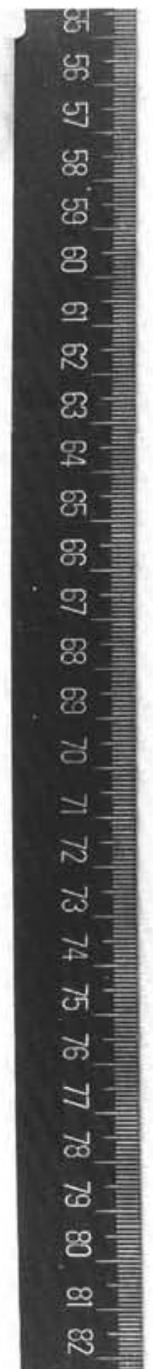

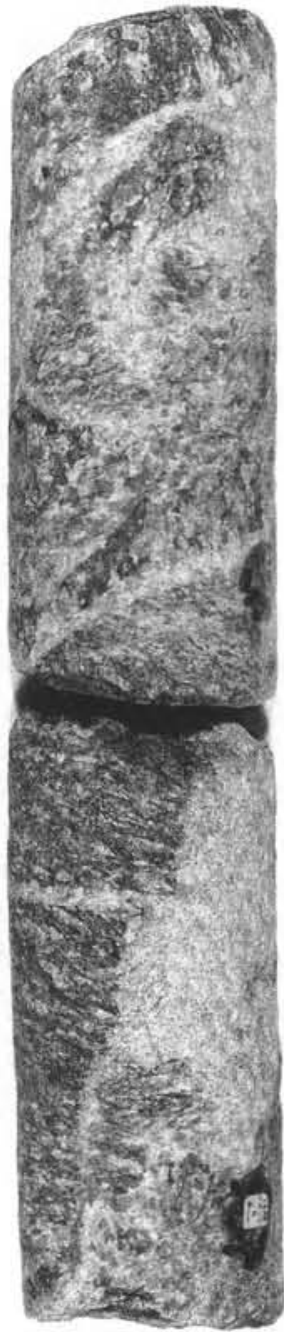

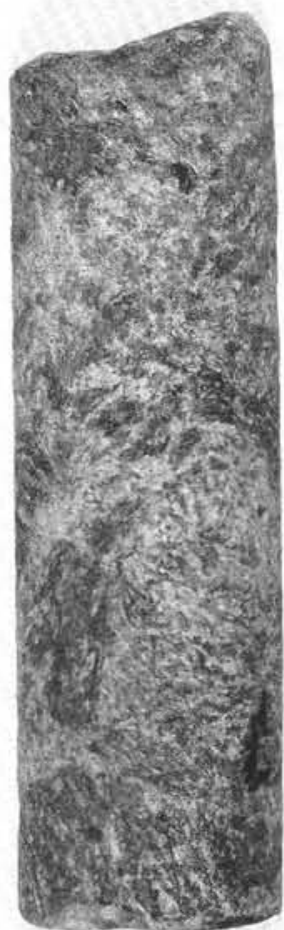

2

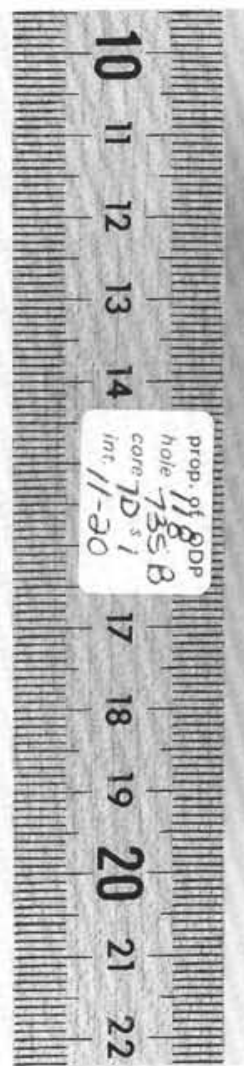

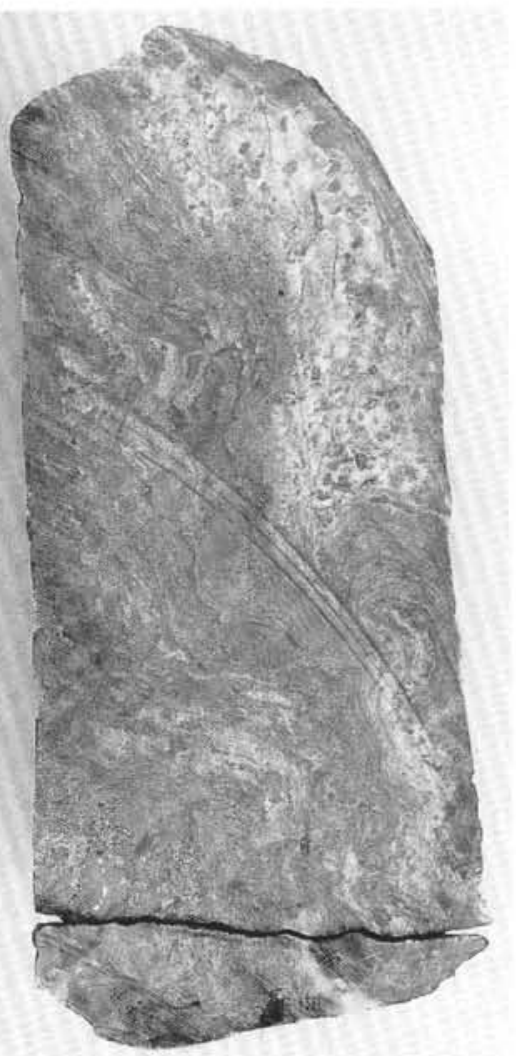

Plate 5. 1. Trondhjemite intrusion breccia crosscutting foliated oxide olivine gabbro in Unit IV (Core 53R-4, Pcs. 5, 6, 7A). 2. Ptygmatically folded, zircon-bearing trondhjemite in Unit I amphibole gneiss (Core 7R-1, Pc. 2). 
4
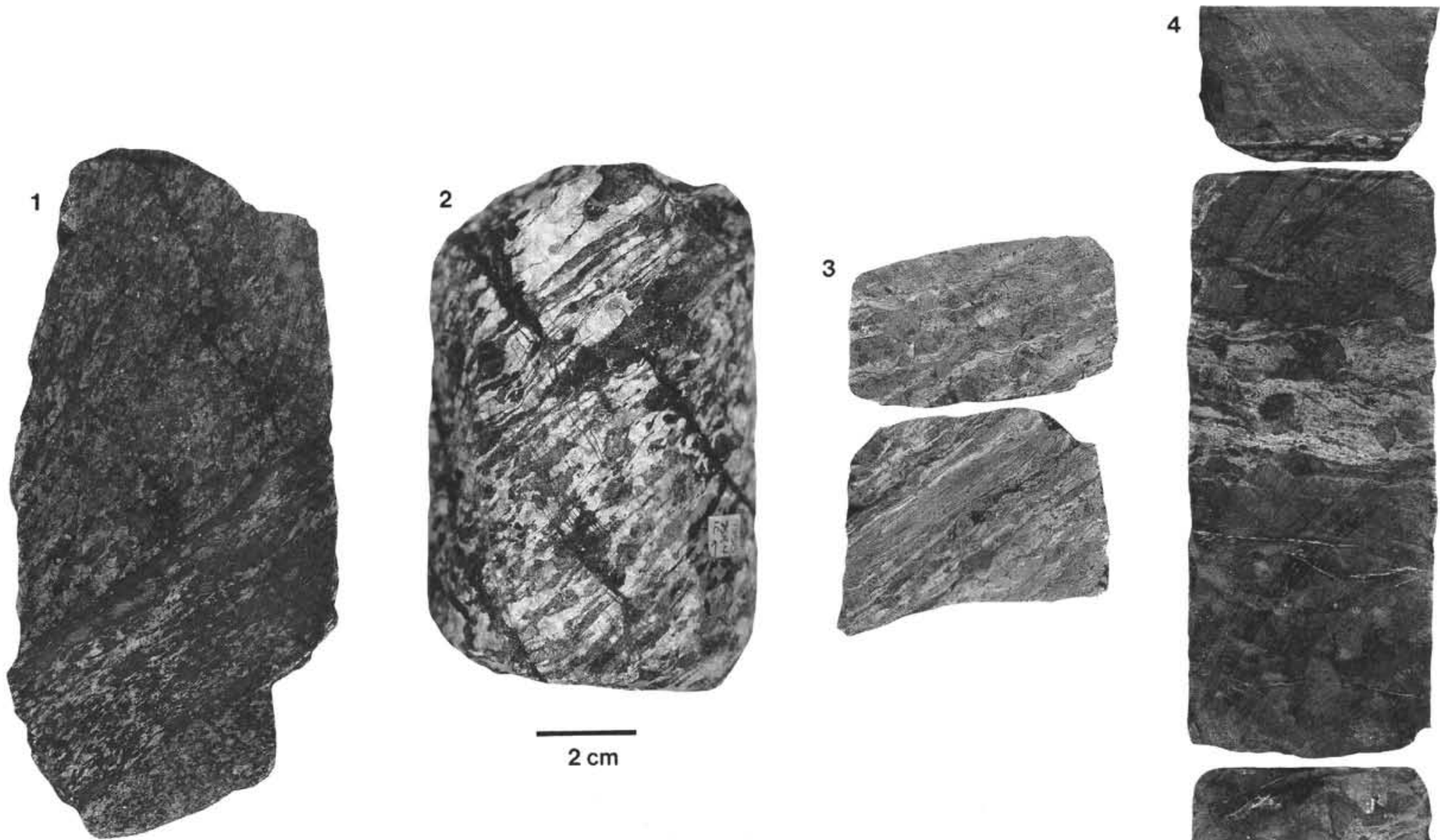

3

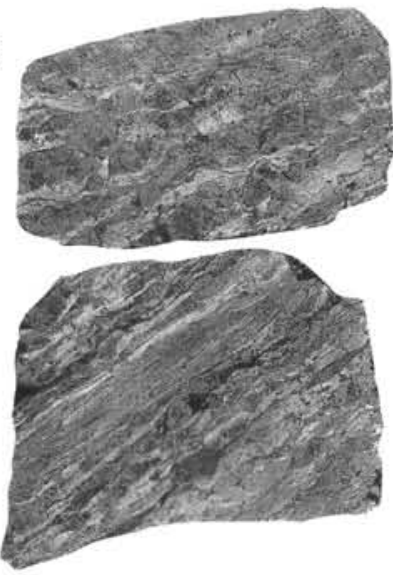

$2 \mathrm{~cm}$

Plate 6. Subsolidus ductile deformation zones ( $\mathrm{S}_{3}$ foliation). 1. Grade 1 weakly deformed Unit II olivine gabbro in direct contact with a 0.2 -cm zone of grade 5 ultramylonite at the edge of a $2.8-\mathrm{cm}$ band of grade 2 strongly foliated olivine gabbro in contact with underlying grade 1 weakly foliated olivine gabbro at $137.5 \mathrm{~m}$ (Core 30R-1, Pc. 12). Note that mylonite crosscuts the amphibole veins, which in turn are crosscutting the weakly deformed gabbro. 2. Grade 3 porphyroclastic Subunit VID olivine gabbro mylonite; part of a broader 3-m zone of fairly uniformly deformed amphibolite gneiss near the base of the hole at $476 \mathrm{~m}$, showing orthogonal black amphibole veins crosscutting the foliation (Core $85 \mathrm{R}-4$, Pc. 1c). 3. Variably deformed Unit I gabbronorite with oxide gabbronorite ( $84-90 \mathrm{~cm}$ ) mylonite band lying in $S_{3}$ plane (Core $1 R-2$, Pcs. 11 through 14). Extreme textural variability might locally be attributed to a less competent oxide-bearing band; however, a texturally similar oxide-free mylonite band exists at 76 to $79 \mathrm{~cm}$ in the same section of core. 4 . Gradational contact from undeformed grade 0 coarse olivine gabbro upward to a grade 4 oxide gabbro mylonite representing overprinting of the $\mathrm{S}_{2}$ late-magmatic foliation by later subsolidus amphibolite facies brittle-ductile deformation $\mathrm{S}_{3}$. Original late-magmatic igneous contact between olivine gabbro and oxide gabbro lies at $23 \mathrm{~cm}$ in the section and has been transposed into the $\mathrm{S}_{3}$ foliation plane (Core 28R-1, Pcs. 2 and 3). 
1

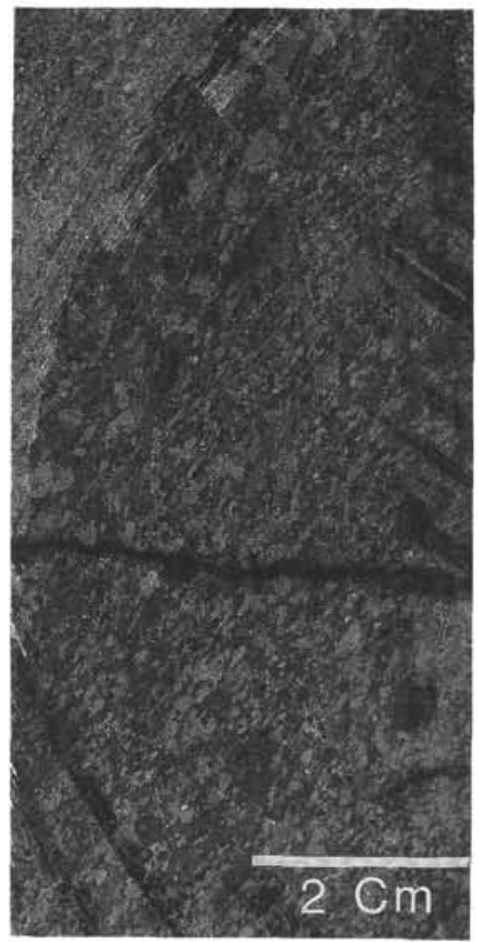

2

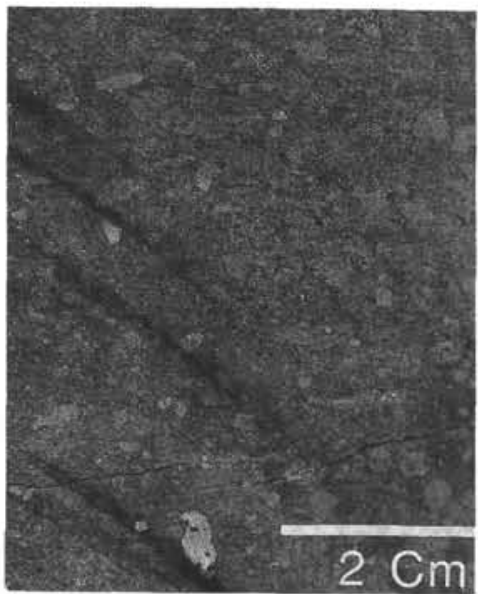

3

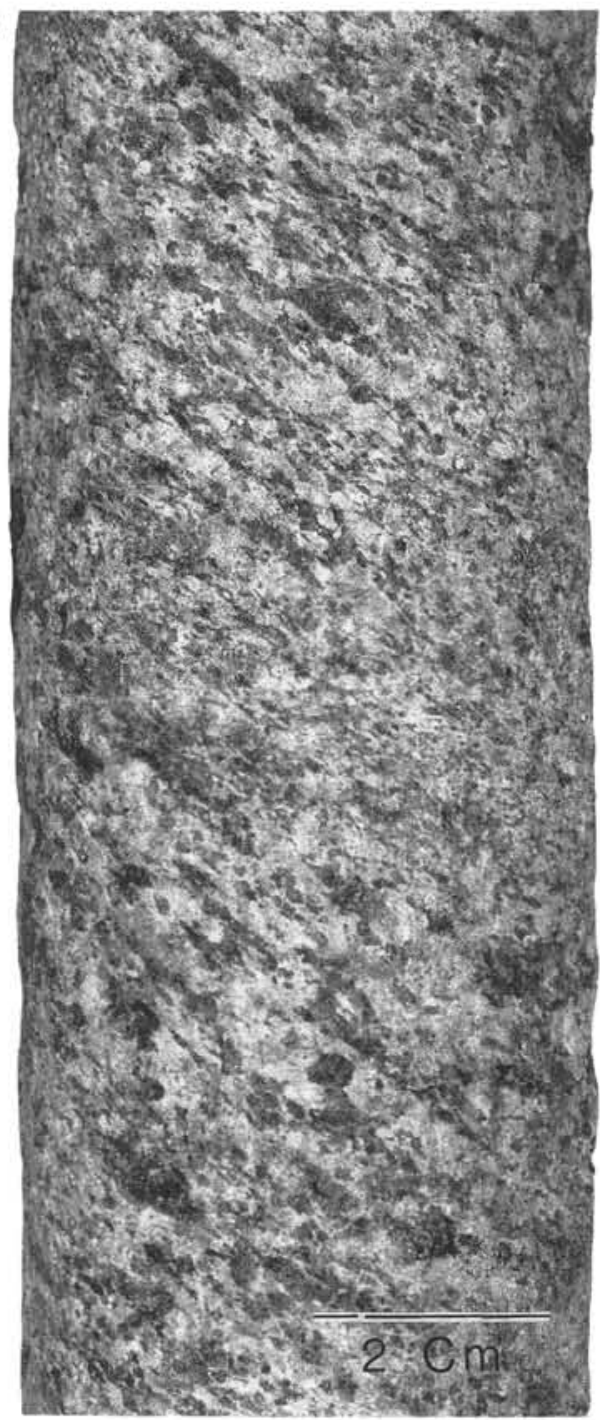

4

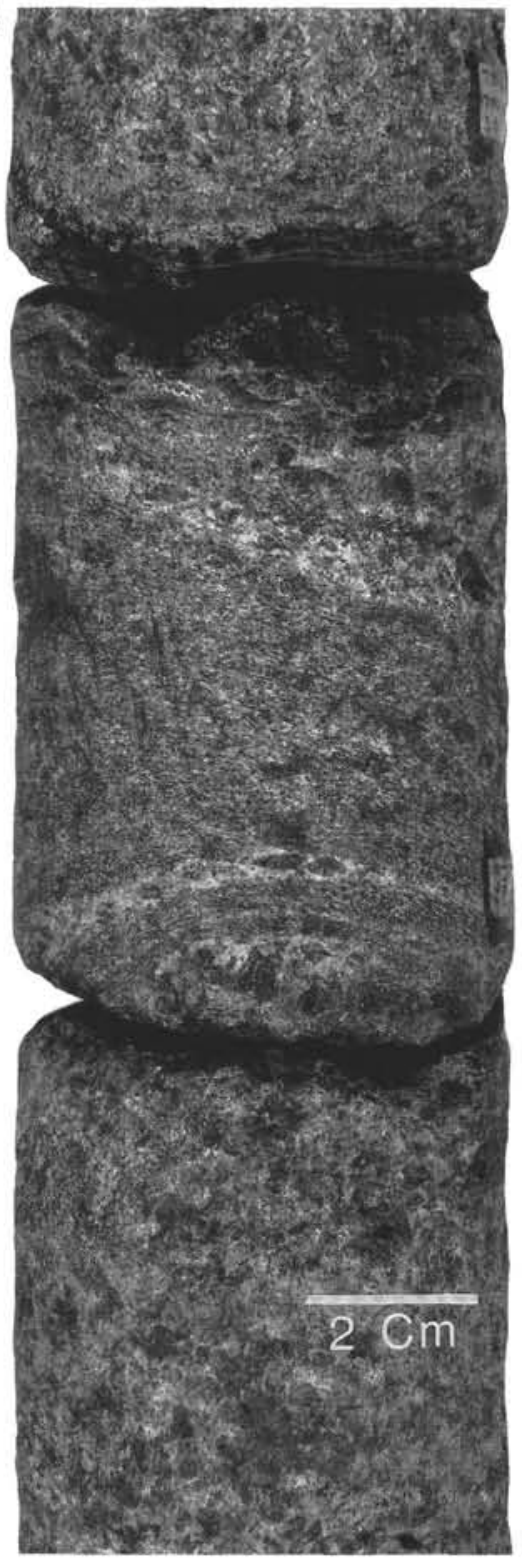

Plate 7. Textural characteristics of late-magmatic deformation. 1. Cut surface of a weakly foliated Subunit IIIB disseminated oxide olivine gabbro showing typical penetrative foliation and sutured igneous grain boundaries characteristic of late-magmatic deformation (Core 38R-4, Pc. 1a). 2. Cut surface of an equigranular Unit IV oxide olivine gabbro showing blocky pyroxene morphology in a relatively unfoliated appearing oxide-bearing gabbro in a zone of massive oxide impregnation (Core 56R-2, Pc. 8). 3. Photograph of back of Core 77R-3, Pc. 5, showing coarse and fine grained patches in patchy oxide-olivine gabbro crosscut by penetrative foliation. 4. Photograph of back of Core 77R-1, Pc. 4, showing foliation in fine-grained oxide olivine gabbro wrapping around coarse-grained undeformed gabbro patches. 
H. J. B. DICK ET AL.

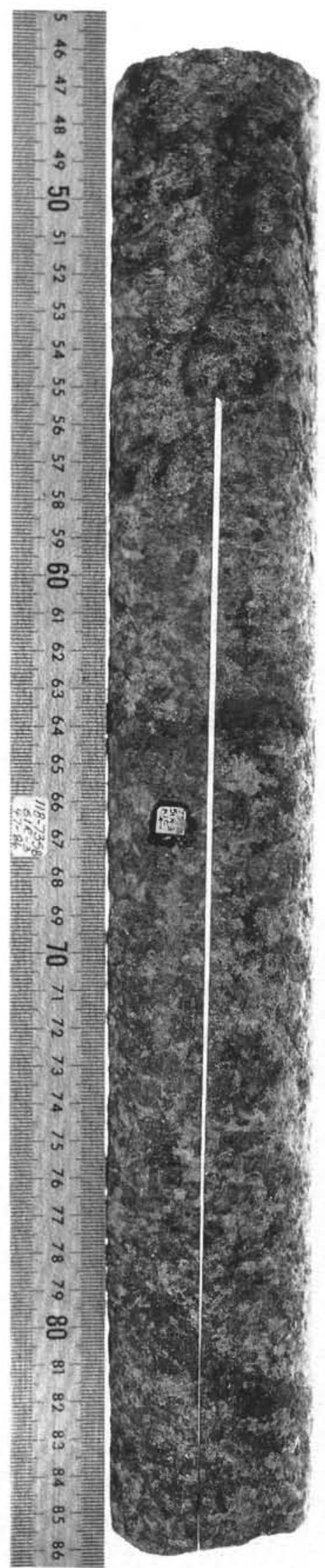

Plate 8. Unit IV foliated oxide olivine gabbro showing clothespin structure produced by the rock spontaneously deforming when cut due to the release of stored elastic strain. 